OTRAS PUBLICACIONES DE LA UNIVERSIDAD

UNIVERSITAS

Revista de Ciencias Sociales y Humanas

ALTERIDAD

Revista de Educación

RETOS

Revista de Ciencias de la Administración y Economía

INGENIUS

Revista de Ciencia y Tecnología

UTOPÍA

Revista de Pastoral Juvenil Universitaria

LA GRANJA

Revista de Ciencias de la Vida

\title{
Pensamiento lógico-ABSTRACto y eduCACión
}

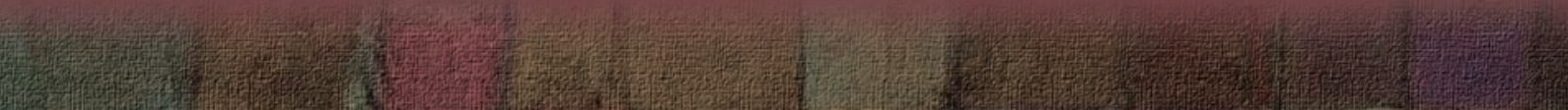

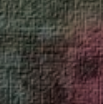 \\ Artículos \\ BASES TEÓRICAS DEL PENSAMIENTO- O Del pensamiento complejo al pensamiento LÓGICO-ABSTRACTO \\ - El pensamiento lógico-abstracto como sustento para potenciar los procesos cognitivos en la educación \\ computacional: retos para la educación contemporánea \\ - La lógica argumentativa y proposicional en el proceso de construcción de argu- mentos cientifico-filosóficos \\ - La proposición lógica como instrumento para la comprensión y transformación de la realidad \\ - Una aproximación desde la lógica de la educación al pensamiento computacional PRAXIS DEL PENSAMIENTO LÓGICO ABSTRACTO EN LA EDUCACIÓN \\ - Razonamiento Lógico Abstracto e Inteli- gencia Emocional: trayectorias en la formación de estudiantes universitarios - ABP como estrategia para desarrollar el - complementariedad, ídentid́a d y contra- pensamiento lógico matemático en alum- diecéón en la lógica de Niels Bohr DINAMISMOO DEL PENSAMIENTO COM- PLEJO, PENSAMIENTO COMPUTACIONAL nos de educación secundaria \\ Contribuciones Especiales \\ DESAFIOOS PARA LA EDUCACIÓN ACTUAL} YEDUCACIÓN

Pensamiento complejo abstracto en aula

- Formación docente y diálogo de saberes en el kairos educativo

ABYA INUEESTDA 


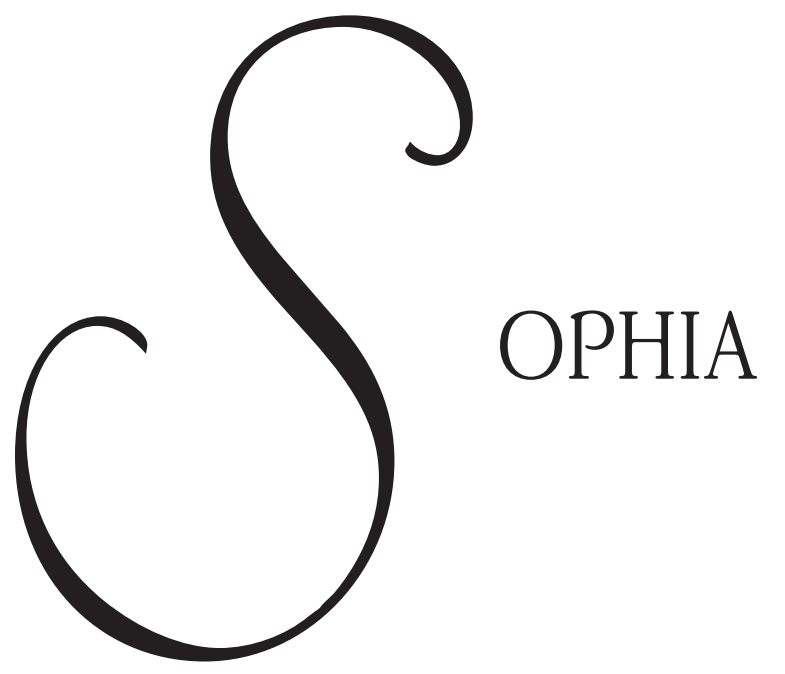

Colección de Filosofía de la Educación

Número 21 / julio-diciembre de 2016

ISSN impreso 1390-3861 / ISSN electrónico 1390-8626

Indexada en:

\section{DOAJ}

Directory of open access journals

Red de Revistas Científicas de América Latina y el Caribe, España y Portugal. lat index Sistema Regional de Información en línea para Revistas Científicas de América Latina, El Caribe, España y Portugal.

REDIB Red Iberoamericana de Innovación y Conocimiento Científico.

Citas Latinoamericanas en Ciencias Sociales y Humanidades.

\section{IRESIE HSUE}

Índice de Revistas de Educación Superior e Investigación Educativa de la Universidad Nacional Autónoma de México.

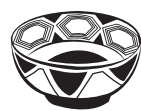

ABYA| UNIVERSIDAD

YALA IALESIANA

\section{Universidad Politécnica Salesiana del Ecuador}


SOPHIA, Colección de Filosofía de la Educación es una publicación filosófica-científica de la Universidad Politécnica Salesiana (UPS), tiene una periodicidad semestral, cuyo primer número apareció en junio de 2006. El objetivo de SOPHIA es teorizar la educación desde un punto de vista filosófico, con datos de la psicología individual y colectiva, de las experiencias de enseñanza-aprendizaje, de la sociología, de la cultura y del desarrollo de las ciencias empíricas, para renovar, actualizar y articular mejor el nivel conceptual, procedimental y experiencial de las ciencias de la educación. La revista promueve la difusión de artículos de carácter monográfico que sean inéditos, científicamente construidos, con un método que articule adecuadamente el análisis y la síntesis; que sean propositivos, en el núcleo de la Filosofía de la Educación. Se edita en versión impresa (ISSN: 1390-3861) y electrónica (ISSN: 1390-8626).

La administración de SOPHIA se realiza a través de los siguientes parámetros:

La revista utiliza los sistemas anti plagio

Crossref

Similarity Check Similarity Check
U R K U N D

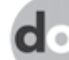

Los artículos cuentan con código de identificación (Digital Object Identifier)

El proceso editorial se gestiona a través del Open Journal System $\frac{\text { OJS }}{\text { openjouras speums }}$

Es una publicación de acceso abierto (Open Access)

con licencia Creative Commons

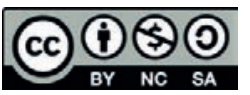

Las políticas copyrighty de uso post print, se encuentran publicadas en el Repositorio de Políticas de Autoarchivo SHERPA/ROMEO.

Los artículos de la presente edición pueden consultarse en:

- http://revistas.ups.edu.ec/index.php/sophia

- http://www.ensayistas.org/critica/revistas.htm

- https://www.redib.org

- http://www.iisue.unam.mx/iresie

- http://iresie.unam.mx

- http://clase.unam.mx 
Rector

Javier Herrán Gómez, sdb

Vicerrector Académico General

Luis Tobar Pesántez

Vicerrector Docente

Fernando Pesántez Avilés

Vicerrector de Investigación

Juan Pablo Salgado

Vicerrectores de sede

César Vásquez (Cuenca)

José Juncosa Blasco (Quito)

Andrés Bayolo Garay (Guayaquil)

Sophia: Colección de Filosofía de la Educación, publicación semestral, N. ${ }^{o}$ 21, juliodiciembre de 2016. Editora responsable: Floralba del Rocío Aguilar Gordón.

Domicilio de la publicación: Universidad Politécnica Salesiana del Ecuador. Casilla postal: 2074, Cuenca-Ecuador. Teléfono: (+5397) 2831745, Cuenca-Ecuador. Correo electrónico: revista-sophia@ups.edu.ec

(c) SOPHIA. Colección de Filosofía de la Educación.

Impreso en Ecuador

Los conceptos expresados en los artículos competen a sus autores. Se permite la reproducción de textos citando la fuente. 


\title{
CONSEJO DE PUBLICACIONES / PUBLISHING BOARD
}

\author{
Javier Herrán Gómez, sdb \\ PRESIDENTE \\ Juan Pablo Salgado \\ Juan Bottasso Boetti, sdb \\ Teodoro Rubio Martín \\ José Juncosa Blasco \\ René Unda Lara \\ Jaime Padilla Verdugo \\ Floralba Aguilar Gordón \\ Sheila Serrano Vicenti \\ Fabricio Freire Morán \\ John Calle Sigüencia \\ Armando Grijalva Brito \\ Andrea De Santis \\ Mónica Ruiz Vásquez \\ Luis Álvarez Rodas \\ EDITOR GENERAL
}

\section{COMITÉ CIENTÍFICO / SCIENTIFIC COMITTEE}

Rómulo Ignacio Sanmartín García

DIRECTOR GENERAL

Universidad Politécnica Salesiana del Ecuador

Carlos Jesús Delgado Díaz

EDITOR EN JEFE

Universidad de La Habana/Cuba

Floralba del Rocío Aguilar Gordón

EDITORA RESPONSABLE

Universidad Politécnica Salesiana del Ecuador

\section{CONSEJO EDITORIAL / EDITORIAL BOARD}

GIUSEPPE ABBÁ

Universidad Pontificia Salesiana de Roma, Italia

FERNANDO ACEVEDO CALAMET

Centro Universitario Regional del Noreste, Universidad de la República, Montevideo

- Uruguay

XIMENA ANDRADE CÁCERES

Universidad Politécnica Salesiana, Ecuador 
MARÍA ELENA ARRIAGADA ARRIAGADA

Universidad Bernardo O'Higgins, Santiago - Chile

Universidad Metropolitana de Ciencias de la Educación, Santiago -Chile

WILLIAM DARÍO ÁVILA DÍAZ

Observatorio Multidisciplinario para la construcción del Conocimiento - OBSK-

NOW, Bogotá DC - Colombia

JOSÉ ALCIDES BALDEÓN ROSERO

Universidad San Jorge de Zaragoza, España

DIEGO ALBERTO BELTRÁN

Universidad Nacional de Rosario, Argentina

JOSÉ ÁNGEL BERMÚDEZ GARCÍA

Universidad Pedagógica Experimental Libertador, Venezuela

ROBERT FERNANDO BOLAÑOS VIVAS

Universidad Politécnica Salesiana, Ecuador

PATRICIA BRAVO

Universidad Nacional de Chimborazo, Ecuador

NELDO CANDELERO

Universidad Nacional de Rosario, Argentina

ELSA BEATRIZ CÁRDENAS SEMPÉRTEGUI

Universidad Técnica Particular de Loja (UTPL), Ecuador

FABIÁN CASTIGLIONE

Instituto Superior de Formación - Docente Espíritu Santo, Argentina

JOSÉ CAVALCANTE LACERDA JUNIOR

Secretaría de Cultura del Estado de Amazonas, Manaus-Amazonas-Brasil

JUAN CEPEDA $H$.

Universidad Santo Tomás, Colombia

RAIMUNDO DE TEIXEIRA BARRADAS

Universidad del Estado de Amazonas (UEA), Manaus-Amazonas - Brasil

JOSÉ RAMÓN FABELO CORZO

Universidad Autónoma de Puebla - México

Instituto de Filosofía de La Habana - Cuba

JUAN LUIS FUENTES

Universidad Complutense de Madrid, Madrid

JEAN CARLOS GARCÍA

Pontificia Universidad Católica del Ecuador, Quito

JOSÉ ENRIQUE GÓMEZ ALVAREZ

Universidad Panamericana y Asociación Filosófica, México

VIRGINIA GONFIANTINI

Multiversidad Mundo Real Edgar Morin, México 
JOSÉ LUIS GÓMEZ-MARTÍNEZ

Profesor Emérito del Departamento de Lenguas Románicas de la Universidad de Georgia, EE. UU.

JUAN CARLOS GRIJALVA

Assumption College, Condado de Worcester, Massachusetts - EE.UU.

PABLO MANUEL GUADARRAMA GONZÁLEZ

Universidad Central de las Villas, Santa Clara - Cuba

SAMUEL GUERRA BRAVO

Pontificia Universidad Católica del Ecuador, Quito

LUCILA GUTIÉRREZ SANTANA

Universidad de Colima, Colima - México

JOSÉ LUIS GUZÓN NESTAR

Universidad Pontifica de Salamanca (UPSA), Burgos - España

ANDRES HERMANN ACOSTA

Universidad Nacional de Educación, Ecuador

ÉDISON FRANCISCO HIGUERA AGUIRRE

Pontificia Universidad Católica del Ecuador, Quito

KUREETHADAM JOSHTROM

Universidad Pontificia Salesiana de Roma, Italia

GERARDO MARCELO KAHAN

Universidad de Rosario, Argentina

SEBASTIÁN KAUFMANN SALINAS

Universidad Alberto Hurtado, Santiago - Chile

JOSÉ ANTONIO LAGO

Universidad Pedagógica Experimental Libertador, Venezuela

RAMÓN LUCAS LUCAS

Pontificia Universidad Gregoriana de Roma, Italia

MAURO MANTOVANI

Universidad Pontificia Salesiana de Roma, Italia

JULIO ALBERTO MÁRQUEZ LANDA

Nafinsa- Fonep y Grupo Qualinet, México

SERGIO MENA MUÑOZ

Universidad Complutense de Madrid, España

JAIR MIRANDA DE PAIVA

Universidad Federal de Espíritu Santo (UFES) Centro Universitario Norte de Espíritu Santo, San Mateo, Es - Brasil

LAURA ELIZABETH MONTENEGRO

Universidad Politécnica Salesiana, Ecuador 
JUAN ANTONIO NICOLÁS MARÍN

Universidad de Granada, España

DORYS ORTIZ

Pontificia Universidad Católica del Ecuador, Quito

LUIS PORTA

Universidad Nacional de Mar del Plata, Argentina

RIGOBERTO PUPO

Universidad de La Habana, Cuba

RAFAEL REPISO CABALLERO

Universidad Internacional de la Rioja (UNIR), Logroño - España

ALBERTO ISAAC RINCÓN RUEDA

Observatorio Multidisciplinario para la construcción del Conocimiento - OBSK-

NOW, Bogotá DC - Colombia

LUIS ROSÓN GALACHE

Universidad Pontificia Salesiana de Roma, Italia

MARÍA JOSÉ RUBIO

Pontificia Universidad Católica del Ecuador, Sede Ibarra - Ecuador

DAMIAN SALCEDO MEGALES

Universidad Complutense de Madrid, España

DAMIÁN SÁNCHEZ SÁNCHEZ

Centro Universitario de Espíritu Santo (UNESC), Colatina - Espíritu Santo, Brasil.

SANDRA SIQUEIRA

Facultad Salesiana Don Bosco Manaus - Amazonas - Brasil

DAVID ALFONSO SOLÍS NOVA

Universidad Católica de la Santísima Concepción, Concepción - Chile

JOSÉ TRANIER

Universidad Nacional de Rosario, Argentina

GUILLERMO URGILÉS CAMPOS

Universidad Politécnica Salesiana, Ecuador

CARMEN VARGUILLAS

Universidad Pedagógica Experimental Libertador, Venezuela

JESSICA LOURDES VILLAMAR MUÑOZ

Universidad Politécnica Salesiana, Ecuador

JAIME YANES GUZMÁN

Academia de Estudios e Investigación Complexus Edgar Morin (AEICEM), Santiago

- Chile 


\section{UNIVERSIDAD POLITÉCNICA SALESIANA DEL ECUADOR}

Javier Herrán Gómez, sdb

\section{Rector}

(C) Universidad Politécnica Salesiana

Turuhuayco 3-69 y Calle Vieja

Casilla postal 2074

Cuenca, Ecuador.

Teléfono: $(+593$ 7) 2050000

Fax: (+593 7) 4088958

E-mail: srector@ups.edu.ec

\section{CANJE}

Se acepta canje con otras publicaciones periódicas.

Dirigirse a:

Secretaría Técnica de Comunicación y Cultura

Universidad Politécnica Salesiana

Av. Turuhuayco 3-69 y Calle Vieja

Casilla postal 2074

Cuenca, Ecuador.

PBX: (+593 7) 2050000 - Ext. 1182

Fax: (+593 7) 4088958

Correo electrónico: rpublicas@ups.edu.ec

www.ups.edu.ec

Cuenca - Ecuador

EQUIPO TÉCNICO

Coordinación Abya-Yala: Hernán Hermosa

Corrección y estilo: Paulina Torres

Diagramación: Martha Vinueza

Diseño de portada: Raysa Andrade

Soporte OJS: Marco Gutiérrez, Tania Barrezueta y Wilson Verdugo

Sophia, Colección de Filosofía de la Educación, publicación semestral, N.o 21, julio-diciembre de 2016.

Editora responsable: Floralba del Rocío Aguilar Gordón.

Diseño: Editorial Universitaria Abya-Yala. Av. 12 de Octubre N22-22 y Wilson UPS-Bloque A.

Telf.: (+593 2) 2506 247, Quito-Ecuador.

Correo electrónico: editorial@abyayala.org

Impresión: Centro Gráfico Salesiano (Antonio Vega Muñoz 10-68 y General Torres).

Telf.: (+593 7) 2831 745, Cuenca-Ecuador.

Correo electrónico: centrograficosalesiano@lns.com.ec 


\section{CÓDIGO DE ÉTICA}

\section{Autores}

El/ la/ los autor/es garantizan la autoría y originalidad del manuscrito presentado, así mismo, se responsabilizan de su contenido y de haber contribuido a la concepción, diseño y realización del trabajo, análisis e interpretación de datos, y de haber participado en la redacción del texto y sus revisiones, así como en la aprobación de la versión que finalmente se remite.

$\mathrm{El} / \mathrm{la}$ / los autor/es certifican que este trabajo no ha sido publicado, ni está en vías de consideración para su publicación en otra revista; además que los resultados que respaldan este trabajo no han sido publicados en artículos científicos de otras revistas.

$\mathrm{El} / \mathrm{la} /$ los autor/es deberán certificar las fuentes y los aportes presentados en su artículo, los mismos que habrán de estar disponibles para el editor, en caso de que se requiera evidencia de la investigación.

$\mathrm{El} / \mathrm{la} /$ los autor/es declaran además estar libres de cualquier asociación personal o comercial que pueda suponer un conflicto de intereses en conexión con el artículo remitido, así como el haber respetado los principios éticos de investigación y la inclusión adecuada de cada una de las personas que colaboraron en el desarrollo de este trabajo investigativo.

En caso de que exista un error en la publicación, el autor deberá notificarlo inmediatamente al editor y enviar la información correctiva, para que sea rectificado, mediante fe de erratas, en la parte inferior del artículo.

\section{Revisores}

Los artículos publicados en esta revista son revisados por pares expertos, profesionales de prestigio, quienes evalúan la calidad científica y académica de los mismos, en el proceso llamado (peer review), donde la identidad de los autores y la de los evaluadores es anónima. Una vez recibida la calificación de los evaluadores académicos se procede a la aceptación o desestimación del artículo.

Por respeto a los autores se fija un tiempo para el proceso de revisión, el mismo que va en concordancia con el cronograma del proceso 
editorial, los revisores deben ser estrictos con el mismo o notificar con antelación si no podrán cumplir con la solicitud de revisión.

Todos los manuscritos recibidos en esta revista son considerados confidenciales durante el proceso de revisión.

La revisión de los manuscritos se realiza de forma objetiva sin que medie ningún tipo de preferencia, al tratarse de pares ciegos; además se siguen protocolos de revisión enviados por la revista y lineamientos especificados en las normas para autores que se encuentran en sistema de administración de la revista (OJS).

Los revisores deberán notificar inmediatamente al editor en caso de observar similitudes a otras investigaciones anteriormente publicadas o si evidencian ausencia de referencias por parte del autor.

\section{Editores}

Los editores serán los encargados de emitir la decisión final para la publicación de un artículo, fundamentando su decisión solo en aspectos de pertinencia en la temática de la revista, originalidad, aporte científico y claridad y en la evaluación crítica de los árbitros; no discrimina género, edad, raza, procedencia, tendencia sexual o tendencia política

Los editores y su consejo editorial se comprometen a mantener confidencialidad acerca de los revisores, autores, así como del contenido expuesto en los manuscritos, respetando la integridad del proceso editorial.

Los editores y su consejo editorial se comprometen a respetar la propiedad intelectual de los artículos sometidos a revisión.

Los editores garantizan que se respetarán los tiempos del proceso editorial, dentro del cual se consideran 30 días para la aceptación o desestimación del manuscrito y 30 días para la evaluación por pares científicos anónimos, favoreciendo al mantenimiento de la vigencia de la información presentada. 


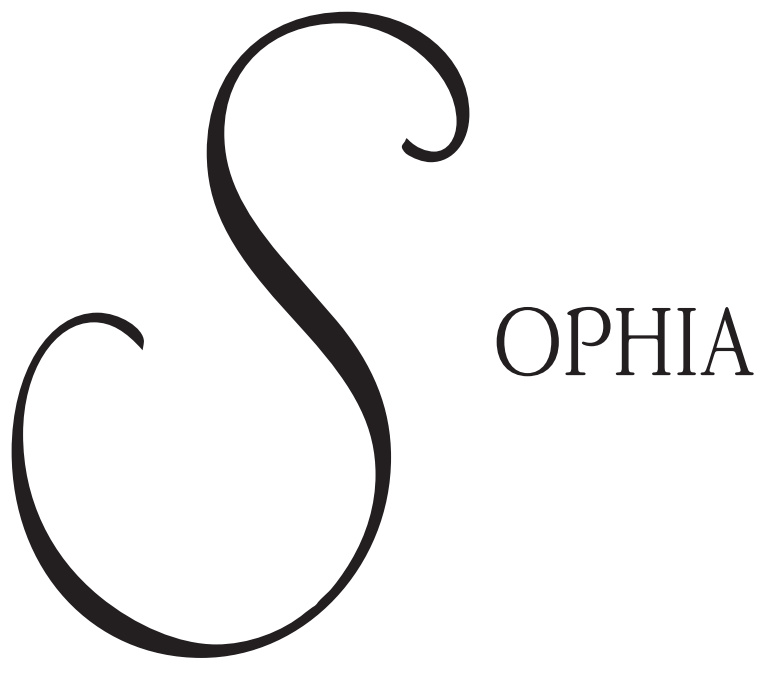

PenSAMIENTO LÓGICO-ABSTRACTO Y EDUCACIÓN Logical-abstract thought and education 



\section{SUMARIO}

Editorial................................... 15-26

\section{ARTÍCULOS/ARTICLES \\ BASES TEÓRICAS DEL PENSAMIENTO LÓGICO-ABSTRACTO \\ Theoretical basis of logical and abstract thinking}

EL PENSAMIENTO LÓGICO-ABSTRACTO COMO SUSTENTO

PARA POTENCIAR LOS PROCESOS COGNITIVOS EN LA EDUCACIÓN

Logical - abstract thought as support to boost

cognitive processes in education

Lilian Mercedes Jaramillo Naranjo y Luis Alberto Puga Peña ...

A LÓGICA ARGUMENTATIVA E PROPOSICIONAL NO PROCESSO

DE CONSTRUÇÃO DE ARGUMENTOS CIENTÍFICO-FILOSOFICOS

LA LOGICA ARGUMENTATIVA Y PROPOSICIONAL EN EL PROCESO

DE CONSTRUCCIÓN DE ARGUMENTOS CIENTÍFICO-FILOSÓFICOS

The argumentative and propositional logic in the construction

of scientific and philosophical arguments process

Jeane Torres da Silva. ..........................

LA PROPOSICIÓN LÓGICA COMO INSTRUMENTO PARA LA COMPRENSIÓN

Y TRANSFORMACIÓN DE LA REALIDAD

Logical proposition as a tool for reality understanding and transformation

William Orlando Cárdenas-Marín.................. 83-99

COMPLEMENTARIEDAD, IDENTIDAD Y CONTRADICCIÓN

en la lógica de Niels BoHr

Complementarity, identity and contradiction in the logic of Niels Bohr

Sara Madera Gómez........................... 101-118

\section{DiNAMISMO DEL PENSAMIENTO COMPLEJO, PENSAMIENTO COMPUTACIONAL Y EDUCACIÓN \\ Dynamism of the complex thought, computational thought and education}

Pensamiento complejo abstracto en el aula

Complex abstract thinking in the classroom

Jaime Rafael Yanes Guzmán ........................ 121-141 
Del PENSAMiento COMPLejo Al PENSAMIENTO

COMPUTACIONAL: RETOS PARA LA EDUCACIÓN CONTEMPORÁNEA

Complex thinking to computational thinking: contemporary

challenges in education

Jorge Antonio Balladares Burgos, Mauro Rodrigo Avilés Salvador

y Hamilton Omar Pérez Narváez . . . . . . . . . . . . . . . . . . . 143-159

UNA APROXIMACIÓN DESDE LA LÓGICA DE LA EDUCACIÓN

AL PENSAMIENTO COMPUTACIONAL

An approach from the logic of the education

to the computational thinking

Alberto Isaac Rincón Rueda y William Darío Ávila Díaz. . . . . 161-176

Praxis del Pensamiento lógico abstracto en la eduCación

Praxis of the logical abstract thought in the education

RAZONAMIENTO LÓGICO ABSTRACTO E INTELIGENCIA EMOCIONAL:

TRAYECTORIAS EN LA FORMACIÓN DE ESTUDIANTES UNIVERSITARIOS

Abstract logical reasoning and emotional intelligence:

trajectories in the training of university students

Patricia Bravo Mancero y Angélica María Urquizo Alcivar . . . 179-208

ABP COMO ESTRATEGIA PARA DESARROLLAR EL PENSAMIENTO

LÓGICO MATEMÁTICO EN ALUMNOS DE EDUCACIÓN SECUNDARIA

$\mathrm{ABP}$ as a strategy to develop mathematical logical thinking

in high school students

Felipe Leiva Sánchez. . . . . . . . . . . . . . . . . . . . . . . . . 209-224

\section{CONTRIBUCIONES ESPECIALES/SPECIAL CONTRIBUTIONS}

Desafíos Para la EDUCaCión ACTUAL

\section{Challenges for the current education}

FORMACIÓN DOCENTE Y DIÁLOGO DE SABERES EN EL KAIROS EDUCATIVO

Teacher training and dialogue of knowledges in the educational kairos

Virginia Gonfiantini. .......................... 229-245

Normas EDITORIALES / BASIC EDITORIAL CONDITIONS . . . . . . . . . 249-274

CONVOCATORIAS 2016-2024 / AnNounCEMENTS 2016-2024 . . . 277-292 


\section{EDITORIAL}

Sophia 21: Pensamiento lógico-abstracto y educación se hace presente con la finalidad de provocar en el lector nuevas inquietudes para la reflexión, para la investigación y para la generación de nuevas propuestas frente a los diversos dilemas, problemas e incertidumbres que puedan ser inferidas como consecuencia de la lectura comprensiva del presente número.

\section{Presentación}

Existe una diversidad de teorías, tipos, formas, momentos y modos de pensamiento. En este número se ha priorizado la reflexión sobre el pensamiento lógico-abstracto, un concepto en sí mismo polisémico y complejo del que se desprende todo un conjunto de manifestaciones filosóficas, científicas, pedagógicas, psicológicas, antropológicas, sociológicas, religiosas, etc., que van configurando una forma determinada de ser, de pensar y de actuar en el mundo.

Reflexionar acerca del pensamiento lógico-abstracto es: interesante por cuanto invita a re-pensar el pensamiento y las diferentes aristas que de él se derivan debido a su multidimensionalidad y a su evidente complejidad; atractivo en la medida que permite revisar los fundamentos, enfoques, perspectivas y contribuciones para el desarrollo individual y social del ser humano; desafiante en la medida que intenta establecer las vinculaciones con el proceso educativo, el mismo que se convierte en el puente fundamental para objetivizar y poner en acción todo tipo de teorías y proposiciones.

En todo caso, reflexionar acerca del pensamiento lógico-abstracto implica un volver al sujeto pensante, a su proceso de cognición, a sus estructuras mentales, a sus operaciones intelectuales y consecuentemente, a las múltiples relaciones que se van generando como producto de su propio dinamismo.

El pensamiento lógico-abstracto nos remite a considerar la totalidad del ser humano, no se restringe a una dimensión puramente cognitiva, también comprende otras instancias como la emoción, la sensación, la percepción, la memoria, la inteligencia, la imaginación, la volición, etc.

El pensamiento lógico-abstracto se va complejizando cada vez más como consecuencia de lo indefinible y complejo que resulta el mundo actual y el hombre que lo representa. El avance científico-tecnológico ha 
generado herramientas cognitivas basadas en la computadora (bases de datos, sistemas expertos, redes semánticas, multimedia e hipermedia basada en simulaciones, etc.) y en ambientes de aprendizaje adaptados para potenciar diversos tipos de pensamiento que pretenden responder a los requerimientos de la sociedad actual pero que a la vez han ido complejizado mucho más la comprensión del hombre y del mundo.

A pesar de ello, el pensamiento lógico abstracto es fundamental para enfrentar diversas problemáticas; para comprender al mundo y para entenderse a sí mismo; para elegir, tomar decisiones oportunas y para resolver diferentes problemas sobre el hombre, la sociedad, la naturaleza, en fin, para establecer hipótesis y para proponer soluciones.

Toda acción humana se encuentra precedida por un tipo de pensamiento, por procesos mentales, cognoscitivos, lógicos y abstractos que se materializan al entrar en contacto con el mundo concreto. En la interacción de pensamiento y acción desempeña un papel importante el lenguaje para la comunicación; y, la educación para dinamizar, dar sentido y significado al pensamiento.

\section{Estructura}

El número 21 de Sophia se encuentra conformado por diez artículos, nueve de ellos corresponden al tema central previsto para esta publicación y uno está vinculado a la sección de contribuciones especiales. Todos en conjunto aportan significativamente para la comprensión del pensamiento, de la educación y de la ciencia.

Los artículos se encuentran organizados en las cuatro secciones fundamentales que a continuación se detallan:

1. Bases teóricas del pensamiento lógico-abstracto

2. Dinamismo del pensamiento complejo, pensamiento computacional y educación

3. Praxis del pensamiento lógico abstracto en la educación

4. Desafíos para la educación actual

En las siguientes líneas se describe brevemente cada una de las secciones y los componentes que las constituyen. 


\section{Bases teóricas del pensamiento lógico abstracto}

Esta primera sección intenta realizar un abordaje del sustento teórico que respalda al pensamiento lógico abstracto y sus vinculaciones con la educación; establece un conjunto de premisas interesantes para comprender el sentido y significado de la lógica argumentativa y proposicional en el proceso de construcción de argumentos científicos-filosóficos; expone las razones por las cuales una proposición lógica puede convertirse en un instrumento válido para la comprensión y transformación de la realidad; reflexiona acerca de los conceptos de complementariedad, identidad y contradicción desde la lógica de Bohr, determina los aspectos contradictorios y superadores de lógica aristotélica.

Desde esta perspectiva, a esta primera sección corresponde el artículo, El pensamiento lógico-abstracto como sustento para potenciar los procesos cognitivos en la educación presentado por Lilian Mercedes Jaramillo Naranjo y Luis Alberto Puga Peña. Los autores consideran que la educación actual debe responder a las exigencias de la nueva sociedad para lo cual es necesario desarrollar en los estudiantes procesos lógicos y abstractos para la construcción y reconstrucción del conocimiento. Analizan las relaciones existentes entre los diversos procesos cognitivos como la percepción, la atención, la memoria, la inteligencia, etc. y sus vinculaciones con la práctica educativa. Defienden la idea que la comprensión del pensamiento lógico-abstracto tiene como sustento tres áreas fundamentales: el pensamiento, los procesos cognitivos y las teorías cognitivas.

En esta misma sección se encuentra el documento La lógica argumentativa y proposicional en el proceso de construcción de argumentos científico-filosóficos de Jeane Torres da Silva. Este artículo presenta un análisis epistemológico de las contribuciones de la lógica argumentativa y de la lógica proposicional basadas en estructuras proposicionales que componen los argumentos lógicos y se constituyen en modelos para la construcción de argumentos científicos y filosóficos. La autora se propone identificar las perspectivas teóricas comunes a la lógica argumentativa y a la lógica proposicional que constituyen el proceso cognitivo del razonamiento lógico y su transposición en el lenguaje lógico.

Otro artículo que se ubica en esta sección se titula La proposición lógica como instrumento para la comprensión y transformación de la realidad elaborado por William Orlando Cárdenas-Marín. En este manuscrito se reflexiona acerca de la importancia de la lógica formal y de la proposición para la comprensión de la realidad; se defiende la idea de que la proposición es un elemento fundamental en la figuración lógica, en el 
proceso de comprensión y en la transformación de la realidad; se analiza la relación existente entre lógica, pensamiento y lenguaje; se explica a breves rasgos la estructura de las proposiciones de forma típica y la relación presente entre nombre, sentido, significado y proposición.

Cerrando esta sección se encuentra el artículo Complementariedad, identidad y contradicción en la lógica de Niels Bohr estructurado por Sara Madera Gómez. En este documento se revisan los principales planteamientos realizados por el físico Niels Bohr en el marco del descubrimiento de la dualidad onda-partícula, esta característica que recae sobre la naturaleza del fotón y que trastoca la noción clásica de identidad, obliga también a realizar un análisis sobre las leyes del pensamiento establecidas por Aristóteles cuando estableció los principios de identidad, de no contradicción y de tercero excluido.

\section{Dinamismo del pensamiento complejo, pensamiento computacional y educación}

Esta segunda sección se caracteriza por explicar el dinamismo del pensamiento complejo y sus diversas manifestaciones; pretende comprender la incidencia de este pensamiento en el aula; revisa el paso del pensamiento complejo y de la lógica de la educación hacia el pensamiento computacional como referentes fundamentales de la educación contemporánea.

Desde este punto de vista, en esta sección se ubica el artículo, Pensamiento complejo abstracto en el aula elaborado por Jaime Yanes Guzmán. Este escrito considera que la sociedad actual se encuentra dirigida por un pensamiento lineal cartesiano que ha provocado crisis a todo nivel. Sugiere la construcción de una nueva forma de pensar y considera que una de las tareas académicas más importantes es determinar las carencias cognitivas de la humanidad y analizar cómo éstas se trasladan a la educación.

La reflexión continúa con las ideas expuestas en el manuscrito Del pensamiento complejo al pensamiento computacional: retos para la educación contemporánea elaborado por Jorge Balladares, Mauro Avilés y Hamilton Pérez. En el documento se considera que una de las problemáticas de la educación actual es que se continúa privilegiando la enseñanza del contenido sobre el desarrollo de destrezas y habilidades cognitivas que permitan un desarrollo del pensamiento de los estudiantes. Los autores consideran que el pensamiento complejo puede contribuir para una mejor comprensión de la realidad contemporánea; establecen la relación en- 
tre pensamiento complejo y pensamiento computacional y determinan la incidencia de ellos en el mejoramiento de la calidad educativa.

Dentro de esta misma sección se sitúa el artículo Una aproximación desde la lógica de la educación al pensamiento computacional desarrollado por Alberto Isaac Rincón Rueda y William Darío Ávila Díaz. Este manuscrito aborda la lógica de la educación, analiza las falencias que se presentan en la educación y caracteriza al pensamiento computacional que facilita la adquisición de criterios y una buena toma de decisiones. El pensamiento computacional es un mecanismo abstracto que se toma como modelo de inteligencia humana y forma parte fundamental del proceso de aprendizaje en todas las edades.

\section{Praxis del pensamiento lógico abstracto en la educación}

Esta tercera sección se refiere a la aplicabilidad del pensamiento lógicoabstracto en contextos y situaciones concretas de la educación; en tal sentido revisa las trayectorias del razonamiento lógico-abstracto e inteligencia emocional en la formación de estudiantes universitarios y el ABP como estrategia para desarrollar el pensamiento lógico-matemático en estudiantes de secundaria.

Es así como en esta sección se presenta el artículo Razonamiento Lógico Abstracto e Inteligencia Emocional: trayectorias en la formación de estudiantes universitario estructurado por Patricia Bravo y Angélica Urquizo. Este documento establece la relación que existe en el desarrollo del razonamiento lógico-abstracto y la inteligencia emocional en estudiantes de la Universidad Nacional de Chimborazo. Considera que existe una relación entre los niveles de desarrollo de la inteligencia lógica abstracta y la inteligencia emocional.

Sigue la propuesta realizada por Felipe Leiva Sánchez en el manuscrito $A B P$ como estrategia para desarrollar el pensamiento lógico matemático en alumnos de educación secundaria. Plantea la necesidad de interpretar y reconocer situaciones en contexto con la finalidad de proponer la implementación de estrategias que permitan alcanzar el nivel IV de las habilidades matemáticas especificados por PISA mismo que establece que los "estudiantes sean capaces de trabajar efectivamente con modelos explícitos para situaciones complejas concretas" con estudiantes de tercer grado de educación secundaria, favoreciendo su pensamiento lógico matemático. 


\section{Contribuciones especiales}

\section{Desafios para la educación actual}

Esta cuarta sección se refiere a los desafíos de la formación docente en contextos singulares, complejos y con sujetos con realidades heterogéneas, únicas, similares y diversas a la vez.

En esta sección es significativo el aporte de Virginia Gonfiantini con el artículo Formación docente y diálogo de saberes en el kairos educativo. Considera que existe cierta ausencia de procesos recursivos y dialógicos en la formación docente que genera la necesidad de un debate sobre la construcción de "otras" vías de mejoramiento. Es preciso comprender el actual desafío que significa educar al ciudadano de hoy en una sociedad democrática, pluralista, inclusiva, compleja. Propone una nueva forma de pensar la formación docente para lo cual analiza cómo el campo disciplinar de la didáctica dialógica o complexa prepara a los futuros profesores para pensar su praxis.

Una vez más, se espera que las ideas expresadas en cada uno de los artículos de este volumen 21 de Sophia se conviertan en simientes cognitivas para seguir pensando, buscando y proponiendo nuevas pautas de reflexión y de investigación. Que cada letra contenida en esta publicación se transforme en una nueva premisa que provoque sospechas y cuestionamientos indefinidos para seguir construyendo.

Floralba del Rocío Aguilar-Gordón 


\section{EDITORIAL}

Sophia 21: Logical - abstract Thought and education, it becomes present by the purpose of provoking in the reader new worries for the reflection, for the investigation and for the generation of new offers opposite to the diverse dilemmas, problems and uncertainties that could be inferred as consequence of the comprehensive reading of the present number.

\section{Presentation}

It exists a diversity of theories, types, forms, moments and manners of thought. In this number the reflection has been prioritized on the logical - abstract thought, a concept in yes same polysemic and complex with that there parts the whole set of philosophical, scientific, pedagogic, psychological, anthropologic, sociological, religious manifestations, etc., that are forming a certain way of being, of thinking and of acting in the world.

To think brings over of the logical - abstract thought is: interesting since it invites to rethink the thought and the different edges that from him stem due to his multidimensionalidad and to his evident complexity; attraction in the measure that allows to check the foundations, approaches, perspectives and contributions for the individual and social development of the human being; challenging in the measure that tries to establish the entails with the educational process, the same one that turns into the fundamental bridge for objetivizar and to put in action all kinds of theories and propositions.

In any case, to think brings over of the logical - abstract thought implies one returning to the thinking subject, to his process of cognition, to his mental structures, to his intellectual operations and consistently, to the multiple relations that are generated as product of his own dynamism.

The logical - abstract thought sends us to considering the totality of the human being, is not restricted to a purely cognitive dimension, also he understands other instances as the emotion, the sensation, the perception, the memory, the intelligence, the imagination, the volición, etc.

The logical - abstract thought goes away complex increasingly as consequence of the undefinable and complex thing that he turns out to be the current world and the man who represents it. The scientific - technological advance has generated cognitive tools based on the computer (databases, expert systems, semantic networks, multimedia and a half ba- 
sed on simulations, etc.) and in environments of learning adapted to promote diverse types of thought that they try to answer to the requirements of the current company but that simultaneously they have gone complejizado much more the comprehension of the man and of the world.

In spite of it, the logical abstract thought is fundamental to face diverse problematic; to understand to the world and to understand itself to yes same; to choose, to take opportune decisions and to solve different problems on the man, the company, the nature, in end, to establish hypothesis and to propose solutions.

Any human action is preceded by a type of thought, for mental, cognitive, logical and abstract processes that materialize on having entered in touch with the concrete world. In the interaction of thought and action the language plays a role importantly for the communication; and, the education to give to stir into action, to give sense and meaning to the thought.

\section{Structure}

The number 21 of Sophia, it is shaped by ten articles, nine of them correspond to the central topic foreseen for this publication and one is linked to the section of special contributions. They all as a whole reach significantly for the comprehension of the thought, of the education and of the science.

The articles are organized in four fundamental sections that later are detailed:

1. Theoretical basis of logical and abstract thinking

2. Dynamism of the complex thought, computational thought and education

3. Praxis of the logical abstract thought in the education

4. Challenges for the current education

In the following lines there are described brief each of the sections and the components that constitute them.

\section{Theoretical basis of logical and abstract thinking}

This first section tries to realize a boarding of the theoretical sustenance that endorses to the logical abstract thought and his entails with the education; it establishes a set of interesting premises to understand the sense and meaning of the argumentative logic and proposicional in 
the process of construction of scientific - philosophical arguments; it exposes the reasons for which a logical proposition can turn into a valid instrument for the comprehension and transformation of the reality; he thinks brings over of the concepts of complementarity, identity and contradiction from Bohr's logic, determines the contradictory aspects and superadore of logic aristotelian.

From this perspective, to this first section the article corresponds The logical - abstract thought as support to boost cognitive processes in the education, presented by Lilian Mercedes Jaramillo Naranjo and Luis Alberto Puga Peña. The authors think that the current education must answer to the requirements of the new company for which is necessary to develop in the students logical and abstract processes for the construction and reconstruction of the knowledge. They analyze the existing relations between the diverse cognitive processes as the perception, the attention, the memory, the intelligence, etc. And his entails with the educational practice.

They defend the idea that the comprehension of the logical - abstract thought takes three fundamental areas as a sustenance: the thought, the cognitive processes and the cognitive theories.

In the same section the document is The argumentative and propositional logic in the construction of scientific and philosophical arguments process, of Jeane Torres. This article presents an epistemological analysis of the contributions of the argumentative logic and of the logic proposicional stocks on propositional structures that compose the logical arguments and are constituted in models for the construction of scientific and philosophical arguments. The authoress proposes to identify the theoretical common perspectives to the argumentative logic and to the logic proposicional that constitute the cognitive process of the logical reasoning and his transposition in the logical language.

Another article that is located in this section titles The logical proposition as a tool for reality understanding and transformation, elaborated by William Orlando Cárdenas-Marín. In this manuscript it is thought over brings over of the importance of the formal logic and of the proposition for the comprehension of the reality; the idea defends itself of that the proposition is a fundamental element in the logical imagination, in the process of comprehension and in the transformation of the reality; the existing relation is analyzed between logic, thought and language; is explained to brief features the structure of the propositions of typical form and the present relation between name, sense, meaning and proposition. 
Closing this section the article is Complementarity, identity and contradiction in Niels Bohr's logic, structured by Sara Madera Gómez. In this document there check the principal expositions realized by the physicist Niels Bohr in the frame of the discovery of the duality wave - particle, this characteristic that relapses on the nature of the photon and that trastoca the classic notion of identity, forces to realize also an analysis on the laws of the thought established by Aristotle when it established the beginning of identity, of not contradiction and of excluded third party.

\section{Dynamism of the complex thought, computational thought and education}

This second section is characterized for explaining the dynamism of the complex thought and his diverse manifestations; it tries to understand the incident of this thought in the classroom; it checks the step of the complex thought and of the logic of the education towards the computational thought as fundamental modals of the contemporary education.

From this point of view, in this section the article locates complex abstract Complex abstract thinking in the classroom, elaborated by Jaime Yanes Guzmán. This writing thinks that the current company is directed by a linear cartesian thought that has provoked crisis any level. It suggests the construction of a new way of thinking and thinks that one of the most important academic tasks is to determine the cognitive lacks of the humanity and to analyze how these move to the education.

The reflection continues with the ideas exposed in the manuscript of Complex thinking to computational thinking: contemporary challenges in education, elaborated by Jorge Balladares, Mauro Avilés and Hamilton Pérez. In the document it thinks that one of the problematic ones of the current education is that it is continued favouring the education of the content on the development of skills and cognitive skills that allow a development of the thought of the students. The authors think that the complex thought can contribute to a better comprehension of the contemporary reality; they establish the relation between complex thought and computational thought and determine the incident of them in the improvement of the educational quality.

Inside the same section the article places An approach from the logic of the education to the computational thinking, developed by Alberto Isaac Rincón Rueda and William Darío Avila Díaz. This manuscript approaches the logic of the education, analyzes the failings that they present 
in the education and characterizes to the computational thought, which facilitates the acquisition of criteria and a good capture of decisions. The computational thought is an abstract mechanism that takes as a model of human intelligence and forms a part fundamentally of the learning process in all the ages.

\section{Praxis of the logical abstract thought in the education}

This third section refers to the applicability of the logical - abstract thought in contexts and concrete situations of the education; to this respect it checks the paths of the logical - abstract reasoning and emotional intelligence in the formation of university students and the ABP as strategy to develop the thought logician - mathematician in students of secondary.

It is as well as in this section one presents the article Abstract logical reasoning and emotional intelligence: trajectories in the training of university students, structured by Patricia Bravo and Angélica Urquizo. This document establishes the relation that exists in the development of the logical - abstract reasoning and the emotional intelligence in students of Chimborazo's National University. He thinks that a relation exists between the levels of development of the logical abstract intelligence and the emotional intelligence.

It follows the offer realized by Philip Leiva Sanchez in the manuscript $A B P$ as a strategy to develop mathematical logical thinking in high school students. It raises the need to interpret and recognize situations in context with the purpose of proposing the implementation of strategies that allow to reach the level the IVth of the mathematical skills specified for HE TREADS same that establishes that the "students are capable of working really with explicit models for complex concrete situations " with students of the third degree of secondary education, favoring his logical mathematical thought.

\section{Challenges for the current education}

This fourth section refers to the challenges of the educational formation in singular, complex contexts and with subjects with the heterogeneous, only, similar and diverse realities simultaneously.

In this section Virginia Gonfiantini's contribution is significant, with the article Teacher training and dialogue of knowledges in the educational kairos, thinks that there exists certain absence of recursive proces- 
ses and dialogic in the educational formation that generates the need of a debate on the construction of "other" routes of improvement. It is necessary to understand the current challenge that means to educate the today citizen in a democratic, pluralist, inclusive, complex company. A new way of thinking proposes the educational formation for which analyzes how the field to discipline of the didactics dialogica or complexa prepares the future teachers to think his practice.

Once again, it hopes that the ideas expressed in each of the articles of this volume 21 of Sophia turn into cognitive seeds to continue thinking, looking and proposing new guidelines of reflection and of investigation. That every letter contained in this publication transforms in a new premise that provokes suspicions and indefinite questions to continue constructing. 


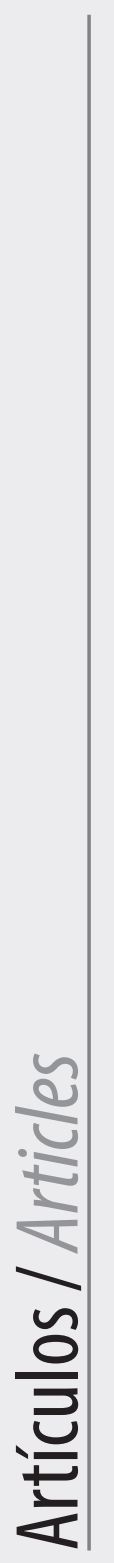



Bases teóricas del pensamiento

lógico-abstracto

Theoretical basis of logical

and abstract thinking 



\title{
EL PENSAMIENTO LÓGICO-ABSTRACTO COMO SUSTENTO
}

\section{PARA POTENCIAR LOS PROCESOS COGNITIVOS EN LA EDUCACIÓN}

Logical - abstract thought as support to boost
cognitive processes in education

\author{
LILIAN MERCEDES JARAMILLO NARANJO* \\ Universidad Tecnológica Equinoccial / Quito, Ecuador \\ lilian.jaramillo@ute.edu.ec \\ Luis Alberto Puga Peña \\ Universidad Tecnológica Equinoccial / Quito, Ecuador \\ luis.puga@ute.edu.ec
}

\begin{abstract}
Resumen
La educación actual debe responder a las exigencias de una nueva sociedad, marcada por la excesiva información proveniente de diferentes fuentes en especial de los medios de comunicación, es por ello que se torna necesario desarrollar en los estudiantes procesos lógicos y abstractos para la construcción y reconstrucción del conocimiento, de manera que logren las destrezas necesarias para que se desempeñen adecuadamente en este mundo competitivo; en virtud de aquello, el presente artículo tiene como objetivo principal propiciar un espacio de reflexión sobre la relación existente entre los procesos cognitivos y el pensamiento lógico y abstracto, y hacer conciencia que para conseguir personas que desarrollen la percepción, atención, memoria, inteligencia, pensamiento, lenguaje, es necesario la aplicación de estrategias pedagógicas que desarrollen estas capacidades, de manera que se considere que la educación además de cumplir un papel importante en la sociedad debe aportar en el desarrollo de la inteligencia a través del pensamiento lógico abstracto.

Por lo escrito, y como parte del análisis de dicha relación existente se comienza contextualizando el problema, posteriormente se aborda varios tópicos sobre la base de consideraciones de autores contemporáneos respecto del: Pensamiento, su clasificación, los procesos cognitivos y las teorías cognitivas. Se plantea que estas tres áreas del conocimiento son relevantes para la comprensión de la relación del pensamiento lógico- abstracto como sustento para potenciar los procesos cognitivos.
\end{abstract}

Forma sugerida de citar: Jaramillo Naranjo, Lilian Mercedes, \& Puga Peña, Luis Alberto (2016). El pensamiento lógico-abstracto como sustento para potenciar los procesos cognitivos en la educación. Sophia, colección de Filosofía de la Educación, 21(2), pp. 31-55.

* Licenciada en Ciencias de la Educación. Dra. en Ciencias de la Educación. MSc. en Educación y Desarrollo Social. Mgs. en Tecnologías para la Gestión y Práctica Docente. Docente de la Carrera de Ciencias de la Educación del Sistema de Educación a Distancia de la Universidad Tecnológica Equinoccial. Publicaciones en la Revista Sophia de la Universidad Politécnica Salesiana del Ecuador.

** Licenciado en Ciencias de la Educación. Profesor de enseñanza media en la Especialización de Matemática y Física. Magister en Docencia Matemática. Docente de la Universidad Tecnológica Equinoccial. 
Logical - abstract thought as support to boost cognitive processes in education

El artículo, además, enfatiza que en estos tiempos los docentes "dejemos de enseñar y hagamos que nuestros estudiantes trabajen" esto implica un desarrollo holístico de los procesos cognitivos a través del pensamiento lógico abstracto, empezando el trabajo con sus estudiantes desde los primeros años de escolaridad, en esta perspectiva para conseguir lo propuesto se deberá aplicar actividades y estrategias acorde a la edad evolutiva cuyo propósito final es conseguir de los educandos potencien sus habilidades cognitivas tan importantes en la época actual.

\section{Palabras clave}

Pensamiento lógico, pensamiento abstracto, procesos cognitivos, educación, fundamentos psicológicos.

\section{Summary}

The current education must meet the demands of a new society, marked by excessive information from different sources especially the media, that is why it is necessary to develop students logical and abstract processes for the construction and reconstruction knowledge, so that achieve the necessary skills to perform properly in this competitive world; under that, this article has as main objective to provide a space for reflection on the relationship between cognitive processes and logical and abstract thinking, and make awareness for people to develop perception, attention, memory, intelligence, thinking, language, you required the application of teaching strategies to develop these skills, so that education is considered in addition to play an important role in society should contribute to the development of intelligence through abstract logical thinking.

By writing, and as part of the analysis of this relationship begins contextualizing the problem, then several topics on the basis of considerations of contemporary authors regard the addresses: Thinking, classification, cognitive processes and cognitive theories. It is argued that these three areas of knowledge are relevant to an understanding of the relationship of abstract logical thought as support for enhancing cognitive processes.

The article also emphasizes that in these times teachers "stop teaching and let our students to work" implies a holistic development of cognitive processes through abstract logical thinking, starting work with students from the early years of schooling, in this perspective for the proposal should be applied activities and strategies according to the developmental age whose ultimate purpose is to get learners enhance their cognitive abilities as important at the present time.

Keywords

Logical thinking, abstract thinking, cognitive processes, education, psychological foundations.

\section{Introducción}

Este artículo pretende proporcionar un espacio de reflexión sobre la relación existente entre el pensamiento lógico abstracto y los procesos cognitivos de la educación. De igual forma busca sensibilizar especialmente a las personas que hacemos educación en el entendimiento de que los procesos cognitivos como la percepción, atención, memoria, inteligencia, pensamiento, lenguaje, son componentes preponderantes en la consecusión de verdaderos aprendizajes significativos. 
Se plantea que entre uno de los problemas que se presentan en nuestro sistema educativo, es la incipiente relación que se establece entre el pensamiento lógico abstracto como sustento de un proceso cognitivo fortalecido, y se cree que son cosas divergentes aisladas sin ninguna relación entre ellas.

En consecuencia el presente documento tiene como propósito analizar los procesos cognitivos y su aplicación práctica en varias áreas de estudio, a fin de fortalecer en los estudiantes respuestas rápidas y concretas en la solución de problemas de acuerdo a la realidad de contexto, y presentar aportes significativos a la educación ecuatoriana.

Por consiguiente, el desarrollo del pensamiento lógico-abstracto es clave para mejorar la inteligencia matemática, que sobrepasa la barrera de las capacidades numéricas y aporta importantes beneficios para entender conceptos en otras áreas del conocimiento, básicas y complementarias, estableciendo así relaciones entre los saberes y articulado a las experiencias de la vida diaria.

La investigación realizada hace un recorrido por las principales corrientes pedagógicas y su inserción en los procesos cognitivos, pretende extrapolar a los docentes criterios pedagógicos a ser aplicados en el aula, haciendo énfasis en la aplicación de procesos lógicos y abstractos a fin de conseguir estudiantes rápidos en razonar, creadores de pensamientos nuevos y significativos, además de ser gestores en plantear y desarrollar problemas de fácil entendimiento para mejorar los procesos cognitivos en la práctica educativa.

Por otro lado, en la actualidad el currículum ecuatoriano tiene un enfoque en el cual se da énfasis al protagonismo en el aula de los estudiantes, por lo cual es importante relacionar los procesos cognitivos a las destrezas con criterio de desempeño. Por ello, es necesario destacar ideas de pensadores como Piaget, Brunner, Ausubel, y Vigotsky, quienes indican que hay que aplicar procesos claros y muy significativos para pensar en aprendizajes que le sirvan a los educandos para la vida.

$\mathrm{Al}$ ser las aulas de clase un laboratorio pedagógico, es el espacio en donde se debe dar énfasis a la construcción y reconstrucción de los nuevos conocimientos en forma acertada, a fin de asegurar nuevos saberes cognitivos y prácticos.

En este contexto el Foro Mundial de la Educación (Corea, 2015) fortaleció e insistió en que los aprendizajes en el aula se transformen en aprendizajes para toda la vida, "es decir que toda persona en cualquier etapa de su vida, debe disponer de oportunidades de aprendizaje perma- 
nentes, a fin de adquirir los conocimientos y las competencias para hacer realidad sus aspiraciones y contribuir a la sociedad" (UNESCO, 2015).

Como complemento a ello, la Reforma Curricular Ecuatoriana (2010), exterioriza que:

[...] el proceso de construcción de conocimiento se orienta al desarrollo de un pensamiento y modo de actuar lógico, crítico y creativo, en la concreción de los objetivos educativos con su sistema de destrezas y conocimientos, a través del enfrentamiento a situaciones y problemas reales de la vida y de métodos participativos de aprendizaje, para conducir al estudiantado a alcanzar los logros de desempeño que demanda el perfil de salida de la Educación Básica (Reforma Curricular, 2010, p. 5). Concomitantemente expresa la Asamblea Nacional (2008) que "La educación es un derecho de las personas a lo largo de su vida y un deber e inexcusable del Estado. Constituye un área prioritaria de la política pública y de la inversión estatal, garantía de la igualdad e inclusión social y condición indispensable para el buen vivir. Las personas, las familias y la sociedad tienen el derecho y la responsabilidad de participar en el proceso educativo".

Con respecto a lo antes mencionado las normativas planteadas buscan en el educando se potencialice el desarrollo del pensamiento lógico, abstracto, crítico y creativo, con el objetivo de articular a los objetivos educativos que posteriormente se evidenciará en los resultados de aprendizaje, mismos que servirán para mejorar la calidad educativa ecuatoriana, solo así reflejaremos el buen vivir como un principio constitucional cuya visión está centrada en el ser humano, como parte de un entorno natural y social.

Este artículo se divide en tres partes, en la primera se expone la fundamentación teórica del pensamiento lógico y abstracto, la segunda hace énfasis en los fundamentos psicopedagógicos fortalecidos de las corrientes psicológicas. En la tercera parte se realiza un análisis para extraer las conclusiones.

Las consideraciones aquí planteadas, responden a las percepciones personales de los investigadores, sustentadas en los autores referidos. Asimismo esta propuesta busca contribuir al logro de uno de los objetivos fundamentales de la Reforma Curricular Ecuatoriana, la cual es, demostrar un pensamiento lógico, crítico y creativo en el análisis y resolución eficaz de problemas de la realidad cotidiana (MINEDUC, 2010, p. 20). Por lo que, se pretende potenciar desde las aulas pedagógicas las formas de razonamiento lógico y pensamiento abstracto al hacer énfasis en fundamentaciones pedagógicas, psicológicas, y otras corrientes que respaldan lo indicado, cuyo propósito es que constituya una contribución para la resolución de problemas implementado desde varias áreas del conoci- 
miento, igualmente se fortalecerá en forma eficiente procesos cognitivos en función del pensamiento lógico y abstracto.

Con base a las reflexiones anteriormente expuestas, a continuación el desarrollo del artículo.

\section{El pensamiento un reflejo de las ideas}

Desde la perpectiva de algunos autores, entre ellos Piaget, Vigotsky, Ausubel, el pensamiento es fundamental para el desarrollo cognoscitivo de los seres humanos, por ello se concibe como la capacidad que tienen la personas para captar y producir ideas en momentos determinados. El pensamiento funciona cuando forma conceptos en el cerebro, resuelve problemas y toma decisiones, todo esto se consigue cuando está un medio para expresar ideas, asi como para concebir las categorías y los conceptos de pensamiento. Esto significa que, "[...] la mente humana trabaja al aplicar procesos básicos a las estructuras simbólicas que representan el contenido de nuestros pensamientos" (Klingler \& Vadillo, 2000, p. 50), es decir que cuando queremos anunciar una idea, comenzamos con un pensamiento, después seleccionamos las palabras y frases para comunicar correctamente.

$\mathrm{Al}$ respecto de los criterios vertidos, Julio César Arboleda indica lo siguiente:

El pensamiento es una función psíquica en virtud de la cual un individuo usa representaciones, estrategias y operaciones frente a situaciones o eventos de orden real, ideal o imaginario. Otras funciones de la dimensión mental son, por ejemplo, la inteligencia, las emociones, la voluntad, la memoria, la atención, la imaginación, la motivación, la cognición y el aprendizaje. [...] así, pensar sería usar la inteligencia, el aprendizaje, la memoria, en fin la cognición, en la experiencia de mundo (Arboleda, 2013, p. 6).

Las ideas exteriorizadas por el autor nos lleva a reflexionar que los seres humanos aplicamos el pensamiento frente a situaciones reales o imaginarias, es poner en juego nuestro pensamiento de varias formas con el fin de captar la idea literal y gráfica que se encuentra en nuestros alrededores, y más aún, si se quiere extrapolar lo concebido en el esquema cognitivo y socializar a otros. Asimismo lo relevante está cuando las personas captan la información en forma significativa y comunican a otro grupo de personas para que a su vez lo multipliquen a varios sujetos formando un tejido social de comprensiones constructivistas para el mundo de la vida. Por ello, en este proceso de pensar se involucra a la inteligencia, 
el aprendizaje y la memoria atributos que conllevarán a un mejor entendimiento de comprensiones conceptuales. Igualmente es oportuno citar que en estos tiempos se requiere que se potencie el pensamiento eficaz.

El pensamiento eficaz se refiere a la aplicación competente y estratégica de destrezas de pensamiento y hábitos de la mente productivos que nos permiten llevar a cabo actos meditados de pensamientos, como tomar decisiones, argumentar y otras acciones analíticas, creativas o críticas. Los individuos que son capaces de pensar con eficiencia pueden emplear, y de hecho emplean, esas destrezas y hábitos por iniciativa propia, y son capaces de monitorizar su uso cuando les hace falta (Swartz et al., 2008, p. 15).

$\mathrm{Al}$ respecto se meciona que los seres humanos poseen la facultad de pensar en forma eficaz, cuando existe una aplicación adecuada y estratégica de habilidades del pensamiento, hábitos producidos en la mente, por ello los seres humanos expresan y comunican sus ideas como "un conjunto de signos estructurados que dan a entender una cosa" (Morris,1985, p. 37). Entonces, el pensamiento constituye la capacidad de pensar y expresar ideas como una necesidad de ponerse en contacto con los demás. Todo esto se conseguirá cuando los individuos ejerciten procesos del pensamiento para transferir notablemente ideas significativas a la sociedad.

El siguiente cuadro nos muestra una síntesis del pensamiento y sus atributos.

\section{Cuadro 1}

El pensamiento y sus atributos

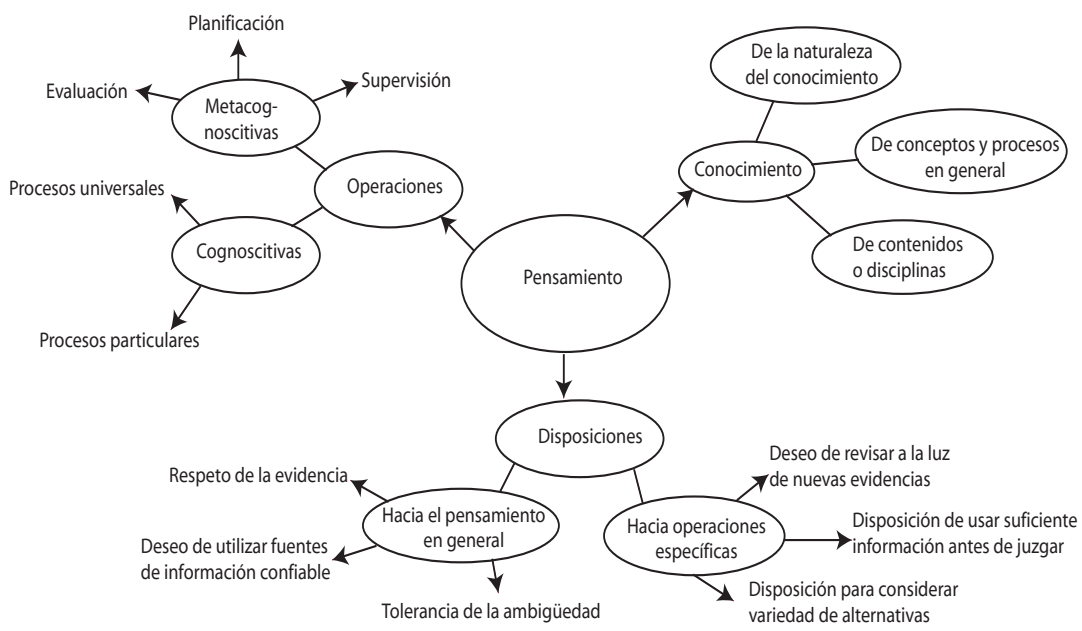

Fuente: Margarita Amestoy, 2002

Elaboración: Jaramillo y Puga 
Margarita Amestoy (2002), resume que el pensamiento involucra tres aspectos: las operaciones cognitivas y metacognitivas. Las cognitivas se refieren a los procesos mentales del pensamiento en una forma rápida fortalecida en procesos lógicos, mientras tanto las metacognitivas son aquellas que permiten dirigir y controlar la producción de significados, procesos y productos del pensamiento y darle sentido a través de los procesos de planificación, supervisión y evaluación del acto mental.

El segundo aspecto se refiere al conocimiento de la materia o área en el cual se piensa, incluye conocer fuentes confiables de datos en un campo particular del conocimiento; útiles para generar, organizar y darle sentido a la información en el área específica (Doyle 1983, citado por Beyer, 1987). Por tanto se relaciona con la información existente ya sea por la naturaleza del conocimiento en general o por la especificidad de acuerdo al entorno de las disciplinas o conocimientos particulares.

$\mathrm{Y}$ el tercero son las disposciones, que pueden ser de dos tipos, hacia el pensamiento en general y hacia las operaciones específicas. En las primeras se destaca las disposiciones tales como la tolerancia de la ambigüedad, deseo de utilizar fuentes de información confiable, y el respeto por la evidencia. Y en las operaciones específcas se destaca la disposición de buscar tanta información como sea posible antes de emitir juicios, y la flexibilidad para cambiar y aceptar enfoques y puntos de vista diferentes a los propios. En fin el pensamiento articula varios aspectos antes de extrapolar ideas que se lo realiza a través de la palabra.

Por otra parte, es importante recordar varios tipos de pensamiento que se maneja en los seres humanos, sin embargo explícitamente se abordará sobre el pensamiento lógico y pensamiento abstracto, mismos que se expondrá mas adelante.

\section{Tipos o clases de pensamiento}

Los tipos de pensamiento o mejor llamados formas de pensamiento, hacen referencia a cómo la mente procesa las acciones e ideas, actividades creativas e intelectuales para trasladarlas a alguna forma de conocimiento. El pensamiento no es unívoco, al contrario, se han identificado diferentes formas particulares de operar el pensamiento; formas que tienen que ver directamente con las características del problema que el individuo enfrenta. De acuerdo a la ponencia realizada por Jhon Fredy Bustos Ruiz (2009), docente de la Universidad Nacional Abierta y a Distancia de Colombia, los tipos de pensamiento se relacionan directamente con la manera particular y la exigencia de cada problema o tarea. 
Varios autores clasifican dos grandes grupos de pensamiento: el convergente y el divergente. El pensamiento convergente se relaciona principalmente con la solución directa de un problema, también definido como racional, lógico, vertical o convencional. Por su parte, el pensamiento divergente hace referencia principalmente a la forma en la que las personas utilizan juicios marginales (intuiciones), para abordar un problema de manera creativa e imaginativa (Pacual, 2006, p. 35). De esta clasificación varios autores desagregan otras sub clasificaciones, tales como pensamiento lógico, crítico, tradicional, creativo, entre otros.

En ese contexto, para definir los tipos de pensamiento se ha utilizado la forma genérica en la que la mente abstrae conocimientos, esto es de manera racional (o lógica), o de manera abstracta (imaginativa). Es decir, todo aquello que sea de naturaleza mental es considerado pensamiento, bien sean estos abstractos, racionales, creativos, artísticos, etc. Con la finalidad de fundamentar adecuadamente la investigación del tema propuesto se describe el pensamiento lógico y el pensamiento abstracto.

\section{Pensamiento lógico}

Antes de definir el pensamiento lógico, es importante definir ¿qué es lógico? La lógica investiga la relación de consecuencia entre una serie de premisas y la conclusión de un argumento correcto (válido), si su conclusión se sigue o es consecuencia de sus premisas (Pascual, 2006, p. 3). A partir de esta definición se deduce que la lógica se refiere a poner en juego procesos lineales hasta conseguir resultados de acuerdo a un formato secuencial.

En las aulas de clase puede ser recurrente que los docentes cuando abordan un tema nuevo entre sus estudiantes, utilicen la frase "lean, analicen y elaboren un resumen" situación que no indica los procesos lógicos-abstractos previo a realizar la actividad solicitada. Sin embargo, de acuerdo a varios autores, realizar este tipo de actividades sin rumbo pedagógico no optimiza significativamente buenos resultados. Para autores como Cerda (2011, p. 72), estas actividades lineales no necesariamente refuerzan la comprensión lectora de arriba hacia abajo o de abajo hacia arriba ni permiten abstraer conclusiones significativas. De acuerdo a lo expuesto por Carbó (2000, p. 92) en el hemisferio izquierdo, para las personas diestras, se producen las conecciones del pensamiento lógico/ razonador/lineal, todo el material sensitivo se procesa como información secuencial siguiendo un orden, por lo que el lenguaje es uno de los ejemplos característicos de este modelo de pensamiento. 
Una vez afianzado el pensamiento lógico, es importante avanzar al pensamiento lateral, el mismo que permite complementar el pensamiento lógico ya que éste por si sólo no basta (Rajadell, 2009, p. 67) manifiesta que la lógica actúa de forma pautada, mecánica, ordenada que muchas veces conduce a vías sin salida ya que, de manera lógica la mente no puede dar saltos que enfoquen el problema desde una perspectiva integral.

En consecuencia se puede anotar que los procesos de pensamiento lógico abstracto, adecuadamente fomentados y aplicados, permiten a los educandos/as conseguir que piensen, razonen, analicen y argumenten de manera lógica, crítica y creativa cualquier conocimiento, los mismos que se convierten en insumos potenciales para aportar en la solución de problemas. De la misma manera el pensamiento lógico permite fortalecer los procesos de enseñanza aprendizaje desde los primeros años de formación hasta la educación superior, sin olvidar que será importante añadir un sistema de reglas, tácticas, procesos que coadyuven al entendimiento de una buena comprensión de saberes e itinerarios educativos. Para profundizar en lo manifestado presentamos un análisis de su definición y alcances.

\section{Definición de pensamiento lógico}

El pensamiento lineal o lógico, es la manera en la cual las personas con especial énfasis los estudiantes, aprenden a pensar desde edades tempranas o a inicios de la vida escolar, que al ser adecuadamente aplicados desde las aulas permiten llegar a una reflexión significativa. Este tipo de pensamiento se desprende de las distintas relaciones que surgen en el cerebro ante la necesidad de encontrar razonamientos lógicos en el accionar diario, cuyo fin es llegar a la construcción de conocimientos y reflexiones que sirvan a lo largo de la vida. El éxito será cuando las estructuras cognitivas se optimicen a través de la lógica del pensamiento. Desde esta perspectiva Oliveros señala que:

El razonamiento lógico es eminentemente deductivo, incluso algunos autores lo definen como tal, mediante este razonamiento se van infiriendo o asegurando nuevas proposiciones a partir de proposiciones conocidas, para lo cual se usan determinadas reglas establecidas o demostradas. [...] el uso del razonamiento lógico permite de forma general analizar y encausar muchas de las situaciones que nos presentan en la vida diaria (Oliveros, 2002, p. 126).

Estas aseveraciones afianzan la importancia de los procesos deductivos en el razonamiento, con lo cual se fortalece el análisis de situaciones 
cotidianas o problemas de contexto en el aula, no necesariamente tienen que apelar a experiencias pasadas, sino más bien aplicar procesos de razonamiento lógico adecuadamente fomentados.

En virtud de aquello, este tipo de razonamiento además de tener buenos procesos de comprensión lógica sirve para resolver problemas codianos de la vida diaria. El propósito es lograr que los saberes y las destrezas se manejen correctamente para llegar a la innovación en la labor educativa con flexibilidad, eficacia y eficiencia en diferentes contextos y llegar a la auto-reflexión sobre el accionar pedagógico.

En consecuencia, se puede concluir que el razonamiento lógico se convierte en una herramienta fundamental para la resolución de problemas de la vida diaria, ya que a través del mismo los individuos analizan, argumentan, clasifican, justifican y prueban hipótesis. Por otra parte para complementar este tipo de pensamiento es importante relacionar con el pensamiento creativo (cuadro 2), el mismo que aporta con varias características y atributos relevantes que fortalecerán el análisis, la síntesis, argumentos de saberes, y abstracción de conclusiones de textos en forma fácil y oportuna.

\section{Cuadro 2}

Análisis comparativo entre el pensamiento lógico vs. el creativo

\begin{tabular}{|l|l|}
\hline \multicolumn{1}{|c|}{ Lógico } & \multicolumn{1}{c|}{ Creativo } \\
\hline Selectivo & Productor de ideas \\
\hline Exacto, racional & Intuitivo \\
\hline Lógico,matemático & Expontáneo, artístico \\
\hline Ordenado & Desordenado \\
\hline Parcializador & Totalizador \\
\hline Secuencial & Globalizador \\
\hline Deductivo & Inductivo \\
\hline Clasificador, categorizador & Reestructura alternativamente \\
\hline Avanza por un camino & Busca nuevos caminos \\
\hline Cada paso debe ser correcto & El resultado ha de ser correcto \\
\hline Aquello normativo y demostrable & Lo original \\
\hline Lenguaje hablado & La expresión no verbal \\
\hline
\end{tabular}

Fuente: Carbó (2000, p. 91)

Elaboración: Jaramillo y Puga

En el resumen comparativo se observa que el pensamiento lógico tiene su fundamentación en seguir un camino trazado, es decir se ma- 
neja con un proceso secuencial de orden deductivo para llegar a generalizaciones en base a un formato planificado y secuenciado. En cambio el pensamiento creativo no maneja procesos establecidos pero las ideas producidas son el resultado de diferentes procesos expontáneos manejándose a través de la intuición y la originalidad. Se deduce que los dos tipos de pensamiento son complementarios en el proceso de la creación de conocimientos.

A fin de fortalecer el análisis realizado sobre el pensamiento lógico, a continuación se analiza las principales características del pensamiento abstracto.

\section{Pensamiento abstracto}

El pensamiento abstracto se convierte en el reflejo próximo y generalizado de la realidad, convirtiéndose en un proceso mental en el cual se destaca lo principal y/o hecho fundamental de una determianda acción o vivencia. Distintos autores consideran que para realizar este proceso de abtracción, el cerebro realiza una separación imaginaria de los distintos elementos que lo generan, para focalizarse únicamente en lo fundamental. Así Castañeda et al. (2007) mencionan:

Abstraer es separar por medio de una operación intelectual las cualidades de un objeto para considerarlos aisladamente o para considerar el mismo objeto en su pura esencia o noción. Abstrarer es captar con el entendimiento el significado o esencia de la cosas. Este hecho es indispensable para que el alumno aprenda a aprender (Castañeda et al., 2007, p. 66).

En virtud de aquello, el pensamiento abstracto permite identificar la esencia de los contenidos cuya particularidad es que luego de señalar los atributos relevantes de un texto se pueda identificar exclusivamente la esencia de las cosas, fortaleciéndose conceptos, juicios de valor y saberes de aprendizaje.

Uno de los beneficios de utilizar el pensamiento abstracto para el análisis y síntesis de nuevos aprendizajes, es la velocidad con que nuestras capacidades cognitivas operan (Ferreira, 2007), esto debido a que permite deducir, sintetizar, interpretar y analizar los distintos fenómenos que nos afectan de manera rápida y asociativa. Este pensamiento permite trascender al conocimiento entre las distintas premisas hipotéticas que en el operan hacia la construcción de pensamientos formales. Autores como Beltrán y Bueno (1995), indican que: 
En esta etapa marca el tercero y último de los estadios evolutivos de la inteligencia; en ella se logra la capacidad de pensamiento abstracto; con él, el sujeto precinde de los estímulos concretos y puede realizar razonamientos formales sobre un nivel abstracto. Su rasgo mas marcado es la capacidad para razonar de un modo lógico, partiendo de premisas y deduciendo las conclusiones pertinentes [...] este pensamiento está implicado en la mayor parte de contenidos y conocimiento de la enseñanza secundaria (p. 76).

Por tanto, este tipo de pensamiento amplía el pensamiento deductivo, ya que permite que se razone desde varias aristas del cerebro y en diferentes contextos, sin embargo, es importante recalcar que en el aula cotidianamente se utliza razonamientos lineales, pero al solicitar se razone de otra forma a los estudiantes contribuirá a complementar procesos de aprendizaje que implícitamente estaría el razonamiento abstracto, mismo que aportará eficazmente al quehacer educativo cotidiano.

\section{Definición de pensamiento abstracto}

El pensamiento abstracto refiere, como se mencionó anteriormente, a la manera en la que el cerebro extrapola y absorve ideas nuevas a través de la imaginación. Fonológicamente nace del verbo “abstraer", que de acuerdo al diccionario de la Real Academia Española significa: considerar aisladamente las cualidades escenciales de un objeto para entender su escencia (RAE, 2016).

Antes de definir el pensamiento abstracto es importante conocer que es la abstracción, al respecto Delval (2001) en su texto Aprender a aprender manifiesta que la abstracción es "la capacidad de deducir, sintetizar, interpretar, analizar los fenómenos que nos afectan” (p. 21).

Es decir la abstracción es un nivel elevado del pensamiento en el cual convergen la deducción, la síntesis, la interpretación y el análisis, con estos antecedente planteados conceptualizamos al pensamiento abstracto, al respecto, Guétmanova (1989) en su libro de Lógica, "el pensamiento abstracto es el medio para la construcción del conocimiento teórico a través del proceso de formación del concepto".

De acuerdo con esta definición, las abstracciones científicas son los conceptos, las categorías y sus relaciones (leyes, hipótesis) que el pensamiento humano elabora con base en la realidad concreta y en los cuales se destacan los aspectos y relaciones fundamentales de los procesos u objetos con el propósito de conocer las leyes por las cuales existen, se desarrollan y transforman. Autores como Guétmanova, sostienen que el 
pensamiento abstracto se manifiesta a través de tres formas escenciales: concepto, juicio y razonamiento como medio para la construcción del conocimiento teórico:

Conocemos las leyes del mundo, la esencia de los objetos y de los fenómenos, lo común de ellos mediante el pensamiento abstracto, la forma más compleja del conocimiento. El pensamiento abastracto o racional refleja al mundo y sus procesos de un modo más pleno y profuncdo que el conocimiento sensitivo. El paso del conocimiento sensitivo al pensamiento abstracto es un salto en el proceso cognoscitivo, un salto del conocimiento ade los hechos al de las leyes (Guétmanova, 1989, p.15).

Por tanto el pensamiento abstracto es el medio para la construcción del conocimiento teórico a través del proceso de formación de conceptos, es un reflejo mediato y generalizado de la realidad, es una forma de conocer el mundo más allá de los sentidos, una característica principal del pensamiento abstracto es la capacidad de procesar varios hechos a la vez, definiendo así prioridades para una respuesta, independientemente de que ésta sea conveniente o no.

Así, el pensamiento abstracto según Delval (2001), en su texto Aprender a aprender "supone también la capacidad de asumir un marco mental de forma voluntaria. Implica la posibilidad de cambiar a voluntad de una situación a otra, de descomponer el todo en partes y de analizar de forma simultánea distintos aspectos de una misma realidad" (p. 21).

Evidentemente por lo citado, el pensamiento abstracto tiene una clara diferencia con el pensamiento formal, en el hecho que el primero supone una serie de actos y pensamientos "simbólicos", en el cual se involucran hechos relacionados a la deducción, síntesis e interpretación de fenómenos; mientras que el segundo, se basa principalmente en experiencias reales, muchas de las veces creadas previamente en nuestra memoria fruto de objetos (hechos) concretos creados.

En virtud de aquello cabe señalar que según Jean Piaget (18961980), importante investigador suizo del aprendizaje y el desarrollo y fundador de la epistemología genética, planteó que el desarrollo cognoscitivo en la persona se da por etapas, así como determina que la etapa de pensamiento formal o abstracto empieza, aproximadamente, a los 11 años y se consolida hacia los 15 años. En esa época, Piaget consideraba inevitable llegar a esta etapa que se caracteriza por el pensamiento hipotético deductivo (método científico), la combinatoria, la lógica proposicional, la reversibilidad y las proporciones. Una vez que se ha explicado el pensamiento lógico y abstracto se presenta un cuadro comparativo que resume las implicaciones citadas. 


\section{Cuadro 3}

\section{Relación entre pensamiento lógico y pensamiento abstracto}

\begin{tabular}{|l|l|}
\hline \multicolumn{1}{|c|}{ Pensamiento lógico } & \multicolumn{1}{c|}{ Pensamiento abstracto } \\
\hline Es reversible e interno, es tangible. & $\begin{array}{l}\text { No tiene forma, no es describible con pa- } \\
\text { labras, es decir es intangible. }\end{array}$ \\
\hline Gobernado por el intelecto. & Gobernado por la imaginación. \\
\hline $\begin{array}{l}\text { Divide al todo en partes y establece rela- } \\
\text { ciones entre ellas. }\end{array}$ & $\begin{array}{l}\text { Capacidad de razonar en forma desliga- } \\
\text { da de lo real. } \\
\text { Se basa en esquemas formales permite } \\
\text { deducir, extrapolar lo aprendido a cual- } \\
\text { quier otra situación, comparar o sacar } \\
\text { conclusiones. }\end{array}$ \\
\hline $\begin{array}{l}\text { Es capaz de atender objetos formales u } \\
\text { objetos abstractos. }\end{array}$ & No parte de relaciones observadas. \\
\hline $\begin{array}{l}\text { Ubica el tiempo de manera lineal y pre- } \\
\text { tende objetividad. }\end{array}$ & $\begin{array}{l}\text { Permite conocer al mundo más allá de } \\
\text { los sentidos. }\end{array}$ \\
\hline $\begin{array}{l}\text { El hemisferio cerebral predominante es } \\
\text { el izquierdo. }\end{array}$ & $\begin{array}{l}\text { Distingue lo esencial de lo secundario, } \\
\text { entre lo interno y externo. }\end{array}$ \\
\hline Genera hipótesis, hace inferencias. & $\begin{array}{l}\text { Resuelve problemas lógicos, imaginan- } \\
\text { do, sin necesidad de hacerlo con algo } \\
\text { tangible. }\end{array}$ \\
\hline $\begin{array}{l}\text { Se expresa mediante proposiciones y } \\
\text { conectivos. }\end{array}$ & $\begin{array}{l}\text { Está desligada del lenguaje, depende de la } \\
\text { conciencia voluntaria y la personalidad. }\end{array}$ \\
\hline
\end{tabular}

Fuente: Resumen de varios autores citados

Elaboración: Jaramillo y Puga

A manera de explicación se manifiesta aspectos relacionados con el pensamiento lógico y el pensamiento abstracto. El pensamiento lógico tiene su fundamentación en seguir un camino trazado, es de carácter lineal, y se optimiza el hemisferio cerebral izquierdo, es decir se maneja con un proceso secuencial para generar hipótesis y hacer inferencias que son proposciones para llegar a conclusiones finales. En cambio, el pensamiento abstracto es gobernado por la imaginación se basa en esquemas formales permite deducir, extrapolar lo aprendido a cualquier otra situación, comparar o extraer conclusiones, es más intuitivo, no se maneja con esquemas trazados y contribuye a resolver problemas lógicos y creativos sin necesidad de hacerlo con algo tangible y con esquemas establecidos.

El escenario observado nos lleva a señalar que estos dos tipos de pensamiento se articulan en bien de la educación, con el fin de que nuestros estudiantes resuelvan problemas de contexto sin dificultad, 
comprendan lo que leen, sean creativos, y resuelvan ejercicios de razonamientos lógico matemático y de razonamiento abstracto, entre otros. Entonces, es importante que los docentes se concienticen sobre el papel trascendente que desempeñan en la formación de los estudiantes y que desde los primeros años de Educación General Básica apliquen procesos lógicos-abstractos en las actividades pedagógicas de aula, a fin de preparar a sus estudiantes para que respondan a las exigencias de la educación actual y se desempeñen eficientemente en actividades puntuales como en la rendición de las pruebas para el ingreso a las universidades sean públicas o privadas.

Seguidamente, se abordarán aspectos relacionados a los procesos cognitivos los mismos que intervienen en los pensamientos indicados anteriormente.

\section{Procesos cognitivos}

Los procesos cognitivos hacen referencia a la habilidad para asimilar nuevos conocimientos a través de la atención, comprensión, memoria y el lenguaje. Un ejemplo práctico: Es usual observar en nuestro medio, la aplicación de las clases magistrales en las cuales únicamente habla el profesor, convirtiéndose los estudiantes en simples receptores, pensando erróneamente que mientras más "hablen" y expliquen un tema, mayor será la capacidad de recepción y comprensión de conocimientos por parte de sus estudiantes. Sin embargo, si se le diera el protagonismo al estudiante, proporcionando las directrices básicas y necesarias para que luego él trabaje mediante la investigación, a base de diferentes técnicas como una "lluvia de ideas" sobre de lo que conocen del tema, se tenga una línea base o hipótesis sobre la cual partirá el tema nuevo, esto significa que se active y se fortalece los procesos cognitivos. De esta forma el docente conectará los conocimientos previos con los conocimientos nuevos, situación recomendada para iniciar una clase pedagógica.

Por lo expuesto, se deduce que lo importante, no es que el maestro enseñe (es decir, que invierta tiempo, esfuerzo y voz, etc.), sino que el alumno/a aprenda (haga suya la información, la almacene después de darle un tratamiento activo, de ajustarla a sus marcos de referencia, de desmenuzarla varias veces y amalgamarla nuevamente a sus esquemas cognitivos). Es decir el docente debe darle las herramientas necesarias al estudiante (procesos cognitivos) para que el aprendizaje día a día sea más significativo. Así, al docente en los procesos de enseñanza y aprendizaje 
le corresponderá aplicar estrategias para iniciar, desarrollar y concluir el aprendizaje.

Por otra parte, las actividades propuestas en los procesos psicopedagógicos de clase deberán ajustarse a los procesos cognitivos respetando el nivel evolutivo de los estudiantes para que se promueva el desarrollo de las diferentes habilidades de pensamiento, proceso de indagación, razonamiento, organización de datos y aplicación del conocimiento con distintos grados de complejidad, los mismos que servirán para encaminarles constantemente a un razonamiento lógico y abstracto.

Por otro lado, estos procesos de clase están relacionacionados con la cognición, a la que iniciaremos indicando el origen etimológico.

\section{Cognición}

Conviene comenzar nuestra exposición explicando lo que se entiende por cognición, este término se relaciona con la práctica educativa cuando los docentes pensamos y decimos que los estudiantes desarrollen su pensamiento para abstraer aprendizajes. En tal sentido esta idea es muy utilizada por los docentes desde las aulas pedagógicas más aún cuando enseñamos para la vida. En relación a lo indicado se explica en el siguiente párrafo.

La palabra cognición corresponde a la etimología latina de los términos conocimiento y conocer. El significado de la palabra conocer es "captar o tener la idea de una cosa, llegar a saber su naturaleza, cualidades y relaciones, mediante las facultades mentales" (Ortiz, 2009). El autor citado indica que cognición se refiere al proceso de conocer ideas, las mismas que pueden ser generales o especificas, cuyo objetivo final es entender el significado de cada cosa, por ello actúa en estos procesos las facultades mentales del pensamiento que poseen los seres humanos.

Este proceso comienza desde edades muy tempranas, inclusive antes de que la persona nazca. Cada uno de los hechos que observamos, sentimos, palpamos, escuchamos y percibimos se convierten automáticamente en conocimientos. Así, nuestros juicios de valor no son netamente propios, son el resultado de cogniciones aprendidas durante todo el proceso de la vida. En este proceso intervienen también factores culturales y costumbristas.

Así mismo Ortiz (2009) indica que, la cognición [...]son las funciones complejas que operan en las representaciones perceptivas o recobradas de la memoria, es decir las estructuras mentales organizadoras que influyen en la interpretación de la información (p.12). 
En este sentido, este término se relaciona con el conocimiento, mediante los cuales la persona adquiere sapiencias, el mismo que debe ser transformado, elaborado y almacenado en el pensamiento del ser humano. Y posteriormente estos procesos se fijan en el cerebro a través del conocimiento aprendido. En virtud de lo expuesto, Piaget argumenta que "el desarrollo cognitivo sucede en forma semejante al desenvolvimiento de un argumento lógico: paso por paso, en una secuencia de etapas y sub etapas [...] por tanto el desarrollo cognitivo efectivamente implica la construcción del conocimiento" (Klingler \& Vadillo, 1997, p. 44).

Por otro lado, estos procesos cognitivos constituyen los ordenamientos para que todo ser humano procese información a fin de incorporar conocimientos nuevos en su esquema cognitivo. Sin olvidar que en el proceso actúan facultades muy diversas, como la comprensión, la memoria y el lenguaje. Esto hace que los procesos cognitivos puedan analizarse desde diferentes disciplinas y áreas del conocimiento. Así mismo otro factor que ayuda a la construcción del conocimiento es la percepción, ya que permite a través de los sentidos, organizar los estímulos y favorecer la continuación del proceso cognitivo en cuestión.

Por lo antes expuesto a continuación se analizan los siguientes conceptos.

\section{Procesos cognitivos}

La mayoría de los docentes estamos conscientes y buscamos que los estudiantes aprendan a aprender, es decir incorporen a su esquema cognitivo conocimientos aprendidos o signficativos desde las aulas de clases, y estamos convencidos que ponen en juego el pensamiento para comprender significativamente los temas tratados. Pero en verdad no es así y nos preguntamos ¿por qué no comprenden los estudiantes temáticas planificadas?, ¿será verdad que no aplican los procedimientos del aprender a aprender?, ¿por qué no resuelven tareas significativas y de contexto? Para responder estas interrogantes exploraremos los procesos cognitivos en función de varios autores.

Para Aurelia Rafael Linares (2009):

Los procesos cognitivos son el conjunto de transformaciones que se dan en el trascurso de la vida, por el cual se aumentan los conocimientos y habilidades para percibir, pensar y comprender, estas habilidades son utilizadas para la resolución de problemas prácticos de la vida cotidiana (p. 2). 
Es decir, estos procesos cognitivos al ser muy bien aplicados desde contextos de aprendizaje que inicialmente constituyen las aulas de clases, será para el ser humano más fácil incorporar conocimientos de una forma significativa y estos a la vez estarán relacionados a la inteligencia, atención, memoria y lenguaje para posteriormente aplicarlos en la solución de problemas de la vida.

En los procesos cognitivos interviene también:

Las estrategias cognitivas las mismas que operan en los procesos de adquisición de nueva información entrante, su organización, recuperación o activación y utilización del conocimiento disponible en la memoria semántica. Las estrategias cognitivas conciernen, pues, a los procesos de regulación y control que gobiernan los procesos mentales envueltos en el aprendizaje y el pensamiento en general, como los procesos de atención, percepción, memoria, etc., [...] (Rivas, 2008, p. 30).

En este sentido, para potencializar los procesos cognitivos desde varios escenarios educativos, es indispensable aplicar estrategias cognitivas los mismos que servirán de apoyo para fijar el conocimiento aprendido en el esquema cognitivo de las personas a fin de ir formando nuevos aprendizajes, los mismos que se evidenciarán cuando se abstrae conocimientos de toda clase de textos y el estudiante tendrá la oportunidad de profundizar y ampliar el nuevo conocimiento aprendido con la investigación en varias fuentes de consulta entre ellas, el internet y más aún si los relaciona con otras áreas del saber, es decir, sabrá elaborar proyectos que le permitan dar solución a los problemas que se presenten en el diario vivir, desde allí se fortalecerá el enseñar para la vida.

Sin embargo, a fin de relacionar los procesos cognitivos enseguida se explica sobre las teorías cognitivas contemporáneas mismas que sustentan la temática.

\section{Teorías cognitivas}

\section{Teoría psicogenética de Jean Piaget}

Jean Piaget fue un epistemólogo, psicólogo y biólogo de formación, se dedicó al estudio del conocimiento. Para este autor el conocimiento se construye en un proceso de interacción sujeto-objeto a partir de la interacción dialéctica que surge entre ambos.

Por ello, nos indica que para que exista construcción cognitiva es necesario tomar en cuenta cuatro factores los mismos que constituyen 
la maduración biológica que se trata de un factor imprescindible como condición necesaria para que surjan algunas conductas. Lo que se explica en lo siguiente:

[...] 1.- Se refiere fundamentalmente al sistema nervioso central. 2.- Experiencia física y lógica matemática sobre los objetos. La experiencia sobre los objetos implica asimilaciones y acomodaciones. 3.- Transmisión social por el hecho de pertenecer a una sociedad se producen interacciones y trasmisiones sociales que implican la participación del sujeto y la asimilación a sus esquemas de lo que es transmitido. 4.- Equilibración se trata del mecanismo que permite compensar las perturbaciones y avanzar en el desarrollo (Elichiry, 2004, p.169).

Las personas requieren de una maduración biológica para abstraer los conocimientos siendo un factor imprescindible para que surjan algunas conductas además del conocimiento adquirido. Así también hay que relacionar lo físico y la lógica matemática sobre los objetos de estudio, el mismo que permitirá que los objetos se asimilen y se acomoden en los esquemas cognitivos. Para que posteriormente exista interacción con la sociedad, en fin es llegar a la equilibración del conocimiento.

Por ello se explica las etapas de la vida en la adquisicion del conocimiento según este autor.

\section{Cuadro 4}

Etapas de la vida y adquisión del conocimiento según Jean Piaget

\begin{tabular}{|c|l|l|l|}
\hline Etapas & \multicolumn{1}{|c|}{$\begin{array}{c}\text { Periodo } \\
\text { de vida }\end{array}$} & \multicolumn{1}{|c|}{ Características } & \multicolumn{1}{c|}{$\begin{array}{c}\text { Principales } \\
\text { adquisiciones }\end{array}$} \\
\hline Sensoriomotora & $\begin{array}{l}\text { Desde el naci- } \\
\text { miento hasta } \\
\text { los 2 años }\end{array}$ & $\begin{array}{l}\text { El niño/a utiliza los sen- } \\
\text { tidos y las habilidades } \\
\text { motoras para entender } \\
\text { el mundo. El aprendi- } \\
\text { zaje es activo no hay } \\
\text { pensamiento conceptual } \\
\text { o reflexivo. }\end{array}$ & $\begin{array}{l}\text { El niño/a aprende } \\
\text { que un objeto to- } \\
\text { davía existe cuando } \\
\text { no esta a la vista y } \\
\text { empieza a pensar } \\
\text { utilizando acciones } \\
\text { mentales. }\end{array}$ \\
\hline Preoperacional & $\begin{array}{l}\text { Se extiende } \\
\text { desde los } 2 \\
\text { años hasta } \\
\text { los } 6 \text { años de } \\
\text { edad }\end{array}$ & $\begin{array}{l}\text { El niño/a utiliza el } \\
\text { pensamento simbólico, } \\
\text { que incluye el lenguaje } \\
\text { para entender el mun- } \\
\text { do. El pensamiento es } \\
\text { egocentrico y eso hace } \\
\text { que el niño/a entienda } \\
\text { el mundo solo desde su } \\
\text { perspectiva. }\end{array}$ & $\begin{array}{l}\text { La imaginación } \\
\text { florece y el lenguaje } \\
\text { se convierte en un } \\
\text { medio importante } \\
\text { de autoexpresión } \\
\text { y de influencia de } \\
\text { otros. }\end{array}$ \\
\hline
\end{tabular}




\begin{tabular}{|l|l|l|l|}
\hline \multirow{2}{*}{\begin{tabular}{|l|l|l|} 
Operacional \\
Concreta
\end{tabular}} & $\begin{array}{l}\text { Conprende } \\
\text { entre los } 6 \text { a } \\
11 \text { años }\end{array}$ & $\begin{array}{l}\text { El niño/a entiende o } \\
\text { aplica operaciones o } \\
\text { principios lógicos para } \\
\text { interpretar las experien- } \\
\text { cias en forma objetiva y } \\
\text { racional. Su pensamien- } \\
\text { to se encuentra limitado } \\
\text { por lo que puede, ver, } \\
\text { oir, y experimentar } \\
\text { personalmente. }\end{array}$ & $\begin{array}{l}\text { Al aplicar capaci- } \\
\text { dades lógicas, los } \\
\text { niños/as aprenden } \\
\text { a comprender los } \\
\text { conceptos de con- } \\
\text { servación, número, } \\
\text { clasificación, y } \\
\text { muchas otras ideas } \\
\text { científicas. }\end{array}$ \\
\hline \multirow{5}{*}{$\begin{array}{l}\text { Operacional } \\
\text { Formal }\end{array}$} & $\begin{array}{l}\text { Comprende } \\
\text { desde los } 12 \\
\text { años hasta la } \\
\text { adultez }\end{array}$ & $\begin{array}{l}\text { El adolescente y adulto } \\
\text { son capaces de pensar } \\
\text { acerca de abstracciones } \\
\text { y conceptos hipotéticos } \\
\text { y razonar en forma ana- } \\
\text { lítica y no solo emocio- } \\
\text { nalmente. Puede incluso } \\
\text { pensar en forma lógica } \\
\text { ante hechos que nunca } \\
\text { experimentaron. }\end{array}$ & $\begin{array}{l}\text { La etica, la política } \\
\text { y los temas sociales } \\
\text { yorales se hacen } \\
\text { más interesantes } \\
\text { a medida que el } \\
\text { adolescente y el } \\
\text { adulto son capaces } \\
\text { de desarrollar un } \\
\text { enfoque mas am- } \\
\text { plio. y mas teórico } \\
\text { de la experiencia. }\end{array}$ \\
\hline
\end{tabular}

Fuente: Alcocer, 2006, p. 47)

Elaboración: Jaramillo y Puga

Esto significa que para captar y aprehender los conocimientos desde varios contextos y obtener resultados satisfactorios, es necesario considerar las etapas evolutivas del hombre. Según este autor, la adquisición del conocimiento también surge por la reorganización de las estructuras cognitivas como consecuencia de procesos adaptativos al medio (contexto), a partir de la asimilación de experiencias y acomodación de las mismas. Proceso en el cual la información previa que posea la persona en las estructuras cognitivas, juega un papel muy importante.

Por ello, es que aprender según Piaget, se consigue a partir de la reorganización de las estructuras cognitivas, de tal forma que al final de un proceso de adquisición del conocimiento se obtendrá nuevos conocimientos acomodados en los esquemas del pensamiento, situación que perdurará para toda la vida.

\section{Teoría del aprendizaje significativo de David Ausubel}

David Ausubel fue un psicólogo y pedagogo estadounidense, considerado uno de los autores mas influyentes en la teoría del constructivismo. En 
ese sentido, para él es fundamental la construcción del aprendizaje significativo, en el cual, el individuo posee una estructura cognitiva que es fruto de una red orgánica de conocimientos previos, hechos e información.

Para Requena \& Sainz (2009), indican que el aprendizaje significativo se da cuando:

Desde este punto de vista el niño aprende cuando es capaz de darle sentido y significado a su aprendizaje. $Y$ da significado cuando establece relación entre lo que ya sabe y lo que está aprendiendo entre los conocimientos previos y los conocimientos nuevos. En este sentido podemos decir que el aprendizaje significativo integra, mejora y completa los conocimientos anteriores [...] sin olvidar que los mismos deben ser funcionales y deben de alguna forma tener la posibilidad de aplicación práctica (p. 101).

Entonces, los docentes en las aulas debemos interactuar con los estudiantes hasta que relacionen sus saberes anteriores con los saberes nuevos, momento en el cual estos procesos cognitivos serán funcionales al verlos aplicados en la vida diaria.

\section{Teoría aprendizaje por descubrimiento de J. Bruner}

J. Bruner fue un psicólogo estadounidense que hizo importantes contribuciones a la psicología cognitiva y a las teorías del aprendizaje, que marcaron toda una revolución en su momento por hacer fuertes críticas a los modelos de aprendizaje o usualmente llamados "memorísticos".

Para Ferreira \& Pedrazzi, el aprendizaje por descubrimiento se da cuando:

Al considerar que la escuela es el espacio para el descubrimiento determina que la labor del docente es presentar situaciones problemas para que ellos descubran por sí mismos, "las ideas fundamentales, relaciones o patrones de materias, esto es, la información esencial" (Woolfo$1 k, 1999)$. Por ende se entiende que la enseñanza debe partir de lo más simple a lo más complejo [...] y considera que los procesos cognitivos son procesos de conceptualización y procesos de codificación y organización de códigos (p. 66).

Esto nos demuestra que el conocimiento se abstrae cuando el docente o el mediador del aprendizaje presentan un problema de estudio convirtiéndose en un objeto de análisis cuyo fin es extraer las caracterís- 
ticas del conocimiento, y estos a la vez se fijarán en el esquema cognitivo provocando la conceptualización de códigos en el pensamiento.

Asimismo, otro autor realimenta este tipo de aprendizaje cuando indica que:

La estrategia de aprendizaje por descubrimiento trata de enseñar al educando la manera de aprender. Lo ayuda a adquirir un conocimiento que solamente es suyo porque él lo descubre por sí mismo [...] y es una cuestión de reordenamiento interno de los datos de manera que uno pueda ir más allá de ellos y formar nuevos conceptos, implica descubrir los significados, la organización y la estructura de ideas (Quezada, 2007, p. 75).

\section{Teoría sociocultural de L. Vigotsky}

L. Vigotsky, considerado uno de los más destacados investigadores de la psicología del desarrollo, en la cual explica que las interacciones sociales de las personas explican fuertemente el desarrollo de las sociedades y la construcción de sus conocimientos. Vigotsky, habla de la zona de desarrollo próximo.

Según Anita Woolfolk, en cualquier nivel de desarrollo existen ciertos problemas que el niño está a punto de resolver, lo único que necesita es ciertos indicadores, estructura, recordatorios, ayuda para recordar los detalles o pasos [...] es decir la zona de desarrollo próximo se crea porque este estudiante no es capaz de resolver un problema por si solo pero podría tener éxito bajo la guía adulta o con la colaboración de un compañero/a más avanzado (Woolfolk, 2010, p. 52).

Por tanto los procesos cognitivos en el individuo se producen cuando existe la zona de desarrollo próximo, el mismo que es mediado con la ayuda de una persona adulta que en este caso es el profesor o entorno familiar, el objetivo es que le fortalezca los conocimientos en la comprensión de los mismos a fin de que los conocimientos tengan éxito formándose un nuevo conocimiento fortalecido, cuyo aprendizaje se fijará en los esquemas del pensamiento, los mismos que servirán de insumo para resolver problemas de la vida cotidiana.

\section{Conclusiones}

Este artículo desarrolla un análisis sobre el pensamiento lógico y abstracto y su inclusión en los procesos cognitivos, situación de relevancia 
en el accionar pedagógico desde la práctica docente. Es en las aulas de clase en donde se forman estudiantes capaces de pensar, razonar, criticar, memorizar y crear, aportan con conocimientos cognitivos, reflexivos, y participativos en nuevos saberes, situación que contribuirá a mejorar la matriz cognitiva y por ende la educación se insertará a la política pública en función de la igualdad de oportunidades, la interculturalidad y la innovación pedagógica cognitiva y social.

De la misma manera, desde este análisis se pretende que los docentes apliquen metodologías de pensamiento lógico y abstracto en los procesos de enseñanza y aprendizaje, respetando la edad evolutiva del estudiante y los fundamentos psicopedagógicos en la creación y construcción de conocimientos nuevos. No obstante, tampoco se puede olvidar que al ser aplicados estos procesos en forma correcta en el aula, este será un aporte para mejorar la calidad educativa, situación que se comprobará desde las evaluaciones organizadas por dependencias externas, obviamente que será en función de los estándares de aprendizaje y a nivel superior desde los resultados de aprendizaje. Con este análisis se espera que los docentes "dejen de enseñar y que hagan que sus estudiantes trabajen" y que esta contribución fortalezca al docente, profesional que constituye el mediador del accionar pedagógico cuando aplica correctamente desde su realidad educativa los procesos lógicos y abstractos en los procesos cognitivos del aprendizaje, cuyo fin es articular aprendizajes aprendidos y extrapolados a la solución de problemas de la vida real, solo así constituirá un aporte para mejorar la calidad educativa y mas que nada emprender en formas de razonar ya sea ésta de forma lógica y abstracta cuyo objetivo final es que los estudiantes resuelvan sin dificultades problemas de contexto.

De igual forma con la optimización de los procesos lógicos y abstractos se fortalecerá el currículum ecuatoriano evidenciado en la Actualización de la Reforma Curricular 2010, situación que al ser aplicado desde los primeros niveles de estudio estos razonamientos optimizarán desde la práctica educativa a que los alumnos aprendan a pensar, leer con lógica, comprendan conceptos, sean creativos y vislumbren los saberes y abordajes desde lo holístico, sistémico e integral, todo esto contribuirá a mejorar los logros de aprendizaje y, por ende, la calidad educativa ecuatoriana.

En definitiva, lo que buscamos como docentes es que los alumnos sean capaces de pensar con lógica y con visiones creativas mismas que servirán para comprender desde varias aristas bajo la responsabilidad de potenciar los saberes cognitivos, psicomotores y socioafectivos, situación que se interiorizarán en los esquemas cognitivos transformándose en apren- 
dizajes perdurables para toda la vida. Asimismo se fortalecerá el espíritu crítico para extrapolar en saberes a través de proyectos de aula integradores, en fin fortalecer con nuevas estrategias didácticas para que investiguen, socialicen y compartan saberes nuevos a la sociedad y al mundo.

\section{Bibliografía}

ALCOCER, Alberto

2006 Psicología del desarrollo infancia y adolescencia. España: Médica Panamericana.

AMESTOY, Margarita 2002 Revista Electrónica de Investigación Educativa.Venezuela.

ASAMBLEA NACIONAL

2008 Constitución de la República del Ecuador https://www.google.com/search?q $=\mathrm{CONSTITUCION}+\mathrm{DE}+\mathrm{LA}+\mathrm{REPUBLICA}+\mathrm{DEL}+\mathrm{ECUADOR} \& \mathrm{ie}=\mathrm{utf}-8 \&$ oe $=$ utf- 8

ARBOLEDA, Julio César

2013 Hacia un nuevo concepto de pensamiento y comprensión. Boletín Virtual Redipe 824. España.

BELTRÁN, J. \& BUENO, J.A

1995 Psicología de la Educación. España: Boixareu Universitaria Marcombo.

BUSTOS, Fredy

2009 Procesos cognitivos superiores, lección 19, Tipos de pensamientos. Elaborado por la Universidad Nacional Abierta y a Distancia de Colombia.

CASTAÑEDA, Juan, CENTENO, Soledad, LOMELÍ, Luz María, LASSO, María de la Luz, \& NAVA, María de Lourdes

2007 Aprendizaje y desarrollo. México: Umbral.

CARBÓ, Esteve

2000 Manual de Psicología aplicada a la empresa, II. España: Gránica S.A.

CERDA, Hugo

2011 La creatividad en la ciencia y educación. Bogotá: Magisterio.

DELVAL, Juan

2001 Aprender a aprender. Madrid: Alhambra Longman.

ELICHIRY, Nora

2004 Procesos cognitivos. Ediciones Manantial.

FERREIRA, Horacio, \& PEDRAZZI, Graciela

2007 Teorías y enfoques psicoeducativos de aprendizaje. Argentina: Noveduc.

GUÉTMANOVA, Alexandra

1989 Lógica. Serie biblioteca del estudiante. Moscú: Progreso.

KLINGLER, Cynthia \& VADILLO, Guadalupe

1997 Psicología cognitiva. Estrategias en la práctica docente. México: McGraw-Hill.

MINISTERIO DE EDUCACIÓN, ECUADOR

2010 http://educacion.gob.ec/curriculo-educacion-general-basica/

MORRIS, Charles

1985 Introducción a la Psicología. España: Pearson. 
LINARES, Aurelia

2009 Desarrollo cognitivo. Las teorías de Piaget y de Vygotsky. España: Universidad Autónoma de Barcelona.

OLIVEROS, Eladio

2002 Metodología de la enseñanza de Matemática. Ed. Santillana.

ORTIZ, Alexander

2009 Aprendizaje basado en el funcionamiento del cerebro humano. Ediciones Litoral.

PASCUAL, Julián

2006 Apuntes de Lógica. España: La Mancha.http://titan.inf-cr.uclm.es/www/pjulian/ teaching/sl_apLO.pdf

PIAGET, Jean

1980 Teoría del desarrollo cognitivo. España: Morata.

QUEZADA, Jeannette

2007 Didáctica de las ciencias experimentales. España: EUNED.

RAJADELL, Manuel

2009 Creación de empresas. España: UPC.

RAMÍREZ, René

2012 Ecuadoruniversitario.Ecuadorhttp://ecuadoruniversitario.com/estudiantiles /snna/el-89-de-los-estudiantes-superaron-el-enes-del-19-de-mayo/

REQUENA, María Dolores, \& SAINZ, Paloma

2009 Didáctica de la educación infantil. España: Editex.

RAE

2006 http://www.rae.es/

RIVAS, Manuel

2008 Procesos cognitivos y aprendizaje significativo. España: BOCM.

SWARTZ, Robert, COSTA, Arthur, BEYER, Barry, REAGAN, Rebeca, \& KALLICK, Bena

2008 El aprendizaje basado en el pensamiento. España: SM.

VYGOTSKY, L

1989 El pensamiento y lenguaje. Buenos Aires, Argentina: Ediciones Fausto.

UNESCO

2015 Foro Mundial de la Educación. Corea https://alcachofaconporotos.files. wordpress.com/2010/07/percepcion.pdf

WOOLFOLK, Anita

2010 Psicología educativa. México: Pearson

Fecha de recepción del documento: 5 de julio de 2016

Fecha de aprobación del documento: 15 de agosto de 2016 



\title{
A LÓGICA ARGUMENTATIVA E PROPOSICIONAL
}

\author{
NO PROCESSO DE CONSTRUÇÃO
}

DE ARGUMENTOS CIENTÍFICO-FILOSÓFICOS

LA LÓGICA ARGUMENTATIVA Y PROPOSICIONAL EN EL PROCESO

DE CONSTRUCCIÓN DE ARGUMENTOS CIENTÍFICO-FILOSÓFICOS

The arsumentative and propositional logic
in the construction of scientific and philosophical arguments process

\author{
JEANE TORRES DA SILVA* \\ Faculdade Salesiana Dom Bosco / FSDB \\ Manaus - Estado do Amazonas - Brasil \\ jeanetorres3@gmail.com
}

\begin{abstract}
Resumo
Este artigo apresenta uma análise epistemológica das contribuições da lógica argumentativa e da lógica proposicional, baseada nas estruturas proposicionais que compõem os argumentos lógicos, como modelos para a construção de argumentos em textos científico-filosóficos. O objetivo da pesquisa foi identificar as perspectivas teóricas comuns da lógica argumentativa e da lógica proposicional, que contribuem com o processo cognitivo do raciocínio lógico e sua transposição em linguagem lógica, visando demonstrar como utilizar a estrutura proposicional e argumentativa na construção de textos científico-filosóficos, para que comuniquem suas ideias com coerência, clareza, objetividade e coesão. As razões que motivaram a pesquisa foram decorrentes da pratica de orientação de trabalhos de conclusão de cursos da graduação, onde foi possível perceber as dificuldades dos estudantes do ensino superior para construir textos com coerência lógica necessária e suficiente para a compreensão do leitor. A fundamentação teórica da pesquisa foi refletida a partir de concepções, ideias e teorias de filósofos, matemáticos e pesquisadores dedicados ao estudo da lógica, principalmente Aristóteles (2010), Kant (1992), Frege (2009), Copi (1981) e Weston (1996). O percurso metodológico foi norteado pelos ditames da pesquisa qualitativa, possibilitando a interpretação dos processos lógicos que podem contribuir com a construção de argumentos em texto científico-filosóficos, a abordagem da pesquisa foi baseada no método dedutivo, com a composição de argumentos lógicos informais, bem como a utilização dos procedimentos da observação e da pesquisa bibliográfica. Os resultados indicaram que a estrutura proposicional dos argumentos dedutivos pode ser utilizada na construção de argumentos lógicos informais, sendo bastante útil para sintetizar informações e comunicar ideias e teorias, em textos científico-filosóficos com níveis de compreensibilidade maior para o leitor.
\end{abstract}

Forma sugerida de citar: Torres da Silva, Jeane (2016). La lógica argumentativa y proposicional en el proceso de construcción de argumentos científico-filosóficos. Sophia, colección de Filosofía de la Educación, 21(2), pp. 57-81.

* Mestra em Educação em Ciência na Amazônia pela Universidade do Estado Amazonas (UEA). Especialista em Psicopedagogia e Graduada em Filosofia pela Universidade Federal do Amazonas (UFAM). Membro do Núcleo de Pesquisa em Neurociência e Educação do Programa de Pós Graduação em Educação e Ensino de Ciências na Amazônia. Professora de Lógica, Metodologia de Pesquisa e Filosofia Moderna da Faculdade Salesiana Dom Bosco (FSDB/Manaus-AM). 


\begin{abstract}
Palavras-chave
Raciocínio lógico, argumento lógico, estrutura proposicional, texto científico-filosófico, sentido lógico textual.
\end{abstract}

\begin{abstract}
Resumen
En este artículo se presenta un análisis epistemológico de las contribuciones de la lógica argumentativa y la lógica proposicional, basado en estructuras proposicionales que componen los argumentos lógicos, como modelos para la construcción de argumentos en los textos científicos y filosóficos. El objetivo de la investigación fue identificar las perspectivas comunes teóricos de la lógica argumentativa y la lógica proposicional, que contribuyen a los procesos cognitivos de razonamiento lógico y su transposición al lenguaje lógico, que muestran cómo utilizar la estructura proposicional y argumentativa en la construcción de textos científicos y filosóficos, para comunicar sus ideas con coherencia, claridad, objetividad y la cohesión. Las razones para el estudio se derivan de la práctica de las obras de terminación de la orientación de los cursos de graduación, en los que era posible percibir las dificultades de los estudiantes de educación superior para construir textos con coherencia lógica necesaria y suficiente para la comprensión del lector. La base teórica de la investigación fue reflejada por los conceptos, las ideas y las teorías de filósofos, matemáticos e investigadores dedicados al estudio de la lógica, especialmente Aristóteles (2010), Kant (1992), Frege (2009), Copi (1981) y Weston ( 1996). El enfoque metodológico se guio por las reglas de la investigación cualitativa, lo que permite la interpretación de los procesos lógicos que pueden contribuir a la construcción de argumentos en el texto enfoque científico-filosófica de la investigación se basó en el método deductivo, con la composición de argumentos lógicos e informales el uso de los procedimientos de observación y la literatura. Los resultados indicaron que la estructura proposicional de los argumentos deductivos se puede utilizar para construir argumentos lógicos informales, siendo útil para sintetizar la información y comunicar ideas y teorías, textos científicos y filosóficos con niveles de mayor comprensión para el lector.
\end{abstract}

\title{
Palabras clave
}

Razonamiento lógico, argumento lógico, estructura proposicional, texto científico y filosófico, pruebas sentido lógico.

\begin{abstract}
The article presents an epistemological analysis of the contributions of argumentative logic and propositional logic, based on propositional structures that make up the logical arguments, as models for the construction of arguments in scientific and philosophical texts. The aim of the research was to identify the common theoretical perspectives of argumentative logic and propositional logic, which contribute to the cognitive process of logical reasoning and its transposition into logical language, which demonstrate how to use the propositional and argumentative structure in the construction of scientific and philosophical texts, to communicate their ideas with consistency, clarity, objectivity and cohesion. The reasons for the study was derived from the practice of orientation completion works of the undergraduate courses, where it was possible to perceive the difficulties of higher education students to build texts with necessary and sufficient logical consistency to the reader's understanding. The theoretical basis of the research was based on concepts, ideas and theories of philosophers, mathematicians and researchers dedicated to the study of logic, especially Aristotle (2010), Kant (1992), Frege (2009), Copi (1981) and Weston (1996). The methodological approach was ushered by the proceedings of qualitative research, enabling the interpretation of the logical processes that can contribute to the construction
\end{abstract}


of arguments in text scientific-philosophical approach the research was based on the deductive method, with the composition of logical reports arguments and the use of the procedures of observation and literature. The results indicated that the propositional structure of deductive arguments can be used to build logical arguments reports, and useful to synthesize information and communicate ideas and theories, scientific and philosophical texts with levels of greater comprehensibility for the reader.

\section{Keywords}

Logical reasoning, logical argument, propositional structure, scientific and philosophical text, textual logical sense.

\section{Introdução}

O tema desta pesquisa se insere no âmbito das competências necessárias para processar um raciocínio lógico e dos procedimentos para construir argumentos lógicos corretos e coerentes em textos científico-filosóficos, que modo a torná-lo compreensível aos leitores, conforme orientam as práticas metodológicas de pesquisa. Para realizar uma pesquisa é preciso conhecer e aplicar os procedimentos metodológicos, saber planejar através de projetos, executar as etapas de investigação e apresentar os resultados da pesquisa por meio de artigo, ensaio, resenha, dossiê, relatório, relato de experiência, nota científica, monografia, dissertação, tese e outras. Mas para realizar uma pesquisa, desde o planejamento até a apresentação dos resultados, é necessário ter algumas competências e habilidades cognitivas fundamentais para a execução desse processo, como a capacidade de raciocínio lógico, abstrato, reflexivo e relacional. Os pesquisadores não fazem pesquisa para si, mas para outrem conhecer, utilizar e promover conjuntamente o avanço do conhecimento no sentido de resolver problemas da vida, da sociedade e do mundo.

O objetivo desta pesquisa é estabelecer uma interação entre a lógica argumentativa e a lógica proposicional, identificando perspectivas epistemologias comum ao processo cognitivo do raciocínio lógico e sua transposição em linguagem lógica informal, demonstrando como construir argumentos coerentes e apropriados à produção de textos científico-filosóficos, para que comuniquem suas ideias com coerência, clareza, objetividade e coesão. Para alcançar esses objetivos é necessário exercitar habilidades cognitivas da abstração e relação conceitual, ordenamento lógico de ideias e reflexão-crítica de conceitos universais.

A problemática desta pesquisa emergiu das experiências de orientação de trabalhos de conclusão de curso na graduação. $O$ trabalho de pesquisa não necessita apenas de orientação metodológica, também ne- 
cessita de ordenamento lógico de ideias, linguagem acessível e compreensível ao leitor, e considerando que os pesquisadores passaram por um longo período escolar de estudo da linguagem -língua e gramática-, é aceitável que seja exigido dos pesquisadores o domínio de uma linguagem correta, objetiva e compreensiva; mas quanto à lógica, em que área de conhecimento o pesquisador estuda sobre o desempenho do raciocínio lógico e como demonstrar esse raciocínio na forma de argumentos corretos e coerentes que possam ser compreendidos facilmente por um leitor? Para responder esta problemática, foi realizada uma análise de conceitos lógicos e matemáticos, refletidos com as necessidades de acadêmicos para produzir textos científico-filosóficos.

Esta temática é importante para refletir uma necessidade prática da pesquisa, que é o ordenamento lógico das ideias e sua transposição em linguagem argumentativa correta, coerente e objetiva, que possibilite os leitores a realizar uma hermenêutica de compreensão das informações comunicadas na pesquisa. Essas dificuldades dos acadêmicos-pesquisadores são perceptíveis durante o acompanhamento e orientação de pesquisa. Vale resaltar que o ordenamento das ideias -clareza, objetividade e coerência- em um texto científico-filosófico, não dependem somente do domínio da gramática ou normas para produção textual, também é necessário exercitar competências e habilidades cognitivas para raciocinar de modo lógico, abstrato e reflexivo, bem como conhecer e saber relacionar signos linguísticos, conceitos, proposições e argumentos. A superação dessas dificuldades pode contribuir para melhorar a qualidade das informações comunicadas em textos científico-filosóficos.

No contexto atual, produzir textos científico-filosóficos, com argumentos lógicos corretos e coerentes à compreensão, parece ser um desafio para muitos acadêmicos-pesquisadores. Ao observar as práticas acadêmicas de pesquisa, é possível perceber que os estudantes conhecem as normas da $\mathrm{ABNT}^{1}$, aprendem a planejar, aplicar procedimentos e executar suas pesquisas, mas quando chega o momento de refletir, relacionar e associar os conceitos pesquisados com a realidade investigada, ou até mesmo relacionar distintas concepções para deduzir outras, nesse momento surge às dificuldades dos estudantes, parece um martírio ter que raciocinar e deduzir suas próprias ideias, provavelmente à fase mais difícil seja transcrever suas ideias abstratas na forma de argumentos lógicos, que demonstrem coerência, correção, objetividade, coesão e clareza. A intenção desta pesquisa é indicar possíveis soluções para o enfrentamento desses desafios.

A metodologia utilizada para realizar esta pesquisa foi a abordagem qualitativa, com análise de informações baseadas no método de pro- 
cedimento da observação e da pesquisa bibliográfica, cujas informações analisadas foram observadas a partir da experiência em orientação de trabalhos de conclusão de curso (TCC) na graduação, bem como a experiência docente no ensino de lógica. Também se realizou o levantamento do material bibliográfico oriundo de filósofos e matemáticos, como Aristóteles, Kant, Whitehead, Copi, Wittgenstein e Severino.

Destarte, a apresentação das informações desta pesquisa, foi organizada em suas partes: A epistemologia da lógica argumentativa e proposicional; e A estrutura lógica argumentativa e proposicional na construção de textos científico-filosóficos. Na primeira parte foram apresentados, analisados e sintetizados os fundamentos epistemológicos da lógica argumentativa e proposicional, destacando sua origem, princípios matemáticos da lógica, elaboração de raciocínio lógico e sua comunicação por meio da linguagem. Na segunda parte foi apresentada a estrutura de composição das proposições simples, compostas e complexas, inerentes ao argumento dedutivo, como propostas modelares, referenciais e estruturais para construir argumentos lógicos informais em textos científico-filosóficos.

\section{A epistemologia da lógica argumentativa e proposicional}

Ao longo do desenvolvimento do estudo da lógica surgiram várias definições, tais como: a lógica é a "ciência das leis necessárias do entendimento e da razão em geral" (KANT, 1992, p.30); a lógica é "o estudo dos métodos e princípios usados para distinguir o raciocínio correto do incorreto" (Copi, 1981, p. 19); a "lógica estuda a razão como instrumento da ciência ou meio de adquirir a verdade" (Maritain, 2001, p.17). Partindo dessas definições pode-se afirmar que à lógica consiste no estudo de princípios cognitivos do pensamento e entendimento humano, que podem ser demonstrados através de linguagem com o intuito de elaborar, identificar e distinguir um argumento correto.

As bases epistemológicas da lógica argumentativa são oriundas da filosofia clássica, sistematizada pelo filósofo Aristóteles (2010), que considerava a lógica uma "ferramenta" de trabalho do processo investigativo para aquisição de conhecimentos, tanto no campo filosófico quanto científico. O estudo da lógica aristotélica perpassou toda a Idade Média e início da Modernidade sem muitas inovações. Durante esse período, a lógica clássica foi apenas aperfeiçoada e sistematizada sua aplicação como instrumento de acessibilidade ao conhecimento. Foi somente no final da 
Idade Moderna que a lógica foi relacionada à matemática, e no início da contemporaneidade surgiram novas teorias significativas no campo da lógica. A relação lógica-matemática deu origem a diversos campos da lógica, como a lógica simbólica, lógica matemática e programação lógica.

Para compreender os fundamentos da lógica argumentativa e proposicional serão destacados dois campos de estudo da lógica: os estudos da lógica clássica aristotélica, que se popularizou como lógica de argumentação ou lógica argumentativa; e os estudos da lógica simbólica, que comumente é dividida em lógica proposicional e lógica predicativa.

A lógica simbólica surgiu no século XIX, seu principal teórico é o matemático Gottlob Frege, que em sua obra Lógica e Filosofia da Linguagem (2009) expõe sua Teoria de Conceitografia (Begriffsschrift), que posteriormente ficou conhecida como Linguagem Simbólica ou Lógica Simbólica. Frege (2009) considera a conceitografia não como lógica, mas sim uma linguagem para demonstrar conceitos e enunciados aritméticos, cujo conteúdo lógico das proposições poderia ser julgado e provado matematicamente. Com o tempo sua teoria sofreu várias críticas e impossibilidades de aplicação em algumas áreas de conhecimento. Atualmente a Lógica Simbólica é bastante utilizada pelas Ciências da Computação principalmente em Programação Lógica.

Como foi afirmado acima, a lógica simbólica se dividida em lógica proposicional e lógica predicativa, no entanto, será destacado e estudo apenas a perspectiva da lógica proposicional, que se originou na escola filosófica Estoicismo ${ }^{2}$. De acordo com os Estoicos, a proposição é "aquilo que se afirma; o enunciado utilizado em uma inferência lógica" (Branquinho; Murcho; Gomes, 2006, p. 628), diferente das proposições simples ou categóricas de Aristóteles, os Estoicos reconheciam o valor-verdade de proposições compostas e hipotéticas, o que serviu de base para a construção da lógica proposicional ou lógica de enunciados, criada no século XIX.

A sistematização da lógica proposicional contou com a contribuição de matemáticos e filósofos, principalmente Frege, Bertrand Russell e Ludwing Wittgenstein, o qual organizou as proposições compostas e hipotéticas em tabelas verdades com o propósito de calcular o valor-verdade dessas proposições. A lógica proposicional ou de enunciados, "tratase de uma conexão de verdade que é enunciada na linguagem cotidiana por meio de conjunções como 'e', 'se...então...”' (Buchholz, 2009, p. 155). A intenção não é demonstrar a construção e o cálculo proposicional das tabelas-verdade, mas apenas demonstrar como as proposições simples e as proposições compostas podem servir de modelos para a construção de proposições e argumentos científico-filosóficos. 
Tanto a lógica argumentativa quanto a lógica proposicional apresentam em sua origem fundamentos matemáticos. Aristóteles (2010, p. 286) reconhece dois tipos essenciais de argumentos lógicos: a dedução e a indução; firma que o argumento dedutivo é um método demonstrativo que procede dos universais, enquanto o argumento indutivo é decorrente da percepção sensorial que procede dos particulares. Essas duas perspectivas da lógica clássica sustentam a base de origem dos métodos de abordagem de pesquisa: dedução e indução. Mas são os argumentos dedutivos que predominam nos estudos da lógica argumentativa, pois são de natureza universal, baseados em princípios matemáticos, como abstração, relação e demonstração.

Desde sua origem, a lógica da argumentação se preocupava com a elaboração abstrata do raciocínio e sua posterior configuração em forma de argumentos. Não havia uma contundente relação entre lógica e matemática, mas já se fazia presente alguns princípios que nortearam essa proximidade, como os princípios lógicos do raciocínio que estabelecem os valores de verdade ou falsidade sobre as afirmações ou negações. Copi (1981, p. 256) sintetiza esses princípios afirmando que:

- Princípio de Identidade: $\mathrm{P}=\mathrm{P}$. Se qualquer proposição for verdadeira, então será verdadeiro, jamais negar uma ocorrência, pois em lógica não é possível criar situações inexistentes para justificar uma hipótese.

- Princípio da não-contradição: $\sim(\mathrm{P} \mathrm{e} \sim \mathrm{P})$. Nenhuma proposição pode ser verdadeira e falsa simultaneamente, em lógica não deve haver contradições ou hipóteses contraditórias.

- Princípio do Terceiro Excluído: P ou P. Uma proposição ou é verdadeira ou é falsa, em lógica não pode haver ambiguidades, por vezes é necessário excluir uma hipótese para poder validar outra.

A natureza matemática das proposições foi gradativamente sendo reconhecida ao longo do processo de compreensão e aplicação das proposições na construção de argumentos. Desde a modernidade até a contemporaneidade, teóricos da filosofia, matemática e linguagem, contribuíram para compreender e ampliar os horizontes do estudo da lógica, como Descartes, Leibniz, Russell, Whitehead, Wittgenstein, Venn, Boole, Peano, Frege e outros. O estudo da lógica envolve matemática e linguagem, por isso seu alcance epistemológico é complexo, e não se restringe apenas a estudos teóricos, a lógica tem finalidade prática, funciona como uma "ferramenta" para o raciocínio lógico, o desempenho cognitivo, a 
comunicação de argumentos, bem como a produção argumentativa em textos científico-filosóficos.

\section{Princípios matemáticos da lógica}

Para compreender a natureza matemática da lógica é necessário conhecer e entender alguns princípios matemáticos, que estão relacionados tanto as competências quanto as habilidades cognitivas, como a capacidade de abstração, relação, associação, combinação, ordenamento, cumprimento de regras, generalização e critérios de universalidade. Um bom desempenho cognitivo do raciocínio lógico-matemático, também é necessário para produzir com qualidade técnica textos científico-filosóficos. Por essas razões, os princípios matemáticos foram classificados em: abstração, ordem, relação, regras e generalização universal.

Abstração - de acordo com Whitehead (2006, p. 37), a "matemática é pensamento movendo-se no âmbito da completa abstração". Acredita que quando se pensa em um número, logo surge uma tendência natural de relação quantitativa, que tem caráter universal e pode ser aplicada em situações distintas. Segundo Silveira (2012, p. 73) a matemática tem como "principais objetivos desenvolver o raciocínio lógico, a capacidade de abstrair, generalizar, projetar etc.", portanto, um bom raciocínio lógico depende de habilidades cognitivas relacionadas à abstração e a relação.

Por meio da abstração é possível perceber e apreender informações, representar conceitos para dar sentido à mente humana, a fim de possibilitar o surgimento de ideias. Através da relação podem-se associar conceitos para formular juízos, que também são relacionados e refletidos para inferir raciocínios, que podem ser comunicados na forma de argumentos.

Segundo Piaget (apud Kamii, 1999, p. 17) há dois tipos de abstração: a empírica, que consiste em focalizar certa propriedade do objeto e ignorar as outras; e a abstração reflexiva que envolve a construção de relações entre os objetos. Por não ter existência na realidade externa, a abstração reflexiva é uma construção realizada pela mente, usada para representar conceitos.

O conhecimento lógico-matemático tem sua base na abstração reflexiva, cujos números e combinações de signos linguísticos são representações elaboradas a partir daquilo que se percebe da realidade, como coisas, objetos, formas, fatos, situações etc.

Para realizar uma investigação ou pesquisa é necessário abstrair conceitos e informações por meio da percepção sensorial (empírica) ou 
da abstração reflexiva. O desempenho da abstração reflexiva é resultante do processo de síntese e/ou dedução das relações qualitativas e/ou quantitativas que se elaboram a partir dos interesses, finalidades e objetivos de aplicação.

\begin{abstract}
Abstração é a meta da escolarização. O professor quer que os alunos sejam capazes de aplicar a aprendizagem de sala de aula em novos contextos, inclusive aqueles fora da escola. O desafio é que a mente não se interessa por abstração, ela prefere o concreto. É por isso que, quando encontramos um princípio abstrato - uma lei da física como força $=$ massa X aceleração - nós solicitamos um exemplo concreto para facilitar a compreensão (Willingham, 2011, p. 86).
\end{abstract}

De acordo com a análise de Willingham, o pensamento abstrato é um desafio para a mente dos estudantes, é mais fácil pensar a partir de um fato concreto do que representar abstrativamente um novo conceito. Haja vista que, representar um conceito novo sem equivalência concreta, demanda um esforço pessoal que nem sempre o estudante esta disposta a fazer. Por isso é importante praticar atividades que desenvolvam habilidades do raciocínio abstrato, como jogos lógico-abstratos de tabuleiro ou eletrônicos, exemplo: Xadrez, Fanorona, Tapatan, Traverse, Liberiano Queah, Ziz-zag e outros.

Relação - a ideia de relação (associação ou combinação) esta presente em todos os outros princípios matemáticos. Quando se pensa em um número, signos linguísticos ou símbolos, e o representa mentalmente, surge na mente um conceito abstrato de alguma coisa, e quando se relaciona conceitos é inferida uma proposição, a partir de relações conceituais. Apreender uma ideia ou conceito abstrato significa agregar novas representações mentais, que podem ser relacionadas e transformadas em informação e conhecimento. Para tanto, é preciso julgar a relação entre os conceitos, enunciando sua veracidade, falsidade ou possibilidade.

De acordo com Durval (2003, p. 22), "a compreensão matemática esta intimamente ligada ao fato de dispor de ao menos dois registros de representação diferentes". Esse entendimento é extensivo ao processo de elaboração do raciocínio lógico, cujos argumentos lógicos dependem da relação conceitual e da relação proposicional.

A noção de relação esta presente no processo investigativo de pesquisa, bem como no processo de aprendizagem, cujos conhecimentos prévios são confrontados, associados, combinados e relacionados com novos conhecimentos. 
Ordem - de acordo com Russell (2006, p. 42), “a ordem não está na classe dos elementos, mas sim numa relação entre os membros da classe, segundo a qual alguns aparecem primeiro e outros depois. $\mathrm{O}$ fato de uma dada classe poder ter muitas ordens resulta de poder haver muitas relações entre os membros de cada classe dada" A ordem não esta nos elementos matemáticos, mais na relação que se pode estabelecer entre os elementos de uma classe. A lógica-matemática é versada na aplicação de variáveis com procedimentos diversificados, o que contribui com possibilidades distintas e criativas de conhecimento.

A noção de ordem depende da relação que se estabelece entre determinados elementos, existem possibilidades distintas para relacionar e estabelecer ordem entre os elementos, isso não significa que uma seja correta e a outra incorreta, apenas são possibilidades diferentes, que por vezes contribuem com a criatividade e o desenvolvimento cognitivo.

De acordo com Chrysikou (2013, p. 21), "executar tarefas comuns em ordem não convencional também pode perturbar o processo habitual de pensamento, aumentando assim suas perspectivas criativas". Diversificar hábitos de ordenamentos das coisas e criar novas possibilidades é imprescindível para desenvolver o desempenho cognitivo.

Regras e generalização universal - o filósofo Kant (1724-1804) considera que existe na natureza uma conexão de fenômenos segundo regras, e por analogia, afirma que o "entendimento deve ser considerado como a fonte e a faculdade de pensar regras em geral" (Kant, 1992, p. 29). Compreende que a lógica é uma ciência racional que abrange tanto a forma (entendimento) quanto a matéria (experiência).

O princípio da universalidade é fundamentado em leis, fórmulas ou regras matemáticas, ou seja, uma regra deve ter aplicabilidade universal, mudando apenas as variáveis, fatos ou situações. No que tange a lógica, os argumentos dedutivos procedem de princípios universais.

A noção de regras universais pressupõe, a priori, relações conceituais caracterizadas por elementos distintos, cuja coerência lógica necessita do estabelecimento de ordem, organização e planejamento. Essa perspectiva das regras universais forma a base de fundamento teórico da lógica-matemática. Para Whitehead (2006, p. 43), "o exercício do raciocínio lógico sempre diz respeito a essas condições absolutamente gerais", considera que o descobrimento de todas as condições abstratas, que são aplicáveis as relações entre os elementos concretos, são correlacionados entre si formando um modelo de relações imposta pela necessidade geral.

Esses princípios matemáticos da lógica estão relacionados a habilidades e capacidades da estrutura cognitiva, em especial o raciocínio 
abstrato e lógico. Assim compreende-se porque a primeira fase de desenvolvimento do raciocínio lógico esta relacionada à cognição.

O estudo e aplicação da lógica, como ferramenta para o processo investigativo, abrangem duas fases de desenvolvimento: a cognição, que são os instrumentos lógicos do pensamento e fazem parte dos processos mentais do entendimento e raciocínio; e a linguagem, que consiste na materialização do pensamento lógico através do uso de signos linguísticos e símbolos matemáticos, que objetivam comunicar ideias, juízos e raciocínios provindos da experiência pessoal, convivência social e percepção de mundo. Essas fases de desenvolvimento lógico se complementam durante o processo de raciocínio e construção de argumentos.

\section{Cognição e raciocínio lógico}

Segundo Maturana (2001, p. 126-127), a palavra cognição está relacionada ao domínio do conhecer, das relações interpessoais e das coordenações de ações. Afirma que "há tantos domínios cognitivos quantos forem os domínios de ações -distinções, operações, comportamentos, pensamentos ou reflexões". No que tange a lógica, a cognição esta relacionada ao domínio do conhecer, da inteligência e do pensamento. A cognição é o processo de surgimento do significado das coisas, ou seja, à medida que os humanos se relacionam com o mundo, estabelecem significados para representar à realidade percebida, abstraída, refletida ou sintetizada.

A lógica de Aristóteles, apresentada nos livros que compõe o Órganon (2010), principalmente Categorias, Da Interpretação e Primeiros Analíticos, faz referência à relação entre conceito (ideias e formas), juízo e raciocínio. Explica que o humano é capaz de raciocinar a partir dos juízos que elabora por meio da experiência, a qual é resultante do conhecimento provindo do entendimento, que são formas ou ideias, denominadas conceitos.

De acordo com Maritain (2001, p. 17), o raciocínio funciona através da inteligência, quando ver e aprende alguma coisa, tais como informação, ideias, teorias e a própria experiência. Os instrumentos lógicos do pensamento, responsáveis pelo processo operacional de aquisição de conhecimentos, ocorrem ordenadamente em quatro etapas cognitivas: a simples apreensão, o conceito, o juízo e o raciocínio.

Simples apreensão - é "o ato pelo qual a inteligência atinge ou percebe alguma coisa sem dela nada afirmar ou negar" (Maritain, 2001, p. 35), ou seja, a apreensão é um ato primário do princípio da inteligibilida- 
de, caracterizado como uma fase de transição entre o desconhecido e o conhecido e será ultrapassado quando conseguir formular um conceito coerente e claro daquilo que busca conhecer.

Conceito - Aristóteles (2010, pp. 39-41) considera o conceito uma representação mental das coisas existentes, são nomes com significado, compreensão e extensão de aplicabilidade. Ocorre no nível da completa abstração. Para Maritain (2001, p. 41), consiste naquilo que a razão, por meio da inteligência, "produz ou exprime em si mesmo, em que ele atinge ou apreende uma coisa". E para Kant (1992, pp. 109-110), o conceito é "uma representação universal ou uma representação daquilo que é comum a diversos objetos", considera que se origina no entendimento e se processa por reflexão e abstração, produzindo ideias na mente ou pensamento, também afirma que "a ideia é um conceito da razão, cujo objeto não se pode de modo algum encontrar na experiência", esclarece que os conceitos são ideias intermediarias para se chegar a um raciocínio. Portanto, a compreensão de um conceito na mente ou pensamento representa a superação da fase da apreensão, pois aprender um conceito é ter uma ideia representativa daquilo que se almeja conhecer.

Juízo - "é o ato pelo qual o espírito compõe ao afirmar ou divide ao negar", o juízo é elaborado mentalmente, "quando o intelecto compara um conceito com outro, como apreendendo a conjunção ou a identidade das coisas de que são as concepções, e divisão quando compara um conceito com outro de modo a apreender que as coisas são diversas" (Maritain, 2001, pp. 109-110). Isso significa que um juízo é formulado por meio de uma relação conceitual, que pode ser afirmativa ou negativa: quando os conceitos dão ideia de união ocorre uma afirmação; e quando os conceitos dão ideia de separação ocorre uma negação. De acordo com Kant (1992, p. 121), "um juízo é a representação da unidade da consciência de diferentes representações, ou a representação da relação das mesmas, na medida em que constituam um conceito". Portanto, um juízo é uma representação mental, afirmativa ou negativa, da relação conceitual (unidade de consciência), e só pode ser pensado quando há compreensão e conhecimento do sentido e significado dos conceitos; é preciso apreender os conceitos para poder elaborar juízos coerentes a respeito das suas possibilidades e contingências relacionais.

Raciocínio - consiste no ato pelo qual a inteligência progride no conhecimento através de um movimento progressivo que vai do conhecido ao desconhecido, adquirindo algo novo por meio do descobrimento ou da invenção, com o intuito de estabelecer ou demonstrar possíveis verdades. De acordo com Maritain (2001, p. 173), "raciocinar é passar de 
uma coisa intelectualmente apreendida a outra intelectualmente aprendida graças à primeira", afirma que raciocinar é progredir de um juízo para outro a fim de conhecer verdades inteligíveis. No ato de raciocinar, o intelecto é movido por dois ou mais juízos (antecedentes), para produzir um juízo conclusivo (consequente) caracterizado como síntese. Esse processo de deduzir um juízo consequente a partir de juízos antecedentes dar-se-á por meio da inferência. Para Kant (1992, p. 135), "por inferir deve-se entender a função do pensamento pela qual um juízo é derivado de outro. Uma inferência em geral é, pois, a derivação de um juízo a partir de outro", portanto, o raciocínio depende da capacidade dedutiva de inferir de juízos antecedentes um juízo consequente, possibilitando a aprendizagem de novos conhecimentos na estrutura cognitiva.

Essas etapas cognitivas do raciocínio lógico, com exceção da simples apreensão, podem ser materializadas e comunicadas através da linguagem, com o proposito de transmitir a outrem aquilo que foi elaborado ou produzido racionalmente.

\section{Linguagem lógica argumentativa e proposicional}

Para a lógica, o principal uso e função da linguagem é a transmissão de informação. Não basta elaborar mentalmente um raciocínio lógico, é precisa saber transpor a cognição lógica em linguagem formal ou informal, observando as seguintes relações: o conceito pode ser expresso em um termo; o juízo pode ser enunciado em uma proposição; e o raciocínio pode ser comunicado em um argumento.

O conceito são ideias que pode ser expressa através de um termo ou combinação de signos com sentido significável em uma linguagem. $\mathrm{O}$ juízo, que é uma relação conceitual, pode ser enunciado através de proposição, cuja estrutura básica é a relação entre os termos mediados por um verbo ou cópula, pois, de acordo com Aristóteles (2010, p. 85), “todas as proposições requerem a presença de um verbo ou da flexão verbal”. O raciocínio é uma relação proposicional deduzida por inferência, e é comunicado através de argumento (veja a figura 1).

Para construir um argumento é preciso saber escrever em linguagem lógica, que pode ser: formal (dedutiva) ou informal (dissertativo-argumentativa). Comumente um texto científico-filosófico utiliza linguagem lógica informal, mas dependendo do autor, o texto pode apresentar bons argumentos lógicos com sentenças proposicionais formais. $\mathrm{O}$ mais importante é saber combinar os conceitos e as proposições de modo a 
tornar o mais coerente possível os argumentos e teorias transmitidas em um texto científico-filosófico.

Figura 1

Estrutura do raciocínio lógico e da linguagem formal

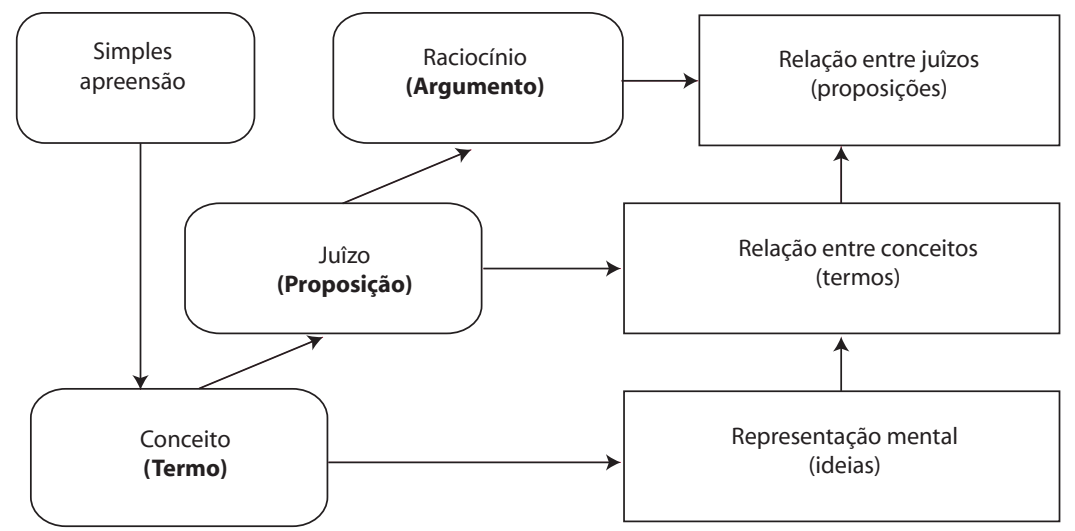

Fonte: Elaborado pela pesquisadora

Lógica formal é o estudo das formas de argumento, modelos abstratos comuns a muitos argumentos distintos [...] Lógica informal é o estudo de argumentos particulares em linguagem natural e do contexto no qual eles ocorrem. Enquanto a Lógica formal realça generalidade e teoria, a lógica informal se concentra numa análise prática de argumentos. Os dois aproches não são opostos, mas um complementa o outro (Nolt; Rohatyn, 1991, pp. 33-34).

Assim como a lógica formal e informal se complementam, o mesmo ocorre com a linguagem lógica formal e informal, cujas estruturas proposicionais podem ser utilizadas tanto pela linguagem lógica formal, quanto informal.

A linguagem lógica formal segue uma estrutura lógica dedutiva ou canônica e é expressa em proposições-premissas e uma proposiçãoconclusiva, enquanto a linguagem lógica informal segue a estrutura de um texto dissertativo-argumentativo e é expresso em sentenças, cujas proposições do argumento estão diluídas com outras expressões complementares, que em lógico se denomina "ruídos" (MURCHO, 2003, pp. 13-14). Veja o exemplo no quadro abaixo: 
Quadro 1

Diferença de argumento em linguagem lógica informal e formal

\begin{tabular}{|c|c|}
\hline Argumento lógico informal & Argumento lógico formal \\
\hline $\begin{array}{l}\text { "A originalidade da matemática consiste } \\
\text { no fato de que na ciência matemática são } \\
\text { apresentadas conexões entre as coisas } \\
\text { que, separadas da intervenção da razão } \\
\text { humana, são extremamente sem evidên- } \\
\text { cias. Assim, as ideias, agora na mente } \\
\text { dos matemáticos contemporâneos, en- } \\
\text { contram-se muito distantes de qualquer } \\
\text { noção que possa derivar imediatamente } \\
\text { pela percepção mediante os sentidos" } \\
\text { (Whitehead, 2006, p. 35). }\end{array}$ & $\begin{array}{l}\text { A originalidade da ciência matemática } \\
\text { são conexões entre as coisas. } \\
\text { Se as coisas estiverem separadas da in- } \\
\text { tervenção da razão, então não haverá } \\
\text { evidências. } \\
\text { Logo, as ideias dos matemáticos contem- } \\
\text { porâneos estão distantes da derivação } \\
\text { pela percepção dos sentidos. }\end{array}$ \\
\hline
\end{tabular}

Fonte: Elaborado pela pesquisadora

De acordo com Branquinho, Murcho e Gomes (2006, p. 442), a linguagem simbólica proposicional são "linguagens artificiais constituídas pelos lógicos com o objetivo, científico, de estudar conceitos lógicos fundamentais". Por causa da sua natureza matemática, a lógica simbólica proposicional enuncia suas proposições apenas em linguagem lógica formal, enquanto que a lógica argumentativa enuncia suas proposições tanto em linguagem lógica formal quanto informal.

Até os anos de 1940, a construção de uma linguagem formal era predominantemente identificada com a elaboração da sua sintaxe lógica. 'Linguagem formal' era, assim, sinônimo de 'sistema sintático não-interpretado. Hoje, considera-se que a interpretação de uma linguagem formal, isto é, o estabelecimento da semântica lógica para essa linguagem, pode ser parte integrante da sua construção, [...] uma linguagem formal pode ser completamente definida sem nenhuma referência a uma interpretação (Branquinho; Murcho; Gomes, 2006, p. 442).

Tradicionalmente, a linguagem formal era caracterizada pela não interpretação. Esse tipo de linguagem valoriza a objetividade do texto, limitando-se a informar apenas aquilo que esta explicitamente sendo comunicado ou enunciado. Atualmente a linguagem formal é compreendida como semântica lógica, que promove interpretações idealizadas, baseadas em conjunto de símbolos e regras de formatação.

Do ponto de vista do leitor ou interprete, a perspectiva da metalinguagem e da hermenêutica é muito importante para a compreensão textual; entretanto, do ponto de vista do autor ou produtor textual 
a semântica lógica é indispensável para a produção científico-filosófica. Apesar de a tradição semântica lógica desvalorizar o conteúdo implícito, restringindo-se a sentenças lógicas de natureza matemática, considera-se que é plausível a utilização das estruturas da lógica proposicional para tornar um texto científico-filosófico mais coerente e objetivo ao leitor, pois as estruturas proposicionais independem da interpretação, entendimento e compreensão textual.

Acredita-se que as características fundamentais da linguagem lógica formal é a mesma que um bom texto científico-filosófico almeja em sua construção, como clareza, certeza, objetividade, validade, verdade, coerência, correção, consequência, consistência e outros atributos semelhantes.

Todavia, para produzir a contento um bom texto científico-filosófico não basta apenas saber processar cognitivamente um raciocínio lógico e transpor em linguagem lógica formal, também é necessário que haja conhecimentos prévios para compor os argumentos.

De acordo com Aristóteles (2010, pp. 251-252), "toda a instrução intelectual procedem de conhecimento pré-existente [...] tanto as ciências matemáticas quanto qualquer outra arte é adquirida dessa forma. $\mathrm{O}$ mesmo ocorre com os argumentos lógicos", que são constituídos de conhecimentos prévios, "por vezes é necessário para supor antecipadamente um fato, por vezes é preciso que compreendamos o significado do termo, e, por vezes, ambos são necessários".

Portanto, os conhecimentos prévios são indispensáveis para o processamento do raciocínio lógico, pois a construção de argumentos depende dos conteúdos ou informações disponíveis na estrutura cognitiva, principalmente na memória. À medida que as informações são compreendidas, sintetizadas e relacionadas, o pensamento tona-se mais apto a organizar ideias, formular raciocínio lógico e comunicar bons argumentos em linguagem lógica.

\section{A estrutura lógica argumentativa e proposicional na construção de textos científico-filosóficos}

O estudo da lógica indica que existem vários tipos de argumentos, como indutivos, dedutivos, silogísticos, hipotéticos, analógicos, retóricos e dialéticos, mas para a lógica proposicional interessa apenas os argumentos dedutivos, que são demonstrativos por causa da sua natureza matemática. E para a lógica argumentativa, seu principal interesse são os argumen- 
tos dedutivos ou demonstrativos, que Aristóteles (2010, p.253) denomina de silogismo, afirma que o silogismo é um argumento demonstrativo e científico pelo "qual compreendemos alguma coisa pelo mero fato de apreendê-la”.

A análise a seguir, se baseia somente na estrutura proposicional dos argumentos dedutivos em linguagem informal, que são apropriados para comunicar raciocínios em textos dissertativo-argumentativos. Nesses argumentos, as proposições "encerram verdade ou falsidade em si mesma" (Aristóteles, 2010, p. 84), ou seja, as proposições são afirmações ou negações que encerram seu valor-verdade na própria relação conceitual. Em um argumento dedutivo, as proposições se classificam em: proposições-premissas (antecedente ou premissas); e proposição-conclusiva (consequente ou conclusão). Pode haver duas ou mais premissas em um argumento, mas sempre haverá somente uma conclusão. As proposiçõespremissas são consideradas provas evidentes da verdade de um raciocínio, pois a estrutura lógica das premissas, "servem para provar ou, pelo menos, fornecer alguma evidência para a conclusão" (Nolt; Rohatyn, 1991, p. 01).

Aprender a estrutura lógica proposicional de um argumento pode ajudar os estudantes tanto a reconhecer os argumentos em um texto científico-filosófico -que são as ideias norteadoras do texto-, quanto saber produzir argumentos lógicos em textos científico-filosóficos.

Segundo Gadamer (2012), em sua perspectiva hermenêutica da interpretação e compreensão textual, não é possível apreender a totalidade das concepções e ideias de um texto, mas é possível apreender as concepções gerais ou argumentos universais apresentados pelo autor. Partindo dessa perspectiva, é relevante que um estudante-pesquisador saiba ler, interpretar, entender, compreender e reconhecer os argumentos norteadores do texto pesquisado, afinal, o que mais importa em um texto científico-filosófico são os argumentos.

Para reconhecer os argumentos em um texto científico-filosófico é necessário saber diferenciar sentença e proposição. De acordo com Aristóteles (2010, p. 84), "sentença é fala dotada de significação, sendo que esta ou aquela parte pode ter um significado particular de alguma coisa, ou seja, que é enunciado, mas não expressa uma afirmação ou uma negação, [...], nem todas as sentenças podem ser classificadas como proposições". Portanto, todo enunciado são sentenças, mas o conteúdo das sentenças nem sempre são proposições, e como os argumentos são constituídos de proposições pode-se dizer que: todo argumento é uma sentença, mas nem toda sentença é um argumento. 
Somente as sentenças declarativas ou demonstrativas formam argumentos lógicos. Há outros tipos de sentenças que comunicam informações não-argumentativas, que visam apenas explicar, descrever, interrogar, ordenar, exclamar, dar exemplos, expressar possibilidades e temporalidade. Essas sentenças não-argumentativas servem para complementar as informações, interligar as proposições e dar sentido ao conteúdo dissertativo-argumentativo textual.

Para Copi (1981, p. 23), o "argumento é qualquer grupo de proposição tal que se afirme ser uma delas derivadas das outras, as quais são consideradas provas evidentes da verdade da primeira". Pode-se dizer que o argumento é constituído de proposições (juízos), derivadas uma das outras com a intenção de fornecer as "provas" ou "razões" que justifiquem a conclusão. Segundo Weston (1996, p. 5):

«Argumentar» quer dizer oferecer um conjunto de razões a favor de uma conclusão ou oferecer dados favoráveis a uma conclusão [...] argumentar não é apenas a afirmação de determinado ponto de vista nem uma discussão. Os argumentos são tentativas de sustentar certos pontos de vista com razões. Neste sentido, os argumentos não são inúteis; na verdade, são essenciais. Os argumentos são essenciais, em primeiro lugar, porque constituem uma forma de tentarmos descobrir quais os melhores pontos de vista. Nem todos os pontos de vista são iguais. Algumas conclusões podem ser defendidas com boas razões e outras com razões menos boas. No entanto, não sabemos na maioria das vezes quais são as melhores conclusões. Precisamos, por isso, de apresentar argumentos para sustentar diferentes conclusões e, depois, avaliar tais argumentos para ver se são realmente bons. Neste sentido, um argumento é uma forma de investigação.

Se o objetivo dos argumentos é descobrir os melhores pontos de vista, então o argumento é uma forma de investigação. Weston (1996, p. 5) considera que os argumentos são essenciais por dois motivos: porque tentam descobrir as melhores razões para apoiar uma conclusão, e depois avaliar se as razões do argumento são realmente boas para justificar a conclusão; e porque quando chega a uma conclusão bem apoiada em suas provas oferece razões sólidas para influenciar a opinião de outrens, e assim convencê-los de suas ideias.

Para Weston (1996, pp. 5-6), apesar das regras da argumentação terem objetivos específicos, nem sempre são compreendidas e respeitadas por estudantes e pesquisadores. Comumente, quando se pedi a um estudante para argumentar a favor do seu ponto de vista acerca de um assunto ou problemática qualquer, "escrevem afirmações intrincadas, mas não oferecem 
verdadeiramente razões que levem a pensar que os seus pontos de vista são corretos. Escrevem um ensaio, mas não escrevem um ensaio argumentativo".

Considerando as explicações de Copi e Weston, as regras da argumentação objetivam provar a verdade de um raciocínio de forma clara, coesa e persuasiva. Para ilustrar a relação entre sentença e argumento, veja o exemplo no quadro 2 , que diferencia uma sentença explicativa de uma sentença argumentativa.

Quadro 2

Sentença argumentativa e não-argumentativa

\begin{tabular}{|c|c|}
\hline \multicolumn{2}{|l|}{ Sentenças } \\
\hline Argumento & Não argumento \\
\hline $\begin{array}{l}\text { Somente um inimigo nos dá a oportunidade de } \\
\text { exercer a paciência. Ninguém mais do que ele } \\
\text { nos concede a oportunidade para a tolerância. } \\
\text { Já que não conhecemos a maioria dos cinco bil- } \\
\text { hões de seres humanos nesta terra, a maioria das } \\
\text { pessoas também não nos dá oportunidade de } \\
\text { mostrar tolerância ou paciência. Somente essas } \\
\text { pessoas que nós conhecemos e que nos criam } \\
\text { problemas é que realmente nos dão uma boa } \\
\text { chance de praticar a tolerância e a paciência } \\
\text { (Dalai Lama). }\end{array}$ & $\begin{array}{l}\text { O historiador e o poeta não se } \\
\text { distinguem um do outro pelo } \\
\text { fato de o primeiro escrever em } \\
\text { prosa e o segundo em verso. } \\
\text { Diferem entre si, porque um es- } \\
\text { creveu o que aconteceu e o ou- } \\
\text { tro o que poderia ter acontecido } \\
\text { (Aristóteles). }\end{array}$ \\
\hline $\begin{array}{l}\text { Comentário: a sentença acima é um argumen- } \\
\text { to composto por quatro proposições, sendo três } \\
\text { premissas (estão sublinhadas) e uma conclusão } \\
\text { (está de negrito). As partes que não estão subl- } \\
\text { inhadas ou em negrito são ruídos que servem } \\
\text { apenas para interligar as premissas. }\end{array}$ & $\begin{array}{l}\text { Comentário: a sentença acima } \\
\text { não é um argumento, trata-se de } \\
\text { uma explicação comparativa. }\end{array}$ \\
\hline
\end{tabular}

Fonte: Elaborado pela pesquisadora

De modo geral, as proposições dos argumentos dedutivos são classificadas em proposições simples ou categóricas e proposições compostas ou hipotéticas. Considera-se plausível a utilização da estrutura proposicional dos argumentos dedutivos -sejam simples, compostas ou complexas-, como modelos para construir argumentos científico-filosóficos.

As proposições simples ou categóricas fazem parte do estudo da lógica clássica aristotélica, sua estrutura básica é formada por: um quantificador universal ou particular, com qualidade afirmativa ou negativa; dois termos ou classe, sendo um o termo sujeito e o outro o termo predicado; e uma cópula verbal que faz a mediação entre os termos sujeito e 
predicado. De acordo com Copi (1981, p. 143), toda proposição categórica tem qualidade (afirmativa ou negativa) e quantidade (universal ou particular), que serve para definir a inclusão, completa ou parcial da classe (ou termo). Exemplo: "todo juiz é honesto"(1) não significa que "todo honesto é juiz"(2), no exemplo (1), a classe "juiz" está incluída completamente na classe "honesto", mas a classe "honesto" não esta incluída na classe "juiz", portanto, não se pode mudar simplesmente a posição dos termos e atribuir o mesmo significado.

As proposições compostas ou hipotéticas fazem parte do estudo da lógica moderna, constituídas principalmente a partir da lógica simbólica proposicional. Os fundamentos basilares das proposições compostas foram apresentados inicialmente na obra Tratados Lógico-filosóficos, pelo filósofo e matemático Wittgenstein (1995), que propôs o cálculo do valor lógico das proposições elementares ou simples, a partir do método das tabelas de verdade. As proposições compostas são formadas pela união de duas proposições elementares ou simples, e as proposições complexas são formadas pela inserção de uma proposição composta dentro de outra. A classificação básica das proposições compostas é: conjunção, disjunção, condicional, bicondicional e negação, que respectivamente, são demonstradas através do uso dos conectivos: "e", "ou", "se...então", "se...somente se" "não" (Copi, 1981, pp. 226-234). O quadro 3 ilustra a classificação das proposições simples e compostas.

Quadro 3

Estrutura formativa das proposições simples e compostas

\begin{tabular}{|c|c|c|c|c|}
\hline $\begin{array}{c}\text { Tipo de } \\
\text { Proposição }\end{array}$ & $\begin{array}{c}\text { Forma } \\
\text { proposicional }\end{array}$ & Quantificador & Conectivos & Exemplos \\
\hline \multirow{4}{*}{$\begin{array}{l}\text { Simples ou } \\
\text { categóricas }\end{array}$} & $\begin{array}{l}\text { Universal } \\
\text { afirmativa }\end{array}$ & Todo Tudo & --- & $\begin{array}{l}\text { Todo cientista é } \\
\text { professor. }\end{array}$ \\
\hline & $\begin{array}{l}\text { Universal } \\
\text { negativa }\end{array}$ & $\begin{array}{l}\text { Nenhum } \\
\text { Nunca }\end{array}$ & --- & $\begin{array}{l}\text { Nenhum cientista } \\
\text { é político. }\end{array}$ \\
\hline & $\begin{array}{l}\text { Particular } \\
\text { afirmativa }\end{array}$ & $\begin{array}{l}\text { Algum } \\
\text { Algo... }\end{array}$ & --- & $\begin{array}{l}\text { Alguns estudantes } \\
\text { são cientistas. }\end{array}$ \\
\hline & $\begin{array}{l}\text { Particular } \\
\text { negativa }\end{array}$ & $\begin{array}{l}\text { Algum } \\
\text { Algo... }\end{array}$ & --- & $\begin{array}{l}\text { Alguns estudantes } \\
\text { não são cientistas. }\end{array}$ \\
\hline \multirow{2}{*}{ Elementar } & $\begin{array}{l}\text { (particular ou } \\
\text { singular) }\end{array}$ & (não é indica) & --- & $\begin{array}{l}\text { Spinoza defende } \\
\text { o racionalismo } \\
\text { absoluto. }\end{array}$ \\
\hline & (classe) & --- & --- & $\begin{array}{l}\text { Os jogadores de } \\
\text { futebol perderam } \\
\text { as olimpíadas }\end{array}$ \\
\hline
\end{tabular}




\begin{tabular}{|c|c|c|c|c|}
\hline \multirow{6}{*}{ Compostas } & Conjunção & --- & e & $\begin{array}{l}\text { Fortaleza tem } \\
\text { belas praias } e \text { o } \\
\text { Amazonas tem } \\
\text { belas florestas. }\end{array}$ \\
\hline & $\begin{array}{l}\text { Disjunção } \\
\text { inclusiva }\end{array}$ & --- & ou & $\begin{array}{l}\text { O professor é } \\
\text { pesquisador ou } \\
\text { o professor é } \\
\text { cientista. }\end{array}$ \\
\hline & $\begin{array}{l}\text { Disjunção } \\
\text { exclusiva }\end{array}$ & --- & ou... & $\begin{array}{l}\text { A aula será na es- } \\
\text { cola ou no Bosque } \\
\text { da Ciência. }\end{array}$ \\
\hline & Condicional & --- & se...então... & $\begin{array}{l}\text { Se a neurociência } \\
\text { for aplicada a } \\
\text { educação, então } \\
\text { os estudantes } \\
\text { terão melhor } \\
\text { desempenho } \\
\text { cognitivo. }\end{array}$ \\
\hline & Bicondicional & --- & $\begin{array}{l}\text { se... so- } \\
\text { mente se }\end{array}$ & $\begin{array}{l}\text { Haverá aula } \\
\text { prática de ciência } \\
\text { se, somente se, não } \\
\text { chover na Reserva } \\
\text { Ducke. }\end{array}$ \\
\hline & Negação & --- & não & $\begin{array}{l}\text { O conhecimento } \\
\text { não é inacessível } \\
\text { àquele que quer } \\
\text { aprender. }\end{array}$ \\
\hline Complexas & $\begin{array}{l}\text { (justapo- } \\
\text { sição de } \\
\text { proposições } \\
\text { compostas) }\end{array}$ & --- & $\begin{array}{l}\text { (conectivos } \\
\text { diversos) }\end{array}$ & $\begin{array}{l}\text { Se o time bra- } \\
\text { sileiro ganhar } \\
\text { o campeonato, } \\
\text { os professores e } \\
\text { meus colegas não } \\
\text { irão à faculdade, } \\
\text { então não haverá } \\
\text { aula. }\end{array}$ \\
\hline
\end{tabular}

Fonte: Síntese e exemplos da pesquisa.

Nesta pesquisa, considera-se que o mais importante não é o valor lógico das proposições nos argumentos, mas sim a estrutura proposicional dos argumentos, que foram exemplificadas no quatro 3. São modelos de afirmações, negações, junção de ideias e condições lógicas que podem indicar como comunicar e expressar a síntese ou a dedução de um ra- 
ciocínio, principalmente a proposição condicional, que pressupõe condições necessárias e suficientes para afirmar uma conclusão, exemplo: Se a potência é uma capacidade inata (ou a priori) do ser humano, então não deriva da experiência, portanto podemos haurir que nascemos com certa disposição potencial natural. Neste exemplo, a conclusão (nascemos com certa disposição potencial natural) é derivada a partir da afirmação e negação da proposição condicional (a potência é uma capacidade inata; a potência não deriva da experiência).

Weston (1996, p. 7) explica que "o primeiro passo para redigirmos um argumento é perguntarmos: que desejamos provar? Qual a conclusão?" Utilizando a forma estrutural das proposições simples e compostas, pode-se afirmar com clareza e objetividade as razões que provam uma conclusão em um argumento.

Para Severino (2007, p. 78), todo texto científico-filosófico é dissertativo-argumentativo, e seu "objetivo é demonstrar, mediante argumentos, uma tese, que é uma solução proposta para um problema, relativo a determinado tema". Também afirma que a "demonstração baseia-se num processo de reflexão por argumentação, ou seja, baseia-se na articulação de ideias [conceito] e fatos, portadores de razões que comprovem aquilo que se quer demonstrar". Dessa maneira compreende-se que a demonstração é um processo sequenciado de argumentos lógicos.

Dissertação é a forma geral do discurso e quer dizer que o discurso está pretendendo demonstrar uma tese mediante argumentos; demonstração é, pois, o conjunto sequenciado de operações lógicas que de conclusão em conclusão chega a uma conclusão final procurada; argumentação é entendida como uma operação, uma atividade executada durante a demonstração pelo uso dos argumentos; já raciocínio é um processo lógico de conhecimento, operação mental específica que pode servir inclusive de argumento para a demonstração (Severino, 2007, p. 80).

Para que um texto dissertativo-argumentativo seja compreensível é preciso que tenha sentido lógico, e uma das formas possível de comunicar um texto com sentido lógico é apresentar suas concepções, ideias ou teorias em linguagem argumentativa com estruturas proposicionais lógicas.

Não basta apenas dizer a um estudante-pesquisador que sua produção deve ser escrita de forma lógica e coerente, é necessário ensinar as estruturas de composição das proposições e argumentos lógicos, bem como exercitar com os estudantes a identificação de argumentos lógicos em textos científico-filosóficos, e desenvolver o desempenho cognitivo de síntese e dedução de juízos e raciocínio, bem como saber produzir e co- 
municar textos científico-filosóficos em linguagem lógica argumentativa (formal e informal). Segundo Copi (1981, p. 26), em um texto demonstrativo pode "conter dois ou mais argumentos, quer em sucessão, quer interligados", por vezes, a conclusão de um argumento se torna premissa para outro argumento, e gradativamente vai surgindo um texto dissertativo-argumentativo com encadeamento de ideias e ordenamento lógico.

Em suma, a intenção desta pesquisa não é defender a aplicabilidade da lógica formal tradicional na produção de textos dissertativoargumentativos, mas sim a utilização das estruturas proposicionais e argumentavas na construção de textos científico-filosóficos ou dissertativo-argumentativos, com o propósito de demonstrar aos estudantespesquisadores como elaborar e comunicar um raciocínio lógico.

\section{Considerações finais}

Acredita-se que o principal cerne valorativo do instrumento da lógica é a composição de argumentos baseados em estruturas proposições apropriadas para comunicar sentenças com clareza, coesão, objetividade e correção, visando sobretudo a compreensibilidade do leitor.

A leitura é fundamental para uma boa produção textual, no entanto, para produzir um texto científico-filosófico, com ideias, teses e teóricas, é necessário saber comunicar de modo lógico argumentativo, o que se aprende a partir da prática de identificação e construção de argumentos lógicos.

Considera-se que o objetivo inicial desta pesquisa foi atingido a contento, haja vista que a análise epistemológica da relação entre a lógica argumentativa e a lógica proposicional, indicou as perspectivas comuns entre essas duas áreas de estudo da lógica, como seus fundamentos matemáticos, processo cognitivo do raciocínio lógico e sua transposição em linguagem formal e informal. A partir dessa análise inicial, foi deduzido e demonstrado como podemos utilizar a estrutura proposicional e argumentativa na construção de textos científico-filosóficos.

Em suma, a base de construção de argumentos lógicos, depende do desenvolvimento e do desempenho de habilidades cognitivas, como pensamento abstrato, reflexivo e crítico, bem como capacidade relacional de conceitos e ordenamento de ideias. 


\section{Notas}

1 Associação Brasileira de Normas Técnicas (ABNT), fundada em 1940, é um órgão sem fins-lucrativos que se destina a regulamentar as técnicas de produção feitas no país. A padronização das normas técnicas dos produtos científicos e tecnológicos documentais é fundamental para a compreensão e identificação dos mesmos.

2 O Estoicismo era uma escola filosófica do início do século III a.C., ensinavam sobre ética e lógica, prezavam a felicidade e desprezavam sentimentos e paixões.

\section{Bibliografia}

\section{ARISTÓTELES}

2010 Órganon: Categorias, Da Interpretação, Analíticos Anteriores, Analíticos posteriores, Tópicos e Refutações Sofísticas. Trad. Bini e Edson. São Paulo: Edipro.

BRANQUINHO, João, MURCHO, Desidério, \& GOMES, Nelson Gonçalves.

2006 Enciclopédia de termos lógico-filosóficos. São Paulo: Martins Fontes.

BUCHHOLZ, Kai

2009 Compreender Wittgenstein. Trad. Vilmar Schneider. 2.ed. Petropolis-RJ: Vozes. CHRYSIKOU, Evangelia G.

2013 Mente criativa em ação. In: Glaucia Leal (Org.), A descoberta da criatividade. Revista Mente Cérebro, 1. São Paulo: Duetto.

COPI, Irving M.

1981 Introdução à Lógica. Trad. Alvaro Cabral. 2a edição. São Paulo: Mestre Jou.

DURVAL, Raymond

2003 Registros de representação semiótica e funcionamento cognitivo da compreensão em matemática. In: Silvia D. A. Machado (Org.), Aprendizagem em Matemática: registros de representação semiótica. São Paulo: Papirus.

FREGE, Gottlob

2009 Lógica e filosofia da linguagem. São Paulo: EDUSP.

GADAMER, Hans-Georg

2012 A Hermenêutica. In: Jean Grondin (Org.), O Pensamento de Gadamer. São Paulo: Paulus.

KAMII, Constance

1999 A criança e o número. 20. Ed. São Paulo: Papirus.

KANT, Immanuel

1992 Lógica. Trad. Gottlob Benjamim J. G. Almeida. Rio de Janeiro: Tempo Brasileiro.

MARITAIN, Jacques

2001 Elementos de Filosofia II: A Ordem dos Conceitos, Lógica Menor (Lógica Formal). Rio de Janeiro: Agir.

MATURANA, R. Humberto.

2001 Cognição, ciência e vida cotidiana. Organização e tradução Cristina Magro, e Victor Paredes. Belo Horizonte-MG: UFMG.

MURCHO, Desidério

2003 O lugar da lógica na filosofia. Lisboa-Portugal: Plátano. 
SEVERINO, Antonio Joaquim

2007 Metodologia do Trabalho Científico. 23.ed. São Paulo: Cortez.

SILVEIRA, Marisa R. Abreu

2012 Matemática é pra poucos - um sentido marcado na historia. In: Ocsana Sonia Danyluk (Org.), Historia da Educação Matemática: escrita e reescrita de historias. Porto Alegre-RS: Sulina.

WESTON, Anthony

1996 A arte de argumentar. Trad. Desidério Murcho. 2. Ed. Lisboa-Portugal: Gradiva.

WHITEHEAD, Alfred North

2006 A ciência e o mundo moderno. Trad. Hermann Herbert. São Paulo: Paulus.

WILLINGHAM, Daniel T

2011 Por que os alunos não gostam da escola? Respostas da ciência cognitiva para tornar a sala de aula atrativa e efetiva. Trad. Marcos Vinícius. Porto AlegreRS: Artmed.

WITTGENSTEIN, Ludwig

1995 Tratados Lógicos-Filosoficos. Tradução e Prefácio M. S. Lourenço. LisboaPortugal: Fundação Calouste Gulbenkian.

Fecha de recepción del documento: 5 de julio de 2016 Fecha de aprobación del documento: 15 de agosto de 2016 



\title{
LA PROPOSICIÓN LÓGICA COMO INSTRUMENTO PARA LA COMPRENSIÓN Y TRANSFORMACIÓN DE LA REALIDAD Logical proposition as a tool for reality understanding and transformation
}

\author{
WILLIAM ORLANDO CÁRDENAS-MARÍN \\ Universidad Politécnica Salesiana del Ecuador/Quito-Ecuador \\ wcardenas@ups.edu.ec
}

\begin{abstract}
Resumen
Se realiza una reflexión sobre la importancia de la lógica formal y de la proposición en la comprensión de la realidad. Se sustenta la idea de que la proposición es un elemento fundamental en la figuración lógica, en el proceso de comprensión y en la transformación de la realidad; para ello se efectúa una distinción de términos utilizados en el campo de la lógica formal, se recurre a una explicación sobre la relación entre lógica pensamiento y lenguaje, se explica a breves rasgos la estructura de las proposiciones de forma típica y la relación presente entre nombre, sentido, significado y proposición, se argumenta en favor de la importancia de la proposición en la comprensión de la realidad y si existen límites para aquello que se puede pensar o representar en proposiciones lógicas. Las ideas que guían el artículo se basan principalmente en los postulados que surgen de la línea del pensamiento conocido como empirismo lógico. Se busca responder a las preguntas: ¿Es necesario que la lógica centre su atención en el lenguaje para la comprensión de la realidad? ¿Qué papel tiene la proposición en el proceso de abstracción de la realidad? ¿Ejerce la proposición, además de permitir la comprensión de la realidad, un papel fundamental en la transformación de la realidad? Para ello se emplea una metodología analítica. Se obtienen así elementos que ayudan a comprender el valor de la proposición en la forma en que el ser humano comprende la realidad -construcción mental de la realidad o figuración-, comunica lo comprendido -por medio del lenguaje- y construye nuevas realidades -creación y modificación de su entorno-.
\end{abstract}

Palabras clave

Lógica, proposición, nombres, significado, realidad.

Forma sugerida de citar: Cárdenas-Marín, William Orlando (2016). La proposición lógica como instrumento para la comprensión y transformación de la realidad. Sophia, colección de Filosofía de la Educación, 21(2), pp. 83-99.

* Máster en Administración de Instituciones Educativas. Licenciado en Filosofía y Pedagogía. Docente a tiempo completo en la Universidad Politécnica Salesiana del Ecuador. Miembro del Grupo de Investigación de Filosofía de la Educación (GIFE) de la Universidad Politécnica Salesiana del Ecuador. 


\begin{abstract}
A reflection on the importance of formal logic, and logic proposition in the understanding of reality is performed. It is supported the idea that the proposition is a fundamental element in logic figuration, in understanding process and reality transformation; in order to that proposal a distinction of terms used in the field of formal logic is realized, an explanation of relationship between logical thought and language is made, brief features about structure of propositions and relationship between names, sense and meaning are explained, importance of the proposition in reality understanding is argued and if there are limits for what can be though or represented in logical propositions. This work's guidelines are mainly based on the principles arising from the line of thought known as logical empiricism. It is sought to give a response to the questions: Is it necessary for logic to focus its attention on language in order to understand reality? Which roll does proposition have on reality abstraction process? Has proposition, besides allowing understanding of reality, a fundamental roll on reality's transformation? For that purpose an analytic methodology is used. There are obtained elements which help to understand proposition's value in the human reality understanding form -mental reality construction or figuration-, communicates what is understood -through language- and builds new realities - environmental creation and modification.
\end{abstract}

Keywords

Logic, proposition, names, meaning, reality.

\title{
Introducción
}

El presente artículo centra su atención en la comprensión de la realidad desde el punto de vista de la lógica específicamente enfocado en la configuración proposicional de la realidad.

El objetivo del artículo es analizar la importancia de la proposición lógica en la comprensión de la realidad y la posterior construcción o modificación de la misma, por medio de un estudio analítico de diversos planteamientos entorno al tema, para la validación de la necesidad de una mejor comprensión de los enunciados proposicionales en el marco de la lógica abstracta

El hecho comunicativo se basa en la transmisión de ideas plasmadas en oraciones ${ }^{1}$, las mismas que recibirán el nombre de proposiciones; la persona en su diario vivir utiliza una gran variedad de construcciones proposicionales con la finalidad de comunicar multitud de eventos y pensamientos.

Imagine un momento que se anulase la posibilidad de comunicar de la persona - esto implica eliminar incluso la posibilidad de hacer señas o cualquier otro artificio que transmita una idea- ¿qué pasaría con él y con la comprensión del mundo? ¿Podrían seguirse dando las construcciones sociales, culturales, políticas, entre otras, sin la comunicación? Se puede fácilmente aseverar que no habría interrelación alguna entre los individuos, se transformaría cada individuo en una isla y el alcance de 
su conocimiento sería el alcance de su propia persona y nada más que ello, no sería posible salir de las fronteras personales, el conocimiento mismo sería solo el conocimiento de cada quien, sin la posibilidad de compartirlo.

Es ante dicha realidad que se evidencia la importancia de la comunicación, como medio de transmisión de información, pero, los datos que se transmiten en la comunicación no son dados al azar, no son elementos que surgen indistintamente de un individuo para llegar desordenados al otro, sino que guardan un orden. Dicho orden es analizado por diversas ramas del conocimiento humano, entre las que existe una rama específica que versa sobre la estructura misma del lenguaje y del pensamiento, la Lógica.

En el estudio de la Lógica se realiza la reflexión sobre la naturaleza e importancia de la proposición en la comprensión y estructuración de la realidad; filósofos y lógicos como Aristóteles, Leibniz, Frege, Moore, Russell, Wittgenstein, Carnap, Shlick, Ryle, Ansconbe, Mounce, Copi, entre otros, han brindado valiosos aportes en la comprensión de la proposición como elemento nuclear para el pensamiento y para la posterior estructuración de la ciencia ${ }^{2}$.

La importancia y actualidad del tema radica en que la persona emplea la comunicación en su cotidianidad, y esos elementos comunicativos tienen una fuerte carga proposicional, de manera que la naturaleza, estructura y versatilidad de la proposición lógica debe ser entendida para que se pueda comunicar de forma eficaz y correcta ${ }^{3}$. Otro punto de valor es que la persona no solo emplea la proposición como elemento de salida de información, sino que también permite al individuo establecer relaciones de lo que acontece y plasmar en términos proposicionales aquello que ha captado. Así la proposición se transforma en un elemento primordial en la comprensión de la realidad y en la forma de enunciar datos sobre lo que acontece.

Para el desarrollo del artículo se han tomado en consideración las siguientes preguntas problematizadas: ¿Es necesario que la lógica centre su atención en el lenguaje para la comprensión de la realidad? ¿Qué papel tiene la proposición en el proceso de abstracción de la realidad? ¿Ejerce la proposición, además de permitir la comprensión de la realidad, un papel fundamental en la transformación de la realidad?

De acuerdo con lo que se ha mencionado, se sustenta la idea de que la proposición es un elemento fundamental en la figuración lógica, en el proceso de comprensión y en la transformación de la realidad. 
La metodología utilizada en el documento es analítica, se realiza una revisión bibliográfica de autores y fuentes especializadas sobre lógica, para luego responder a las preguntas guía que se plantean como en el artículo.

En un primer momento se hace una aclaración de los términos utilizados en lógica, donde se distingue entre lógica y sentido común; como segundo punto se argumentan los porqués del estudio del lenguaje por parte de la lógica; en el tercer apartado se analiza la estructura de la proposición, enfocando la atención en los nombres y el significado dentro de la proposición; en un cuarto momento se explican los aportes más relevantes sobre las implicaciones de la proposición en la comprensión de la realidad; por último, se efectúa un análisis de la existencia o no de límites sobre lo que podría enunciarse proposicionalmente.

\section{Sobre lo que se entiende por lógica y proposición}

Ciertos términos empleados en Lógica -incluido el mismo término lógica- son bastante utilizados por las personas en situaciones cotidianas, es ahí donde radica la necesidad de clarificar los términos para captar los sentidos a los que en este artículo se hace referencia.

Cuando se habla de lógica muchas personas emplean el término con un uso deformado, lo toman como un sinónimo de sentido común, pero dicha concepción no es apropiada.

Imagine por un momento que una persona está próxima a cruzar una calle por donde pasan muchos automóviles y existe solamente un semáforo para los conductores de los vehículos; en dicho momento el semáforo se encuentra en color verde, pero la persona cruza de todas formas... hasta ese momento ¿podría decirse que tal individuo no actuó de forma lógica? En realidad no se podría aseverar aquello, dado que el individuo no actuó conforme dicta el sentido común, elementos que difieren de la naturaleza de la lógica.

George Edward Moore fue quien trabajó con mayor detenimiento los elementos que comprenden el sentido común, así hace referencia al sentido común como aquello que compete a varios individuos, por ejemplo nociones elementales como que el ser humano tiene vida o que se comunica, hasta llegar a nociones más complejas pero que respetan la común experiencia de los individuos (Soames, The Dawn of Analysis, 2003). Por su parte "La lógica es el estudio de los métodos y principios usados para distinguir el buen (correcto) razonamiento del malo (inco- 
rrecto)" (Copi, 1999, p. 3)4, definición que la diferencia de lo que es sentido común, en definitiva no son lo mismo.

$\mathrm{Al}$ tener claro a qué se hace alusión cuando se habla de lógica en términos académicos, se puede notar que se habla de la estructura del pensamiento. Dicha estructura no puede ser manipulada directamente, dado que el pensamiento no es material, sino que se debe enfocar la labor en aquellos que esté directamente vinculado al proceso del pensamiento, el lenguaje.

Como se ha mencionado antes, la persona al comunicarse utiliza oraciones, estas oraciones plasman un proceso básico del pensamiento, el juicio, el cual pone en relación conceptos para hacer afirmaciones o negaciones con respecto a propiedades de un objeto; dichas oraciones reciben en el plano lógico el nombre de proposiciones. Tales proposiciones tienen estructuras definidas, las mismas que fueron catalogadas históricamente por Aristóteles ${ }^{5}$ de acuerdo con su calidad y cantidad, así como se encuentra en Copi (1999):

Proposición de la forma típica A: Todo $\mathrm{S}^{6}$ es $\mathrm{P}^{7}$

Proposición de la forma típica E: Ningún $\mathrm{S}$ es $\mathrm{P}$

Proposición de la forma típica I: Algún $S$ es $P$

Proposición de la forma típica O: Algún $\mathrm{S}$ no es $\mathrm{P}$

Estas formas proposicionales denotan los primeros esfuerzos de los filósofos por formalizar el lenguaje y dar a éste un nivel de perfección más elevado que el lenguaje que se utiliza cotidianamente.

Es cierto que un individuo en su comunicación diaria no es capaz de emplear proposiciones de forma típica como las que se han señalado -a menos que tenga mucha práctica en la formalización lógica de lenguaje cotidiano-, pero lo cierto es que el lenguaje empleado por la persona para argumentar -quedan descartados los lenguajes emotivos y directivos- siempre podrá ser sometido a reglas de formalización y de análisis lógico para demostrar su validez. Cabe considerar las palabras de Wittgenstein (2014 [1933]) cuando menciona que "Una proposición es todo aquello por medio de lo cual digo algo" (p. 91), de manera que todo aquello comunicado es proposición. A estos elementos son a los que se hace referencia cuando se habla de proposición.

Un dato interesante que se debe tener en cuenta es que la lógica y sus procesos no pueden ser explicados más allá de las definiciones y aproximaciones que hace la persona en sus intentos por definirla, es en ese sentido que Mounce (1983) enuncia lo siguiente: "La lógica, en suma, no es aquello de lo que hablan los enunciados; es lo que los capacita a hablar 
de algo distinto, a saber: el mundo de los hechos... Porque la lógica no es algo que es representado; es lo que hace posible la representación" (p. 26)

El autor pone de manifiesto así el carácter instrumental de la lógica, al habilitar al individuo para desplegar de mejor manera su pensamiento y su capacidad comunicativa, develar las potencialidades que tiene la persona para comunicar algo a los demás.

Luego de haber realizado una aclaración de términos, compete analizar de forma más detenida los elementos con los cuales aporta la lógica al conocimiento, para luego enfocar la atención en la importancia del componente proposicional para la comprensión de la realidad.

\section{¿Por qué la lógica enfoca su atención en el lenguaje?}

De forma breve se ha enunciado anteriormente que pensamiento y lenguaje tienen relación. En este punto se legitima de mejor manera dicho postulado.

El pensamiento no tiene un componente material; se podría decir que se conoce dónde se elabora el proceso del pensamiento, e incluso una aseveración de dicho tipo tendría graves falencias de acuerdo con los estudios actuales del proceso cognitivo. Entonces no puede enfocarse concretamente la atención en algo, porque no hay ese algo físico, sino la manifestación de aquello, y dicha manifestación es el lenguaje. En ese sentido "Tanto lenguaje como pensamiento llegan a tener así una relación intrínseca, en cuanto que no puede desarrollarse el pensamiento sin el lenguaje, y no puede darse el lenguaje sin el pensamiento" (CárdenasMarín, 2011, p. 12).

Wittgenstein en su obra el Tratado lógico-filosófico, aborda el problema del pensamiento con respecto al lenguaje y menciona que "Es humanamente imposible extraer de él [del lenguaje ordinario] inmediatamente la lógica del lenguaje. El lenguaje disfraza el pensamiento" (4.002), y es por ello que si se desea estructurar el pensamiento de acuerdo con las leyes lógicas se debe prestar atención a la forma en la que el individuo utiliza el lenguaje, de manera que "En cuanto la lógica formal vaya moldeando el lenguaje, igualmente el pensamiento se irá estructurando de acuerdo a las leyes que se sigan, dada la ya mencionada relación entre pensamiento y lenguaje, sobre todo lenguaje cotidiano" (Cárdenas-Marín, 2011, p. 13).

Se debe tener en cuenta que, a pesar de que la lógica es empleada para la estructuración correcta del lenguaje y pensamiento, esta no aña- 
de elementos ajenos a la estructura propia del ser humano, sino que se fundamenta en los mismos procesos del pensamiento que la persona ha desarrollado a lo largo de su historia. Es por ello que "Lo que pensaba [Wittgenstein], en la época del Tractatus, era que un cálculo formal sería útil para mostrar la lógica ya inherente al lenguaje ordinario" (Mounce, 1983, p. 28), leyes que eran propias del mismo pensar de la persona, y únicamente serían categorizadas para establecer reglas universales del pensamiento.

Con lo anterior se entiende de mejor manera que la lógica no es ajena al pensamiento, sino que lo define, lo estructura y lo hace manifiesto de forma universal, por lo que la lógica no hace más complicada la labor comunicativa sino, por el contrario, la simplifica, hace del hecho comunicativo algo estandarizado, regido a leyes globales; es por ello que "El uso de un cálculo lógico, pensaba Wittgenstein, era mostrar la lógica del lenguaje ordinario de manera más clara que lo hace el propio lenguaje ordinario" (Mounce, 1983, p. 29), y podría decirse que su pensamiento era bastante acertado.

Se debe tener en cuenta que a través de la comprensión y estructuración del lenguaje "Desde el orden lógico es posible delinear y dar coherencia a todas las dimensiones de la realidad de la persona" (CárdenasMarín, 2011, p. 16), porque todas las dimensiones humanas comprenden pensamientos, que no escapan a las leyes de la lógica.

Luego de validar por qué la lógica se enfoca en el lenguaje, compete centrar la atención en la estructura lógica mínima que comprende dicho lenguaje, la proposición. En el siguiente apartado se realizará un análisis de la estructura de la proposición junto con la aclaración de dos elementos importantes para su comprensión: los nombres que la constituyen y el significado que lleva o no consigo cada proposición.

\section{Análisis estructural de la proposición}

Es una realidad que la proposición no es la parte mínima del lenguaje que tiene sentido -la gramática se encarga de esas partes mínimas en términos de monemas- pero es la composición lógica mínima que capta una realidad y la enuncia de forma intencionada y con sentido y significado.

Si bien la composición proposicional tiene partes, dichas partes no transmiten sentidos sueltas, sino que es la proposición la que atribuye dichos significados; bien trabajaron Russell y Wittgenstein dicha división de la proposición en hechos atómicos - nombres- y moleculares -la 
proposición propiamente dicha- (Russell, 1967; Russell, 1997; Russell, 2009 [1903-1959]; Wittgenstein, 2001 [1921]; Wittgenstein, 2014 [1933]; Mounce, 1983; Soames, 2003; Soames, 2005).

A continuación se hará un recorrido por los elementos que determinan a una proposición lógica: nombres y significado.

\section{El nombre en la proposición}

La proposición categórica es una cadena en la que a un sujeto se le atribuye un predicado y, entre ellos versa una relación proporcionada por un verbo -comúnmente el verbo ser-que recibe el nombre de cópula. El sujeto mencionado dentro de la proposición, e incluso los términos predicativos, son términos o nombres, los mismos que ejercen la función de 90 tomar el lugar del objeto en el plano lógico del pensamiento, "Los signos simples usados en la proposición se llaman nombres" (3.202). En línea con lo anterior es importante recalcar que "El análisis de Aristóteles dependía de que se dividieran las proposiciones contenidas en la inferencia en sujeto y predicado" (Mounce, 1983, p. 14), una visión clásica que aún se considera en el estudio de la lógica.

Dichos nombres son elementos atómicos, mínimos dentro de la trama proposicional, y son necesarios para que la proposición tenga sentido y haga referencia a algo o alguien. Pero dichos tales nombres en sí no tienen aún sentido, sino que requieren de la proposición para finalmente ganar sentido (Wittgenstein, 2001 [1921]; Anscombe (1963 [1959]); Kripke, 1972; Macià, 2004; Santamaría, 2011; Cárdenas-Marín, 2016).

Decir que los nombres son parte atómica de las proposiciones y que por sí solo no tienen sentido, sino referencia, no resta la importancia que el nombre tiene en la construcción proposicional; al respecto Kenny (2006 [1973]) postula:

Entonces esa es una diferencia entre un nombre y una proposición: entender un nombre es entender su referencia, entender una proposición es entender su sentido. Pero otra, importante, diferencia es esta. Para entender la referencia de un nombre, uno debe tener la referencia explicada (tlp 4.026); para entender el sentido de una proposición uno no debe tener el sentido explicado (tlp 4.02). Solo cuando estamos tratando con un lenguaje no familiar con la ayuda de una libro de frases tomamos los significados de las proposiciones como unidades singulares: la comprensión real de proposiciones surge del entendimiento de sus partes constitutivas, las palabras que las componen (tlp 4.024-5) (p. 50; traducido por W. Cárdenas-Marín). 
Así se enfatiza que el nombre es necesario en la proposición, sobre todo es imperante comprender el término o nombre para poder comprender una oración. En esa línea se puede ejemplificar lo siguiente: si una persona dice el ascensor es espacioso - una proposición bastante simple, pero servirá para el ejemplo- entonces el oyente o receptor deberá ser capaz de identificar cada uno de los términos que constituyen la proposición, caso contrario no será capaz de captar el sentido de la misma, no porque la proposición sea incorrecta o no haga referencia a un hecho real, sino porque se da un corte en la comprensión de los términos; si el oyente no supiese qué es ascensor -porque es de una comunidad donde no existen estos mecanismos u otras razones- entonces la proposición no podrá formar un sentido en la mente del individuo.

Puede darse el caso de nombres que no tengan conexión con un elemento en la realidad -muchos términos o nombres utilizados por el ser humano sirven para referenciar elementos intangibles-, pero es importante aclarar que en lógica y las diversas construcciones proposicionales se requiere de un elemento real, fáctico, que permita verificar en primera instancia lo que se dice; entonces "Una proposición, sin embargo, no es solo un conjunto de nombres, y en adición a correlacionar nombres con objetos tenemos que correlacionar relaciones entre nombres en una proposición con relaciones entre objetos en hechos" (Kenny, 2006 [1973], p. 52; traducido por W. Cárdenas-Marín).

El postulado anterior plantea un problema de índole lógico y epistemológico, sobre las construcciones proposicionales que solo se deberían centrar en datos concretos, corroborables; pero, si bien las categorías lógicas en un primer momento se basan en tales datos directos para la estructuración mental de la realidad, varios autores han trabajado la posibilidad de elementos proposicionales que no requieren de elementos fácticos, sino que la razón humana es capaz de trazar múltiples vías lógicas que tengan probabilidad de darse, por ejemplo el trabajo de Kripke (1972).

Luego de considerar puntos elementales como nombres, sentido y referencia en la proposición, compete realizar un recorrido por el significado atribuíble a una proposición y cómo es posible captar el mismo.

\section{El significado y la proposición}

Cuando se aborda el tema del significado en las estructuras proposicionales, es necesario hacer alusión a las aseveraciones de diversos autores que son catalogados como neopositivistas lógicos. Esto se debe a que fueron ellos quienes abordaron de forma más detallada la noción del significado 
de las proposiciones, y aquello que se puede decir en pro de un lenguaje mejor estructurado y con mayores potencialidades para la ciencia.

Se podrá apreciar que en un primer momento el significado de una proposición es entendido desde la afirmación que se hace sobre un estado de cosas, sobre algo que se da efectivamente en la realidad (Wittgenstein, 2001 [1921]); en ese sentido, para Schlick (1981 [1059]) "El significado de una proposición indudablemente consiste solo en esto, en que expresa un estado definido de cosas Este estado de cosas debe ser señalado para dar el significado a una proposición" (p. 93).

Con respecto al significado (Wittgenstein, 2001 [1921]), con las tablas de verdad, quiso expresar que "una proposición es una función de verdad de proposiciones elementales" (Mounce, 1983, p. 59).

Aquel significado marcado por el darse del estado de cosas que es enunciado es capaz de determinar la verdad o falsedad de un enunciado. Es importante aclarar que desde esta comprensión lógica será verdadero aquello que se da efectivamente en la realidad, en el mundo, y falso aquello que no se da efectivamente (Schlick, 1981 [1959], pp. 92-93). Esta visión ha recibido muchas críticas en los años posteriores desde otras comprensiones o líneas filosóficas, pero ¿̇e qué otra forma podría decirse que algo es verdadero en un primer momento si no es por medio de la experiencia de lo que se da efectivamente en el mundo, en la realidad?

Carnap (1981 [1959]) sigue una línea cercana a lo planteado por Wittgenstein y Schlick, pero tiene una flexibilidad especial ante los valores de verdad y falsedad atribuidos por la experiencia directa, $y$ al respecto menciona:

En la teoría de conocimiento se acostumbra decir que las proposiciones primarias se refieren a 'lo dado', pero no ha habido unanimidad respecto a qué es lo dado. A veces se ha sostenido que en una proposición de este género, lo dado se refiere a las cualidades sensoriales más simples o a algún orden de sentimientos... en otras, el criterio se ha inclinado a la concepción de que las proposiciones primarias no pueden referirse sino a experiencias globales y a relaciones de semejanza entre ellas... (p. 69).

En el postulado anterior, el autor presenta un cuestionamiento bastante interesante, que proporciona muchas posibilidades de reflexión, y es que la proposición lógica no se limita únicamente a los elementos reales corroborables, sino que expande su reflexión a nuevas fronteras del pensamiento humano; en ese sentido "Toda proposición tiene lo que aquí llamamos ciertos 'poderes lógicos'; es decir, que se relaciona con otras proposiciones en diversas relaciones lógicas que es posible descubrir" 
(Ryle, 1981 [1959], p. 335), así se da la posibilidad de nuevas construcción silogísticas con base en conexione proposicionales que escapan de lo que se da sensiblemente.

Como se puede apreciar, el significado de una proposición está definido por su verdad, y dicha verdad se valida en cuanto se da en la realidad; es este el elemento que debe ser considerado en la estructuración de proposiciones y, a partir de dichas afirmaciones, es posible la construcción de otras proposiciones lógicamente válidas, siempre que respeten las leyes de la lógica.

Al haber analizado la relación de términos dentro de la proposición junto con la forma en la que se construyen significados a través de la proposición, siempre y cuando exista una relación entre lo que se dice y lo que se da efectivamente en la realidad, se puede apreciar que la lógica, específicamente la proposición lógica, tiene la capacidad de presentar una realidad captada sensorialmente. A continuación se argumentará cómo permite la proposición la comprensión de la realidad y la posterior -o posible- transformación de dicha realidad.

\section{Comprensión de la realidad a través de la proposición}

En la historia de la Lógica se ha mencionado que la forma lógica guarda estrecha relación con la realidad, se plantea así una relación isomorfa entre realidad y lógica, y por ende pensamiento.

El lenguaje tiene la capacidad de compartir realidades, y al mismo tiempo crearlas, de manera que se hace necesario, como se ha analizado anteriormente, un componente verdadero o real que sirva de soporte para lo que se dice, es ahí donde entra el componente proposicional como elemento que sirve para validar y regir la forma en la que se ordenan los datos sensoriales y cómo se enuncia la información sobre dicha realidad.

Wittgenstein (2001 [1921]) en su Tratado realiza una argumentación bastante interesante sobre la comprensión del mundo a través de la lógica y de los elementos proposicionales del lenguaje. Para hacer alusión a las aseveraciones del autor es necesario traer a la memoria que su explicación en esta fase de su pensamiento, conocida tradicionalmente como el primer Wittgenstein, tiene una fuerte carga empírica y es por ello que se conoce como el pensamiento empirista lógico del autor; por esa razón se aprecia en la mayor parte de la obra el gran peso que coloca en la realidad, en lo sensible.

El autor realiza varias aclaraciones al respecto de la realidad y la comprensión lógica. Marca la primacía de los estados de cosas para defi- 
nir la estructura de los hechos (2.034), después planea que la realidad está conformada por todos los estados de cosas que se dan efectivamente, por hechos positivos (2.06). Esas primeras afirmaciones sientan las bases de aquello que se considera como realidad, aquello que existe en términos sensibles, comprobables, medibles.

Ahora bien, dicha realidad puede ser captada por la mente humana a través de la figura que constituye un modelo conceptual de la misma (2.12), esta figura constituye el pensamiento, que contiene la totalidad de figuras de hechos que son verdaderos $(3,3.01)$. Estos postulados manifiestan el proceso de abstracción primordial que realiza la mente humana de la realidad, la mente figura la realidad y es el pensamiento el que contiene esos datos figurados de la realidad.

Podría pensarse que la proposición se estructura luego del proceso que se mencionó en el párrafo anterior, pero eso no es cierto, la proposición está ya dada en la forma figurada de la realidad que el individuo hace de la realidad, simplemente no es enunciada aún.

Al momento de ser lanzada, dicha, la proposición, se puede apreciar que el pensamiento está presente en ella, dado que se dicen, en la medida de lo posible, las cosas como son $(3.1,3.221)$ y se hacen manifiestos los sentidos construidos por la persona (4). De manera que la realidad es captada y expresada por una gran cantidad de proposiciones, que en conjunto, en su totalidad, conforman el lenguaje (4.001), el lenguaje presenta la comprensión de la realidad.

De acuerdo con lo anterior, "El mundo, entonces, es la totalidad de los hechos en el espacio lógico; o, también, es la totalidad de estados de cosas, los cuales se componen de objetos que encajan entre sí de un determinado modo" (Mounce, 1983, pp. 34-35). Así, lo que se expresa con el lenguaje, lo que se piensa, es en gran medida lo que se comprende del mundo, lo que hay.

Lo que se ha mencionado denota la relevancia que tienen el pensamiento y el lenguaje en la comprensión de la realidad y, luego, el modo de compartir esas comprensiones con otros individuos; son el lenguaje y el pensamiento los que dinamizan el proceso del conocimiento, pero aquello no sería posible sin la ayuda de las construcciones proposicionales, en ese sentido Wittgenstein (2014 [1933]) menciona que "El lenguaje tiene que tener la misma multiplicidad que una torre de control, que promueve las acciones que corresponden a sus proposiciones" (p. 113).

Se tiene que considerar que, a pesar de ser muy cuidadosos con respecto a las representaciones proposicionales que se dan de la realidad, la persona puede cometer errores de figuración, se corre el riesgo de caer 
en falacias en la afirmaciones sobre el mundo, es por ello que Kenny (2006 [1973]) presta especial atención a la representación e indica lo siguiente:

Cualquier representación puede ser una representación exacta o inexacta: esta puede dar una figura verdadera o falsa de lo que representa. Es este hecho lo que llevó a Wittgenstein a tratar de aclarar la naturaleza de la proposición por medio de una teoría de la representación general. En cualquier representación hay 2 cosas que considerar: (a) de qué es esta representación; (b) si esta representa lo que representa exactamente o inexactamente. La distinción entre estas dos características de una representación corresponden a la distinción, concerniente a la proposición, entre qué significa la proposición y si lo que significa es verdadero o falso -entre sentido y valor de verdad (p. 44; traducido por W. Cárdenas-Marín).

Así se sientan algunos criterios para someter una proposición a análisis, con la finalidad de que las comprensiones de la realidad sean más certeras y los sentidos sean plenamente captados y transmitidos.

Se ha presentado en este apartado la forma en la que el mundo es comprendido desde el plano lógico del pensamiento y cómo la proposición tiene la versatilidad de figurar los hechos en el pensamiento para luego transmitirlos por medio del lenguaje. A continuación se realizará una reflexión sobre los límites, si es que los hubiere, de la proposición en cuanto a la representación de la realidad y creación de realidades probables.

\section{Sobre los limites de la proposición}

Un cuestionamiento latente en el campo del conocimiento y de la lógica radica en si existen límites para el pensamiento que, de haberlos, repercutiría en los límites del lenguaje, dada la conexión antes abordada de lenguaje y pensamiento.

Ante tal interrogante Wittgenstein (2001 [1921]) plantea que "El pensamiento contiene la posibilidad del estado de cosas que piensa. Lo que es pensable es también posible" (3.02), situación que parece limitar el pensamiento a la realidad, a los estados de cosas que se dan efectivamente, pero también puede volcarse a afirmación hacia el otro extremo, al plantear la posibilidad de darse efectivamente de aquello que se puede pensar. Quiere esto decir que la realidad puede llevarse más allá debido a la versatilidad del pensamiento y de la proposición, alguien puede pensar en muchos inexistentes -cosas que no se dan efectivamente, o que aún no se han podido demostrar-pero hay probabilidad de ocurrencia de lo pensado. 
Quiere decir que la proposición, y por ende pensamiento y lenguaje, no tiene límites que la hagan retroceder en algún momento, siempre y cuando se rija a las leyes lógicas definidas, las mismas que no constituyen límites, sino elementos válidos que permitirán la construcción de nuevas formas proposicionales válidas. A estas leyes lógicas del pensamiento hace referencia Wittgenstein (2001 [1921]) cuando menciona que "No podríamos pensar nada ilógico, porque de lo contrario tendríamos que pensar ilógicamente" (3.03), y la mente humana va de la mano con las leyes lógicas, como se ha afirmado al inicio de este artículo, a pesar de que en ocasiones parezca que no se siguen cabalmente. Ante la situación en mención, Kenny (2006 [1973]) postula algunas tesis, a partir del estudio de Wittgenstein, que permiten comprender las relaciones y límites entre la proposición y la realidad:

... (1) Una proposición es esencialmente compuesta. (2) Los elementos que componen una proposición están correlacionados por decisiones humanas con elementos de la realidad. (3) La combinación de tales elementos correlacionados en una proposición presentan -sin necesidad de intervención humana- un posible estado de cosas. (4) Una proposición se encuentra en una relación interna con el posible estado de cosas que representa. (5) Esta relación interna solo puede ser mostrada, no puede ser declarada informativamente. (6) Una proposición es verdadera o falsa en virtud de su concordancia o no con la realidad. (7) Una proposición debe ser independiente del estado real de las cosas que las hace verdaderas o falsas. (8) Ninguna proposición es una verdad a priori (pp. 50-51; traducido por W. Cárdenas-Marín).

Las tesis que menciona el autor permiten ver la ausencia de límites en la proposición lógica, a la que se le permite enunciar diversos elementos que luego deberán ser corroborados, pero que en primera instancia son aceptados, a pesar de no darse en la realidad. Quiere esto decir que la proposición no se rige solamente a decir la realidad como es, sino que su versatilidad permite a la persona pensar en nuevas posibilidades para el mundo, de manera que está implicada también en la transformación de la realidad, en la creatividad; aunque parece ser que en ocasiones no se respetan las leyes de la lógica, situación que podría provocar comprensiones distorsionadas.

Sucede que el lenguaje cotidiano es el responsable de confundir la correcta representación de la realidad, la presencia de "Ciertos rasgos accidentales o engañosos de sus formulaciones en el lenguaje pueden hacer más difícil la tarea de investigar las relaciones lógicas entre las proposiciones" (Copi, 1999, p. 37) y es por ello que, en muchos casos, parece que 
los individuos tienen problemas de representación, pero son en realidad problemas de lenguaje, problemas que deberán ser abordados por los lógicos en la búsqueda de un lenguaje que permita comunicar con mayores niveles de perfección.

\section{Conclusiones}

Ciertos términos lógicos son utilizados erróneamente en la cotidianidad. Se piensa que lógica es sinónimo de sentido común, pero son términos diversos; la lógica versa sobre la correcta estructuración del pensamiento, mientras que sentido común hace referencia a las experiencias individuales y colectivas.

La lógica centra su atención en el lenguaje por éste es la manifestación sensible del pensamiento, dado que el pensamiento no es tangible. Esto quiere decir que en la medida en que se estructuren correctamente los enunciados lingüísticos, también se estructurará el pensamiento. La lógica no es ajena al pensamiento sino, por el contrario, el pensamiento humano es lógico y es de esas estructuras lógicas desde donde se extraen las leyes del pensamiento.

La proposición ha sido estudiada históricamente por diversos filósofos, siendo Aristóteles quien sienta las bases formales iniciales para el análisis académico de la misma. La proposición tiene una estructura que relaciona sujeto y predicado con un verbo como cópulas pero, además, tiene elementos que requieren un análisis más detenido: nombres, sentido y significado. Los nombres en una proposición toman el lugar de los objetos en el mundo real, además, no poseen sentido, solo significado; en la medida en que la persona entienda el significado de las palabras que conforman el nombre, podrá captar el sentido completo de la proposición.

El lenguaje manifiesta la forma en la que la persona capta la realidad y crea nuevas realidades, es decir que modifica la realidad existente; en ese sentido la proposición presenta el darse y no darse de los estados de cosas en la realidad, situación que se rige en un primer momento a los valores de verdad o falsedad que dependen de si lo que se menciona existe o no en el mundo. La lógica y la proposición permiten que la persona haga figuras de los hechos, y la totalidad de dichas figuras corresponden al mundo que se da efectivamente. La proposición permite realizar un análisis certero de la realidad, al mismo tiempo que permite comprender el mundo de forma ordenada. 
La proposición no tiene límites definidos; a pesar de regirse a las leyes lógicas, estas leyes no constituyen límites sino guías para que la estructuración de argumentos a partir de las proposiciones sean eficaces. Existe un momento en el que ya no es necesario que la proposición se rija a un estado de cosas, sino que ésta puede explorar nuevos horizontes del pensamiento con base en las proposiciones formuladas anteriormente, es así que aparece el criterio de posibilidad o probabilidad como una respuesta a aquello que no se puede comprobar.

\section{Notas}

1 Se tomará como referencia la comunicación oral y escrita, puesto que son los elementos de mayor empleo en la cotidianidad de los individuos.

2 Se considera aquí ciencia en el sentido positivista del término.

3 Correcto no en el sentido moral, sino en el sentido lógico que hace referencia a la validez de un enunciado.

4 Esta definición es bastante sintética pero presenta en pocas palabras el objeto de estudio de la lógica.

5 Se hace referencia aquí a la denominada Lógica Clásica o Aristotélica, no se aborda la estructura de la proposición como más adelante la analizó Frege.

6 Sujeto.

7 Predicado.

\section{Bibliografía}

ANSCOMBE, Gertrude

1963 [1959] An introduction to Wittgenstein's tractatus. New York: Harper Torchbooks. CÁRDENAS-MARÍN, William

2011 Contribuciones de la lógica formal para el desarrollo del pensamiento en los niños de 12 años de edad de la Unidad Educativa San Patricio (Tesis de grado). Quito: Universidad Politécnica Salesiana.

2016 Reflexiones sobre el nombrar a partir de la comprensión del lenguaje de Saul Kripke/Reflections on naming from Saul Kripke's language comprehension. Sophia, 20(1), 103-116.

CARNAP, Rudolf

1981 [1959] La superación de la metafísica mediante el análisis lógico del lenguaje. In A. Ayer, El positivismo lógico (pp. 66-87). México: Fondo de Cultura Económica.

COPI, Irving

1999 Introducción a la Lógica. Buenos Aires: Eudeba.

KENNY, Anthony

2006 [1973] Wittgenstein. USA: Blackwell Publishing. 
KRIPKE, Saul

1972 Naming and Necessity. En: D. Davidson, \& G. Harman, Semantics of Natural Language (pp. 253-355). Dordrecht: D. Reidel Publishing Company.

MACIÀ, Josep

2004 Proper Names: Ideas and Chains. Canadian Journal of Philosophy, 30, 129155.

MOUNCE, Howard

1983 Introducción al "Tractatus" de Wittgenstein. Madrid: Tecnos.

RUSSELL, Bertrand

1967 El atomismo lógico. En: A. Ayer, El positivismo lógico (pp. 30-100). México: Fondo de Cultura Económica.

1997 The problems of Philosophy. United Kingdom: Oxford University Press.

2009 [1903-1959] The Basic Writings of Bertrand Russell. (R. Egner, \& L. Denonn, Eds.) New York: Routledge.

RYLE, Gilbert

1981 [1959] Argumentos filosóficos. En: A. Ayer, El positivismo lógico (pp. 331-348). México: Fondo de Cultura Económica.

SANTAMARÍA, Freddy

2011 El nombrar, la necesidad y la identidad. Kripke y la teoría de la referencia. Escritos, 19(43), 401-419.

SCHLICK, Moritz

1981 [1959] Positivismo y realismo. En: A. Ayer, El positivismo lógico (pp. 88-114). México: Fondo de Cultura Económica.

SOAMES, Scott

2003 Philosophical Analysis in the Twentieth Century (Vol. 1). New Jersey: Princeton University Press.

2005 Philosophical Analysis in the Twentieth Century (Vol. 2). New Jersey: Princeton University Press.

WITTGENSTEIN, Ludwig

2001 [1921] Tractatus logico-philosophicus. Madrid: Alianza Editorial.

2014 [1933] Escrito a máquina [The Big Typescript]. Madrid: Trotta.

Fecha de recepción del documento: 5 de julio de 2016

Fecha de aprobación del documento: 15 de agosto de 2016 



\title{
COMPLEMENTARIEDAD, IDENTIDAD Y CONTRADICCIÓN \\ EN LA LÓGICA DE NIELS BOHR \\ Complementarity, identity and contradiction in the logic of Niels Bohr
}

\author{
SARA MADERA GÓMEZ* \\ Universidad Politécnica Salesiana / Quito-Ecuador \\ sarymadera@hotmail.com
}

\begin{abstract}
Resumen
Los descubrimientos de la física cuántica, acontecidos en el siglo XX, plantean numerosos retos a nivel experimental y conceptual. Junto con el advenimiento de dichos hallazgos, aparecen también teorías y principios que buscan explicarlos y que en ocasiones rompen con paradigmas que corresponden a otros ámbitos investigativos. Este es justamente el caso del principio de complementariedad, desarrollado por el físico danés Niels Bohr en el marco del descubrimiento de la dualidad onda-partícula.

Esta característica que recae sobre la naturaleza del fotón y que trastoca la noción clásica de identidad, obliga también a realizar un análisis sobre las leyes del pensamiento como fueron establecidas por Aristóteles -de identidad, de no contradicción y de tercero excluido- ya que, de cierta manera, las contradicen. Esta es la discusión sobre la cual se cierne el presente artículo, que en un primer momento presenta una descripción del trabajo de Bohr dentro del ámbito de la investigación cuántica, posteriormente se realiza una exposición de las leyes aristotélicas que han marcado el trabajo de la lógica durante siglos, aunque hoy en día muchas escuelas las hayan superado, dentro de esta misma problemática se establece el problema de la relación entre lógica y ontología para finalmente analizar el caso de la luz y realizar una breve referencia al tema de la identidad.

Las conclusiones se refieren a la generalidad del problema ya que resulta imposible establecer una solución clara al problema, en última instancia este respondería a la perspectiva que se tenga sobre la relación entre lógica, ontología y lenguaje.
\end{abstract}

Palabras clave

Física cuántica, filosofía de la ciencia, Niels Bohr, dualidad onda-partícula.

Forma sugerida de citar: Madera Gómez, Sara (2016). Niels Bohr: complementariedad, identidad y contradicción en lógica. Sophia, colección de Filosofía de la Educación, 21(2), pp. 101-118.

* Licenciada en Filosofía y Pedagogía. Maestrante en la carrera de Filosofía de la Ciencia por la Universidad Nacional Quilmes-Argentina. Miembro del Grupo de Investigación en Filosofía de la Educación (GIFE) de la Universidad Politécnica Salesiana del Ecuador. 


\begin{abstract}
The discoveries of quantum physics, that occurred in the twentieth century, pose many challenges to the experimental and conceptual level. Along with the advent of these findings, there are also theories and principles that seek to explain them and sometimes break with paradigms that correspond to other areas of research. This is precisely the case of the principle of complementarity, developed by the Danish physicist Niels Bohr in the context of the discovery of the wave-particle duality. This feature that lies to the nature of the photon and transforms the classical notion of identity, obliged to perform an analysis of the laws of thought as were set by Aristotle -identity, non-contradiction and of excluded middle- because, in some way, it contradicts them. This is the discussion of which looms the present article, which at first presents a description of the work of Bohr within the scope of the quantum research, subsequently conduces an exhibition of the aristotelian laws that have marked the work of logic for centuries, although nowadays many schools have passed, within the same problem set the problem of the relationship between logic and ontology in order to finally, analyze the case of light and make a brief reference to the topic of identity.

The conclusiones relate to the generality of the problem since it is impossible to establish a clear-cut solution to the problem, in the last instance, it would respond to the perspective you have about the relationship between logic, ontology and language.
\end{abstract}

Keywords

Quantum physics, philosophy of science, Niels Bohr, wave-particle duality.

Sécuál es mi nombre no es necesario escribirlo por todos lados

ni tatuarlo en la retina sé cómo me llamo suelo incluso responder con gentileza pero

¿cuál es mi nombre?

(Patricio Aguirre Negrete)

\title{
Introducción
}

El advenimiento de la física cuántica a inicios del siglo XX significó una revolución dentro del campo científico, y dejó planteadas numerosas preguntas para la física y la filosofía. Los descubrimientos acarreados por esta nueva rama de la física no solo presentan retos para la aplicación de métodos experimentales -casi completamente inexistentes hasta el momento- sino que también han trastocado principios que hasta el siglo pasado se tenían por certeros e indubitables.

Este es el caso del principio de identidad en lógica, así como el de contradicción y exclusión, que se han visto confrontados con la dualidad onda-partícula de la luz, cuya superación se dio gracias al trabajo del fí- 
sico danés Niels Bohr y su principio de complementariedad. Cabe aquí destacar que la solución viene desde la física misma y no desde la lógica, ni desde la reflexión filosófica, de manera que el establecimiento de estas nuevas relaciones es el tema del presente artículo.

Desde ahí se desprenden los objetivos del artículo: primeramente brindar una exposición clara sobre el principio de complementariedad desarrollado por Niels Bohr, el contexto en el cual surge y su incidencia sobre la dualidad onda-partícula que caracteriza al fotón. Realizar, además, una lectura sobre los principios de identidad y contradicción en lógica y finalmente contrastarlos y exponer lo que su relación implica para el mundo de la epistemología y la filosofía.

Sin desmerecer el magnífico trabajo realizado por Bohr: ¿es realmente satisfactoria su propuesta para la filosofía? ¿Cuál es el verdadero significado de la dualidad y cómo puede relacionarse con el advenimiento de una nueva ontología? ¿Está completa la educación filosófica sin el análisis de corrientes contemporáneas de la ciencia?

Estas y otras preguntas son los puntales que guían el presente artículo, donde el problema en cuestión es cómo relacionar los principios de identidad y contradicción de la lógica con una evidencia empírica que lo desmiente. El análisis sobre este tema parece importante considerando que existen pocos trabajos filosóficos que se hayan acercado a la física cuántica, y que hayan reflexionado sobre su verdadero impacto para nuestra comprensión del mundo. Si bien es cierto que el discurso científico avanza a pasos agigantados, no significa que deba evadir el análisis filosófico ya que entonces carecerá de profundidad y de los elementos que permiten elaborar una explicación más completa sobre la realidad. La física cuántica en sí misma, junto con sus descubrimientos, representan un tema de actualidad no solo a nivel teórico sino también práctico ya que muchos de las plataformas tecnológicas que hoy utilizamos, son el resultado de sus aplicaciones. Carece, sin embargo, de un marco crítico y filosófico que analice los alcances de su discurso, a partir de esto se infiere entonces la importancia y actualidad del tema presentado, ya que no solamente brinda nuevas lecturas epistemológicas sino que también plantea preguntas sobre la forma en que comprendemos nuestro entorno.

Para la redacción de este artículo se aplicó una investigación bibliográfica, aunque con numerosas dificultades para localizar textos originales en las bibliotecas de las universidades de la capital, situación que demuestra la poca importancia que se le ha brindado a este tema de la filosofía de la ciencia. A pesar de estos percances se ha procurado recurrir a textos especializados y que contengan referencias directas a los textos originales, específicamente en el caso de Bohr. 
La estructura del artículo se desprende a partir de sus objetivos, así, consta de cuatro partes principales distribuidas entre el análisis de Bohr, la lectura sobre los principios lógicos, una breve referencia al tema de la identidad y finalmente las conclusiones.

La principal aportación del artículo reside en las nuevas preguntas que puede plantear para otros trabajos en el ámbito filosófico y científico. Deja también planteado un reto para la educación en filosofía ya que, al parecer, la época actual necesita más análisis sobre los discursos científicos; en cierto sentido la filosofía ha cedido ese espacio que le pertenece, abandonando así una actividad clara en su quehacer histórico. Si bien es cierto que los conocimientos científicos han pasado a validarse dentro de su misma comunidad y esfera de trabajo, desde la perspectiva de la autora del presente artículo la filosofía tiene el deber de acercarse a sus 104 presupuestos teóricos ya que-como se demostrará más adelante- tienen una clara influencia en la explicación que quiere darse sobre el cosmos, y en última instancia sobre nosotros mismos.

A continuación se presenta la primera sección del artículo donde se analizará el aporte conceptual de Niels Bohr.

\section{Cuantos de acción y complementariedad}

Realizar un recorrido histórico sobre los antecedentes del principio de complementariedad implicaría la redacción de otro artículo mucho más extenso. Es necesario sin embargo, brindar al menos una perspectiva sobre los sucesos más importantes que llevaron a Niels Bohr a realizar su planteamiento.

Primeramente cabe destacar que para la física clásica, los fenómenos del mundo podían estudiarse a partir de ondas o partículas. Ambas, elementos que poseen propiedades mutuamente excluyentes, Hewitt lo explica en su texto "Física Conceptual", afirmando que: "las partículas son objetos diminutos, como balas. Tienen masa y obedecen las leyes de Newton; viajan por el espacio en línea recta a menos que actúe sobre ellas una fuerza" (2004, p. 605), un ejemplo de partícula es el electrón, descubierto hacia 1897.

Las ondas por su parte "son fenómenos que se extienden en el espacio. Cuando una onda se propaga por una abertura o rodea una barrera, se difracta y se interfieren algunas de sus partes" (Hewitt, 2004, p. 605). Ejemplos de ondas son aquellas de radiofrecuencia que al golpear con elementos masivos los rodean. 
Es decir que la naturaleza de una onda difiere completamente de la de una partícula, su movimiento en el espacio es diferente y también sus propiedades.

Tras dejar sentados estos supuestos, es necesario explicar cuál era uno de los problemas con los que lidiaba la física a finales del siglo XIX y que sentó la base de la física cuántica. El problema era aquel de la radiación electromagnética en los cuerpos. Ana María Cetto describe este problema en su texto: "La luz en la naturaleza y el laboratorio" de la siguiente manera:

Sabemos que todo objeto emite una cierta cantidad de radiación térmica, o sea radiación electromagnética de espectro continuo, que cambia de color según la temperatura del objeto. Al aumentar la temperatura del cuerpo emisor, el máximo de intensidad de su espectro de radiación se va corriendo del infrarrojo al rojo, al anaranjado, al amarillo, al azul, etc. (...) Pero lo curioso es que aunque se siga calentando el material, la radiación nunca llega al ultravioleta: más bien cubre todo el espectro, dando como resultado una luz esencialmente blanca. Según la física clásica, sin embargo, la radiación del extremo violeta debería dominar por su intensidad. ¿Por qué falla la predicción clásica? (2012, p. 88).

Este problema se evidencia, por ejemplo, al calentar un metal: a medida que la temperatura aumenta, la zona donde se ejerce el calor cambia de color y atraviesa toda la gama antes señalada. Sin embargo, el tema de la radiación térmica se volvía aún más complejo cuando se lo aplicaba a cuerpos negros, es decir cuerpos totalmente oscuros que absorbían toda la luz, no la reflejaban y aún así los cálculos predecían que debía irradiar una cantidad infinita de energía. Hasta antes del siglo XX se consideraba que los cuerpos irradiaban esta energía de manera constante, en la forma de ondas que suceden unas a otras y en esta suposición radicaba justamente el problema.

En 1900 el físico alemán Max Planck propone una solución radical, su teoría acaba con el "carácter continuo de la imagen ondulatoria de la energía” (Cadenas, 2004, p. 46), es decir que niega el supuesto según el cual la radiación de energía se da como un continuum de ondas inseparables.

Planck "supuso que los cuerpos calientes emiten energía radiante en paquetes discretos, que llamó quanta" (Hewitt, 2004, p. 606), este término latino es el plural de quantum y significa cantidad, se traduce al español como cuanto e implica una visión del microcosmos como una realidad granulada y no como algo uniformemente continuo. Dentro del 
discurso científico estos pequeños paquetes energéticos son también conocidos como cuantos de acción.

El plantemiento de Planck fue duramente criticado en su tiempo, sin embargo los cálculos a partir de él eran correctos y lograban solucionar finalmente el problema de la radiación térmica. Con este descubrimiento se abandonó finalmente la idea de que la energía era irradiada como un conjunto continuo de ondas. Queda ahora analizar cuál fue el impacto de este descubrimiento con respecto al fenómeno lumínico.

Ya en 1801 el físico inglés Thomas Young había realizado un famoso experimento con el cual se confirmaba la naturaleza ondulatoria de la luz. Se trataba de "el experimento de la doble rendija", que implica permitir que un delgado haz de luz atraviese por dos ranuras colocadas muy cerca la una de la otra. Al otro lado se coloca una pantalla donde se 106 obtendrá un patrón: franjas de luz alternadas con franjas oscuras (Cetto, 2011; Hewitt, 2004).

Se puede suponer entonces que el haz de luz se mueve en forma de ondas y, cuando estas se encuentran con rendijas separadas, chocan entre sí brindando ese patrón tan particular. Un experimento similar puede realizarse en el agua, generando ondas que choquen entre sí.

A pesar de que, a partir de ese y otros experimentos, se tomaba a la naturaleza ondulatoria de la luz como una verdad evidente, en 1905 Albert Einstein afirmó que la luz debía entenderse a partir de la formulación realizada por Plank unos años antes. Einstein analizó el llamado efecto fotoeléctrico -que, por falta de espacio, tampoco se tratará en este artículo- y concluyó que la luz interactúa con la materia como paquetes pequeños de energía, es decir como cuantos (Cadenas, 2004; Hewitt, 2004). Algunos años después, en 1926, el químico estadounidense Gilbert Lewis utilizaba en sus trabajos el término "fotón", por primera vez, para referirse a los cuantos lumínicos. El trabajo de Einstein, que además le valió el Premio Nobel, polemizó nuevamente un problema que se había desarrollado durante el siglo XVIII cuando Newton proponía un modelo corpuscular de la luz y Huygens un modelo ondulatorio.

Como ya se había señalado previamente, el concepto de onda y el concepto de partícula son irreductibles: "ya que, si partimos de que la energía es puntual [partícula], no puede estar difundida [onda]" (Cadenas, 2004, p. 71), sin embargo según el experimento aplicado podían realizarse observaciones que confirmaban ambas naturalezas contradictorias para un mismo fenómeno.

En este contexto aparece Niels Bohr, quien dicta una conferencia en la ciudad de Como, Italia en 1927 donde plantea la idea de comple- 
mentariedad. En su artículo "El surgimiento de la complementariedad: Niels Bohr y la Conferencia de Como", Óscar Navarro (2010, pp. 65-66) explica que este principio se basa sobre tres elementos de índole empírico, que son:

1. La tesis de la condición cuántica, que plantea al cuanto de acción como un descubrimiento universal y elemental.

2. Las implicaciones del postulado cuántico, implican una discontinuidad en los fenómenos de la naturaleza.

3. La dualidad onda-partícula, en cuanto evidencia empírica que manifiesta la existencia de dos formalismos que son mutuamente excluyentes pero que son necesarios para describir la totalidad de los fenómenos.

Resulta especialmente interesante el segundo postulado, ya que plantea preguntas acerca de la continuidad de nuestra experiencia real en el mundo. Para Bohr la continuidad espacio-temporal podía comprenderse únicamente en el tratamiento clásico de los conceptos, pero es incompleto para analizar la realidad cuántica. La discontinuidad en los fenómenos también podría afectar a otros conceptos como son la causalidad y el tiempo-espacio. Para Bohr, los descubrimientos realizados en la física cuántica permitían negar la continuidad de los fenómenos, al menos en un nivel microscópico. Esta afirmación, ¿no implica en sí misma un problema para la percepción de la realidad? ¿no debería estar siendo analizando por la filosofía?

El tercer postulado se puede comprender como una "relación de incertidumbre", es decir como una situación donde existe una clara paradoja en la observación y recolección de datos. El físico alemán Werner Heisenberg planteó el llamado "principio de incertidumbre", mismo que implica "que en la mecánica cuántica es imposible mantener el ideal clásico de descripción además del límite de la aplicación de los conceptos clásicos" (Navarro, 2010, p. 70). Lo que Heisenberg descubrió fue que, al menos en física cuántica, el sujeto altera -irremediablemente- el objeto de estudio, impidiendo conocer con exactitud más de uno de sus valores, es decir que puede conocerse la velocidad a la que viaja una partícula elemental pero no su posición exacta, ni viceversa.

Parece evidente que, con su principio, Heisenberg plantea un problema epistemológico bastante serio y que tampoco ha sido tratado con suficiente rigurosidad por la filosofía. ¿Cuál es la relación entre sujeto y objeto? ¿Debería replantearse? ¿Están realmente separados? Si, con cada 
observación alteramos el objeto de estudio, ¿qué es lo que conocemos? O mejor aún: ¿conocemos algo realmente?

Ahora bien, retomando el tercer presupuesto nos encontramos con una realidad que incluye dos conceptos mutuamente excluyentes, tanto empírica cuanto lógicamente; frente a esta realidad Bohr plantea el concepto de "mutuo complemento" en el que "ambos conceptos conjuntamente constituyen los requisitos para una descripción completa, es decir, ambos son necesarios para poder agotar toda la información acerca del sistema atómico" (Cadenas, 2004, p. 172). Con este planteamiento Bohr parece querer defender lo indefendible, la aceptación de que se necesitan de los dos conceptos excluyentes para brindar una visión completa del fenómeno. Las repercusiones que esta afirmación tiene en materia ontológica son también evidentes; puede llevar además a nuevas lecturas 108 sobre los conceptos aristotélicos básicos de sustancia y accidente.

Heisenberg, realiza una clara explicación sobre Bohr y su principio, señala:

En el centro de sus reflexiones estaba el concepto de complementariedad -por él [Bohr] recién acuñado, cuya función era describir una situación en la cual podemos conocer el mismo suceso bajo dos aspectos distintos. Aunque estos dos aspectos se excluyan mutuamente también se complementan, y sólo por la yuxtaposición de ambos aspectos opuestos se agota totalmente el contenido intuitivo del fenómeno (Heisenberg en Cadenas, 2004, p. 172).

Es decir, que no solamente el principio de complementariedad "podría" aplicarse para comprender fenómenos paradigmáticos sino que "debería" aplicarse para agotar totalmente la comprensión de dicho fenómeno.

Ciertamente se trata de un principio relevante para el discurso de la física cuántica, y tal vez justamente el supuesto problema sea solo lingüístico. No tenemos ningún problema en afirmar que la luz es una onda $y$ una partícula, excepto que a nivel de análisis lógico ese conector no encaja.

A continuación se analizará los principios lógicos que se ven aludidos tras el trabajo de Bohr.

\section{Las "leyes del pensamiento"}

Irving Copi, en su clásico manual "Introducción a la lógica", plantea que "quienes han definido la lógica como el estudio de las leyes del pensamiento, frecuentemente han sostenido que hay exactamente tres leyes fundamentales del pensamiento, que son necesarias y suficientes para que 
el pensamiento discurra por causes "exactos"” (1962, p, 367). Es decir que para que un razonamiento pueda ser calificado como tal debería cumplir con estos principios. Más aún que el razonamiento, probablemente nuestro discurso es el que podrá ser calificado de "racional" si se siguen dichas leyes. Continuando con esta misma acepción, Ruiz señala que "los principios lógicos son afirmaciones de validez universal que hacen posible el pensamiento mismo" (1992, p. 71), de manera que se trata de máximas que permiten la estructuración de discursos racionales. Copi (1962, p. 367), las describe de la siguiente manera:

- El principio de identidad afirma que si cualquier enunciado es verdadero, entonces es verdadero.

- El principio de contradicción afirma que ningún enunciado puede ser verdadero y falso a la vez.

- El principio de tercero excluido afirma que cualquier enunciado es o bien verdadero o falso.

Con respecto al primer principio, se podría pensar en una fácil anulación del mismo al afirmar que algo es cierto ahora, pero podría no serlo en algunos años. Sin embargo "aquellos "enunciados" cuyos valores de verdad cambian con el tiempo son expresiones elípticas o incompletas de proposiciones que no se modifican, y es precisamente de estas últimas de las que trata la lógica" (Copi, 1962, p. 368). Para este autor el principio de contradicción no requiere de ningún análisis ulterior a pesar de las críticas recibidas por seguidores del hegelianismo y el marxismo, pues para Copi la negación de un elemento por otro es evidente cuando sucede y no debería ser aplicado en casos rebuscados como la lucha de clases.

Una conceptualización un tanto diferente de estos principios se encuentra en el trabajo de Bustamante (2008, p. 25) quien los describe así:

1. Algo no puede ser y no ser. Este es el llamado "principio de identidad": A=A.

O sea: si A es, A no puede no ser, al mismo tiempo y dentro de la misma relación.

2. Es imposible que un atributo pertenezca y no pertenezca al mismo sujeto. Este es el llamado "principio de no contradicción": si $\{$ A es $x\}$ entonces $\{\mathrm{A} n o$ es $n o-x\}$, donde $x$ y no- $x$ son atributos contrarios, ejemplo: algo no puede ser blanco y no-blanco al mismo tiempo y dentro de la misma relación. 
3. Dos proposiciones contradictorias no pueden ser verdaderas ambas. Este es el llamado "principio del tercero excluido": dado los enunciados $\{A$ es $\mathrm{x}\}$ y $\{$ A es diferentes de $\mathrm{x}\}$, solo uno de los dos puede ser verdadero, al mismo tiempo y dentro de la misma relación.

Esta formulación presentada por Bustamante resulta más clara que la de Copi para el objetivo de este artículo sin embargo, en última instancia, ambos se corresponden.

Ruiz señala con respecto al primer principio: "La noción de identidad implica, pues, la de unidad" (1993, p. 72), con ello se acerca a la definición aristotélica que cita: "La identidad es una especie de unidad" (Aristóteles en Ruiz, 1993, p. 72). De manera que este principio afirma que una cosa es una cosa, es sí misma. Sin embargo cabe aquí referirnos a una especificación realizada por Ruiz, quien señala:

Pero la lógica no estudia cosas, sino pensamientos. La ciencia que estudia las cosas o entes es la ontología. Si nos atenemos a ese enunciado, el principio es ontológico, y no lógico. Para que hablemos de principio lógico de identidad, es necesario que lo enunciemos de manera que diga algo con respecto a los pensamientos, que es lo que la lógica estudia. Y lo que el principio dice, entendido lógicamente, es que todo juicio analítico es verdadero (Ruiz, 1993, p. 73).

Los juicios analíticos son aquellos cuyo predicado está implícito en el sujeto. Aquello que pueda ser considerado como verdadero dentro de la ontología no comprende la finalidad de este artículo, sin embargo existe una relación, entre la evidencia ontológica y el principio lógico o al menos eso sería lo esperable.

Con respecto al principio de contradicción, Ruiz señala que "es imposible que algo sea y no sea al mismo tiempo y en el mismo sentido" (1993, p. 74). Es decir que es imposible que un círculo sea un círculo y no lo sea, al mismo tiempo ${ }^{1}$. Para este principio, ya no se habla únicamente de juicios analíticos sino también de juicios sintéticos, en los cuales se enuncia algo sobre el predicado que no está incluido en el sujeto; sin embargo hay que tener la salvedad de no contradecir la realidad de ese predicado.

$\mathrm{Al}$ encontrarnos con dos juicios sintéticos de tipo "A es B $y$ A es no B", este principio afirma que ambos juicios no pueden ser verdaderos al mismo tiempo.

Finalmente, el principio de tercero excluido declara que "todo tiene que ser o no ser" (Ruiz, 1993, p. 76) e implica que dos juicios de tipo "A es B y A es no B" no pueden ser falsos. De manera que, el principio de tercero excluido se sigue del principio de no contradicción y, conjunta- 
mente, permiten afirmar que uno de los juicios debe ser verdadero y el otro debe ser falso.

No queda mucho más por agregar el tema de los principios, se trata de implicaciones lógicas que fueron establecidas por Aristóteles y que de una u otra manera han moldeado a la física hasta nuestros días. Eso no significa que sean aceptadas en todos los discursos, existen en la actualidad escuelas de lógica que desafían la veracidad de estos principios y proponen nuevas formas de lectura. Probablemente sean estas nuevas lógicas las que deban tratar también el discurso científico.

Se podría resumir toda esta sección considerando que, para la lógica y probablemente para la ontología, la realidad se estructura de una forma ordenada y siguiendo un modelo binario: es o no es, ser o no ser. El problema es, sin embargo, que la realidad se nos está presentando por fuera de este modelo y la filosofía debería ser la encargada de analizar estas implicaciones.

A continuación se presenta un breve subtema que trata sobre la posible relación entre lógica y ontología.

\section{Lógica y ontología, una relación complicada}

Parece importante denotar que el presente artículo presupone, de una $\mathrm{u}$ otra manera, la existencia de una relación entre lógica y ontología. Especialmente entre las leyes del pensamiento desarrolladas por Aristóteles y lo que existiría en el mundo o en cómo este se organiza. Esta presunción, sin embargo, es susceptible de ser criticada ya que durante la historia de la filosofía han existido corrientes y pensadores que o bien han reconocido una relación íntima entre ambas disciplinas -como Leibniz-o bien han negado de plano cualquier tipo de conexión entre ambas, como el caso de Nagel.

A decir de Józef Maria Bochenski (1977, pp. 11-12), las relaciones entre lógica y ontología pueden darse desde tres perspectivas diferentes, cuando:

1. Ambas se contemplan como conjuntos de leyes y/o reglas y se las considera objetivamente. En este caso el problema es meramente lógico.

2. Ambas son consideradas objetivamente, se analiza su relación a partir de cómo fueron concebidas por pensadores y escuelas en el pasado o cómo son concebidas en la época presente. En este caso el problema es histórico.

3. Lo que se considera de ambas son las opiniones meta-teóricas, es decir cuando no se analiza a los sistemas como tales sino lo 
que se ha dicho sobre su estructura. En este caso el problema puede ser lógico o histórico según la perspectiva que se tome.

Para Bochenski, cuya obra se titula justamente "Lógica y Ontología”, la única discusión válida se correspondería con el primer problema, es decir con el análisis de la lógica y la ontología como disciplinas que representan un conjunto de normas o leyes. Desde su análisis, la lógica es "una teoría máximamente abstracta de objetos cualesquiera" (Bochenski, 1977, p. 45). Donde estos objetos no se restringen a entidades reales o entidades ideales, para hablar de estos objetos Bochenski recurre a la explicación brindada por Juan de Santo Tomás en el siglo XVII: el objeto de la lógica es el "ens supertranscendentale -esto es, abstraído tanto del ens reales (entidades reales) como del ens rationis (entidades ideales)" (1977, p. 45). Con respecto a la ontología, Bochenski recurre a la herencia aristotélica para afirmar que: "La ontología, cuando está presente, es en su conjunto de tipo aristotélico, una teoría general de las entidades reales" (p. 33). Y desde esta perspectiva tanto la lógica como la ontología tendrían campos acción similares, a decir de Bochenski "ambas disciplinas se muestran ahora como conjuntos de enunciados acerca del "ser en general", esto es, acerca de entidades cualesquiera -como una "física del objeto en general" (1977, pp. 38-39).

El análisis de Bochenski responde a una lectura más "clásica" del problema en cuestión, y aunque resulta satisfactoria para el objetivo del presente artículo puede también resultar insuficiente. Thomas Hofweber realiza un examen mucho más pormenorizado de las posibles relaciones entre estas dos disciplinas en el artículo "Logic and Ontology" que se encuentra publicado en la Stanford Encyclopedia of Philosophy, versión online.

Para Hofweber, existen al menos cuatro posibilidades de entender la lógica: como el estudio de lenguajes formales artificiales, como el estudio de las inferencias formalmente válidas y las consecuencias lógicas, como el estudio de las verdades lógicas y finalmente como el estudio de las características generales o forma de los juicios (Hofweber, 2014, s/p).

Para el presente análisis, la segunda definición es la más importante ya que implica rastrear la validez de una inferencia hasta sus características formales, lo que a su vez brinda gran importancia al concepto de consecuencia lógica entendida como aquel caso donde la conclusión se sigue de las premisas.

Con respecto a la ontología, Hofweber también señala al menos cuatro posibles acepciones, a saber: como estudio del compromiso ontológico, como estudio de "lo que es", como el estudio de las características 
más generales sobre "lo que es" y como las cosas que existen se relacionan unas con otros en manera metafísica y finalmente como el estudio de la meta-ontología (Hofweber, 2014, s/p). De igual manera, la segunda definición es la que corresponde con el objetivo del presente artículo, ya que nuestra pesquisa se centra en comprender cómo "lo que es" se relaciona con ciertas leyes del pensamiento que hablan sobre aquello que existe.

En su artículo Hofweber se pregunta acerca de las diferentes combinaciones que pueden darse entre las definiciones de lógica y de ontología, cuando analiza justamente la posible relación entre las segundas definiciones de ambas disciplinas, la pregunta que plantea es la siguiente: “LLas verdades lógicas implican la existencia de las entidades, o esta verdad es independiente de lo que existe?” (Hofweber, 2014, s/p).

Las respuestas que brinda corresponden justamente a la discusión histórica sobre este problema: "A pesar de cualquier cosa que uno diga sobre la posibilidad de que se pueda probar la existencia de un objeto solamente a partir de verdades conceptuales, muchos filósofos mantienen que al menos la lógica debe ser neutral con respecto a "lo que es"” (Hofweber, 2014, s/p). Todo esto conduce al problema que ya planteó el trabajo de Ludwing Wittgenstein y que podría establecerse a partir de la pregunta por el lenguaje, ¿hasta qué punto el lenguaje se relaciona con la realidad?

Si se responde afirmando que no existe relación alguna, caemos en una evidente contradicción, ya que la representación simbólica requiere de un referente. Sin embargo también es cierto que el lenguaje nombra entidades y relaciones cuyo referente no puede rastrearse en el mundo concreto. Por tanto la solución a este problema no es unívoco, sino que responde a concepciones personales sobre el verdadero objetivo de la lógica, la ontología y el lenguaje en sí mismo.

A continuación se analizan las particularidades de la entidad que ha inspirado la redacción del presente artículo.

\section{La luz, el caso límite}

Pocos fenómenos naturales han cautivado tanto al ser humano como la luz. Y el hecho de que su naturaleza sea problemática solo ha servido para establecer nuevas preguntas y cuestionamientos. Segura, Nieto y Segura en su artículo "Un análisis profundo del fenómeno dualidad onda partícula para la comprensión del mundo cuántico", brindan una lectura sobre esta dicotomía: "Desde la mecánica cuántica, la dualidad onda-partícula se ilustra como aquella teoría unificada de los fenómenos lumino- 
sos (fusión), donde se tiene conciencia de que determinados fenómenos se explican mejor desde el punto de vista ondulatorio mientras otros se explican mejor desde el punto de vista corpuscular" (2012, p. 140). Podría considerarse entonces que, según el tipo de observación que se realice, la luz puede actuar bien como una partícula, bien como una onda. Pero al realizar una afirmación sustancial, ¿qué diríamos sobre la luz? ¿es una onda o una partícula?

$\mathrm{Al}$ traducir este problema al lenguaje nos encontramos con esto:

1. La luz es una onda.

2. La luz es una onda y no puede no ser una onda.

3. La luz es una onda o la luz no es una onda.

1. La luz es una partícula.

2. La luz es una partícula y no puede no ser una partícula.

3. La luz es una partícula o la luz no es una partícula.

Las implicaciones son las siguientes:

1. La luz se presenta como una onda pero también se presenta como una partícula. ¿Cuál es su identidad, si hemos convenido en la primera sección de este artículo que una onda y una partícula son irreductibles entre sí?

2. Si se parte de cualquiera de las dos afirmaciones (onda/partícula) y se acepta también a la otra, incurrimos en una contradicción. Es decir: Si la luz es una onda [pero, la luz es una partícula] entonces la luz no es una onda.

3. Una de las dos acepciones tiene que ser verdadera y la otra falsa. Sin embargo, según el experimento encontramos que ambas tienen carácter de verdad.

Todo este planteamiento implica que desde el punto de vista teórico se debe "escoger una especie de entidad como el objeto fundamental de una teoría, donde ambas características de partícula y onda tienen derechos iguales, estableciendo aquel puente natural que comunica el mundo cuántico con el mundo clásico en una única dirección" (Segura et al., 2012, p. 141).

Queda por aclarar la pertinencia y papel de ese "puente natural" que, principalmente, ha roto con cierta tradición lógica y que ahora plantea cuestionamientos para la epistemología y la filosofía en general. Como habíamos señalado previamente, sería posible reducir este problema a una escaramuza lingüística, sin embargo esto no solucionaría la evi- 
dencia empírica. ¿Estamos ante la necesidad de la creación de un nuevo tipo de categorías? ¿Un lenguaje transracional que de cuenta de aquello que todavía no comprendemos?

Lo cierto es que el principio de complementariedad de Bohr resulta limitado para solucionar el problema: señalar que ambos elementos no se contradicen, si no se complementan juega claramente con los principios lógicos. Juega claramente con lo que podemos concebir como "posible".

La aceptación de la realidad lumínica puede traer importantes aportes para la lectura de toda la realidad, si consideramos que:

Un fotón tiene un comportamiento corpuscular, por ejemplo, cuando colisiona con otro fotón o, como ocurre en el efecto fotoeléctrico, con partículas (electrones, protones, etc.), pero un haz luminoso (un haz de fotones) manifiesta un comportamiento ondulatorio (onda electromagnética) cuando se difracta, se polariza o produce interferencias luminosas (Segura et al., 2012, p. 141).

Aquello que conocemos como "identidad" puede ser desmentido o al menos debe ser reelaborado. El análisis sobre el uso y la resemantización de estos conceptos debería ser trabajo de la filosofía, y más aún de los filósofos contemporáneos con acceso al discurso científico y sus "descubrimientos".

En la siguiente sección se realiza una breve referencia al tema de la identidad, que puede establecer nuevas preguntas para el tratamiento de temas donde lógica y ontología presentan intersecciones.

\section{La identidad como relatividad}

El análisis que se ha brindado hasta el momento parece remitirnos a la pregunta por la indentidad. Este tema que puede tratarse desde diversas disciplinas como la psicología, sociología o antropología, en realidad posee un claro trasfondo filosófico y por qué no decirlo, ontológico. Y por si fuera poco tiene también claras implicaciones con el lenguaje y la lógica.

Daros, en su artículo "El problema de la identidad. Sugerencias desde la filosofía clásica" destaca la etimología de la palabra identidad tanto en su raíz griega cuanto en la raíz latina. Con respecto a la primera señala: "identidad, en el griego clásico, se expresaba mediante el adjetivo y pronombre $[\ldots]$ con función de demostrativo. En estos casos, el demostrativo aparece utilizado para indicar que un sujeto o un objeto es el mismo" (Daros, 2005, p. 32), de manera que la identidad referida a un sujeto o objetivo se evidenciaba para no confundirlo con otro y para demostrar que es en sí, siempre igual. En el caso del latín, también aparece 
como un adjetivo o pronombre demostrativo donde "la "autentidad" o autenticidad estaba dada por la misma entidad en cuanto era ella misma, no teniendo motivo para cambiar en su esencia, en lo que era, como sucedía con las cosas sensibles, finitas, temporales" (Daros, 2005, p. 32). Se entiende de esta manera que la identidad se mantiene a pesar de los accidentes y de la temporalidad.

Esta perspectiva clásica de identidad ha sido repensada en la historia de la filosofía por las paradojas a las que conduce, especialmente cuando consideramos el tema del cambio a través del tiempo.

Frente a esta y otras paradojas -como la que se ha presentadoparece necesario el establecimiento de nuevos criterios de identidad, que sean capaces de dar cuenta de su verdadera problemática. Una de las propuestas que ya se han planteado es la de Peter Geach, quien habla de la 116 necesidad de una "identidad relativa", aunque su análisis se constituya bajo el estudio de identidades numéricas y no cualitativas, como el caso que compete al presente artículo.

Sin embargo, el principio de Geach podría también ser aplicado al concepto de identidad con respecto a las entidades, Noonan y Curtis en su artículo "Identity" explican la compleja teoría de Geach de las siguiente manera: "dado que no puede brindarse ningún criterio por el cual un predicado, expresando un predicado-I, debería ser expresado no solamente por la indiscernibilidad relativa al lenguaje al cual pertenece, sino también con respecto a la indiscernibilidad absoluta, se debe abandonar la noción clásica de identidad" (Noonan et al., 2014, s/p). En última instancia la teoría de Geach busca acabar con la "identidad absoluta", es decir con la nominación cerrada de un sujeto u objeto y reemplazarla con una identidad relativa, de características abiertas.

Esta identidad relativa podría responder finalmente a los problemas causados por la relación entre lógica y filosofía.

\section{Conclusiones}

Es evidente que existe algo como un barranco, profundo, entre la evidencia empírica y las categorías que utiliza el discurso científico para representar la realidad. Sin embargo, esto no parece nada nuevo. Desde los albores del pensamiento científico se han dado numerosos cismas en las explicaciones teóricas sobre la realidad, lo cierto es que al tratarse de un sistema completamente autorreferencial, cualquier cosa puede quedar demostrada si se siguen los modelos correctos. 
La naturaleza del fotón nos muestra que la realidad nunca ha sido simple y que nuestras categorías no pueden funcionar como marcos cerrados. En una entidad tan pequeña se dan cita grandes contradicciones que nos invitan a repensar la lógica misma y su incidencia sobre el pensamiento, ¿cuáles son los verdaderos límites de lo racional cuando la contradicción es la norma? ¿qué es la identidad y cuál es su relación con la ontología?

Frente a esta y otras preguntas parece necesaria la formación filosófica en ciencia. No porque el discurso científico sea el correcto, sino porque ha moldado nuestra historia en las últimas décadas y lo ha hecho sin ningún filtro. La educación tiene aquí un papel fundamental ya que debe ser capaz de brindar las suficientes herramientas conceptuales para relacionar campos diversos y preguntarse sobre las co-implicaciones presentes y sus consecuencias.

Es evidente que a partir de la física cuántica se puede elaborar una nueva ontología, probablemente más comprometida con lo real; o se puede continuar el trabajo iniciado por otros filósofos en el campo de la metafísica, analizando nuevamente las categorías clásicas y su actual pertinencia.

A pesar de que el trabajo de Niels Bohr ha sido de vital importancia dentro del campo de la física, es casi desconocido en el de la filosofía. Situación que se repite con otros científicos que tuvieron dudas filosóficas y que comprendían que el advenimiento de la física cuántica implicaba una ruptura en el curso normal de la epistemología. El trabajo de Bohr y de sus compañeros debería ser tratado también desde la filosofía, un marco conceptual filosófico puede brindar una estructura mucho más fuerte al principio de complementariedad e inaugurar una nueva época para la filosofía de la ciencia.

\section{Notas}

1 Este principio podría también ser analizado en referencia a los experimentos mentales del físico Erwin Schrödinger. Especialmente para el caso donde un gato, dentro de una caja con veneno, está vivo y muerto mientras no se abra la caja.

\section{Bibliografía}

\section{BOCHENSKI, Józef}

1977 Lógica y Ontología. Valencia: Teorema

BUSTAMANTE, Guillermo

2008 Los tres principios de la lógica aristotélica: ¿son del mundo o del hablar? Folios, 24-30. 
CADENAS, Yolanda

2004 Epistemología, ontología y complementariedad en Niels Bohr. Madrid: Universidad Complutense de Madrid.

CETTO, Ana María

2012 La luz en la naturaleza y en el laboratorio. México: Fondo de Cultura Económica.

COPI, Irving

1962 Introducción a la lógica. México: Limusa.

DAROS, William

2005 El problema de la identidad. Sugerencias desde la filosofía clásica. Invenio, 31-44. Recuperado el 4 de Agosto de 2016.

HEWITT, Paul

2004 Física conceptual. México: Pearson Education.

HOFWEBER, Thomas

2014 Logic and Ontology. En: Stanford Encyclopedia of Philosophy. [En línea] Otoño 2014, disponible en: http://plato.stanford.edu/entries/logic-ontology/ [Accesado el 4 de Agosto de 2016].

NAVARRO, Oscar

2010 El surgimiento de la complementariedad: Niels Bohr y la Conferencia de Como. Revista de Filosofía de la Universidad de Costa Rica, 65-76. Recuperado el 23 Junio de 2016.

NOONAN, Harold, \& CURTIS, Ben

2014 Identity. En: Stanford Encyclopedia of Philosophy. [En línea] Otoño 2014, disponible en: http://plato.stanford.edu/entries/identity/ [Accesado el 4 de Agosto de 2016].

RUIZ, Marcos

1993 Introducción a la lógica. Nuevo León: Universidad Autónoma de Nuevo León.

SEGURA, Aarón; NIETO, Viviana, \& SEGURA, Esteban

2012 Un análisis profundo del fenómeno dualidad onda partícula para la comprensión del mundo cuántico. Latin American Journal of Physics Education, 137- 142. Recuperado el 23 de Junio de 2016.

Fecha de recepción del documento: 5 de julio de 2016

Fecha de aprobación del documento: 15 de agosto de 2016 


\section{Dinamismo del pensamiento}

complejo, pensamiento computacional y educación

Dynamism of the complex thought, computational thought and education 



\title{
Pensamiento complejo abstracto en el aula Complex abstract thinking in the classroom
}

\author{
JAIME RAFAEL YANES GUZMÁN \\ Academia de Estudios e Investigación Complexus Edgar Morín / Santiago-Chile \\ jaimeyanesguz@gmail.com
}

\begin{abstract}
Resumen
Actualmente impera en nuestra sociedad el pensamiento lineal cartesiano. Esto ha provocado en el mundo actual una profunda crisis social, cultural y política. La educación también es atravesada por esta crisis. Los cambios que han ocurrido en el mundo que transitó desde un largo período industrial a uno distinto caracterizado por la información, las comunicaciones, la movilidad, el desarrollo del conocimiento y la complejidad, no ha tenido aún su correlato en la forma de comprenderla.

El actual paradigma cartesiano o ingenieril impide que las actuales generaciones sepan vivir en la sociedad contemporánea. Esto ha significado un daño planetario de enormes proporciones que puede poner en tela de juicio incluso la vida humana. En necesario, entonces, la construcción de una nueva forma de pensar.

Una de las tareas académicas más importantes en la actualidad es tratar de determinar las carencias cognitivas de la humanidad y cómo éstas se trasladan a la educación. Al mismo tiempo, se plantea la misión de superarlas, de descubrir la manera de configurar una nueva forma de pensar, de formar, de educar, una nueva epistemología paradigmática que nos permita entender nuestro hogar planetario a través de un paradigma sistémico, holístico, lógico, transdisciplinar y complejo.

Desde esta perspectiva es posible provocar los cambios trascendentales que la educación y la formación de los ciudadanos necesitan para entregar una visión compleja y de calidad a los niños, jóvenes estudiantes y los profesionales que hoy día están emergiendo desde las universidades.
\end{abstract}

\section{Palabras clave}

Abstracción, complejidad, lógica, transdisciplinar, sistémico, aprendizaje.

Forma sugerida de citar: Jaime Rafael Yanes Guzmán (2016). Pensamiento complejo abstracto en el aula. Sophia, colección de Filosofía de la Educación, 21(2), pp. 121-141.

* Licenciado en Ciencia Política. Especialización en Teoría de Sistemas Políticos y del Estado en la Universidad Kliment Ojridski de Bulgaria. Doctor en Filosofía por la Academia de Ciencias y de Tecnologías de Bulgaria. Doctor en Pensamiento Complejo por La Multiversidad Mundo Real Edgar Morin de México. Académico del Claustro de Profesores Multiversidad Edgar Morín. Publicaciones en diversos medios Latinoamericanos. 


\begin{abstract}
Currently it prevails in our society the Cartesian linear thinking. This has resulted in today's world a profound social, cultural and political crisis. Education also is crossed by this crisis. The changes that have occurred in the world transitioned from a long industrial period to a different one characterized by information, communications, mobility, development of knowledge and complexity, has not yet had its counterpart in the way of understanding

The current Cartesian or engineering paradigm prevents current generations know how to live in contemporary society. This has meant a daunting planetary damage that can put into question even human life. In necessary, then the construction of a new way of thinking

One of the most important academic tasks today is to try to determine the cognitive deficits of humanity and how they are transferred to education. At the same time, the mission of overcoming them, to discover how to set up a new way of thinking, to train, to educate, a new paradigm epistemology that allows us to understand our planetary home through a systemic, holistic paradigm, logical arises, transdisciplinary and complex

From this perspective it is possible to cause the momentous changes that education and training of citizens need to deliver a complex vision and quality to children, young students and professionals today are emerging from universities
\end{abstract}

\title{
Keywords
}

Abstraction, complexity, logic, transdisciplinary, systemic, learning.

\section{Introducción}

A pesar de vivir en una sociedad de alta complejidad, los habitantes del planeta siguen viendo los sucesos que nos afligen de manera lineal cartesiana. Con esta mirada están provocando una profunda crisis en todas las esferas de nuestro mundo, amenazando con ello incluso su existencia. Entender esta crisis nos obliga a comprender las actuales propiedades de nuestra sociedad y el entorno en que vivimos de manera distinta a como se ha hecho hasta el momento. Ya no basta con estudiar las características secundarias del que hacer planetario como simples percepciones. El objetivo de este artículo es presentar lo que creemos son las nuevas exigencias de la complejidad que nos obligan a entender los sucesos del orbe con nuevas abstracciones ${ }^{1}$ científicas que nos proporcione una idea de la realidad más allá de las sensaciones inmediatas. Los hechos que afligen a nuestra sociedad no pueden seguir siendo observados en los diversos centros académicos de manera aislada unos de otros, desvinculados entre sí.

Nuestro objetivo es tratar de demostrar que la abstracción compleja de las cosas resulta de la generalización de las propiedades esenciales de una gran cantidad de hechos individuales. Esto nos exige generalizar la totalidad de los hechos posibles de conocer a través de conceptos, categorías y leyes que reflejen los vínculos esenciales, internos de los fenómenos y sus relaciones externas con los demás hechos. 
El pensamiento abstracto y la conciencia del ser humano (Yanes, 2015) reflejan subjetivamente en alumnos y alumnas pero con un toque de objetividad, el mundo que nos rodea, la naturaleza y la vida social. El pensamiento y la conciencia se desarrollan en el transcurso de su historia por la práctica social de la humanidad, en su trabajo cotidiano transformando la naturaleza.

El pensamiento complejo ${ }^{2}$ abstracto que se debe desarrollar en la sala de clase debe tender a penetrar las leyes de la naturaleza, la sociedad y el cosmos. La importancia de esta nueva forma de pensar hace posible la actividad práctica consciente de los y las estudiantes y sus profesores.

La lógica se desarrolla a partir del conocimiento de estas leyes del desarrollo de todas las cosas materiales, naturales y espirituales, del devenir y del conocimiento del universo. La lógica surge de esta manera desde la comprensión del mundo circundante en la conciencia subjetiva del discente. Ella desarrolla sus leyes al estudiar todos los aspectos y vínculos del mundo real. Pero al mismo tiempo, busca entender las cosas en su devenir, en su auto movimiento, en su complejidad, en su desarrollo, en sus transformaciones permanentes, comprendiendo de esta manera los pasos de una forma a otra de todos los objetos y sucesos.

La lógica dialéctica se transforma en dialógica del pensamiento; las leyes del pensar dialéctico en leyes del pensamiento. Esto nos permite afirmar que los conceptos y las categorías, no reflejando absolutamente la realidad objetiva "tal cual es", expresan en el pensamiento subjetivo de los educandos esa realidad, es decir, reflejan la realidad en los marcos de la subjetividad de cada uno de ellos, como son cada uno de los observadores. Pero además los conceptos y categorías del pensamiento complejo abstracto están ligados entre sí, interactuando con los fenómenos a los cuales pretende explicar.

La lógica dialéctica compleja o dialógica del pensamiento abstracto es la interdependencia de todos los conceptos y las transiciones mutuas entre ellos. Y esta dialógica, al igual que el pensamiento, surge desde el terreno de la actividad práctica de los discípulos. La importancia de aproximarnos a este nuevo paradigma del pensamiento consiste en que nos permitiría sortear de mejor manera la actual crisis que vive la sociedad planetaria.

Desde esta perspectiva, todo lo señalado anteriormente es fundamental para entender el desarrollo de la actual sociedad compleja. Para ello se analizarán distintos autores que nos plantean la necesidad de un pensamiento abstracto lógico y complejo o dialógico para comprender nuestro mundo. Presentaremos en este artículo temas importantes como construcción y descontrucción constante del pensamiento, teoría de la 
autopoiésis, comprensión del significado de la mundialidad del cerebro, enfoques cognitivos, pensamiento transdiciplinar, entre otros temas.

\section{La crisis del viejo paradigma industrial}

Andrade et al. (2001), recuerdan que todo período histórico crea en ese espíritu de los tiempos en que se vive, un determinado modo de comprender el mundo que lo rodea, que lo expresa y que se plasma en las aulas de las escuelas. Con esa visión epistémica, con esa cultura, con ese espíritu, con ese paradigma, en los hemiciclos de las escuelas se le da significado a la vida y a las cosas de la vida, delineando al mismo tiempo, un modo de pensar y generar conocimientos en los alumnos y alumnas, un modo de hacer las cosas y un modo de ser, como asimismo metodologías, métodos y técnicas de evaluación.

En la sociedad industrial (Yanes, 2012), la ciencia tradicional positivista obligaba a las escuelas y sus salas de clases a funcionar con principios como la objetividad del conocimiento, la simple descripción de las cosas, el análisis desagregando la realidad en sus partes más pequeñas, en las relaciones de causa y efecto lineales y, con ello, en la absolutización del determinismo en el surgimiento de los fenómenos y de los sucesos, la validez indiscutible de la experiencia sensible, el análisis de procesos, la lógica formal aristotélica y la verificación empírica como única forma de entender que un suceso es real. El cartesianismo carga el enfoque de los estudiantes en el estudio de los casos aisladamente considerados, hacen hincapié en el análisis de los componentes, con frecuencia, a expensas del contexto.

Hawking (2008) denuncia que desde la física clásica, se señalaba la posibilidad de evaluar y medir la realidad a través de un conjunto de condiciones iniciales, una cantidad determinada de causas que son las que definirían el comportamiento de sucesos con casi absoluta certeza. Hawking (2004) agrega en otro artículo, que la física tradicional plantea que la existencia de determinadas causas provocaba determinadas consecuencias y que las mismas causas provocaban situaciones iguales, es decir, en condiciones idénticas, los resultados deberían ser también idénticos. Resumiendo, podemos señalar que para el positivismo existen las certezas de la emergencia de determinados sucesos porque hay entendimiento de las causas de ellos. En fin, es una teoría determinista, de relación de causa-efecto que invade la escuela y sus aulas y las relaciones profesores-alumnos/as. 


\section{Un nuevo paradigma para la sala de clases}

Frente a la actual crisis planetaria, es urgente hoy día construir un nuevo paradigma que plantee un modelo pedagógico liberador de alumnos y tutores, que supere la tradicional contradicción educador-educandos como una forma de establecer una relación dialógica en el proceso de enseñanza/aprendizaje. Se trata de configurar en el aula ${ }^{3}$ un proceso donde no hay maestros y estudiantes, sino que ambos enseñan y aprenden al mismo tiempo. La centralidad está en ambos y a partir de ahí crecen en comunión mediatizados por el entorno en que están situados. Freire (1969) rechaza la idea tradicional de educación bancaria, donde los educandos son dóciles receptores de saberes, depósitos de almacenaje de los mensajes de los educadores. Por el contrario, el aula exige un educando como un investigador crítico en diálogo constante con el educador, la realidad y las redes.

El rol del educador es proporcionar las condiciones para que el educando reconstruya constantemente sus propios conocimientos, entregue educación -como señala Freire- en la perspectiva de una práctica de la libertad, donde el hombre y la mujer no se conciben en forma abstracta, aislados, desligados del mundo y éste separado del ser de lo humano, porque hombres y mujeres son seres situados.

Desde estos dominios de acción los pupilos deben pensarse a sí mismo como una realidad en constante transformación, no quieta, donde siempre está pasando algo, como señala Freire (2012), como un mundo en proceso de construcción y descontrucción, para volver a rearmarse en una situación de permanente incertidumbre. La educación debe tener presente esta situación de mundo inacabado, y de ahí entender que la propia educación es incompleta porque corresponde a la condición de ser histórico del ser humano/estudiante, un ser vivo en constante proceso de autocreación, autopoiésis ${ }^{4}$. Esta característica de los educandos (Yanes, 2011) permite enfrentar los procesos de formación como procesos en los que los alumnos deben apropiarse de su propia realidad histórica y transformarla en un desafío permanente de superación constante de sí mismo en compañía solidaria de los otros en dominios de praxis colectiva.

\section{Campbell y la mundialidad del cerebro}

La crisis de la sociedad actual se fundamenta también en el desarrollo tecnológico que hoy día atraviesa a la sociedad. Este desarrollo de la ciencia y 
la tecnología ha permitido el surgimiento de la era de la inteligencia artificial. Asumir exitosamente este proceso exige la construcción de un nuevo sistema conceptual lógico que nos facilite comprender la construcción de máquinas inspiradas en el cerebro humano. Han pretendido imitar las miles de conexiones que él tiene. Según Campbell (1997), el cerebro puede ejecutar hasta doscientos billones de operaciones en un segundo simultáneamente. Éste no llega serialmente a una conclusión, paso a paso a partir de determinadas premisas o programa, como lo podría hacer un computador. El cerebro humano carece de estos programas, y lo que hace es analizar sucesos a partir de una vasta red de conocimientos, de visiones, de valores adquiridos en su mundialidad, en su vivir constante.

Las computadoras hacen cálculos y superan a la mente humana con sus capacidades maratónicas para manipular números. Trabajan con algoritmos que son instrucciones precisas para resolver problemas y que están programados en la máquina que computa. Esos algoritmos no pueden actuar como la mente humana, que frente a un determinado conjunto de información puede descartar parte importante de ella porque podría estimar que no le sirve. La máquina, por el contrario, la utilizaría toda si el programa así lo tiene estipulado. Son máquinas que no pueden lidiar con el mundo real. Porque no poseen los aspectos mundanos lógicos de la inteligencia, construidos en el largo proceso de desarrollo de la especie humana y que orientan nuestra cotidianidad. No poseen las características del razonamiento humano dialógico que permite trabajar con agrupamientos de sucesos y a partir de ellos, llegar a conclusiones interesantes.

Esta mundialidad vinculada al conocimiento es una ciencia aún en pañales se separa radicalmente de lo que se denomina sólo como información: no es lo mismo información que conocimiento. El conocimiento no es sólo lógico, es además la historia del cerebro, y en ese sentido los discentes entendidos como seres energocibernéticos ${ }^{5}$ hacen posible su viaje por el espacio porque son capaces de tomar decisiones con los conocimientos que poseen, adquiridos en el contexto cotidiano de su actividad, lo cual les permite entender la información que reciben, transformándolos en nuevos conocimientos. Podríamos decir que el ser energocibernético, a partir de sus saberes ya sabidos transforma la nueva información en saberes por conocer, es decir, en nuevos conocimientos.

La Inteligencia Artificial es un universo abstracto y vacío de cosas materiales, pasivo, mera copia de la experiencia. Según Campbell, Piaget plantea que el conocimiento es activo y que va cambiando en los distintos períodos de desarrollo del ser humano, porque la mente va dotando de sentido al mundo y a alumnos y alumnas, que se plasman en principios 
que constituyen su estructura cognitiva y que va construyendo en su interacción con el entorno. La inteligencia de los discípulos en la sala de clases se manifiesta porque tiene estructuras innatas en su sistema nervioso que le da conocimientos previos. Son conjeturas como, según Campbell (1997, p. 190), lo señala Popper, “....redes en las que tratamos de atrapar al mundo real". Este autor señala que las opiniones que tenemos no son espejos de la realidad, sino que sólo un conjunto de relaciones que nos permiten interpretar esa realidad con los datos que recibimos.

Los discentes como seres energocibernéticos deben ser capaces de construir constantemente esas visiones pertinentes y adecuadas para entender las perturbaciones que el mundo les gatilla constantemente. Y estas visiones no son productos de la existencia de algún patrón que brotó de algún modo, sino que son redes neuronales específicas que evolucionan y aprenden constantemente, se trata de esa mundialidad de que habla Campbell, de esa historia del vivir en el mundo, desde los orígenes del ser humano como tal, una inteligencia mundana desde el comienzo de sus tiempos, característica que la inteligencia artificial no tiene.

\section{Enfoque cognitivo piagetano}

El desarrollo cognitivo es fundamental para superar la actual crisis del conocimiento que dificulta entender las características del mundo actual. Piaget e Inhelder (1973) señalan respecto al desarrollo cognitivo, que él se encuentra en el centro del organismo humano. El desarrollo del ser humano se consigue a partir de las estructuras cognitivas que construye y que va renovando constantemente en un proceso de interacción entre la realidad y estas estructuras, choque en el cual los conocimientos previos se van acomodando a lo nuevo. Esta concordancia entre los esquemas cognitivos y el medio y que permite a los discípulos adaptarse al medio que lo rodea en una interacción con los demás estudiantes y profesores a través del lenguaje, alcanzando con ello estabilidad cognoscitiva.

En esta perspectiva el proceso de aprendizaje de los seres humanos según el mismo Piaget, es un proceso de construcción muy personal a partir de las estructuras culturales mentales que el sujeto ya posee. Sobre esta base se ha levantado el enfoque curricular cognitivo que identifica los objetivos de la educación en el fortalecimiento y perfeccionamiento de los procesos intelectuales y las destrezas cognitivas para formar un estudiante adaptativo e interactivo que se desarrolla sin límites en forma autónoma. 
En la misma dirección que plantea este autor, Gagné (1970) afirma que el aprendizaje es un cambio conductual, un cambio en la capacidad humana de carácter duradero. Por ello el alumno debe fortalecer su estructura cultural constantemente y desarrollar sus destrezas intelectuales como conceptos y reglas, y estrategias cognoscitivas con relación a su atención, lectura, memoria, pensamiento, etc. Estas destrezas cognoscitivas, según el mismo autor, son organizadores previos que permiten a las personas regir su propio proceso de aprendizaje y desarrollo de sus estructuras cognitivas. Desde esta perspectiva, el profesor en el aula juega el rol de facilitar los procesos cognitivos abstractos lógicos de sus alumnos que les permita percibir, asimilar y almacenar conocimientos fortaleciendo sus destrezas mentales eficientes, transformándola en estrategia cognitiva cuando estas destrezas se aplican a diversas tareas.

Este enfoque cognitivo piagetano es un aspecto en el proceso de aprendizaje y puede ser aplicado plenamente a un estudiante o investigador de postgrado también en ambientes virtuales (Yanes, 2011). $\mathrm{Su}$ éxito va a depender de quién utilice este enfoque. También esto sucede en ambientes virtuales, porque efectivamente un investigador en un ambiente de esta característica está permanentemente realizando un juego dialéctico entre conocimientos previos y nuevos conocimientos, y el fortalecimiento de sus estructuras cognoscitivas a través de un proceso constante inteligente de su acomodación al entorno sin perder su identidad. La diferencia está en que el ambiente es distinto -virtual y no presencial- y por ello los medios que se utilizan difieren de un evento de carácter presencial.

Por supuesto que hay otras exigencias que se las pone a este proceso por ejemplo, desde la biología del conocimiento del profesor Humberto Maturana, como entender a los seres humanos como seres autopoiéticos y su proceso de aprendizaje como autopoiético autorefencial con respeto a la identidad de los que aprenden.

\section{El pensar de Maturana}

Los aportes de Maturana son importante para disminuir los efectos negativos del actual desarrollo de la humanidad. Maturana y Nisis señalan que:

... el fenómeno del conocer tiene lugar en la relación cuando la conducta de un organismo resulta adecuada a la conservación de su existencia en un dominio particular. El fenómeno del conocer no ocurre en el sistema nervioso. El sistema nervioso participa en el fluir de las interacciones del 
organismo en su circunstancia y modula este fluir, pero no constituye a la conducta porque ésta es un fenómeno relacional (1999, p. 186).

Entonces el fenómeno del conocer no es un fenómeno neurofisiológico, sino de la relación entre un organismo y la circunstancia en la que conserva organización y adaptación.

Maturana y Nisis sostienen que el entender (comprensión):

...requiere un espacio relacional amplio, en el cual uno encuentra una explicación. Yo entiendo una experiencia, en tanto me la explico en un contexto relacional más amplio, por eso es que para entender uno tiene que, por así decirlo, saber mucho más de lo que entiende. Tengo que saber mucho más porque el entender consiste en poder mirar aquello que entiendo, en su dinámica, en los procesos que los constituyen en un espacio relacional mucho más grande. (1999, p. 244).

Maturana y Varela (1995) nos plantean que todo conocer es un hacer por el que conoce, es decir, que todo conocer en el hacer depende de la estructura cognitiva del que conoce. Afirman además que la descripción científica de un fenómeno -en un ambiente presencial o virtual-, es dada por un investigador que está involucrado en dicho fenómeno, pretendiendo que no lo está. Frente a la posición tradicional que el conocer es un conocer "objetivo" del mundo, y por tanto, independiente del observador que hace la interpretación del fenómeno, Varela y Maturana señalan categóricamente que no es posible conocer "objetivamente" fenómenos sociales en los que el propio observador-investigador que describe el fenómeno está involucrado.

Esta afirmación de los biólogos se sostiene en la afirmación de que el contenido del conocimiento es el conocimiento mismo. Plantean una teoría explicativa del proceso operacional que nos muestre cómo surge esta facultad del observador de dar descripciones sobre sí mismo, que nos explique el surgimiento del ser observador, del ser autoconsciente, que no sólo conoce, sino que además comprende. Esta teoría explicativa parte del supuesto que el ser humano, en nuestro caso los estudiantes, se hace continuamente a sí mismo en un operar recursivo, en donde se generan permanentemente la autoconciencia de lo que el propio observador hace. Como no es posible conocer sino lo que hacemos, es decir, cómo nos hacemos, los estudiantes son una continua creación y recreación, un hacerse continuamente a sí mismo. Esto se desprende de las dos propiedades fundamentales del conocer: por una parte, ser conexión entre el observador y su entorno, lo que le permite mantener su individualidad, y al mismo 
tiempo, la dimensión interpretativa del conocer, de excedente de significación. El ser cognitivo implica, según Varela en que el:

...organismo, mediante su actividad autoproducida, llega a ser entidad distinta en el espacio, aunque siempre acoplada a su correspondiente medioambiente, del cual, no obstante, será siempre diferente. Un ser distinto coherente que, por el proceso mismo de constituirse (a sí mismo), configura un modelo externo de percepción y acción (2000, p. 66).

Maturana y Varela (1995) nos proponen su teoría de la "circularidad cognoscitiva tautológica" para explicarnos el surgimiento del ser autoconsciente, capaz de comprender. Para explicar el fenómeno de la tautología cognoscitiva, ellos parten de la premisa ya señalada anteriormente, que el contenido del conocimiento es el conocimiento mismo, 130 que los sistemas vivos no actúan por instrucciones o información que surge como anomalía desde el entorno porque no son sistemas triviales. Los seres humanos y los estudiantes entre ellos, son capaces de generar mecanismos explicativos, coherencias operacionales, diversas teorías explicativas que genere por sí misma el fenómeno que se quiere explicar, es decir el fenómeno en el cual el propio observador participa, hablándose por ello de una auto-descripción o auto-conciencia. Estas teorías explicativas son afirmaciones que se validan por sí misma porque el contenido del conocimiento es el propio conocimiento. Es una invitación a enfrentar lo "conocido por crear" como un acto colectivo generoso de aceptación mutua y preocupación por los demás.

\section{La abstracción en el complejo bucle orden/desorden}

Otro de los conceptos que interesa desarrollar para la comprensión de los problemas que genera la actual sociedad compleja es la relación orden/desorden. Según Morin (1999), el problema de esta ligazón entre el orden y el desorden es de nivel radical o paradigmático: la definición de una relación tal controla todas las teorías, todos los discursos, toda praxis y por supuesto toda política. Esta relación no debe ser vista como opuestos que se niegan y se buscan para aniquilarse, desintegrarse una en manos de la otra.

La evolución del universo no ha ido en la dirección de la degradación sino que en el incremento de la complejidad, donde las estructuras que van apareciendo presentan relaciones ambiguas, múltiples con un sentido de orden y desorden simultáneo difíciles de abstraer. Prigogine (2000) plantea que el universo se inicia con una inestabilidad como un 
cambio de fase, como una transformación irreversible que proviene de otro estado físico anterior al universo que desconocemos.

La materia entonces, se transforma en estructura disipativa con propiedades de mucha sensibilidad, generando entre ellos movimientos coherentes que tienen un alcance mayúsculo en estados múltiples. Según Morín, este segundo principio de la termodinámica plantea una estrecha relación entre orden (organización) y desorden, pero a la vez una relación inversa entre desorden y orden. Cuando el equilibrio se produce, cada molécula sólo ve lo más próximo de su entorno, facilitando su comprensión e idealización. Pero frente a estructuras de no-equilibrio, los elementos de la materia ven más allá de su entorno cercano, volviéndose ésta más "sensible", viendo más "lejos", complicando con ello la abstracción.

Todo sistema tiene una función de entropía. Según este último autor, esta función es una función termodinámica que refleja la parte no utilizada aún de la energía de un sistema cualquiera, transformándose en una medida del posible desorden del mismo, creando incertidumbres difíciles de entender pero que desarrollan su movimiento en marcos extremadamente coherentes. Docentes y discentes deben comprender que el no-equilibrio constituye el dominio de la multiplicidad de soluciones, correlaciones de largo alcance que facilitan la construcción de estados coherentes que se dan en áreas de la física, de la química y de la propia vida con su tiempo interno que prosigue durante miles de millones de años, transmitiéndose de una generación a otra, de una especie a otra en un sentido de complejidad.

Pupilos y pupilas no pueden entender el orden y el desorden como polos opuestos, excluyentes aniquiladores el uno del otro. Por el contrario, tienen una función que podríamos llamar poética, porque se van autoorganizando, autocreando en la interrelación, en la interacción. En el desorden se van generando los propios procesos de producción de los componentes que van a constituir las relaciones dentro de un sistema, generando orden posible de abstraer, hasta que elementos entrópicos internos y externos vuelvan a desordenarlos y dificultando su comprensión, su conceptualización por parte de los estudiantes e incluso de los maestros.

Los participantes de un salón de clases deben comprender guiados por su tutor o tutora que el orden es no sólo exterior, sino que por el contrario es interno, inseparable de la materialidad específica de los elementos en interacciones y de esas interacciones mismas. Es decir, es regido por los fenómenos que rige. Morín agrega que cada uno de los átomos de nuestro cuerpo depende de un orden gravitacional, el cual está ligado a su vez de las interacciones de cada átomo de nuestro cuerpo con su entorno. 
El orden entonces debe ser entendido por los estudiantes como interdependiente, además de relativo y relacional, local pero de largo alcance y con capacidad de enfrentar las perturbaciones incluso del entorno más lejano. Y finalmente, podemos decir con este autor que el orden es capaz de progresar, transformándose constantemente. A mayor complejidad de la organización, los estudiantes tienen que asumir que la realidad es mucho más rico en desorden y más difícil su abstracción.

\section{Pensamiento transdisciplinar y la abstracción}

Frente a la actual crisis, es importante el rol del pensamiento, lógico, complejo y abstracto en el aula para que discentes y docentes entiendan las incertidumbres que nos entrega el mundo actual real en su desarrollo. Buganza y Sarquís (2009) plantean que la teoría de la transdisciplina ${ }^{6}$ aparece como una respuesta filosófica para la mejor comprensión a los descubrimientos de la física cuántica, al surgimiento de las nuevas ciencias de la información y al desarrollo de la sociedad y de la teoría general de sistemas a partir de la segunda mitad del siglo pasado. Según estos autores, la transdisciplina propone de manera urgente un cambio de visión del ser humano y su sociedad para entender los actuales caminos de la compleja sociedad planetaria.

Desde la perspectiva señalada, Buganza y Sarquís indican que si:

... uno acepta una nueva causalidad global que concierne al sistema de todas las entidades físicas en su conjunto, la paradoja se diluye. Sólo hay que reconocer la "sinergía": una colectividad siempre es más que la suma de sus partes. Pero este principio fundamental no puede ser apreciado desde cualquier posición no holística, que presupone lo observado como un conjunto de partes interdependientes entre sí, donde el investigador trata de considerar la forma en que todas estas partes trabajan, se afectan y condicionan mutuamente en forma simultánea; de ahí que se deba considerar el fenómeno estudiado como un todo (2009, p. 48).

La sinergía debe ser enseñada a los estudiantes como posible de observar cuando emerge un nuevo fenómeno en los marcos de un todo que se puede apreciar funcionando, porque la realidad no está fragmentada sino unida por vínculos que no siempre son fáciles de percibir.

Esta crisis que vive la humanidad está generando en la población mundial grandes movimientos sociales que cuestionan la situación actual que provocan las políticas de los gobiernos. Los actuales grupos sociales 
y políticos emergentes empiezan a tomar conciencia que la racionalidad clásica cartesiana con base en simples percepciones con la cual se ha construido la vida social hasta hoy día, ya no permite ni entender el mundo en que vivimos, ni proponer cambios sustantivos para cambiar la amenaza crucial a que ha sido sometido el planeta. La exigencia es crear una nueva forma de pensar, en especial en el sistema educacional planetario en relación a nuestro mundo, con una epistemología distinta construida con abstracciones científicas que nos proporcione una idea de la realidad más allá de las sensaciones inmediatas.

Martínez señala que:

En los seres vivos, y sobre todo en los seres humanos, se dan estructuras de un altísimo nivel de complejidad, las cuales están constituías por sistemas de sistemas (...). La naturaleza es un todo polisistémico que se rebela cuando es reducido a sus elementos. (...) porque, así reducido, pierde las cualidades emergentes del "todo" y la acción de éstas sobre cada una de las partes (2003, pp. 129-130).

Es decir, los estudiantes lo ven como pensamiento simple que no ve más allá de su entorno cercano. Por el contrario, este todo es polisistémico, agrega Martínez, que “...nos obligan a adoptar una metodología transdisciplinaria para poder captar la riqueza de la interacción entre los diferentes subsistemas que estudian las disciplinas particulares". Y esta transdisciplinariedad es una nueva forma de pensar que conduce a los discípulos en su paraninfo a una abstracción dialógica porque no es simplemente la suma de varias disciplinas o multidisciplinariedad. Se trata, según Martínez, de que en este proceso cognitivo se exija "respetar la interacción entre los objetos de estudio de las diferentes disciplinas y lograr la transformación e integración de sus aportes respectivos en un todo coherente y lógico".

La transdisciplinariedad es una forma de organizar el conocimiento a través de abstracciones científicas lógicas que articula de una nueva manera los saberes. Esta nueva forma de ver, de abstraer lógicamente el mundo real, debiera entregar en el sistema escolar una mejor comprensión de nuestra existencia para posibilitarnos una forma distinta de habitar la tierra en esta era planetaria.

Nicolescu señala que:

La transdisciplinariedad comprende, como el prefijo "trans" lo indica, lo que está, a la vez, entre las disciplinas, a través de las diferentes disciplinas y más allá de toda disciplina. Su finalidad es la comprensión del mundo presente, y uno de sus imperativos es la unidad del conocimiento (1996, p. 37). 
La transdiciplinariedad invita a docentes y discentes a entender que cada fragmento de la visión piramidal del conocimiento no es una pirámide continua, entera. Existe espacio entre los objetos de las disciplinas y más allá de ellas, y la transdisciplinariedad lo supone lleno como el vacío cuántico, vacío fracturado pero que reúne todas las potencialidades de la emergencia de nuevos sucesos, a pesar de las dificultades para realizar abstracciones de esos momentos. Es una visión holística de la realidad a través de un pensamiento ecologizado. El conocimiento transdisciplinar (Yanes, 2015) busca que los estudiantes asuman la comprensión multidimensional y multirreferencial de la realidad, desarrollando y fortaleciendo el "conocimiento del conocimiento" como una característica fundamental de la epistemología dialógica del pensamiento complejo, con el fin de avanzar en la unidad del conocimiento en la búsqueda de una nueva racionalidad. Esto significa que los diferentes niveles de realidad son posibles de conocer porque a su vez existen diferentes niveles de percepción entre los observadores que incluye zonas de no-resistencia a esa percepción. El sujeto transdisciplinario es configurado a partir de estos niveles de percepción y sus zonas complementarias de no-resistencia. Nicolescu nos dice que:

La estructura discontinua de los niveles de realidad ${ }^{7}$ determina la estructura discontinua del espacio transdisciplinario que, a su vez, explica a los participantes en el proceso educativo, por qué la investigación transdisciplinaria es radicalmente diferente de la investigación disciplinaria, siendo a su vez complementarias. La investigación disciplinaria concierne, a lo sumo, a un solo y mismo nivel de realidad, de hecho, en la mayoría de los casos comprende fragmentos de un único y mismo nivel de realidad. En cambio, la transdisciplinariedad se interesa por la dinámica generada por la acción de varios niveles de realidad a la vez. El descubrimiento de esta dinámica tiene que pasar por el conocimiento disciplinar. La transdisciplinariedad, sin ser una nueva disciplina o una nueva hiperdisciplina, se nutre de la investigación disciplinaria que, a su vez, se explica de una manera nueva y fecunda por medio del conocimiento transdisciplinar. En este sentido, los investigadores y docentes disciplinarios y transdisciplinarios no son antagónicos, sino complementarios (1996, pp. 37-38).

El enfoque transdisciplinar provocará una transcendental revolución en la educación con sus abstracciones dialógicas, porque busca en la sala de clases superar el paradigma disciplinar simple y su único nivel de realidad. Por el contrario, comprender que lo que nos constituye supera las barreras demarcatorias de la simplicidad de las disciplinas, y para su 
comprensión entre los estudiantes pasa por desarrollar multicapacidades con abstracciones complejas para construir una visión sistémica y transdisciplinar de la realidad en la cual nos formamos y vivimos.

El sistema educacional debe asumir también como uno de sus fundamentos, la existencia de un nuevo principio de la relatividad que nos permitiría comprender que muchos componentes de la realidad son realidades diversas el mismo tiempo constituyendo un mundo complejo, por ejemplo, para entender religión, política, arte, etc. Esta complejidad socio-ideológica de las diversas realidades entendidas en su conjunto, podría cambiar la perspectiva de muchos de sus componentes.

Desde este supuesto teórico epistemológico se plantea un nuevo tipo de causalidad. A los estudiantes debe ser explicada que esta causalidad es a escala cuántica de lo infinitamente pequeño y breve. Buganza y Sarquís indican que:

Frente a la continuidad y certidumbre mecánica del mundo macroscópico, el mundo subatómico que es discontinuo y probabilístico ofrece un panorama inexplicable para la física newtoniana. Una nueva causalidad existe en la escala cuántica: la escala de lo infinitamente pequeño e infinitamente breve. Una cantidad física tiene, según la mecánica cuántica, varios valores posibles, afectados por probabilidades (2009, p. 46).

Pero hay que advertir a los educandos que de acuerdo a Nicolescu, a pesar de la probabilidad de varios valores posibles, en realidad:

... en una medida experimental, se obtiene un sólo resultado para la cantidad física en cuestión. Esta brusca abolición de la pluralidad de los valores posibles de una "observable" física, por medio del acto de medida, tenía una naturaleza oscura, pero indicaba claramente la existencia de un nuevo tipo de causalidad (1996, p. 21).

Sólo muchas décadas después se puede aclarar esta nueva causalidad, según Nicolescu, con el teorema de $\mathrm{Bell}^{8}$ y con experiencias además de gran precisión.

Buganza y Sarquís agregan que si:

... uno acepta una nueva causalidad global que concierne al sistema de todas las entidades físicas en su conjunto, la paradoja se diluye. Sólo hay que reconocer la "sinergía": una colectividad siempre es más que la suma de sus partes. Pero este principio fundamental no puede ser apreciado (y abstraído) desde cualquier posición no holística, que presupone lo observado como un conjunto de partes interdependientes entre sí, donde el investigador trata de considerar la forma en que todas estas partes trabajan, se afectan y condicionan mutuamente en forma 
simultánea; de ahí que se deba considerar el fenómeno estudiado como un todo $(2009$, p. 48$)$.

La sinergia debe ser enseñada a los estudiantes como posible de observar cuando emerge un nuevo fenómeno en los marcos de un todo que se puede apreciar funcionando, porque la realidad no está fragmentada sino unida por vínculos que no siempre son fáciles de percibir.

\section{La Lógica del tercero incluido en el proceso de aprendizaje}

Otro aspecto importante a desarrollar para entender la crisis actual de la sociedad mundial, es la creación de una nueva lógica formal. Como otra característica de las abstracciones que nacen de la transdisciplinariedad, se plantea a partir de Lupasco (1951) una nueva lógica formal, matematizable, no contradictoria y multivalente de tres valores: A, no-A y Tercero (T) incluido. Nicolescu señala que:

La comprensión del axioma del tercero incluido -existe un tercer término T que es a la vez A y no A- se aclara por completo cuando se introduce la noción de "niveles de realidad". Para obtener una imagen clara del sentido del tercero incluido, representemos los tres términos de la nueva lógica -A, no-A y T- y sus dinamismos asociados por un triángulo del que uno de sus vértices se sitúa a un nivel de realidad y los otros dos vértices en otro nivel de realidad. Si uno se queda en un solo nivel de realidad, cualquier manifestación aparece como una lucha entre dos elementos contradictorios (ejemplo: onda A y corpúsculo no-A). El tercer dinamismo, el del estado T, se ejerce en otro nivel de realidad, donde lo que aparece como desunido (onda o corpúsculo) en realidad está unido (quanton), y lo que aparece contradictorio se percibe como no-contradictorio. La proyección de $\mathrm{T}$ sobre un único y mismo nivel de realidad produce la apariencia de los pares antagónicos, mutuamente excluyentes (A y no-A). Un único y mismo nivel de realidad de T sólo puede engendrar oposiciones antagónicas. Por su propia naturaleza, es auto-destructor si se separa del todo de los demás niveles de realidad. Un tercer término, digamos $\mathrm{T}$, que está situado sobre el mismo nivel derealidad que los opuestos A y no-A, no puede conciliar. La "síntesis" entre A y no-A sería más bien una explosión de inmensa energía, como la producida por el encuentro entre la materia y la antimateria (1996, pp. 28-29).

Podemos sostener con Nicolescu, que con el postulado del tercero incluido se supera en el aula la comprensión binaria sujeto/objeto de la 
física clásica pasando a un comprensión ternaria, donde el sujeto transdisciplinario-tercero incluido-objeto transdisciplinario se transforman en los constituyentes lógicos de esta nueva visión entre investigadores, estudiantes y sus tutores. Se supera la concepción de pares de contradictorios que se excluyen mutuamente (A y no-A), que implica por ejemplo la exclusión mutua de onda y corpúsculo, de continuidad y discontinuidad, causalidad local y regional y global, separabilidad y no-separabilidad. Los alumnos deben comprender que un nivel único de realidad crea entre estos pares contradictorios sólo oposiciones antagonistas, transformándose en autodestructivas por estar separados los niveles entre sí, y porque T no puede realizar su conciliación. En la lógica del tercero incluido, tanto los aprendices como los tutores deben asumir que si hay conciliación es porque la triada hegeliana coexiste en el mismo momento, permitiendo que estos componentes contradictorios construyan una unidad más amplia que los incluya. Esta lógica del tercero incluido no supera la lógica del tercero excluido. Esta última sigue siendo válida para situaciones simples, distintas a los casos complejos transdiciplinarios. Pero es un nuevo tipo de simplicidad que se encuentra restringido en su ámbito de validez.

Se puede concluir que en el sistema educacional, la unidad unidimensional del pensamiento clásico puede ser reemplazado con el enfoque transdisciplinario por una realidad multidimensional, donde existen un cierto número de niveles de realidad. Estos niveles cuando son adyacentes están conectados por la lógica del medio incluido. Hay una coherencia entre estos diferentes niveles de realidad, una auto consistencia, que en el mundo cósmico pareciera que rige su evolución a través de un flujo de información que todo lo atraviesa, de un nivel de realidad a otro nivel. Pero esta descripción de la coherencia entre los diversos niveles de realidad no supone una teoría completa, cerrada en sí misma. Es una estructura teórica abierta de la unidad de los niveles de realidad. Y es abierta porque cuando ella recorre varios pares mutuamente excluyentes, la teoría que permitió ese recorrido se agota y es necesario construir nuevas teorías que eliminen las contradicciones. Esto nos lleva a descubrir nuevos niveles contradictorios situados en un nivel distinto de realidad. Y así, cada comprensión de niveles superiores de realidad conducirá a los estudiantes hacia la construcción de teorías aún más unificadas, proceso que continuara indefinidamente sin producir jamás una teoría completamente unificada. Es la base del desarrollo del conocimiento, que es siempre abierto y se mueve a través de una flecha como rastreo permanente en la transmisión de información de un nivel a otro cada vez más complejo y unificador, pero sin posibilidad de construir una teoría completa final. 
Las transformaciones que las teorías de la complejidad y transdisciplinariedad podrían provocar en el sistema educacional planetario, permitiría a los aprendices y tutores establecer en el aula vínculos entre las personas, hechos, imágenes, sucesos, acontecimientos, representaciones y diversas acciones, entre otros, lo que nos permitiría entender mejor el Eros del aprendizaje constante, permanente, de toda la vida, porque la creatividad de los seres humanos, y en particular de los estudiantes e investigadores, se basa en esta forma de ver la realidad que los envuelve como algo en permanente vinculación de todos los sucesos, de esta interacción permanente, de la búsqueda de conocer todos los niveles posibles de realidad.

\section{Conclusiones}

Transformar la educación es una de las tareas principales de nuestros países en Latinoamérica. Estos cambios permitirían desarrollar una nueva forma de pensar entre los estudiantes en todos sus niveles de formación, en los profesores y en los profesionales en general. Esto crearía una nueva situación cultural, científica y tecnológica que nos permitiría entender mejor los problemas críticos que hoy día sumergen a nuestras naciones en el subdesarrollo, y ayudar a superar las profundas crisis ecológicas y de cambio climático que amenazan la vida de millones de seres humanos Transformaciones de esta envergadura obliga a nuestros pueblos y gobiernos a modificar sus visiones de la vida social, y contraer paradigmas no muy conocidos en la cultura actual de nuestra sociedad. Exige con urgencia alcanzar una mirada distinta basada en el pensamiento sistémico, transdisciplinar, holístico y complejo, basado en todas las ciencias de punta que hoy día imperan en el mundo. La aplicación de la física cuántica, de los adelantos de la química, de la biología del conocer no puede seguir manteniéndose desconocidos para nuestros profesores y alumnos. El camino obligado es hoy construir una nueva epistemología a partir de estas ciencias, superando de una vez por todo el pensamiento tradicional cartesiano e ingenieril basado en la física clásica newtoniana.

\section{Notas}

1 Abstracción (Nicolescu, 1996: 23): Afirma que "La física cuántica nos ha permitido descubrir que la abstracción no es sólo un intermediario entre nosotros y la Naturaleza, una herramienta para describir la realidad, sino una de las partes constitutivas de la Naturaleza. En la física cuántica, el formalismo matemático es inseparable de 
la experiencia. Resiste a su manera, tanto por su preocupación de auto-consistencia interna como por su necesidad de integrar los datos experimentales sin destruir dicha auto-consistencia. Por otra parte, en la realidad llamada "virtual" o en las imágenes de síntesis, las ecuaciones matemáticas resisten: la misma ecuación matemática hace surgir infinitas imágenes. Las imágenes germinan en las ecuaciones o en las series de números. Así, la abstracción hace parte integral de la realidad".

2 Complejidad (Morín): La complejidad plantea incertidumbre e indecibilidad, sin llegar al escepticismo. El pensamiento está condenado a afrontar las contradicciones sin poder jamás terminar con ellas. Ello obliga a la necesidad de buscar una meta-nivel para "superar" esta contradicción sin negarla. No es lograr la síntesis porque sigue incluyendo incertidumbres y problemas por la aventura sin límites del conocimiento. La complejidad es la unión de la simplicidad y de la complejidad; es la unión de los procesos de simplificación que implican selección, jerarquización, separación, reducción, con los otros contra-procesos que implican la comunicación, la articulación de aquello que está disociado y distinguido; y es el escapar de la alternativa entre el pensamiento reductor que no ve más que los elementos y el pensamiento globalista que no ve más que el todo. Es decir, la complejidad se halla en el corazón de la relación entre lo simple y lo complejo porque es a la vez antagonista y complementaria. Es la integración de lo local en lo global y viceversa.

3 Aula (Maturana): Las relaciones y la interactividad en el aula es un dominio de acciones donde aprendices y tutores viven lo que viven en el fluir del lenguaje, que funda lo humano en la convivencia de conversaciones. En el aula se abren espacios de interacciones recurrentes con alumnos/as donde la presencia de todos/as debe ser legítima, y toda negación sea responsable porque se hace sólo desde el punto de vista del que la efectúa y no sobre la base de alguna verdad absoluta. Es una unidad discreta que opera en una dinámica interna y relacional que tiene como fin la continua realización de cada uno de sus integrantes y del grupo como colectivo. En el aula, tutores/as y aprendices generan constantemente la red de producciones y transformaciones que la definen como esa aula y no otra.

4 Condición Autopoiética (Yanes): La concepción de autopoiésis de Maturana aplicada por extención a los alumnos consiste en que se trata de unidades organizadas como sistemas que generan sus propios procesos de producción de componentes y relaciones entre ellos a través de sus continuas interacciones y transformaciones, y constituyéndose de esta manera como unidad en un espacio físico determinado. Los estudiantes se transforman en sus procesos de entropías internas gatillados -y sólo gatillados- por el entorno con sus anomalías y perturbaciones, pero los cambios que se especifican dentro de ellos son seleccionados por los propios estudiantes afectados en función de su mantención como seres con características autopoiéticas. Los seres vivos, entre ellos los alumnos/as en aprendizaje poseen un cierre autorreferencial que implica que no aceptan que sus conductas sean rendimientos o expresiones del input exterior. Es el alumno/a como ser vivo el que construye todo lo que cuenta en el propio sistema.

5 Seres energocibernéticos (Yanes): Están relacionado con su carácter de máquinas (biológicas) con capacidades de incrementar constantemente, a través de nuevas formas de pensar, la variedad residual estructural que poseen como seres humanos, lo cual les permite generar profundos cambios internos con el fin de superar la resistencia del medio o entorno caosógeno condicionado por la complejidad, la incertidumbre y el caos. Esta propiedad de los seres humanos como seres energocibernéticos complejos, les permite crear o inventar los sistemas adaptativos corres- 
pondientes, conservando sus propiedades autopoiéticas y de identidad a través de las diversidades de lenguaje, sistemas de comunicación, visiones paradigmáticas y epistemológicas, nuevas invenciones, conocimiento profundo de la sociedad, inteligencia artificial, en fin con el conjunto de la cultura que la sociedad ha ido creando. Todo lo cual ayuda no sólo a garantizar su existencia, desarrollo y permanencia como organismo vivo complejo, sino que lo deja en condiciones de provocar mutaciones fundamentales en ese entorno que lo perturba con sus anomalías.

6 Transdiciplina (Nicolescu): Para entender la transdisciplina, tutores y aprendices tienen que avanzar más allá de la ruptura sistémica. Es necesario comprender también la ruptura epistemológica de segundo orden, es decir, la dinámica interna de un objeto. Ella busca romper la noción de sujeto separado del objeto, incluyendo en cambio lo que se denomina actividad objetivadora del sujeto, ampliando los límites de la objetividad. La transdiciplina indica "ir más allá" de las disciplinas, trascenderlas. Las disciplinas no son capaces de dar cuenta de la interacción sujeto-objeto y de la trascendencia del primero. Si las disciplinas establecen campos de indagación de fragmentos del cosmos, la naturaleza y la sociedad, la transdisciplina trata de comprender el mundo desde la unidad del conocimiento, desde la totalidad como diálogo de perspectivas, como diversidad, no como unificación.

7 Niveles de Realidad (Nicolescu): Es todo aquello que en nuestras imágenes y abstracciones, e incluso formulaciones matemáticas tiene dificultad para ser representadas. Es una realidad accesible a nuestros conocimientos pero con un nivel de resistencia para ser efectivamente representada, incluso habrá parte de ella que permanecerá siempre oculta a nuestra visión humana, pero que paradójicamente nos constituye, nos configura pero no con la claridad innegable de la representación. Las formulaciones matemáticas preocupadas de su consistencia interna, también tiene dificultades para integrar los datos de esa realidad que se muestra esquiva

8 Teorema de Bell: Se aplica en mecánica cuántica para cuantificar matemáticamente las implicaciones planteadas teóricamente en la paradoja de Einstein-Podolsky-Rosen y permitir así su demostración experimental. Debe su nombre al científico norirlandés John S. Bell, que la presentó en 1964. El teorema de Bell es un metateorema que muestra que las predicciones de la mecánica cuántica (MC) no son intuitivas, y afecta a temas filosóficos fundamentales de la física moderna. Es el legado más famoso del físico John S. Bell. El teorema de Bell es un teorema de imposibilidad, que afirma que: Ninguna teoría física de variables ocultas locales puede reproducir todas las predicciones de la mecánica cuántica (Wikipedia, visitado el 31 de mayo de 2014).

\section{Bibliografía}

ANDRADE, Raisa et al.

2001 El paradigma complejo. Un cadáver exquisito. Panamá: Universidad Interamericana de Educación a Distancia de Panamá.

BUGANZA, Jorge y Sarquis, Jacob

2009 La teoría del conocimiento transdisciplinar a partir del Manifiesto de Basarab Nicolescu. Argentina. Universidad Nacional de San Luis Fundamentos en Humanidades -Año X - Número I.

CAMPBELL Jeremy

1997 La máquina increíble. Santiago: Fondo de Cultura Económica. 
FREIRE, Paulo

1969 La educación como práctica de la libertad. España: Siglo XXI.

2012 Educación problematizadora. En: http://futuroseducadoresvedia.blogspot. com/2012/11/educacion-problematizadora.html [En línea].

HAWKING, Stephen

2004 A hombros de gigantes Las grandes obras de la Física y la Astronomía. Edición de Stephen Hawking. Barcelona: Crítica.

2008 La Teoría del Todo. El origen y el destino del Universo. Debate. Buenos Aires. LUPASCO, Stéphane

1951 Le principe d'antagonisme et la logique de l'énergie. Prolégomènes à une science de la contradiction. Paris: Hermann \& Co.

MARTÍNEZ, Miguel

2003 Transdisciplinariedad un enfoque para la complejidad del mundo. En: Revista Visión docente con-ciencia, No. 1 Julio. Disponible en: http://es.slideshare. net/edelinbravo29/1-lg-transdisciplinariedad-miguel-martinez-migulez [En línea].

MATURANA, Humberto \& VARELA, Francisco

1995 De máquinas y seres vivos. Autopoiésis: la organización de lo vivo Santiago de Chile: Editorial Universitaria.

MATURANA, Humberto \& NISIS, Sima

1999 Transformación en la convivencia. Santiago de Chile: Dolmen.

MORIN, Edgar

19997 saberes. Traducción Mercedes Vallejo Gómez. México: Multiversidad Mundo Real Edgar Morín.

NICOLESCU, Basarab

1996 La transdisciplinariedad. Manifiesto. México: Multiversidad Mundo Real Edgar Morín.

PIAGET, Jean, \& INHELDER, Bärbel

1973 Memory and intelligence. Londres: Routledge y Kegan Paul.

PRIGOGINE, Ilya

2000 El nacimiento del tiempo. Barcelona: Tusquets Editores. VARELA, Francisco

2000 El fenómeno de la vida. Santiago de Chile: Ediciones Dolmen.

YANES, Jaime

2011 Paulo Freire, la "educación problematizadora" y los ambientes virtuales de aprendizaje”. En: http://www.pensarlopensado.com/2011/11/paulo-freirela-educacion.html [En línea].

2012 El caos, el orden y la escuela. En: http://www.pensarlopensado.com/2012/07/ el-caos-el-orden-y-la-escuela.html [En línea].

2015 Complejidad y calidad de la educación. Santiago de Chile: Ediciones Ril.

Fecha de recepción del documento: 5 de julio de 2016 Fecha de aprobación del documento: 15 de agosto de 2016 



\title{
Del PENSAMIENTO COMPLejO Al PENSAMIENTO
}

\section{COMPUTACIONAL: RETOS PARA LA EDUCACIÓN CONTEMPORÁNEA} Complex thinking to computational thinking: contemporary challenges in education

\author{
Jorge ANTONIO BALLADARES BURGOS \\ Universidad Tecnológica Equinoccial/Quito-Ecuador \\ jballadares@ute.edu.ec \\ MaUro Rodrigo AviLÉs SALVADOR \\ Pontificia Universidad Católica/ Quito-Ecuador \\ mraviles@puce.edu.ec \\ Hamilton OMar PÉrez NarVÁez ${ }^{* * *}$ \\ Universidad Central del Ecuador/Quito-Ecuador \\ hperez@uce.edu.ec
}

\begin{abstract}
Resumen
Una de las problemáticas de la educación hoy en día es que se continúa privilegiando la enseñanza del contenido sobre el desarrollo de destrezas y habilidades cognitivas que permitan un desarrollo del pensamiento de los estudiantes. Frente a una educación tradicional, se considera que una reflexión del pensamiento complejo puede contribuir a una mejor comprensión de una realidad contemporánea. La educación hoy tiene como reto el explicar y el comprender, desde una perspectiva hermenéutica, las nuevas complejidades de la realidad con la aparición y utilización cotidiana del internet, de las TIC, de la web 2.0 y de las redes sociales. Por este motivo, se plantea una relación entre pensamiento complejo y el pensamiento computacional que incide en un mejoramiento de la calidad educativa. En el presente artículo se iniciará con una reflexión en torno a la educación a partir de la concepción de incertidumbre del pensamiento complejo. Luego se plantearán elementos de conexión entre un pensamiento complejo y un pensamiento computacional a partir del conectivismo y los desafíos de una sociedad 3.0 en la que las tecnologías de la información y comunicación se encuentran incorporadas en la vida cotidiana de los seres humanos. A su vez, una definición de pensamiento computacional nos situará sobre esta nueva forma de pensar a partir de problemas reales a través de una nueva lógica computacional para lograr resoluciones. El pensamiento computacional desafía a la educación contemporánea a incorporar este nuevo enfoque para la solución de problemas, construcción de sistemas y comprensión de la relación prospectiva entre la ciencia, la tecnología y una sociedad 3.0.
\end{abstract}

Forma sugerida de citar: Balladares Burgos, Jorge Antonio, Avilés Salvador, Mauro Rodrigo, \& Pérez Narváez, Hamilton Omar (2016). Del pensamiento complejo al pensamiento computacional: retos para la educación contemporánea. Sophia, colección de Filosofía de la Educación, 21(1), pp. 143-159.

* Docente universitario; Licenciado en Filosofía; Magíster en Filosofía y Magíster en Tecnologías aplicadas a la práctica y gestión docente. Realiza estudios de doctorado. Publicaciones en la Revista Sophia y en la Revista Nuevo Pensamiento.

** Docente universitario, tutor de tesis de Maestría en Literatura Infantil y Juvenil; docente de Ética en la Maestría en TIC y Gestión de la Educación. Docente de Investigación; docente en las áreas de Ética, Filosofía y Ciencias Sociales; Master en Filosofía. Publicaciones en la Revista Sophia y en la Revista Eidos.

*** Profesor universitario; Licenciado en Ciencias de la Educación especialización Informática, Especialista en Entornos Virtuales OEI. Magíster en Educación Superior. 
Palabras clave

Pensamiento complejo, pensamiento computacional, conectivismo, sociedad 3.0

\begin{abstract}
One of the problems of education today is that it continues to favoring the teaching of contents instead applying skills and cognitive abilities that allow a development of the thought of the students. Besides a traditional education, it is considered that a reflection of the complex thought can contribute to a better understanding of a contemporary reality. Education today has as a challenge the explanation and understanding, from a hermeneutic perspective, of the new complexities of reality to the occurrence and the everyday use of the internet, ICTS web 2.0 and social networks. For this reason, the proposal of this article is that there is a relationship between complex thinking and computational thinking that affects an improvement of the quality of education. This research focuses on a reflection on education from the conception of uncertainty and complexity. It refer to the relationship between a complex thought and a computational thinking from connectivism and the challenges of a society 3.0 in which ICT is incorporated into the daily life of human beings. In the other hand, a definition of computational thinking will put us on this new way of thinking from real problems through a new computational logic to achieve solutions. The computational thinking challenges the contemporary education to incorporate this new approach to the solution of problems, building systems and prospective understanding of the relationship between science, technology and society 3.0.
\end{abstract}

Keywords

Complex thinking, computational thinking, connectivism, society 3.0

\title{
Introducción
}

¿En qué nuevos escenarios se ubica el educador contemporáneo? ¿Qué desafíos presentan las nuevas tecnologías de la información y comunicación (TIC) para la enseñanza y el aprendizaje? ¿De qué manera el internet, la web 2.0 y las diferentes herramientas digitales inciden en el desarrollo del pensamiento? Estas preguntas guían el itinerario especulativo del artículo titulado "Del pensamiento complejo al pensamiento computacional: retos para la educación contemporánea". Este esfuerzo investigativo tiene como objetivo encontrar una relación entre el pensamiento complejo y el pensamiento computacional, encontrando puntos de coincidencia que permita fortalecer los procesos de enseñanza-aprendizaje.

Una de las problemáticas de la educación hoy en día es que se continúa privilegiando la enseñanza del contenido sobre el desarrollo de destrezas y habilidades cognitivas que permitan un desarrollo del pensamiento de los estudiantes. Ante esta vigencia de una educación "enciclopédica" en las prácticas educativas todavía, se considera que una reflexión del pensamiento complejo puede contribuir a una mejor comprensión de una realidad contemporánea, y que el pensamiento computacional 
mediado por el uso de las tecnologías de la información y comunicación permite lograr una comprensión de estos nuevos escenarios complejos.

Por esta razón, consideramos que entre los retos que tiene la educación contemporánea se encuentran el explicar y el comprender, desde una perspectiva hermenéutica, las nuevas complejidades de la realidad con la aparición y utilización cotidiana del internet, de las TIC, de la web 2.0 y de las redes sociales y la configuración de los modos de vidas de las generaciones actuales y del futuro. En este sentido, el presente artículo realiza un esfuerzo de compresión e infiere una evolución del pensamiento complejo al pensamiento computacional que incida en un mejoramiento de la calidad educativa para las nuevas generaciones que se constituyen en nativos digitales de la tecnología.

En el presente artículo se iniciará con una reflexión en torno a la educación a partir de la concepción de incertidumbre del pensamiento complejo. Luego se plantearán elementos de conexión entre un pensamiento complejo y un pensamiento computacional a partir del conectivismo y los desafíos de una sociedad 3.0 en la que las tecnologías de la información y comunicación se encuentran incorporadas en la vida cotidiana de los seres humanos. A su vez, una definición de pensamiento computacional nos situará sobre esta nueva forma de pensar a partir de problemas reales a través de una nueva lógica computacional para lograr resoluciones.

A partir de una revisión de la literatura, el método utilizado es el hermenéutico que nos permite una explicación y comprensión de los textos que fundamentan este itinerario especulativo. En el ámbito sobre la temática propuesta y se inspira en investigaciones realizadas sobre educación digital. La hermenéutica analógica será el método usado para la comprensión de la relación entre el pensamiento complejo y el pensamiento computacional, y de qué manera esta conexión desafía a la educación contemporánea.

Este tipo de investigaciones se constituye en una invitación a reflexionar desde el desarrollo del pensamiento filosófico sobre otros modos de pensar y pensamientos alternativos que respondan a la complejidad de nuestro mundo contemporáneo. A su vez, esta reflexión contribuye a una filosofía de la educación digital a partir del uso de las Tecnologías de la Información y Comunicación (TIC), la web 2.0 y las redes sociales.

\section{Pensar la educación desde la incertidumbre del pensamiento complejo}

El conocimiento, tradicionalmente, ha tendido una visión unidimensional y simplificadora. Esta forma de concebir el mundo mutila el conoci- 
miento y desfigura la realidad. La visión de Morín sobre el conocimiento parte de la reflexión de paradigma y busca cuestionar los fundamentos mismos de la lógica occidental.

Todo conocimiento opera mediante la selección de datos significativos y rechazo de datos no significativos: separa (distingue o desarticula) y une (asocia, identifica); jerarquiza (lo principal, lo secundario) y centraliza (en función de un núcleo de nociones maestras). Estas operaciones, que utilizan la lógica, son de hecho comandadas por principios "supra lógicos" de organización del pensamiento o paradigmas, principios ocultos que gobiernan nuestra visión de las cosas y del mundo sin que tengamos conciencia de ello (Morin, 2007, p. 28).

Los principios supra lógicos, como los denomina Morin, son visiones del mundo que nos permiten conocer y reflexionar desde esa realidad.

Esta visión, en términos de Kuhn, la denominaríamos "propia del paradigma dominante" y lleva consigo una óptica parcial de la realidad. "Se trata de evitar la visión unidimensional, abstracta. Es por ello que es necesario, ante todo, tomar conciencia de la naturaleza y de las consecuencias de los paradigmas que mutilan el conocimiento y desfiguran lo real" (Morin, 2007, p. 29). Esta lógica hegemónica o dominante tiene principios que rigen su forma de pensar y sobre los cuales se construye el conocimiento. Este paradigma, en la visión de Edgar Morín, está constituido por los principios antes mencionados. En este sentido la disyunción, debido a su carácter dicotomizador, dificulta las relaciones entre conocimiento científico y reflexión filosófica (Avilés, 2013). De esta forma, priva a la ciencia de la posibilidad de conocerse, de reflexionar sobre sí misma. Un pensamiento simple unívoco no es capaz de comprender la relación entre lo uno y lo múltiple, puesto que o unifica abstractamente anulando la diversidad o, por el contrario, yuxtapone la diversidad sin concebir la unidad.

Frente a esta visión unidimensional o simplificadora de la realidad, Morín propone una visión compleja debido a que la serie de tragedias que el pensamiento simplificador, y por ello dogmático, ha traído consigo (Avilés, 2013). Esta crítica y esta visión es posible aplicarla, afirma el filósofo, hasta en los planos de la vida y las ciencias sociales:

La incapacidad para concebir la complejidad de la realidad antroposocial, en su microdimensión (el conjunto planetario de la humanidad), ha conducido a infinitas tragedias y nos condujo a la tragedia suprema. Se nos dijo que la política "debe" ser simplificante y maniquea. Lo es... en su versión manipulativa que utiliza a las pulsiones ciegas. Pero la estrategia política requiere al conocimiento complejo, porque la estrategia 
surge trabajando con y contra lo incierto, lo aleatorio, el juego múltiple de las interacciones y las retroacciones (Morin, 2007, p. 32).

Al ubicarse este pensamiento complejo como una propuesta alternativa, es necesario puntualizar qué es para Morín esta forma distinta de concebir el mundo y la realidad, y por ende, es importante ubicar una definición. Edgar Morín define a la complejidad como:

Un tejido...de constituyentes heterogéneos inseparablemente asociados: presenta la paradoja de lo uno y lo múltiple...La complejidad se presenta con los rasgos inquietantes de lo enredado, de lo inextricable, del desorden, la ambigüedad, la incertidumbre (Morin, 2007, p. 32).

Para Morín la vida y los fenómenos antropo-sociales son fenómenos que se auto-eco-organizan de forma compleja. En la complejidad conviven los elementos yuxtapuestos, los componentes dicotómicos, lo similar y lo contrario, lo lógico y lo contradictorio, lo unívoco, lo equívoco y lo analógico a la vez. Por este, estos nuevos escenarios complejos parten de la certeza de la incertidumbre.

François Houtart (2006), en su conferencia titulada La ética de la incertidumbre en las Ciencias Sociales propone algunos elementos de reflexión a partir del pensamiento complejo. Esta reflexión tendrá una incidencia en la epistemología reconociendo la importancia de la temporalidad, la multidimensionalidad y la transdisciplinareidad:

Reconstruir una epistemología compleja, que reconoce los límites de la elementariedad, la importancia de la temporalidad, la multidimensionalidad y lo transdisciplinario. Tal visión de la realidad conduce al crecimiento de la conciencia de la ambivalencia de lo real, de la aleatoriedad, de la incertidumbre, así como de la pluralidad de las instancias epistemológicas (Houtart, 2006, p. 17).

El tomar en cuenta la incertidumbre como instancia posible de conocimiento -antes desechada por la lógica dominante que buscaba ante todo la certeza- recupera en la realidad su dimensión compleja y extensa que lo caracteriza, superando así las visiones simplificadoras que critica Morín.

Esta visión empata, de alguna forma, con algunas de las características del pensamiento postmoderno. Para ello Houtart, a partir de las Ciencias Sociales, ubica al pensamiento complejo como característico de la posmodernidad y como consecuencia de una crisis de la modernidad:

En ciencias sociales, esta visión de base desarrolló dos orientaciones que podemos llamar de tipo postmoderno. La primera desembocó en 
el rechazo de la existencia de sistemas y de estructuras, para valorizar lo inmediato, el sujeto, la historia cotidiana. La segunda reconoce que la incertidumbre no significa la ausencia de paradigma y de referencias... la observación de base es que en la modernidad la racionalidad tecnocientífica se impuso como la única y que eso tuvo como consecuencia una reducción del abanico de los saberes (Houtart, 2006, p. 17).

El pensamiento postmoderno busca nuevos métodos de razonamiento: el valor del afecto frente a lo racional, del pensamiento analógico frente al analítico, de lo parcial frente a la totalidad. Y eso tiene importantes consecuencias sobre la manera de aprehender lo real. Es este el espacio apropiado para que, superada esta concepción marcadamente racionalista de la modernidad, se dé paso a un pensamiento que integre los otros elementos que la postmodernidad ha permitido que realicen su aparecimiento o develación. Cada comunidad es un texto que se debe estudiar con el método de la crítica literaria: una interpretación y no explicación $\mathrm{o}$, si se trata de historia, una interpretación de interpretaciones. Lo que se necesita es una hermenéutica, lo que es el papel principal de las ciencias sociales (Houtart, 2006).

En consecuencia, lo real se presenta como cultura y pluralidad de textos. Jacques Derridá es quien habla de "juego infinito de textos sin sentido dado". Los hechos sociales son expresiones simbólicas y deben leerse como textos. Como lo expresa bien Amando Robles, se trata de la "conciencia de saber que no pueden sustituir aquellos referentes (metasociales) por otros nuevos... Lo más que puede aspirar es a 'escribir', dejar 'textos', no obras con sello definitivo, y a descubrir y recuperar las 'escrituras' de otras épocas, los 'textos' que fueron dejando, sus huellas" (Robles, 1995, citado por Houtart, 2006, p. 19).

Reflexionar sobre la educación hoy, por tanto, es una actividad multidisciplinaria, de ninguna forma orientada bajo cánones ni perspectivas univocas. En el marco de la reflexión teórica sobre la educación es necesario tomar en cuenta aquellos conocimientos y saberes que, muchas de las veces, aparecen olvidados al conocimiento tradicional, o se presentan como totalmente nuevos o desconocidos. La complejidad, gracias al aporte de Morín, es el espacio apropiado de integración de expresiones diversas y de nuevas relaciones simbólicas el espacio propicio para reflexionar sobre el futuro de la educación a partir de la mediación de las tecnologías de la información y comunicación, las redes sociales y el internet. En este sentido, el pensamiento computacional aparece como una alternativa de estas nuevas expresiones del pensamiento. 


\section{Del pensamiento complejo al pensamiento computacional: el desafío prospectivo de una sociedad 3.0}

Si Morin nos plantea que la complejidad es expresión de la incertidumbre en el que conviven el orden y el caos, hoy en día las sociedades contemporáneas enfrentan escenarios complejos. Para comprender lo que implica una incertidumbre contemporánea, se debe mencionar el aporte de Byung-Chul Han, quien reconoce un exceso de positividad en las sociedades contemporáneas que las inserta en una hiperactividad multitasking, fuera de todo tipo de orden o de equilibrio en sí. Para que el individuo recupere un punto de equilibrio, se debe considerar la negatividad de la negación para que el ser humano encuentre su libertad (Han, 2012).

Se puede inferir del pensamiento de Han que tanto la positividad como la negatividad conviven y se complementan entre sí desde un punto de vista dialéctico. Esta convivencia de la afirmación y negación de las sociedades contemporáneas puede brindar pistas para una comprensión de una percepción del caos producido por las conexiones, las redes y los nodos a partir del uso de las tecnologías, e inclusive reconocer un entorno como enjambre digital entre los usuarios de las sociedades del conocimiento (Han, 2012).

Se puede reconocer que el contexto de la vida contemporánea se centra en un entorno digital e interconectado. Para ello, hay que mencionar lo que propone el conectivismo como una nueva teoría del aprendizaje. Siemmens (2004) plantea que el conductismo, el cognitivismo y el constructivismo son las tres grandes teorías de aprendizaje utilizadas en educación. Sin embargo, estas teorías fueron desarrolladas en una época en la que el aprendizaje no había sido impactado por la tecnología. A partir de esta nueva realidad, el conectivismo aparece como una nueva teoría alternativa, en la que se incluye a la tecnología y se identifica conexiones como actividades de aprendizaje en la era digital; integra principios de las teorías de caos, redes, complejidad y auto-organización.

Por ende, en el conectivismo se puede encontrar el nexo idóneo para ligar el pensamiento complejo con el pensamiento computacional. Llama la atención la resignificación que realiza el conectivismo en torno al caos. El caos se lo considera como la interrupción de la posibilidad de predecir, aquello que desafía el orden. A diferencia del constructivismo que incide a que los estudiantes realicen tareas significativas, el caos señala que el significado existe, y que el reto del aprendiz es reconocer los patrones que parecen estar escondidos, como las conexiones entre los diferentes elementos (Siemens, 2014). 
Ángel Pérez Gómez (2010) menciona que el docente se encuentra en medio de la atención y la polémica, al reconocer una percepción generalizada de insatisfacción respecto a la calidad de los procesos educativos, pues los contenidos que se enseñan no generan conocimientos útiles para comprender la vida personal, social y profesional de los individuos. La profesión docente se enfrenta hoy en día a nuevos desafíos y contextos en la era de la información y de la incertidumbre, y percibe un distanciamiento generacional entre el docente y el estudiante que incide en los procesos educativos contemporáneos:

Los contextos y escenarios sociales que rodean la vida de las nuevas generaciones en nada se parecen a los escenarios y contextos que rodeaban el crecimiento de las generaciones del siglo XIX y primera mitad del siglo XX. Sin embargo, el dispositivo escolar vigente, el curriculum escolar organizado en disciplinas, la forma habitual de organizar el espacio y el tiempo, los modos de agrupar a los estudiantes, los métodos de enseñanza, los sistemas de evaluación y calificación del alumnado, y los sistemas, programas e instituciones de formación de docentes son esencialmente los mismos que se establecieron ya en el siglo XIX y que, con modificaciones cosméticas, se han mantenido y reproducido hasta nuestros días (Pérez Gómez, 2010, p. 18).

En este sentido, la educación contemporánea se enfrenta a nuevos desafíos, dado que "la era de la información y de la incertidumbre requiere ciudadanos capaces de entender la complejidad de situaciones y el incremento exponencial de la información, así como de adaptarse creativamente a la velocidad del cambio y a la incertidumbre que le acompaña" (Pérez Gómez, 2010, p. 37). En esta perspectiva, se requiere plantear nuevas pautas para la formación del profesorado, y a su vez, que incorpore en sus prácticas el aprender a educar.

Moravec (2013) menciona que hoy en día se vive una sociedad knowmad, constituida por nuevas generaciones nómadas del conocimiento, a partir del desarrollo de las sociedades y nuevos retos en el ámbito laboral. Se reconoce una evolución de la sociedad desde la época agraria o sociedad 1.0, pasando por una sociedad industrializada o sociedad 2.0, hasta llegar a la sociedad del conocimiento y la información hoy en día o sociedad 3.0. Estas nuevas generaciones de knowmads o nómadas del conocimiento pueden trabajar en cualquier tiempo y lugar, con cualquier persona, ante cualquier desafío (Moravec, 2013).

A partir de una sociedad 3.0 en la que se privilegia el uso de las tecnologías de la información y comunicación (TIC), Cobo y Moravec (2011) plantean su propuesta de aprendizaje invisible como un paradigma alter- 
nativo de educación inclusiva donde se articula el aprendizaje informal y no-formal con el aprendizaje formal. Desde del aprendizaje invisible, se pretende reconocer el uso de las TIC y herramientas digitales en la cotidianeidad, donde la utilización de estos medios digitales ya no se aprenden exclusivamente en los espacios formales, sino que se aprende en ámbitos informales, de la vida cotidiana, en el uso de mediaciones tecnológicas del diario vivir, a lo largo de la vida. Desde esta reflexión, los autores se cuestionan de qué manera una universidad 1.0, que se ha quedado anquilosada en el tiempo de la sociedad agraria, puede formar estudiantes 3.0 que pertenecen a la sociedad de los nómadas del conocimiento y de la información.

Cobo y Moravec hacen énfasis en la crisis de la universidad contemporánea al percibir la brecha entre lo que se enseña en sus aulas y las exigencias del mundo laboral así como los cambios constantes en el conocimiento:

Muchas universidades fallan en áreas como cobertura e inclusión, pero también en aspectos relacionados con pertinencia, eficacia, flexibilidad e innovación. En este marco surgen voces como la de Jan Philipp Schmidt (2010), docente de la Universidad de las Naciones Unidas, quien plantea que los actuales modelos de la educación (superior) están en crisis, a causa de problemas como: el desfase entre las habilidades enseñadas y las requeridas en el mundo técnico-profesional; un alza desmesurada del precio de las matrículas; una formación de corto alcance que no prepara adecuadamente para los desafíos del mañana; o la adopción de planes de formación rígidos, fragmentados y expuestos a quedar obsoletos tras tres o cuatro años de estudio (Cobo \& Moravec, 2011, p. 19).

Frente a este desfase, la pregunta que estos autores se realizan es "cómo hacer para que la enseñanza "invisibilice" a las TIC como tal y sea capaz de estimular la capacidad humana de generar, conectar y reproducir nuevos conocimientos de manera continua, sin casarse con ninguna tecnología en particular y sin que ello implique renunciar a la adaptación y a la actualización continuas" (Cobo \& Moravec, 2011, p. 35).

Laurillard (2002) coincide con esta perspectiva al mencionar que hay que repensar la educación, en especial la educación superior, en la sociedad del conocimiento. Por años se ha presionado a las universidades a expandir tanto su oferta académica y el libre acceso de nuevos estudiantes por las necesidades del mundo laboral. Sin embargo, las instituciones educativas se enfrentan con industrias del conocimiento que proponen el desarrollo de competencias inmediatas que un profesional necesita para responder a la sociedad del conocimiento; por ende, los profesionales graduados se cuestionan sobre el real beneficio de una educación versus 
lo que las nuevas industrias del conocimiento le ofrecen para su desarrollo profesional (Laurillard, 2002, p. 17). Es importante que las instituciones educativas incorporen el uso de las tecnologías digitales en su proceso educativo para responder las demandas laborales de la era digital, además de la relación entre teoría y práctica a través de un marco dialógico, donde la práctica pre-profesional de los estudiantes marque la reflexión de los estudiantes y la incorporación de competencias prácticas y concretas que demanda el ámbito laboral en una sociedad de la información (pp. 21-22).

La propuesta de una sociedad knowmad y el aprendizaje invisible invita a comprender a las nuevas generaciones o nativos digitales, y a su vez, reconocer otros ámbitos educativos informales, no-formales y alternativos mediados por el uso de las tecnologías de la información y comunicación. Los estudiantes 3.0 desafían a una educación 1.0 y al staff

152 docente a incorporar y desarrollar nuevas competencias digitales para generar nuevos aprendizajes en la sociedad 3.0. No basta solamente familiarizarse con el uso y manejo instrumental de las nuevas tecnologías, sino también incorporarlas a procesos de creación, innovación y gestión del conocimiento a través del pensamiento computacional. Un aprendizaje a través del uso de las tecnologías de la información y comunicación (TIC) y las redes sociales invita a reflexionar sobre la incidencia de un pensamiento computacional en el aprendizaje de las nuevas generaciones, mediadas por el pensamiento complejo, el conectivismo y un aprendizaje invisible en función de una sociedad 3.0.

\section{El pensamiento computacional y algunas experiencias educativas}

Varias teorías relacionadas con la informática y las tecnologías de la información y comunicación (TIC) han hecho su aparición en los últimos años. Una de ellas es el pensamiento computacional que nace de la reflexión acerca de la ubicuidad de la computación en la vida cotidiana y la necesidad de obtener mayores ventajas. Greenfield afirma la incidencia de la computación de la vida cotidiana:

Cada vez más generalizada, cada vez más difícil de percibir, la computación ha dado un salto fuera del escritorio inusual a la vida cotidiana. Dicha información ubicua "tecnología presente en cualquier lugar" aparecer en muchos diferentes contextos y tienen una amplia variedad de formas, pero que afectarán a casi cada uno de nosotros, ya sea somos conscientes de ello o no (Greenfield, 2006, p. 11). 
El concepto "pensamiento computacional” tiene su complejidad en sí, dando que se lo puede relacionar con una competencia compleja de u grado de dificultad alto, que puede relacionar con niveles de pensamiento abstracto, matemático, pragmático e ingenieril aplicados en diferentes momentos de nuestra vida cotidiana (Valverde, Fernández, \& Garrido, 2015). Este tipo de pensamiento no es sinónimo de programación de un computador, ya que "se puede desarrollar pensamiento computacional sin utilizar ordenadores (basta papel y lápiz), si bien los dispositivos digitales nos permiten abordar problemas que sin ellos no nos atreveríamos a enfrentar" (2015, p. 4).

Esta afirmación en la que concordaron varios autores es una de las fuentes de origen del término pensamiento computacional de reciente creación y que pretende atender a la necesidad social de resolver problemas de diferente tipo con ayuda de herramientas informáticas, que son tan comunes en nuestro medio. También se estableció que el uso mecánico de la tecnología computacional se había convertido en una limitación por lo que era necesario desarrollar ciertas habilidades informacionales y del pensamiento. Wing (2006) describe al pensamiento computacional como fundamental para la vivir en el siglo XXI, así como las matemáticas y la escritura, por lo que no sólo se compete a los informáticos sino a todas las personas ya que mejora la capacidad analítica de los individuos:

Se basa en el poder y límites de la computación procesos, ya sean realizadas por un humano o por una máquina. Métodos y modelos computacionales nos dan la posibilidad para resolver problemas y diseñar sistemas que ninguno de nosotros lo haría ser capaz de hacer frente por sí solo. El pensamiento computacional se enfrenta al enigma de la inteligencia artificial: ¿Qué pueden hacer los seres humanos mejor que los ordenadores? y ¿Qué pueden hacer los ordenadores mejor que los seres humanos? (Wing, 2006, p. 33).

Este nuevo tipo de pensamiento, mediado por las computadoras, sitúa al ser humano frente a la tecnología como medio para la supervivencia humana. El mejoramiento del pensamiento humano se enfrenta al desarrollo de una inteligencia artificial a partir de las computadores, en el que visualiza la disyuntiva entre si un pensamiento humano es mejor que un pensamiento artificial, o viceversa. Posteriormente Wing, en una conferencia desarrollada en la Universidad de Pensacola (2009) aclara mejor las implicaciones que posee el término cuando afirma que:

El pensamiento computacional es un enfoque para la solución de problemas, construcción de sistemas, y la comprensión del comportamiento humano que se basa en el poder y los límites de la computación. 
Si bien, el pensamiento computacional ya ha comenzado a influir en muchas disciplinas, desde las ciencias de las humanidades, lo mejor está aún por venir. De cara al futuro, podemos anticipar incluso efectos más profundos del pensamiento computacional en la ciencia, la tecnología y la sociedad (Wing, 2009, p. 1).

Es importante aclarar que el pensamiento computacional va más allá de la programación o el diseño e implementación de un sistema informático. Este pensamiento amplía nuestras facultades a niveles insospechados con la ayuda de las herramientas informáticas donde la imaginación y la creatividad encuentran el terreno fértil para las ideas en mundos virtuales. La inteligencia humana unida a la informática no deja de ser humana sino que se enriquece haciendo posible resolver problemas de manera más rápida, eficiente y con niveles de complejidad y organización que a las máquinas no les representa el mismo esfuerzo que a las personas.

Con la intención de comprender mejor el pensamiento computacional se describen a continuación algunos de sus elementos y las relaciones con otros tipos de pensamiento con los que converge en varios aspectos. Chun y Piotrowski (2012) señalan los siguientes:

- Análisis de los efectos de la computación: se refiere a establecer los alcances, ventajas así como limitaciones que pueden presentar el uso de herramientas informáticas para la solución de un problema.

- Producir artefactos computacionales: es importante que las nuevas generaciones pasen de un cómodo e irreflexivo uso de la tecnología informática que los limita a ser consumidores a productores de sus propias tecnologías.

- Uso de abstracción y modelos: muchos de los problemas reales encuentran solución cuando se abstrae sus elementos o propiedades fundamentales y a partir de ellos se construyen modelos que permitan analizarlos o modificar sus condiciones este elemento es fundamental puesto que muchos de los fenómenos naturales o sociales no pueden ser manipulados de forma directa.

- Analizar problemas y artefactos: la descomposición de los problemas es un método de solución que ha permitido elaborar sistemas informáticos complejos, acerca del proceso de análisis que permiten resolver problemas.

- Reconocimiento y generalización de patrones: para el pensamiento computacional el mundo que nos rodea se compone de elementos que interactúan y muestran procesos repetitivos 
que a partir de su detección y determinación de las características pueden ser clasificados, este proceso pueden realizarlo tanto los individuos como las computadoras con la única diferencia en tiempos de respuesta.

- Algoritmización: es la habilidad de organizar procesos secuenciales y lógicos de forma que resuelvan problemas. En el caso del pensamiento computacional corresponde a un paso previo a la utilización de las herramientas informáticas y los lenguajes de programación. Los seres humanos enseñamos a las máquinas los algoritmos que permiten realizar acciones frente a una situación específica, pero se considera que a futuro ellas serán capaces de aprender por si solas estos algoritmos.

- Comunicar procesos y resultados: es otro pilar del pensamiento computacional compartir la información de manera que esta sea puesta al servicio de la sociedad y además sirva de base para la creación de nuevos conocimientos.

- Trabajo efectivo en equipo: la construcción de conocimientos y la resolución de problemas pueden alcanzar mejores rendimientos cuando existen grupos de personas compartiendo sus experiencias e ideas (Chun \& Piotrowski, 2012).

Hoy en día existen esfuerzos por incorporar el pensamiento computacional en ámbitos educativos. Una de las de mayor impacto por el número de involucrados y tiempo que lleva ejecutándose es CODE, propuesta desarrollada en Estados Unidos, cuya intención es promover la enseñanza de programación motivando a los estudiantes por el estudio de carreras a nivel superior relacionadas con el tema (CODE, 2015). Este país enfrenta problemas ocasionados por la exclusión en el currículo escolar de conocimientos relacionados con las ciencias computacionales. El Reino Unido posee una red de voluntarios que comparten sus conocimientos informáticos con estudiantes de nueve a once años llamada Code Club, consideran importante desarrollar desde niños la creatividad, pensamiento lógico y solución de problemas (Code Club, 2016).

En el caso de América Latina, hay que mencionar la experiencia de Colombia y el proyecto Coderise cuya intención es posibilitar, además de la adquisición de las habilidades del pensamiento computacional, la oportunidad de mejorar las condiciones económicas de los jóvenes a través de la generación de emprendimientos (Coderise, 2016). Cabe también destacar los esfuerzos desarrollados por Eduteka, portal educativo de libre acceso que ha publicado artículos, herramientas y experiencias 
sobre tema elaboradas por investigadores nacionales e internacionales sobre herramientas TIC aplicadas para el mejoramiento de procesos educativos en el aula (Eduteka, 2016).

Entre las experiencias educativas, cabe destacar la utilización del programa Scratch ${ }^{1}$, uno de los lenguajes más conocidos y aplicados a nivel mundial. Este lenguaje posibilita elaborar algoritmos para crear historias interactivas, juegos y animaciones, además de compartir los proyectos con otros participantes en su portal:

A medida que los jóvenes diseñan medios interactivos con Scratch, comienzan a interactuar con un conjunto de conceptos computacionales (esquema de los bloques para programar con Scratch), comunes a muchos lenguajes de programación. Hemos identificado siete conceptos que son muy útiles para una amplia gama de proyectos con Scratch y pueden transferirse a otros contextos ya sean estos de programación o no: secuencias, ciclos, paralelismo, eventos, condicionales, operadores y datos (Brenan \& Resnick, 2012).

El lenguaje Scratch fue seleccionado como recurso para formación inicial de los estudiantes de la Carrera de Informática de la Facultad de Filosofía, Letras y Ciencias de la Educación de la Universidad Central del Ecuador, por facilitar el trabajo metodológico en la resolución de problemas en contraposición a las estrategias tradicionales de aprendizaje a través de flujogramas y seudocódigos. Pérez y Roig-Vila (2015) argumentan acerca de las ventajas que muestra su utilización:

Respecto a la creatividad, un alto porcentaje de estudiantes expresa que el trabajo con Scratch, a partir de los recursos que proporciona y las posibilidades que posee la herramienta, promueve dicha habilidad. Al mismo tiempo, manifiestan que ven potencializada su imaginación y el pensamiento computacional (Pérez \& Roig-Vila, 2015, p. 15).

El pensamiento computacional, a partir de diferentes recursos y lenguajes digitales, desafía a los educadores a conocer estas nuevas herramientas virtuales y desarrollar el pensamiento en los procesos de enseñanza-aprendizaje. Las posibilidades de generación de conocimiento que nos presentan las nuevas tecnologías de la información y comunicación son amplias y diversas, por lo que se presentan como un desafío para el profesorado de los próximos años.

Finalmente el pensamiento computacional no debe limitarse a la implementación de una determinada asignatura dentro del currículo, cuando el mismo pensamiento computacional contribuye a la construcción de una ciudadanía en sociedades complejas e hiperconectadas 
(Valverde, Fernández, \& Garrido, 2015). Por ende, la tendencia de la educación de incorporar las TIC en sus procesos debe considerar que estas tecnologías también pueden generar aprendizajes y conocimiento: pasar de las TIC (Tecnologías de la Información y Comunicación) a las TAC (Tecnologías del Aprendizaje y Conocimiento) (Moya, 2013).

\section{Conclusiones}

El educador hoy en día enfrenta nuevos escenarios donde su creatividad para la formulación de problemas y situaciones reales, diseño de actividades y otros elementos educativos deben permitir al estudiante enfrentarse a situaciones que exploten su creatividad y desarrollen el pensamiento complejo a través del pensamiento computacional. Una educación contemporánea debe responder a una sociedad 3.0, en el que el uso de las tecnologías de la información y comunicación y las redes sociales conforman la cotidianeidad de nuestras vidas. Por ende, comprender esta nueva lógica compleja a través de lo computacional se constituye en un reto para el profesorado ecuatoriano.

Para promover el desarrollo de un pensamiento computacional es necesario iniciar con una alfabetización digital del profesorado. El uso y conocimiento de las TIC no es suficiente para generar procesos de enseñanza-aprendizaje, sino que ellas deben convertirse en generadoras del conocimiento y promover el desarrollo de estrategias metodológicas tanto dentro como fuera del aula. Tampoco deben limitarse a una determinada asignatura o contenido, sino que este pensamiento debe considerarse como transversal en el proceso educativo mediado por las tecnologías de la información y comunicación (TIC).

A partir de este esfuerzo especulativo de ligar un pensamiento complejo con un pensamiento computacional, quedan planteadas las siguientes preguntas a futuro: ¿de qué manera el sistema educativo ecuatoriano incorpora el desarrollo de pensamiento computacional en el currículo nacional? ¿Cuáles son las herramientas digitales que presentan las mejores condiciones para su desarrollo? ¿De qué manera el pensamiento computacional contribuye al perfil de egreso del bachiller ecuatoriano? Estas inquietudes quedan abiertas para que el lector se incorpore a la reflexión en torno a este nuevo enfoque en función de promover una educación 3.0 en el Ecuador. 


\section{Notas}

1 Es un programa desarrollado por el Instituto Tecnológico de Massachusetts (MIT) por el grupo permanente "Kindergarten".

\section{Bibliografía}

CODE

2015 Recuperado el 22 de agosto de 2016, de https://code.org/

Code Club

2016 Recuperado el 22 de agosto de 2016, de https://www.codeclubworld.org/

Coderise

2016 Recuperado el 22 de agosto de 2016, de http://coderise.org

Eduteka

2016 Recuperado el 22 de agosto de 2016, de http://eduteka.icesi.edu.co/ AVILÉS, Mauro

2013 Hermenéutica analógica y educación superior. Revista Sophia: Colección en Filosofía de la Educación, 15, 149-163.

BRENAN, Karen, \& RESNICK, Mitchel

2012 Nuevas propuestas para evaluar el desarrollo dell pensamiento computacional. Obtenido de Eduteka: http://eduteka.icesi.edu.co/articulos/EvaluarPensamientoComputacional

CHUN, Benjamin, \& PIOTROWSKI, Tim

2012 Pensamiento computacional ilustrado. Obtenido de Eduteka: http://www.calameo.com/read/0001706218d162b5b27f9

COBO, Cristóbal, \& MORAVEC, John

2011 Aprendizaje invisible. Hacia una nueva ecología de la educación. Barcelona: Publicacions i Edicions de la Universitat de Barcelona.

GREENFIELD, Adam

2006 Everyware. The dawning age of ubiquitous computing. Obtenido de http:// www.pdf-archive.com/2014/07/26/everyware/everyware.pdf

HAN, Byung-Chul

2012 La sociedad del cansancio. Barcelona: Herdes.

HOUTART, Francois

2006 La Ética de la incertidumbre en las ciencias sociales. La Habana: Casa Editorial Ruth.

MORAVEC, John

2013 Knowmad society. Minneapolis: Education Futures.

MORIN, Edgar

2007 Introducción al pensamiento complejo. Barcelona: Gedisa.

MOYA, Mónica

2013 De las TICs a las TACs: la importancia de crear contenidos educativos. Revista DIM (27).

PÉREZ-GÓMEZ, Ángel

2010 Aprender a educar. Nuevos desafíos para la formación de docentes. Revista Interuniversitaria de Formación del Profesorado, 68 (24,2), 37-60. 
PÉREZ, Hamilton, \& ROIG-VILA, Rosabel

2015 Entornos de programación no mediados simbólicamente para el desarrollo del pensamiento computacional. Una experiencia en la formación de profesores de Informática de la Universidad Central del Ecuador. RED. Revista de Educación a Distancia, 46(9), 22. 15 de septiembre.

SIEMENS, George

2014 Conectivismo: una teoría de aprendizaje para la era digital. Obtenido de http://www.diegoleal.org/docs/2007/Siemens(2004)-Conectivismo.doc

VALVERDE, Jesús, FERNÁNDEZ, Rosa, \& GARRIDO, María del Carmen

2015 El pensamiento computacional y las nuevas ecologías del aprendizaje. RED. Revista de Educación a Distancia, 46(9). 15 de septiembre

WING, Jeannette

2006 Computational Thinking. Obtenido de CACM viewpoint: https://www. cs.cmu.edu/ 15110-s13/Wing06-ct.pdf

2009 Obtenido de Computational Thinking and Thinking About Computing: https://competencias3m.files.wordpress.com/2011/08/traduccion-jeannet te-m-wing-computational-thinking-and-thinking-about-computing.pdf, 10 de octubre

Fecha de recepción del documento: 5 de julio de 2016 Fecha de aprobación del documento: 15 de agosto de 2016 



\title{
UNA APROXIMACIÓN DESDE LA LÓGICA
}

\author{
DE LA EDUCACIÓN AL PENSAMIENTO COMPUTACIONAL
}

\section{An approach from the logic of the education to the computational thinking}

\author{
ALBERTO ISAAC RINCÓN RUEDA* \\ Fundación Observatorio Multidisciplinario para la Construcción \\ del Conocimiento/Bogotá, Colombia \\ aisaac_rincon@yahoo.es \\ WiLLIAM DaRío ÁVILA Díaz \\ Fundación Observatorio Multidisciplinario para la Construcción \\ del Conocimiento/Bogotá, Colombia \\ wavila@uniandino.com.co
}

Forma sugerida de citar: Rincón Rueda, Alberto Isaac \& Ávila Díaz, William Darío (2016). Una aproximación desde la lógica de la educación al pensamiento computacional. Sophia: colección de Filosofía de la educación, 21(1), pp. 161-176.

* Posdoctoral en comunicación, educación y cultura de las Universidades Santo Tomás (Bogotá, Colombia) y Nacional de Córdoba (Argentina). Doctor en ciencias pedagógicas del Instituto Central de Ciencias Pedagógicas (La Habana, Cuba). Magíster en historia de la Universidad Externado (Bogotá, Colombia). Licenciado en ciencias religiosas de la Pontificia Universidad Javeriana (Bogotá, Colombia).

** Posdoctoral en Manuel Castells y la era de la información del Centro de Estudios Avanzados de la Universidad Nacional de Córdoba (Argentina). Posdoctoral en economía, sociedad y la construcción del conocimiento en el mundo contemporáneo del Centro de Estudios Avanzados de la Universidad Nacional de Córdoba (Argentina). Posdoctoral en comunicación, educación y cultura de las Universidades Santo Tomás (Bogotá, Colombia) y Nacional de Córdoba (Argentina). Philosophiae doctor (PhD) in Business Administration de Newport Internacional University (CA, Estados Unidos). Magíster en ingeniería de sistemas y computación de la Universidad de los Andes (Bogotá, Colombia). Especialista en gestión gerencial de la Universidad Central (Bogotá, Colombia). Ingeniero de sistemas y egresado distinguido de la Universidad Católica de Colombia. 


\begin{abstract}
Resumen
La lógica de la educación aborda las políticas que en la materia se aplican en los sistemas educativos de las naciones y estudia los métodos empleados en la educación, en el aprendizaje del hombre, en las comunidades y en los resultados que se dan en las sociedades. Esto ayuda a razonar sobre las falencias que se presentan en la educación y también en los buenos resultados que se consolidan en los sistemas educativos. Asimismo, constituye una propuesta académica en estos tiempos de cambio, innovación y transformación, que afectan a la sociedad hoy en día, para mejorar la acción pedagógica, el desarrollo y el progreso de la humanidad y de la sociedad con valores éticos y morales. La educación ha permitido la inclusión de tecnologías que van mucho más allá de las paredes del aula de clase, así como la irrupción y difusión de la enseñanza metodológica. De esta manera se facilita una nueva dinámica docente, se estimula la creatividad de los estudiantes y se promueve el trabajo cooperativo, para motivar el mundo académico. En la actualidad, las instituciones educativas tienen un aprendizaje adicional como una herramienta pedagógica; es el pensamiento computacional, que facilita la adquisición de la base de criterios y una buena toma de decisiones. Este es un mecanismo abstracto que se toma como modelo de inteligencia humana y de nociones de completitud y aleatoriedad. También, el pensamiento computacional forma parte fundamental del proceso de aprendizaje en todas las edades, pero básicamente en niños, ya que estos ahora están aprendiendo las bases de un lenguaje de comunicación y de tecnología para crear animaciones y así desarrollar sus capacidades. Cabe señalar que la abstracción del pensamiento computacional ayuda a crear soluciones para problemas en el mundo real del siglo XXI. Puede utilizarse en dos vías primordiales: para los usuarios y para las máquinas en sí mismas.
\end{abstract}

Palabras clave

Educación, lógica educacional, pensamiento, pensamiento computacional.

\begin{abstract}
The logic of education addresses the policies that in matter is applied in education systems of nations and studying the methods used in education, learning, man, communities and the results given in societies. This helps to reason about the failures that occur in education and also in the good results are consolidated into education systems. It also serves as an academic proposal in these times of change, innovation and transformation, affecting society today, to improve pedagogical action, development and progress of mankind and society with ethical and moral values. Education has allowed the inclusion of technologies that go far beyond the walls of the classroom, as well as the emergence and dissemination of methodological teaching. Thus it is facilitating a new teaching dynamics, student creativity is stimulated and promoted cooperative work, to motivate the world academic. Currently, educational institutions have an learning additional as a pedagogical tool; is computational thinking, which facilitates the acquisition of the basis of criteria and good decision making. This is an abstract mechanism inspired by human intelligence and notions of integrity and randomness. Also, computational thinking is a fundamental part of the learning process at all ages, but mainly in children, as they now are learning the basics of a language of communication and technology to create animations and develop their abilities. It should be noted that the abstraction of computational thinking helps create solutions for problems in the real world of the XXI century. It can be used in two primary ways: for users and for the machines themselves.
\end{abstract}

Keywords

Education, educational logic, thought, computational thinking. 


\section{Introducción}

Este siglo ha cobrado una sólida formación cultural, imprescindible para la comprensión global de la época. Sin duda, la educación representa una herramienta primordial y transformadora, que contribuye a configurar la estructura cognitiva. Esto permite la adquisición de conocimientos teóricos y prácticos que facilitan una armónica coexistencia. Aquí encontramos el principal agente de transformación para el desarrollo sostenible, que conduce a la obtención de mejores condiciones de vida. Asimismo, es un ingrediente fundamental en la vida del hombre, pues da vigor a la cultura y hace que el espíritu de la persona la asimile y la haga florecer. Con ello se abren múltiples caminos para su perfeccionamiento. Esta premisa se traduce en una gran capacidad en los planos intelectual, moral y espiritual, ya que es una educación auténtica, que adquiere mayor percepción en la medida en que el sujeto domina, controla y dirige sus potencialidades.

Hoy en día, las sociedades experimentan profundas transformaciones, que las llevan a la consolidación de una sociedad humanista, democrática, protagónica, participativa, multiétnica, plurilingüe e intercultural. Esto se ha conseguido gracias al pensamiento computacional, que abre las puertas a la comunicación con el entorno. Aquí está la base para la adquisición de conocimientos en todas las áreas académicas a la vez que se constituye en un instrumento mediante el cual se asegura la interacción humana. De ahí la importancia del desarrollo de un modelo educativo basado en una programación que siga una estructura lógica en la que se usen, además, un lenguaje de programación muy extendido y un programa informático libre, de código abierto, cuya presencia en los diferentes ambientes de aprendizaje aumenta rápidamente.

Cabe señalar que este es el pensamiento computacional: una competencia básica que permite abordar problemas para desenvolverse, en la sociedad actual digital, de manera inteligente y con imaginación, al combinar la abstracción y el pragmatismo, puesto que se basa en un mundo de ideas desarrolladas para un mundo real.

Hoy, los niños necesitan aprender y practicar nuevas habilidades, para tomar ventaja en la transformación revolucionaria, producida por los rápidos cambios tecnológicos que actualmente ocurren, y, de esta manera, en el futuro, hacer sus propias contribuciones con el fin de enfrentar los grandes retos del siglo XXI.

A partir de lo anterior, surgió la necesidad de escribir este artículo, en el que se combinaron dos disciplinas del conocimiento (la filosofía y la tecnología) para armonizar ideas y construir un texto en el que se muestre 
la importancia de la lógica de la educación en nuestro contexto académico, dentro de la sociedad y cómo esta ha impactado en la calidad de vida a fin de encontrar soluciones más efectivas y eficientes. La lógica de la educación también mejora la calidad del pensamiento, al ampliar su raciocinio para deducir expresiones que identifican dificultades vitales para el crecimiento integral y el desarrollo. Por otra parte, el pensamiento, con la ayuda de la computadora, ha llegado a cuestionar de forma constructiva el punto de vista crítico de las personas para resolver las situaciones con argumentos.

En cuanto al desarrollo del presente artículo, este se ha dividido en dos grandes temáticas. La primera está centrada en la educación como proceso lógico que permite construir progreso y la segunda se relaciona con entender el pensamiento como una toma de decisiones de la naturaleza y el crecimiento humano. En el tratamiento y el desarrollo de ambas temáticas se ha tenido el apoyo de fuentes bibliográficas y académicas.

La primera se enfoca brevemente en el proceso de construcción de pensamiento que permita alcanzar calidad de vida, promovido por la lógica de la educación; es decir, el desarrollo del pensamiento coherente en los hombres, que ha propiciado el saber y que rompe con el mal uso del aprendizaje, que destruye a las personas y a la humanidad.

La segunda es un análisis conciso sobre la transformación del mundo mediante el fomento de la práctica de la enseñanza en relación con el poder computacional y el pensamiento crítico.

En correspondencia con el desarrollo de este breve escrito, esencialmente se partió del planteamiento de una pregunta central: ¿será que el pensamiento computacional servirá como un instrumento para la lógica de la educación? A partir de aquí se enunciaron dos preguntas para cada uno de los temas tratados. Con respecto a la lógica de la educación, surgió esta inquietud: ¿la educación se ha convertido en un proceso lógico para el desarrollo del buen uso del conocimiento? Y con base en el pensamiento computacional salió a flote el siguiente interrogante: ¿el pensamiento computacional servirá como una justificación para el proceso lógico de la educación?

Finalmente, como autores del presente escrito, somos conscientes de que este es un tema bastante amplio y se requiere un estudio adicional para abordar aspectos estratégicos de la educación, que esté apoyada por los avances recientes en las técnicas de modelaje informático, con el propósito de mejorar y desarrollar las capacidades cognitivas, sociales y metacognitivas; sin embargo, el escrito se limita, básicamente, a conceptualizar, por un lado, la comprensión de la lógica de la educación, para beneficio de los seres humanos y los grupos sociales de una socie- 
dad cambiante y transformadora, $y$, por otro, abordar la naturaleza de la combinación entre la computadora y su punto epistémico como proceso de desarrollo de cada ser humano.

\section{La educación como proceso lógico que permite construir progreso}

Los hombres progresan en el tiempo, así como también se produce el desarrollo de las culturas y las civilizaciones. Esto se logra gracias a los aportes del avance científico y tecnológico y de la educación. De esta manera, la educación se ha convertido en un motor que facilita el progreso de las sociedades y de los hombres; estos lo utilizan para mejorar su calidad de vida y lograr prosperidad. Ello ha impulsado y permitido el crecimiento de la ciencia y la tecnología en beneficio de la sociedad y de los seres humanos; por lo tanto, se puede decir que la "educación es una actividad dirigida intencionalmente a promover el desarrollo de la persona humana y su integración en la vida social" (Laeng, 1982, p. 59), la cual se convierte en parte vital para los hombres que están en un proceso de cambio permanente.

Es necesario destacar que es la construcción del pensamiento, o sea la elaboración de las ideas, la que se aplicará en la cotidianidad del hombre en la sociedad, la política y la economía. Ese pensamiento ha de emplearse de una manera concreta donde el hombre debe razonar y reflexionar con una actitud crítica.

Se precisa reconocer que el conocimiento se construye a partir de los elementos que nos da la lógica. Esta es el producto fundamental de una educación que permite difundir los elementos propios del conocimiento y que le ha facilitado hacer ciencia, explorar mundos que eran imaginarios y ficticios y que hoy están al alcance del individuo y las sociedades. Todo eso ha sido posible desde la lógica de la educación, la cual, con el respaldo del conocimiento, la ciencia, la técnica y la tecnología, ha logrado salvar vidas e intentar la solución de algunos de los graves problemas que afrontan el individuo y las comunidades.

Ahora bien, algunas personas y pueblos han usado las herramientas que les ofrecen la ciencia, la tecnología y la educación para cometer atrocidades, desatar guerras con armas sofisticadas, ejecutar genocidios, generar pobreza y someter a sus semejantes a condiciones infrahumanas. Con este proceder han pervertido la lógica, que debe caracterizar a la educación en todo sistema sociopolítico, tal como lo propusieron los griegos: 
La idea griega general de la educación como formación del hombre y reflejada luego en variantes como la de ejemplo o modelo ( $\pi \alpha \rho \alpha \delta \varepsilon \iota \gamma \mu \alpha)$, poner el sello ( $\beta \alpha \lambda \varepsilon \iota \tau \eta \sigma \phi \rho \alpha \gamma i \delta \alpha)$ e imitar ( $\mu \mu \eta \eta \theta o v v)$. Lo único que se discute es cómo esta formación puede convertirse de una bella imagen en una realidad práctica; es, por tanto, el método de esta formación y, por consiguiente, el último resultado, la visión que se tenga de la naturaleza del espíritu humano (Jaeger, 1992, p. 82).

A partir del desarrollo de esta idea griega, lo que permite es que las culturas puedan crecer, al proyectar el futuro en el que los beneficiados serán el hombre y, por ende, los grupos sociales, según los intereses y propósitos que tengan los gobernantes y los encargados de dirigir y organizar la educación; esto para que los gobernados cumplan con las políticas que cada Estado va estableciendo, a fin de que sus ciudadanos se eduquen, te166 niendo presente que la "educación es una experiencia que entraña creación de una novedad cuyo principal reto es pensar y crear un mundo no totalitario" (Bárcena y Mèlich, 2000, p. 60). En efecto, un mundo donde la educación sea un factor inclusivo que facilite el fortalecimiento de la democracia, la libertad del hombre y su capacidad de decidir sobre cuestiones que tienen que ver con lo individual, lo social, lo cultural, lo económico, lo político o lo religioso. Un mundo donde la educación de cada ser humano sea promovida por el Estado y sus gobernantes, quienes son los responsables de que el pueblo aprenda y no permanezca en la ignorancia; donde las políticas que se definan correspondan a la época en que se desarrollen o se proyecten, al entenderse que el andamiaje de la educación está construido sobre un sistema lógico que estimula el desarrollo del pensamiento.

Lo mucho que representa la educación para los hombres y las personas está contenido en la lógica de la educación. Esta, a menudo, se ha definido como "la ciencia de las leyes del pensamiento" (Copi, 2014, p. 4). Se dice que la lógica es la ciencia que le permite al hombre desarrollar pensamiento, razonamiento y orden para llegar a la verdad e incrementar el conocimiento en un mundo laboral que sea vida y felicidad.

Por lo tanto, la lógica de la educación se entiende como una propuesta académica, que es concebida por los hombres y los Estados. Esta da sentido al desarrollo y progreso de la humanidad, la sociedad y el mismo Estado, con el fin de coadyuvar, en muchos casos, para salir de la ignorancia y la pobreza. Es así como la educación liberal pretendía en su desarrollo lógico ideas como la que se enuncia a continuación:

a) se entiende que la educación no debe estar dirigida hacia la transmisión de unos saberes meramente prácticos, sino que, al contrario, b) la 
educación debe pretender conseguir que los hombres aprendan a pensar (Ibáñez, 1984, p. 17).

En efecto, la lógica de la educación, en su proceder, aplicación y desarrollo, está para que los hombres piensen y construyan el conocimiento. Este conocimiento debe aplicarse a la calidad de vida de los grupos sociales.

La educación es el andamiaje esencial para que, en esencia, las sociedades y los hombres excluidos, pero en general todos los individuos, tengan la posibilidad de sustentar su ser de personas libres y autónomas. Esto se logra cuando la lógica de la educación admita el diseño de propuestas que sean pertinentes y que los educandos se apropien de ellas. La lógica de la educación hace que las personas lleguen a ser pensantes, razonables, críticas y reflexivas, y permite el empoderamiento del aprender y el conocimiento que le brinda esa misma lógica. Para ello se requieren:

La disciplina y la libertad, (que) no constituyen conceptos opuestos, por el contrario, se complementan. Un hombre libre es aquel que desarrolla todas sus facultades en relación con la realidad exterior y que conscientemente puede obedecerse a sí mismo y continuando como lo dijo la pedagoga italiana María Montessori, la lógica de la educación es, que los sujetos al elegir espontáneamente su trabajo y repetir el ejercicio elegido, un impulso vital se convierte en acto deseado (Yaglis, 2004, p. 55).

Hombres y mujeres se han dedicado a la educación con propuestas teóricas, siempre con la intención de buscar el mejoramiento de la acción pedagógica y, con sus investigaciones, han contribuido para que la lógica de la educación sea una realidad y se cumpla en la práctica educativa. Con referencia a la formación de los hombres en la escuela, en todos los niveles de escolaridad que puede cursar una persona, para el pedagogo alemán Federico Fröbel -cita de la filósofa mexicana Hortensia Cuéllar (2003, p. 33)- la lógica de la educación está en la formación del hombre: es una pedagogía y una filosofía; es decir:

Para no descuidar ninguno de estos aspectos necesarios para ofrecer al hombre una educación integral, entendiendo esta última en su sentido total, sin descuidar ninguna de las facetas de la personalidad del hombre. Querer suprimir alguna de ellas desorienta al hombre, no le educa y le impide el encuentro con su verdadera vocación.

Por otro lado, según el filósofo alemán Johann Friedrich Herbart, según refiere el pedagogo francés Gabriel Compayré (2005, p. 55), la lógica educativa se sustenta en la moral que debe desarrollar el hombre para, 
desde allí, construir una sociedad con valores éticos y morales. Afirma lo siguiente: "El valor de un hombre no se mide por su saber sino por su querer"; es decir, la cultura moral que forma la voluntad es más importante todavía que la cultura intelectual como fuente del saber. Por otro lado, considera: "La instrucción solo es válida si es para fines morales. La idea de la moralidad es dominar toda enseñanza, la virtud es el fin supremo de la educación".

Así, en su proceder, la lógica de la educación está encaminada a que la educación y la cultura, cuando se acude a las instituciones educativas, deben ser libres y desarrollarse con independencia, sin miedo ni prejuicios ni creencias. En su rutina diaria, la educación debe trabajar en la persona humana; o sea, constituir personas iguales con derechos y deberes. De acuerdo con lo anterior se podrá:

Llegar a vivir dentro de una sociedad justa, donde la alegría y la libertad sea la condición de la vida de todo el pueblo. Así, niños y jóvenes, hombres y mujeres aprenderían a hablar, a pensar y actuar con sinceridad, rigurosidad, reciprocidad, equilibrio, persistencia, frugalidad, probidad, utopía y absoluta sencillez con el fin de que todas las personas gobernantes y gobernados, maestros y estudiantes, padres e hijos, médicos y pacientes, escritores y lectores sientan el deseo de cultivarse permanentemente y lleguen a ascender dentro de la escala humana de la vida (García, 2015, p. 46).

Lo que hace avanzar la lógica de la educación es la certeza de que el centro de este proceso es el hombre. Hombre que debe educarse en el conocimiento y que también debe desplegar pensamientos para aprender y ser participativo; eso sí, con valores que le permitirán actuar libremente, con responsabilidad como ciudadano de una nación y del mundo cuidando la casa común: la tierra. Esta es su responsabilidad frente a la gente irresponsable, que busca el beneficio personal y que ha ocasionado el deterioro del planeta sin ninguna consideración por la humanidad.

Así que la lógica de la educación se centra en el trabajo por el planeta y debe propiciar la concientización de las personas, especialmente desde la escuela, en el aula de clase. Allí se construye el conocimiento, ya que:

Si es posible hacer conocimiento, este elemento es crucial para países como el nuestro que culturalmente ha negado la posibilidad de crear, de construir y de inventar. Es necesario redimensionar el conocimiento y en ello ver como nuestra creatividad, intuición y pensamiento divergente son útiles a la hora de resolver problemas con otros (Segura, 1999, p. 85). 
Tales problemas deben abordarse desde la lógica de la educación para transformar esto y que ella también transforme la realidad de los hombres que están en condiciones de exclusión.

En cuanto a los términos de la "lógica de la educación como una realidad concreta", los planteamientos pedagógicos educativos hechos por el pedagogo brasileño Paulo Freire en sus diversos escritos se enmarcan en este contexto y con ellos busca una propuesta para que las personas excluidas y oprimidas por el sistema político y social sean la razón de la existencia: "No podemos olvidar que la liberación de los oprimidos es la liberación del hombre y no de cosas" (Freire, 1978, p. 57). La lógica de la educación responde a los procedimientos educativos que requiere la sociedad, de la que se hacen múltiples propuestas destinadas a la mejora de la calidad de la educación; pero, en una sociedad globalizada, que es manejada por los intereses económicos de los grandes capitales, la educación no es la protagonista principal.

La crisis del estado benefactor es un fenómeno mundial asociado con la globalización: en efecto, la presión de la competencia internacional, obliga en todas partes a reducir el peso muerto de los impuestos y la ineficiencia del gasto social (Gómez, 1998, p. 138).

La lógica de la educación plantea un dilema que representa cambios significativos cuando los Estados dejan el manejo de la formación de sus ciudadanos, de sus niños y jóvenes a los particulares. Allí, su función se limita a aportar los recursos económicos según la lógica educativa de la globalización del mercado educativo, en la que, como afirma el investigador francés Christian Laval:

La transformación mercantil del servicio educativo público no solo se explica por la moda ideológica, sino que se inscribe en el proceso en curso de liberalización de los intercambios y en el desarrollo de las nuevas tecnologías de información y comunicación a escala mundial. La gran tendencia del periodo es la competición más directa de los sistemas educativos de los dogmas libre-cambistas y estimula la utopía de una vasta red educativa mundial transfronteriza y posnacional (Laval, 2004, p. 187).

Para algunas escuelas se ha convertido en un gran negocio, donde no se tienen en cuenta las propuestas educativas de la lógica. Los gobiernos de los países de América Latina ya han implementado una serie de cambios y reformas en su afán de ser consistentes con las políticas que impulsan los organismos multilaterales, como el Banco Mundial, el Fondo Monetario Internacional y la OCDE (Organización para la Coopera- 
ción y el Desarrollo Económicos) o PISA (Programme for International Student Assessment/Programa Internacional para la Evaluación de Estudiantes). Supuestamente, estas reformas educativas mejorarían su calidad y pertinencia. Así se plantea la educación media por ciclos, con el trabajo por competencias, y con otras propuestas que no permitirán el desarrollo lógico de la educación. La idea principal está en que la educación se presenta como propuesta para superar la pobreza económica y social, pero los escolares que están llegando a las aulas no tienen un verdadero interés en aprender; la mediocridad y el facilismo, así como la superficialidad del conocimiento y de las relaciones sociales, han generado esta circunstancia. Es una superficialidad que se basa en los aparatos tecnológicos de comunicación social, correos electrónicos e internet, que son utilizados por los escolares para amenazar a las personas, cometer delitos informáticos, copiar tareas y provocar otras situaciones que van destruyendo a la persona y la sociedad.

Por consiguiente, frente a tal situación, tanto las instituciones como los docentes, conjuntamente, deben oponerse al mal uso de los sistemas, que hacen los estudiantes, y, más bien, estimular el pensamiento computacional como un proyecto de crecimiento lógico de la realidad actual de la educación, el cual se explicará a continuación. Para comprender el pensamiento computacional, es necesario comenzar por entender qué son el pensamiento y su dialéctica, los elementos que lo componen.

\section{El pensamiento}

Nuestra vida depende de la manera como pensamos, ya que el pensamiento es la habilidad que nos permite tomar decisiones y resolver problemas. El pensamiento forma parte de la naturaleza humana; sin embargo, este suele ser totalitario, distorsionado, parcial, desinformado o sesgado. Como resultado, el pensamiento humano de buena calidad propicia una excelente calidad de vida.

Para lograr una mejor calidad de vida, debe ejercitarse el pensamiento humano. Precisamente, la computadora ejerce sistemáticamente las habilidades de pensamiento crítico y procede para la solución de problemas con base en los conceptos de la informática. La fórmula que nos permite recordar e identificar los componentes del pensamiento computacional es la siguiente:

Pensamiento computacional $=$ pensamiento $c$ rítico + poder de la computación 
Se entiende por "poder de la computación" los conceptos de la computación que hacen posible comprender qué aspectos de un problema son susceptibles de resolverse (Zapotecatl, 2014, p. 8). Aquel se extiende desde el nivel microscópico (comunicación entre neuronas), pasa por un nivel macroscópico (conjunto de sistemas que integran redes y ciclos neuronales, los cuales se activan en paralelo y se sincronizan en el tiempo) y llega hasta el uso de las herramientas culturales, no solo para ampliar y especializarse en las redes del cerebro, sino también para poder alcanzar, así, la comprensión consciente de nuestra propia subjetividad (García, 2007, p. 15).

El investigador estadounidense Raymond Kurzweil, en su libro $\mathrm{La}$ singularidad está cerca, dice que el poder de la computación ha evolucionado hasta tal punto que ha sido como la trama primordial de nuestro mundo, pues cada fase ha utilizado métodos de procesamiento de información pertenecientes a la fase anterior para crear la siguiente. Cabe señalar que la evolución del poder computacional se ha mostrado en seis etapas y ha impactado tanto en lo biológico como en lo tecnológico. En estas seis etapas se ha venido trabajando la evolución del poder computacional hasta llegar a ser humanas, y más que humanas. El paso de una etapa a otra representa, en su rendimiento evolutivo, la velocidad, el resultado, la rentabilidad y, en general, la potencia de un proceso que se incrementará con el paso del tiempo al menos de forma exponencial.

Cada una de estas etapas de desarrollo proporciona herramientas más potentes para la siguiente. Por ejemplo, en la evolución biológica, la aparición del ADN permitió experimentos evolutivamente más rápidos y más capaces. $\mathrm{O}$, por presentar otro ejemplo más reciente, la aparición de herramientas de diseño asistido por computadora ha ocasionado un rápido desarrollo de la próxima generación de ordenadores (Kurzweil, 2012, pp. 15-23, 45, 46, 51).

El investigador sudafricano Henry Markram, en su proyecto Blue Brain, planea simular el cerebro humano, incluida la columna neocortical, que es considerada por algunos investigadores la más pequeña unidad funcional del neocórtex, la parte del cerebro que, se cree, es responsable de funciones superiores como el pensamiento consciente (Kurzweil, 2012, pp. 124, 125).

Otra fuente necesaria para un crecimiento exponencial continuo en el orden es el caos, en el entorno donde el proceso evolutivo tiene lugar y ofrece opciones para una mayor diversidad. Es importante decir que el caos proporciona la variabilidad que facilita un proceso evolutivo para encontrar soluciones más efectivas y eficientes (Kurzweil, 2012, p. 51). 
En relación con el "pensamiento crítico", este se concibe como el modo de pensar sobre cualquier tema, contenido o problema. En este, el pensante mejora la calidad de su pensamiento al apoderarse de las estructuras inherentes del acto de pensar y al someterlas a estándares intelectuales sensibles a la globalización, incluidas características de curiosidad, preocupación, oportunidad y confianza. Esto permite un criterio de razón, honestidad intelectual y amplitud mental abierta y flexible (Facione, 2007, p. 20; Rodríguez, 2011, pp. 30, 32; Zapotecatl, 2014, p. 8).

Hay que destacar que, por ser el pensamiento crítico una capacidad tan compleja, los investigadores, como el estadounidense Peter Facione, encontraron que la habilidad de pensar críticamente supone destrezas relacionadas con diferentes capacidades como deducir, con claridad y precisión, expresiones que identifican dificultades y preguntas vitales; almacenar y evaluar información relevante y utilizar ideas abstractas para interpretar esa información; además, sacar conclusiones y plantear soluciones, que se prueban con criterios y esquemas distinguidos con calidad (Facione, 2007, p. 15; López, 2012, p. 43; Paul and Elder, 2003, p. 4). Con respecto a este tema, señala el educador británico John Barell que la destreza del pensamiento crítico está sujetada a las emociones, el autoconcepto, la actitud abierta a las ideas y los sentimientos sobre el aprendizaje (Rodríguez, 2011, p. 33).

Entre los teóricos más influyentes que se han propuesto definir el pensamiento crítico se encuentra el filósofo y educador estadounidense Robert Ennis. Para Ennis, el pensamiento crítico se concibe como el pensamiento racional y reflexivo, interesado en deducir qué hacer o creer; es decir, constituye un proceso cognitivo complejo de pensamiento que reconoce el predominio de la razón sobre las otras dimensiones del pensamiento. Su finalidad es reconocer aquello que es justo y lo que es verdadero; o sea, el pensamiento de un ser humano racional (López, 2012, p. 43).

Otro teórico, entre los influyentes, es el filósofo estadounidense Matthew Lipman. Su idea apunta a la práctica de entrenar a los estudiantes en el análisis de textos novelados y cuidadosamente diseñados para presentarles una serie de conflictos de juicio acordes con su nivel madurativo. Esto tiene como finalidad que los estudiantes se involucren en discusiones críticas mutuas y emitan opiniones escrupulosamente formuladas (Castellano, 2007, p. 180), para generar, de esta manera, una postura que proporcione juicios fundados, confianza en el criterio, autocorrección y susceptibilidad al contexto.

Así pues, el pensamiento crítico es una actividad reflexiva porque analiza lo que está bien fundado, tanto de los resultados de su propia 
reflexión como los de la abstracción ajena. Hace hincapié en el hecho de que se trata de un pensamiento totalmente orientado a la acción. Siempre hace su aparición en un contexto de resolución de problemas y en la interacción con otras personas, pero más en función de comprender la naturaleza de los problemas que en proponer soluciones. En cuanto a la evaluación de la información y los conocimientos previos, se fundamenta en la toma de decisiones en distintos ámbitos del quehacer humano y tiene en cuenta que nuestras conductas y acciones se basan en lo que creemos y en lo que decidimos hacer. Igualmente, debemos recordar que Ennis ha destacado que el pensamiento crítico está compuesto de habilidades (vertiente cognitiva) y disposiciones (vertiente afectiva) (López, 2012, pp. 43, 44).

Otro punto tiene que ver con el "pensamiento computacional", donde se deduce cómo la abstracción y la descomposición de problemas pueden aplicarse a cualquier área del conocimiento. Cuando una persona utiliza el pensamiento computacional piensa críticamente sobre el aprendizaje: tiene un propósito claro; cuestiona de manera constructiva la información, las conclusiones y los puntos de vista; se empeña en ser clara, exacta, precisa y relevante y busca profundizar con lógica e imparcialidad.

Mediante el pensamiento computacional, puede utilizarse la computadora de diversas maneras como un nuevo instrumento científico (así como en un momento de la historia lo fueron el telescopio o el microscopio) para beneficiar a los estudiantes, las instituciones en todos los niveles de educación y, finalmente, el desarrollo humano, científico y tecnológico global, que lleva a tomar decisiones (Zapotecatl, 2014, pp. 8, 10).

Circunstancialmente, el pensamiento computacional tiene como finalidad desarrollar en los estudiantes el pensamiento crítico en coalición con los conceptos clave del poder de la computación, tales como abstracción, algoritmos, lenguajes de programación, simulación, modelos de estructura de datos e inteligencia artificial, entre otros (Thagard, 2008, pp. 30, 32; Zapotecatl, 2014, p. 11). También crea un nuevo paradigma de enseñanza-aprendizaje cuantitativo, intuitivo y de ensayo y error (Álvarez, 2013).

Se puede decir que el pensamiento computacional es un enfoque que tiene por objeto resolver problemas que hacen hincapié en la integración del pensamiento crítico y el poder de la computación. Con la computadora se mejoran las formas de estructuración de un problema con los conceptos subyacentes de la computación y reorienta la creatividad humana. Esto permite considerar las posibilidades para resolver problemas con la ayuda del procesamiento de información de las computadoras (Zapotecatl, 2014, p. 9). 
Cabe destacar que el pensamiento computacional incluye lo siguiente: formular problemas de tal manera que sea posible utilizar computadoras y otras herramientas para solucionarlos, tales como diseño de sistemas y comprender el comportamiento humano, mediante el uso de los fundamentos de la informática, como lo dice la investigadora en ciencias de la computación, la estadounidense Jeannette Wing (Moreno, 2014), en su libro Computational thinking (Wing, 2014); organizar datos de manera lógica y analizarlos; representar datos con el recurso de las abstracciones, como modelos y simulaciones; automatizar soluciones mediante el pensamiento algorítmico; identificar, analizar e implementar posibles soluciones para encontrar la combinación más eficiente y efectiva de pasos y recursos y generalizar y transferir el proceso de solución de problemas a una gran diversidad de estos.

Brevemente, se puede precisar que el pensamiento computacional se utiliza como complemento de las asignaturas y los estudiantes empiezan a darse cuenta de la gran utilidad del pensamiento crítico y el poder de la computación (Zapotecatl, 2014, pp. 12, 13, 15).

\section{Consideraciones}

Una vez abordado, por los autores, el tema "una aproximación desde la lógica de la educación al pensamiento computacional”, consideramos, desde nuestro punto de vista, las siguientes deferencias:

1. El pensamiento computacional sirve como instrumento para la lógica de la educación, ya que vivimos en un ecosistema digital completo, de objetos programables, controlados por software educativo que está destinado para la enseñanza y el aprendizaje eficaz.

2. Ha sido acuñado el concepto del pensamiento computacional para referirse al proceso de enseñanza y aprendizaje de la alfabetización con lenguajes de programación de computadoras.

3. Hoy en día, una persona se considera codigoalfabetizada cuando es capaz de leer y escribir en el lenguaje de las computadoras y de otras máquinas y pensar computacionalmente.

4. El pensamiento computacional es una variante del dominio metodológico, que se conoce como resolución de problemas, y su resolución se puede implementar con computadoras. En este caso, es importante destacar que los estudiantes son cons- 
tructores en los autores de objetos de herramientas de conocimiento y conceptos que son dominios del saber.

5. Creemos que la educación se ha convertido en un proceso lógico dentro de la revolución tecnológica por cuanto redunda en tomas de decisiones coherentes para resolver problemas y dificultades que se plantean en ella.

6. Todo progreso en la educación se ha logrado con avances en las tecnologías, como impulso del conocimiento infalible, y ha conseguido explorar nuevas alternativas para la construcción de una sociedad con más valores éticos y morales.

7. Se enfatiza en la formación de los docentes para generar espacios de articulación adecuados a la construcción y formación del conocimiento.

8. Apoya el estudio de los problemas, hechos y fenómenos educativos basados en la cotidianidad contextual de situaciones educacionales.

\section{Bibliografía}

ÁLVAREZ, José Enrique

2013 Pensamiento computacional y multimedia: un cambio en el paradigma educativo [web log post]. Recuperado de http://es.slideshare.net/LeonardoDaVinciMX/pensamiento-computacional-y-multimedia-un-cambio-en-elparadigma-educativo.

BÁRCENA, Fernando \& MÈLICH, Joan-Carles

2000 La educación como acontecimiento ético. Barcelona, España: Paidós.

CASTELLANO, Hugo

2007 El pensamiento crítico en la escuela. Recuperado de https://books.google. com.co/books?id=6DqO6IvJgtYC\&pg=PA180\&dq=matthew+lipman\&hl= es\&sa $=$ X\&ved=0ahUKEwjp1 ufZu4TNAhXKXh4KHXueAnA4KBC7BQg3

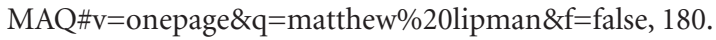

COMPAYRÉ, Gabriel

2005 Herbart: La educación a través de la instrucción. México, D. F., México: Trillos.

COPI, Irving

2014 Introducción a la lógica. Buenos Aires, Argentina: Euduba.

CUÉLLAR, Hortensia

2013 Fröbel: La educación del hombre. México, D. F., México: Trillos.

FACIONE, Peter

2007 Pensamiento crítico ¿qué es y por qué es importante? Recuperado de https://

FREIRE, Paulo comenio.files.wordpress.com/2007/09/pensamiento_critico.pdf.

1978 Pedagogía del oprimido. Bogotá, Colombia: América Latina. 
GARCÍA, Emilio

2007 Teoría de la mente y ciencias cognitivas. Nuevas perspectivas científicas y filosóficas sobre el ser humano. Recuperado de http://eprints.ucm.es/8607/1/AS INJA.\%2520Teoria\%2520de\%2520la\%2520mente.pdf, 15.

GARCÍA, Jairo

2015 Las Analectas: Una cultura milenaria. Educación y Pedagogía (20). Ibagué, Colombia.

GÓMEZ, Hernando

1998 Educación: la agenda del siglo XXI. Bogotá, Colombia: Tercer Mundo.

KURZWEIL, Raymond

2012 La singularidad está cerca. Berlín, Alemania: Lolabooks.

IBÁÑEZ, José

1984 Hacia una formación humanística. Barcelona, España: Herder.

JAEGER, Werner

1992 Paideia. México, D. F., México: Fondo de Cultura Económica.

LAENG, Mauro

1982 Vocabulario pedagógico. Barcelona, España: Herder.

LAVAL, Christian

2004 La escuela no es una empresa. Barcelona, España: Paidós.

LÓPEZ, Gabriela

2012 Pensamiento crítico en el aula. Docencia e investigación. Recuperado de http://educacion.to.uclm.es/pdf/revistaDI/3_22_2012.pdf, 43, 44.

MORENO, Jesús

2014 ¿Qué es el pensamiento computacional? [web log post]. Recuperado de http:// programamos.es/que-es-el-pensamiento-computacional/.

PAUL, Richard \& ELDER, Linda

2003 La miniguía para el pensamiento crítico. Conceptos y herramientas. Recuperado del sitio de internet de la Fundación para el Pensamiento Crítico: https:// www.criticalthinking.org/resources/PDF/SP-ConceptsandTools.pdf, 4.

RODRÍGUEZ, María del Pilar

2011 Pensamiento crítico y aprendizaje. México, D. F., México: Limusa.

SEGURA, Dino

1999 La construcción de la confianza. Bogotá, Colombia: IDEP.

THAGARD, Paul

2008 La mente: introducción a las ciencias cognitivas. Buenos Aires, Argentina: Katz. WING, Jeannette

2016 Wikipedia, la encyclopedia libre [versión electrónica]. Recuperado de https:// en.wikipedia.org/wiki/Jeannette_Wing.

YAGLIS, Dimitrios

2004 Montessori: La educación natural y el medio. México, D. F., México: Trillos.

ZAPOTECATL, Jorge Luis

2014 Pensamiento computacional [web log post]. Recuperado de http://www.pensa mientocomputacional.org/Files/pensamientocomputacional.pdf, 8, 9-13, 15.

Fecha de recepción del documento: 5 de julio de 2016

Fecha de aprobación del documento: 15 de agosto de 2016 
Praxis del pensamiento lógico

abstracto en la educación

Praxis of the logical abstract

thought in the education 



\title{
RAZONAMIENTO LÓGICO ABSTRACTO E INTELIGENCIA EMOCIONAL:
}

TRAYECTORIAS EN LA FORMACIÓN DE ESTUDIANTES

UNIVERSITARIOS

\section{Abstract logical reasoning and emotional intelligence: trajectories in the training of university students}

\author{
Patricia Bravo Mancero* \\ Universidad Nacional de Chimborazo/Riobamba - Ecuador \\ patybravom@hotmail.com \\ AngÉLICA MARÍa URQUIZO ALCIVAR ${ }^{* *}$ \\ Universidad Nacional de Chimborazo/Riobamba - Ecuador \\ aurquizo@unach.edu.ec
}

Quien no comprende una mirada tampoco comprenderá una larga explicación.

(Proverbio árabe)

Forma sugerida de citar: Bravo Mancero, Patricia, \& Urquizo Alcivar, Angélica María (2016). Razonamiento lógico abstracto e inteligencia emocional: trayectorias en la formación de estudiantes universitarios. Sophia, colección de Filosofía de la Educación, 21(2), pp. 179-208.

* Psicóloga Educativa; Diplomada en Proyectos; Magíster en Docencia Universitaria; Aspirante a Doctorado en Educación; Experiencia profesional en Educación Básica, Especial y Superior; Docente de niños y niñas con necesidades educativas especiales; Capacitadora de cursos; Ponente en Congresos a nivel nacional e internacional; Publicaciones en revistas indexadas; Autora de proyectos de investigación y Vinculación con la Colectividad; Facilitadora Académica Externa del CES.

** Magíster en Docencia Universitaria e Investigación educativa; Magíster en Informática Aplicada; Doctora en Matemática; profesora universitaria. 


\begin{abstract}
Resumen
En este artículo se establece la relación que existe en el desarrollo del razonamiento lógicoabstracto y la inteligencia emocional en estudiantes de la Facultad de Ciencias de la Educación, Humanas y Tecnologías de la Universidad Nacional de Chimborazo. La pregunta que orienta el estudio es: ¿Existe relación entre los niveles de desarrollo del razonamiento lógico-abstracto y la inteligencia emocional? El estudio fue de carácter cuantitativo, descriptivo, correlacional, explicativo, no experimental y transversal. Participaron cuarenta y seis alumnos de tres carreras: Ciencias Exactas, Ciencias Sociales y Cultura Estética. Para la exploración se utilizaron dos instrumentos: la prueba de razonamiento lógico- abstracto, constituida de cuatro subáreas: series gráficas, operaciones aritméticas con símbolos abstractos, analogías gráficas y razonamiento lógico-analítico; y la TMMS-24, una escala auto informada de los niveles de inteligencia emocional, constituida por tres factores: percepción, comprensión y regulación. La hipótesis planteada sostiene que existe relación entre los niveles de desarrollo de la inteligencia lógica abstracta y la inteligencia emocional. Los resultados evidencian que el 52\% de los estudiantes se encuentran en un nivel regular de razonamiento lógico-abstracto, frente al 48\% que tiene un nivel bueno; en los factores de la Inteligencia Emocional, el 57\% alcanzan niveles adecuados de percepción, el 70\% buena comprensión y el $64 \%$ con adecuada regulación de sus emociones. En el análisis de los datos por género se advierten diferencias en los resultados, no así en los obtenidos por carrera. Para comprobar la hipótesis se realizó la prueba de correlación utilizando el SPSS. Como conclusión general se establece que existe relación entre los niveles de desarrollo de las dos habilidades, pero no así entre el Razonamiento Lógico-Abstracto y los factores de la Inteligencia Emocional. Por lo tanto, la enseñanza universitaria debe valorar las trayectorias de las inteligencias y proponer rutas alternas para alcanzar los objetivos educativos.
\end{abstract}

Inteligencia, emoción, razonamiento lógico-abstracto, inteligencia emocional, capacidad.

\begin{abstract}
In this research the relationship between logical-abstract reasoning and emotional intelligence that have students from the National University of Chimborazo is established. The study was quantitative, descriptive, correlational, explanatory, non-experimental and transversal nature. Forty-six students participated in three races: Exact Sciences, Social Sciences and Culture Aesthetics. Reasoning test logic abstract, consisting of four sub areas: exploration for two instruments were used graphic series, arithmetic operations with abstract symbols, graphic analogies and logical analytical reasoning; and TMMS-24, a self-reported levels of emotional intelligence scale consists of three factors: perception, understanding and regulation. The hypothesis holds that a relationship exists between the abstract logic intelligence and emotional intelligence factors. The results show that $52 \%$ of students are in a regular level of logical-abstract reasoning, compared with $48 \%$ having a good level; the factors of Emotional Intelligence, 57\% reach adequate levels of perception, 70\% good and $64 \%$ understanding lies with proper regulation of their emotions. In the analysis of the data by gender differences are apparent in the results, but not in those obtained by race. To test the hypothesis correlation test we were performed using SPSS. As a general conclusion states that there is no relationship between logical-abstract reasoning and emotional intelligence. Finally, we must consider that a real training requires intellectual development and also the work of emotional competencies.
\end{abstract}

\title{
Keywords
}

Intelligence, emotional, logical-abstract reasoning, emotional intelligence, capacity. 


\section{Introducción}

En el sistema de educación superior del país, no se considera la relación que guardan las emociones con el desarrollo intelectual de los estudiantes, un ejemplo de esto, es que se continúa utilizando la prueba ENES, que comprende ítems de aptitud-verbal, de cálculo y de razonamiento abstracto, como único criterio para el ingreso a las universidades públicas. Según las autoridades gubernamentales, éstas predecirían el éxito académico de los estudiantes y ahorrarían presupuesto al estado ya que se evitarían situaciones de deserción. No obstante, estudios realizados en países que optaron por su aplicación, como Estados Unidos, Chile y Colombia, han comprobado su baja capacidad de anticipación, ya que los estudiantes que aprueban son aquellos que han sido entrenados en el desarrollo de las habilidades de pensamiento. Además, cabe mencionar que las aptitudes no surgen de la nada, se construyen por la interacción de varios factores, como las relaciones con el entorno, las oportunidades y las emociones (Martínez, 2010, p.11). A esta realidad se suma la del currículo universitario, que está diseñado para el fomento de las habilidades de pensamiento lógico, existiendo carencia de programas orientados a fortalecer las habilidades afectivas, emocionales y sociales de los estudiantes.

Además, tradicionalmente se pensaba que la inteligencia era algo innato que no cambiaba, hoy se sabe que los estudiantes poseen talentos, habilidades, experiencias, e intereses diversos que pueden variar gracias a la relación del organismo con su medio. De esta manera, la Inteligencia en general es concebida como la capacidad de solucionar problemas o adaptarse al entorno que les rodea; mientras que el razonamiento lógico hace referencia a las competencias para usar los números eficazmente, analizar problemas lógicamente e investigar soluciones científicamente, en tanto que el razonamiento abstracto involucra destrezas para formar e imaginar diseños así como la habilidad de comprender, manejar y cambiar las organizaciones del espacio amplio y limitado (Gardner, 1993, p. 38). Por su parte, el término inteligencia emocional -IE-, incluye las diversas formas en que las emociones pueden ser monitoreadas, a través de la capacidad para percibir, asimilar, comprender y regular las emociones propias y de los demás (Fernández Berrocal y Extremera Pacheco, 2005, p. 68).

Si bien, en el siglo XX, los estudios se centraron en la mente racional, en el XXI están orientados a desarrollar la mente emocional, ya que el fomento de las habilidades lógicas no garantiza por sí sola el éxito en la vida personal, profesional o laboral. De ahí que las investigaciones realizadas por Howard Gardner, la inteligencia es un concepto multivariado 
que incluye además de los componentes tradicionales (inteligencia lógica, lingüística y abstracta), cinco tipos más: inteligencia visual/espacial, musical/corporal, cenestésica/interpersonal/intrapersonal y naturalista.

Para explorar lo que sucede en el ámbito educativo universitario, se presenta este artículo titulado: "Razonamiento lógico abstracto e inteligencia emocional: trayectorias en la formación de estudiantes universitarios", cuyo objetivo es establecer la relación entre los niveles de RLA y de IE en estudiantes de tres carreras de la Universidad Nacional de Chimborazo: Ciencias Exactas, Ciencias Sociales y Cultura Estética, durante el período académico 2016-I. Asimismo, este análisis es necesario e impostergable para evidenciar la importancia que tiene trabajar en el desarrollo de habilidades racionales y emocionales, de ahí que los objetos de estudio son el RLA y la IE. La pregunta que orienta el estudio es: ¿Existe relación 182 entre los niveles de RLA y de IE?.

Se dice que el ámbito educativo es un contexto en constante cambio y transformación y que por lo tanto se requiere repensar la educación, las prácticas y la forma de ver a los actores que participan en ella. De ahí que los beneficiarios directos de los resultados de esta exploración serán los estudiantes de la Facultad de Ciencias de la Educación, Humanas y Tecnologías en general y de las carreras investigadas en particular.

De manera precisa se puede señalar que el artículo inicia realizando un recorrido histórico por el desarrollo del concepto de inteligencia y a continuación se abordan los principales postulados sobre razonamiento lógico-abstracto, teoría que expone la concepción general de los procesos que incluye, así como de sus implicaciones en el proceso de aprendizaje. A continuación se revisa la teoría de la Inteligencia Emocional, los factores que la componen, los enfoques que explican su desarrollo y la relación con otros procesos mentales que trabajados de forma conjunta lograrían un eficiente fomento de las competencias cognitivas y actitudinales en los estudiantes universitarios.

En el siguiente apartado se aborda la metodología utilizada para la ejecución de la investigación, la misma que corresponde a un estudio cuantitativo, de tipo descriptivo, correlacional, explicativo y transversal. La muestra estuvo compuesta 46 estudiantes de las carreras ya mencionadas y en el período de tiempo indicado. Para la recolección de la información se utilizaron técnicas psicométricas. Se aplicaron tres instrumentos, un cuestionario base, para indagar datos informativos, una prueba de RLA, en el que se incluyeron cuatro sub áreas: series gráficas, operaciones aritméticas con símbolos abstractos, analogías gráficas y razonamiento lógico-analítico, y, la escala auto informada de los niveles de Inteligencia 
Emocional -TMS-24- que exploró tres factores: percepción, comprensión y regulación de las emociones.

Por consiguiente, los resultados obtenidos demuestran que los estudiantes poseen niveles buenos tanto de RLA como de IE, sin embargo, no existe relación entre las dos habilidades, lo cual confirma que cada una contiene rasgos específicos que las diferencian pero que son interdependientes, es decir, que las emociones ayudarían a mejorar las habilidades de RLA y viceversa.

\section{De la razón a la emoción: línea de tiempo del concepto de inteligencia}

Dado que persiste el debate por la división entre mente racional y la mente emocional, a la vez, se mantiene también la duda sobre la validez teórica del constructo Inteligencia Emocional-IE-, al cual se lo relaciona con términos como: personalidad, autoestima o estados de ánimo (Matthews, Zeidner y Roberts, 2004, p. 183). Por consiguiente, antes de hablar de sus connotaciones, se debe primero comprender la evolución histórica del concepto de inteligencia.

Inteligencia es un término de la psicología, utilizado en el lenguaje cotidiano para explicar las capacidades de las personas para solucionar problemas o adaptarse al entorno que les rodea. El estudio de la relación entre inteligencia, aprendizaje y adaptación al entorno surge con la teoría evolucionista de Charles Darwin y a partir de la publicación de su obra titulada La evolución de las especies (1859), se inician una serie de trabajos cuyo principal interés es evaluar estos factores. Como consecuencia de esto, Francis Galton (1822-1911) primo de Darwin, junto con Cattell (1860-1944) impulsaron el estudio de las diferencias individuales e intentaron medir la inteligencia a través de respuestas sensoriales simples y tiempos de reacción.

Para inicios del siglo XX, Alfred Binet y Théodore Simon, psicólogos franceses, propusieron una manera de examinar la inteligencia de los niños que presentaban dificultades académicas y para ello construyeron el primer test de inteligencia (Gardner, 1993, p. 34). Por esta misma época, Charles Spearman, psicólogo educativo inglés, planteó la existencia del factor $g$, y mencionó que era factor general y predominante de la inteligencia humana. Él afirmaba que el factor $g$ se podía medir en todas los aspectos de una prueba de inteligencia y por lo tanto aseveró que ésta, era única e innata en cada persona y no cambiaba de manera significativa 
con la edad o la experiencia (Gardner, 1993, p. 36). Cabe destacar que esta concepción de inteligencia continúa vigente hasta la actualidad.

Más adelante, en 1912, Wilhelm Stern concibió una forma de representar la inteligencia de un individuo con un solo número: el Cociente Intelectual, o CI, que es una medida en la cual la edad mental se divide para la edad cronológica y el resultado es multiplicado por 100 (Gardner, 1993, p. 46). Al finalizar la década de los treinta, Louis Thurstone, psicólogo americano y con experiencia en psicométrica, explica una teoría de la inteligencia que era más difícil de entender que el factor g; él pensó "la existencia de siete tipos de inteligencia: espacial, numérica, fluidez verbal, comprensión verbal, velocidad perceptiva, razonamiento abstracto, y memoria asociativa" En sus conclusiones sobre el estudio de la inteligencia, niega la existencia de un concepto general y único de inteligencia (Guz184 mán \& Castro, 2005, p. 181).

Durante los años sesenta, Joy Paúl Guildford aportó un nuevo enfoque a la Psicología a través del cual analizó a la inteligencia desde varias dimensiones, en contraposición a las concepciones cerradas originadas en los aportes de Spearman que presentan sus principales deficiencias en la cosificación, limitación e inmutabilidad de la inteligencia (Gutiérrez, 1991, p. 125). Este modelo de inteligencia contenía ciento veinte componentes independientes y que constaba de pruebas específicas para evaluar cada uno de sus factores. A través de estas pruebas se formaba una idea general de la inteligencia (Smith, 2001, pp. 2, 3).

Más tarde, en la década de los ochenta, Robert Sternberg plantea que la inteligencia humana está contenida en aspectos, que los agrupó en tres subteorías: la contextual, la experiencial, y la componencial (Smith, 2001, pp. 32, 33). Por consiguiente, los estudios de Sternberg cambiaron la percepción que la inteligencia humana es algo singular e independiente (Smith, 2001, p. 33).

Cabe destacar que a principios de siglo, la idea que había dos o tres subgrupos de inteligencia, tuvo gran acogida. El primer subgrupo comprendía la inteligencia verbal-proposicional que incluía medidas de vocabulario, fluidez verbal y habilidades para percibir similitudes y pensar lógicamente. El segundo subgrupo la inteligencia espacial, que contenía destrezas para ensamblar objetos, reconocer y construir diseños y patrones. El tercer subgrupo, la inteligencia social, que se refería a las habilidades de las personas para relacionarse con los demás. Por consiguiente, a través del tiempo, se han presentado dificultades para desarrollar el concepto de inteligencia social ya que se la confundía con las dos primeras. A mitad de siglo, la escala de inteligencia de Weschler medía la inteligencia verbal y la espacial (Abarca, 2003, p. 76). 
Posteriormente, surge la teoría de las inteligencias múltiples del Doctor Howard Gardner que toma en cuenta dos tipos de inteligencia no reconocidas hasta el momento: inteligencia intrapersonal e interpersonal (Mayer y Salovey, 1997, p. 10). A diferencia de la mayor parte de las teorías antes expuestas, ésta presenta una perspectiva pluralista de la inteligencia ya que sostiene que todas las personas son diversas y manifiestan varias capacidades de pensar, por lo tanto diferentes maneras de aprender, de manera que el docente debería implementar en el ambiente educativo, estrategias variadas que respondan a las características de los estudiantes (Fonseca Mora, 2007, p. 2). Esta nueva concepción de inteligencia, reconoce la diversidad de características que poseen los estudiantes al momento de aprender, y plantea la necesidad de responder a esos requerimientos, con distintas propuestas metodológicas.

Ya en 1983 Gardner, plantea la existencia de siete tipos de inteligencia y posteriormente agregó una más que son: "la lingüística, la musical, la lógica-matemática, la espacial, la corporal-kinestésica, la intrapersonal, la interpersonal, y la naturalista" (Shannon, 2013, p. 13). Por ende, el autor considera que la inteligencia implica "talentos, habilidades y capacidades mentales de un individuo" (Shannon, 2013, p. 11). Dice también que estos talentos pueden estar presentes en todas las personas, pero que cada individuo por diferentes factores, desarrollará un talento más que otro. En consecuencia, analiza que todos se pueden optimizar a través del trabajo y el aprendizaje, dejando a un lado la idea que la inteligencia depende de sólo de factores genéticos.

$\mathrm{Al}$ respecto Fonseca Mora aduce que:

Este concepto de inteligencia o capacidades, reconoce la diversidad, la existencia de distintas formas de ser que son de igual estatus. Ser inteligente puede significar tener una gran capacidad memorística, tener un amplio conocimiento, pero también puede referirse a la capacidad de conseguir convencer a los demás, saber estar, expresar de forma adecuada sus ideas, ya sea con palabras o con cualquier otro medio de índole artístico, controlar su ira, o saber localizar lo que se quiere, es decir, significa saber solucionar distintos problemas e distintos ámbitos, Además, la formación integral de los alumnos ha de entenderse también como la formación de lo emocional y no solo como formación de lo cognitivo (Fonseca Mora, 2007, p. 13 citado en Shannon, 2003, p. 11).

Esto indica que los seres humanos, poseen un conjunto de capacidades para enfrentar y resolver distintos tipos de problemas, en función de los contextos en los que éstos se desarrollan. Por lo tanto, la inteligencia no es una capacidad única a la que se recurre para solucionar proble- 
mas, más bien son aptitudes con un nivel significativo de independencia entre sí.

En realidad, al inicio de su carrera profesional, Gardner concordaba con la teoría cognitiva de Jean Piaget y sus postulados de los cuatro estadios de desarrollo cognitivo. No obstante, cuando realizó sus propias investigaciones, sus opiniones acerca del aprendizaje dieron un giro. Él intentó proponer una teoría más profunda de la inteligencia que tomara en cuenta la variedad de papeles que desarrollan las personas en la sociedad. En las teorías que precedieron a la suya, Gardner había advertido una perspectiva similar frente a la solución de problemas lógico-matemáticos y lingüísticos, ignorando la creatividad humana (Lazear, 1991, p. 57).

\section{Consideraciones acerca de la inteligencia}

\section{lógica-abstracta}

Del análisis anterior se establece que uno de los aspectos más utilizados en cuanto a pruebas de inteligencia, es la inteligencia lógica-abstracta, pues "se corresponde con el modo de pensamiento del hemisferio lógico y por lo que en nuestra cultura se la ha considerado siempre como la única inteligencia" (Morchio, 2004, p. 4); a la cual también se le da mucha importancia en nuestro sistema educativo. A pesar de que la inteligencia lógica-abstracta se sitúa en el hemisferio izquierdo e incluye la habilidad de solucionar problemas, producir, leer, y comprender símbolos matemáticos, utiliza también el hemisferio derecho, porque supone la habilidad de comprender conceptos numéricos en una manera más general (Lazear, 1991, p. 19).

Puesto que esta inteligencia, requiere la capacidad de usar los números eficazmente, analizar problemas lógicamente e investigar problemas científicamente (Gardner, 1993, p. 36). A las personas que la poseen les gusta solucionar misterios, trabajar con números y cálculos complejos, contar, organizar información en tablas, arreglar ordenadores, resolver rompecabezas de ingenio y lógica, jugar videojuegos, tienen facilidad para adivinar, estimar, recordar estadísticas y números con facilidad (Armstrong, 2003, p. 45). Es la inteligencia característica de los matemáticos, los científicos, los ingenieros y los lógicos. También resuelven problemas extraordinariamente rápido, pues tienen la capacidad de manejar simultáneamente muchas variables (Gardner, 1993a, p. 45).

Por otra parte, la inteligencia espacial, implica aptitudes para formar e imaginar diseños de dos y tres dimensiones (Armstrong, 2000, p. 
17) y la habilidad de comprender, manipular y modificar las configuraciones del espacio amplio y limitado (Gardner, 1993, p. 23). Quienes la tienen más desarrollada, evocan fácilmente imágenes, fotos y objetos en lugar de palabras; se fijan más en las partes que en el todo (Armstrong, 2003, p. 46), les gusta dibujar, garabatear, pintando, jugar videojuegos, construir modelos, leer mapas, estudiar ilusiones ópticas y laberintos.

Es la inteligencia característica de los arquitectos, los pintores, los pilotos, los navegantes, los artistas gráficos, los jugadores de ajedrez, los cirujanos, los artistas y los escultores (Gardner, 1993a, p. 43). Gardner describe la amplitud y la evolución de esta inteligencia: "Las formas de amplio alcance en el que la inteligencia espacial se implementa en diferentes culturas muestran claramente cómo un potencial bio-psicológico puede ser aprovechada por los dominios que se han desarrollado para una variedad de propósitos (1993a, p. 43)".

Es por eso que las pruebas psicotécnicas de aptitud suelen tener un importante componente de ítems encaminados a medir estas habilidades.

Al respecto, Jesús Alonso Tapia (1992, p. 187) manifiesta que los procesos de razonamiento son consustanciales al pensamiento; permiten ampliar el conocimiento del mundo e ir más allá de la experiencia. Afirma también que, para el funcionamiento del pensamiento, existen al menos dos sistemas importantes: el de representación y el lógico, los cuales están conectados entre sí estrechamente. El sistema de representación depende de operaciones lógicas. Para resolver un problema, una persona requiere comprender qué se debe hacer, entender la información disponible para buscar la solución y seleccionar estrategias adecuadas que en base a la información disponible le permita llegar a la solución; pero para ello se apoya en el análisis y el razonamiento.

Todo razonamiento tiene una estructura que consiste en: las premisas, la conclusión y el nexo lógico entre ellos. La ilación lógica de las premisas a la conclusión se llama "inferencia". El razonamiento es uno de los procesos cognitivos básicos por medio del cual utilizamos y aplicamos nuestro conocimiento. Sin la posibilidad de hacer inferencias, el sistema de procesamiento humano se vería obligado a depender de un conocimiento específico y exacto para cada una de las situaciones con las que se encuentra (Iriarte et al., 2010, p. 42).

Desde este punto de vista, el trabajo del docente debe ir enfocado a proponer diversidad de estrategias, como por ejemplo a plantearle problemas que supongan diferentes niveles de esfuerzo, hacerle reflexionar sobre las cosas, hechos o situaciones o animarles a plantear posibilidades y establecer hipótesis. 
Es preciso señalar que el razonamiento lógico-abstracto implica varios procesos, los más importantes son la inducción y la deducción. La inducción que permite desarrollar reglas, ideas o conceptos generales partiendo de aspectos específicos, ya sea a través de semejanzas o diferencias y se hace visible a partir de actividades como clasificar, completar series, realizar analogías y comparaciones, que permiten establecer inferencias (Iriarte et al., 2010, p. 42). Por otra parte, Bluedorn (1995, p. 1) manifiesta que el razonamiento inductivo, reúne observaciones particulares en forma de premisas, luego, a partir de estas premisas particulares se llega a una conclusión general, siendo la forma más común de razonamiento.

Adicionalmente, Serna y Polo (2014, p. 305) exponen un interesante análisis de la relación entre la lógica y la abstracción que, aunque estuvo enfocado a los procesos formativos de carreras de ingeniería, brinda aspectos 188 importantes y comunes para cualquier carrera. Estos autores afirman que la lógica se relaciona no sólo con el pensamiento abstracto sino además con aquel que permite generar un nuevo pensamiento; que ser lógico presupone tener una habilidad para utilizar efectivamente el lenguaje, tener respeto por el escenario mundial ya que la lógica trata de la realidad, conciencia viva de cómo los hechos se relacionan con los objetos del mundo dado que la lógica trata de hallar la verdad (Serna y Polo, 2014, p. 304).

Otros investigadores consideran al razonamiento abstracto como:

[....] la capacidad para procesar información a través de herramientas del pensamiento tales como el análisis y la síntesis, la imaginación espacial, el reconocimiento de patrones y la habilidad de trabajar y razonar con símbolos o situaciones no verbales, principalmente las analogías gráficas, secuenciación y matrices gráficas (Narváez, 2015, p. 79).

Esto significa que las personas que lo desarrollan son capaces de encontrar soluciones novedosas y originales a los problemas. A su vez, tienen habilidades para desarrollar la imaginación, ya que separan los conceptos reales y que son percibidos mediantes los sentidos, de los que no son reales y que pueden ser materializadas en el pensamiento.

Brizzio, Carreras y Fernández (2008, p. 15) afirman que da cuenta de la aptitud de los sujetos para generalizar y deducir principios a partir de esquemas no verbales. Quienes están inmersos en el área de la matemática defienden las ventajas que trae su estudio y dicen que sus aplicaciones van más allá de situaciones académicas. Por ejemplo Pérez y Gardey (2011, p. 1) lo asocian con la habilidad para comprender conceptos de distinta naturaleza y relacionarlos, basándose en esquemas y técnicas ordenadas, pues permite transformar cálculos, hipótesis, cuantificaciones 
y proposiciones en un proceso mental natural del cerebro, lo cual ayuda a mejorar la capacidad de resolver problemas en diversos ámbitos de la vida; también permite relacionar conceptos que aparentemente serían distantes entre sí; a la vez despierta la necesidad de ordenar y analizar los actos y las decisiones que se realizan a diario y mejoran el rendimiento en general.

Mientras más temprano se inicie su estimulación, mejores resultados se obtendrán. Por esta razón Sánchez dice que:

...se debe iniciar a los niños, desde las primeras edades, en pequeños razonamientos, adaptados a su nivel de desarrollo, que progresivamente van haciéndose un poco más difíciles, según van madurando, para que puedan llegar, en un futuro, a realizar otros razonamientos mucho más complejos. También hay que fomentar su capacidad de abstracción, que, en el niño, no ha de ser poca, teniendo en cuenta su gran imaginación (2014, p. 109).

A propósito de lo expuesto, Serna et al. (2013, p. 7) presentan argumentos de la importancia del razonamiento lógico, de modo que sostienen que éste ayuda a desarrollar las habilidades de comunicación, puesto que de la forma cómo se expresa una persona depende que otros comprendan la solución que describe, además beneficia para que las ideas se presenten a través de argumentos bien construidos, sistematizados y razonados; también mejora el poder de persuasión, pues es necesario aprender a construir y defender los puntos de vista propios e indicar con firmeza por qué se los consideran como la mejor alternativa; a la par fortalece las habilidades de escritura, mediante la realización de escritura interpretativa y argumentativa, retratando detalles de ejemplos concretos.

En contraposición de lo que tradicionalmente se pensaba, la abstracción no es importante únicamente para las ciencias denominadas duras, al respecto, Serna (2013, p. 80) asegura que "la abstracción es ampliamente utilizada en otras disciplinas como el arte, la escritura y la música" y como ejemplos menciona entre otros, la pintura de Katsushika Hokusai (1760-1849), denominada "South Wind, Clear Sky", donde utiliza un equilibrio perfecto de color y composición representando una forma abstracta de la montaña para capturar su esencia.

\section{Un nuevo campo de estudio: La inteligencia emocional}

Del análisis anterior se establece que la definición de inteligencia emocional es contraria a la tradicional, basada en una perspectiva psicométrica, 
y por lo tanto sus potenciales alcances en la vida diaria se deben a la incursión de un nuevo campo de estudio considerado más global, legítimo e integral (Gardner, 1993a, p. 34).

Dado que se presentan diferentes enfoques respecto al concepto de IE, existen autores que exponen sus teorías, las mismas que se encuentran agrupadas en tres tendencias: el modelo de habilidades formulado por Mayer y Salovey en 1990, el modelo mixto representado por Daniel Goleman en 1995 y el modelo de rasgos por Reuven Bar-On en 2006. A continuación se exponen los principales elementos conceptuales que los sostienen.

\section{Modelo de habilidad de inteligencia emocional de Mayer y Salovey}

El equipo de Mayer y Salovey (1997) concibieron un modelo de IE cognitivista basado en el procesamiento emocional de la información, en consecuencia afirman que el manejo adecuado de las emociones puede mejorar las habilidades de razonamiento (Extremera Pacheco \& Fernández-Berrocal, 2003, pp. 98, 99).

En esta línea, Mayer y Salovey definieron por primera vez a la IE como "una parte de la inteligencia social que incluye la capacidad de controlar nuestras emociones y las de los demás, discriminar entre ellas y usar dicha información para guiar nuestro pensamiento y nuestros comportamientos" (Extremera Pacheco \& Fernández-Berrocal, 2003, p. 99). Es decir que inicialmente, su teoría contempló una serie de habilidades emocionales adaptativas y conceptualmente relacionadas: evaluación y expresión de las emociones; regulación de las emociones y utilización de las emociones de forma adaptativa.

Según los autores, las habilidades emocionales que integran el concepto de IE, se estructuran como un modelo de cuatro líneas que se relacionan entre sí y que contienen los procesos psicológicos más básicos como la percepción emocional, hasta los de mayor complejidad, tal es el caso de la regulación de los estados afectivos.

En el siguiente apartado se realiza un análisis de cada uno.

\section{Percepción, evaluación y expresión de las emociones}

Esta competencia tiene que ver con el nivel en el que las personas son capaces de identificar sus propias emociones, así como los estados y sen- 
saciones fisiológicas y cognitivas que éstas conllevan. De la misma manera, se considera la discriminación de las emociones de otras personas, objetos, colores e imágenes, mediante el lenguaje, la conducta, el sonido o el aspecto. A la vez abarcaría la destreza para manifestar apropiadamente las emociones y los sentimientos encontrados en los demás tanto como las expectativas relacionadas a los mismos de forma adecuada (Extremera Pacheco \& Fernández-Berrocal, 2003, p. 101). En definitiva, la percepción requiere la capacidad de sentir y expresar las propias emociones.

\section{Facilitación y asimilación emocional}

Como lo establecen Mayer y Salovey (citados en Cabrera, 2011, p. 18), poseer IE no significa sólo discriminar las emociones, sino comprender que éstas a su vez actúan sobre los pensamientos y el modo de procesar la información de manera funcional. Así, las emociones sirven para modelar y mejorar el pensamiento al enviar nuestra atención hacia la información significativa de modo más rápido. Entonces, las emociones facilitan nuevas formas de pensar, elaboración de juicios y consideración de nuevos puntos de vista de los problemas debido a las continuas fluctuaciones emocionales. $\mathrm{Al}$ respecto, Damasio menciona que significa "ser capaz de anticipar cómo uno se sentiría si cierto acontecimiento sucediera puede ayudar a elegir decisiones acertadas en el momento oportuno" (1994, p. 34).

Los diferentes tipos de humor facilitan el surgimiento de estilos distintos de razonamiento (por ejemplo, deductivo vs. inductivo). Los estados de humor positivos conducen a un pensamiento más creativo y son beneficiosos para resolver problemas que requieren reestructuración, razonamiento inductivo, ruptura del pensamiento convencional y realizar conexiones entre conceptos aparentemente no relacionados (Palfai y Salovey, 1993, p. 59). Por otro lado, las emociones de tristeza serían más eficaces para desarrollar tareas de detección de errores, atención sistemática de la información, razonar deductivamente y resolver problemas que requieren un procesamiento lógico de la información (Extremera Pacheco \& Fernández-Berrocal, 2003, p. 78).

\section{Comprensión y análisis de las emociones: conocimiento emocional}

Para Mayer y Salovey (Fernández-Berrocal \& Extremera 2005, p. 83), conocer las emociones comprendería la habilidad para entenderlas y lograr 
una mayor comprensión de los lazos entre pensamientos y sentimientos, sus implicaciones y resultados. Además, tendría que ver con la capacidad para nombrar o etiquetar las emociones y reconocer los enlaces entre la palabra y el estado emocional, así como entender las conexiones entre las diversas emociones y las situaciones a las que satisfacen.

De la misma manera, contiene la capacidad para dilucidar el sentido de las emociones complejas, como de las creadas en un ambiente interpersonal, junto a la experiencia para reconocer las evoluciones de unos periodos emocionales a otros, la comprensión emocional incluye la capacidad de ser sensible a ligeras variaciones en las emociones, así como la capacidad de reconocer y describir cómo evolucionan con el tiempo (Extremera Pacheco \& Fernández-Berrocal, 2003, p. 102).

\section{Regulación reflexiva de las emociones}

La regulación integraría los procesos emocionales más complejos, los que se refieren a la capacidad de regular las emociones, tanto en sí mismos como en los demás. De esta manera, la persona emocionalmente inteligente puede aprovechar las emociones, incluso las negativas, y gestionarlas para alcanzar los objetivos previstos, en otras palabras, regular conscientemente las emociones para lograr un crecimiento emocional e intelectual (Extremera y Fernández-Berrocal, 2003, p. 102).

Para lograr dicha regulación, tanto personal como de las personas que conforman el entorno social, se requiere primero percibir, evaluar y expresar los estados afectivos; utilizar efectivamente las emociones relacionándolas con la forma de pensar; y, finalmente, advertir cómo se desenvuelve y evolucionan. Las personas poseen habilidades individuales para regular con efectividad los estados afectivos (Extremera Pacheco \& Fernández-Berrocal, 2003, p. 102).

Finalmente, la teoría facilita un nuevo marco para comprender la adaptación social y emocional en la medida en que la IE jugaría un papel elemental en el establecimiento y mantenimiento de las relaciones interpersonales, así como en el desarrollo del razonamiento lógico-abstracto.

\section{Modelo de rasgos de la Bar-On}

Para Reuven Bar-On (citado en Cabrera 2011, p. 17) la inteligencia emocional se define como "un conjunto de habilidades y competencias, que representan una colección de conocimientos usados para afrontar diver- 
sas situaciones". De ahí que el autor cree que este tipo de inteligencia es diferente a la inteligencia cognitiva. También acepta que el término IE no fue creado por él y que lo tomó de las investigaciones de Salovey y Mayer.

De manera que este modelo es multifactorial y propone el concepto de Cociente Emocional -CE. A su vez, está compuesto por cinco componentes: intrapersonal, interpersonal, adaptabilidad, manejo del estrés y estado de ánimo en general.

Por lo tanto, el modelo de rasgos le concede categoría de predictores del comportamiento tanto a los componentes personales como a los contextuales.

\section{Modelo mixto de Goleman}

En 1995, Daniel Goleman publica el libro Inteligencia emocional que se convierte en un betseller a nivel mundial. En su obra, analiza cuatro postulados de la inteligencia emocional: autoconciencia (capacidad para interpretar las propias emociones y reconocer su influencia al tomar decisiones de manera visceral); autogestión (implica controlar las propias emociones e impulsos y adaptarse a las circunstancias cambiantes); conciencia social (capacidad para sentir, entender y reaccionar ante las emociones del otro, comprendiendo las redes sociales); gestión de relaciones (capacidad de inspirar a otros, influir sobre ellos y contribuir a su desarrollo en la gestión de conflictos) (Extremera \& Fernández-Berrocal, 2003, p. 100).

Del recorrido realizado por los diferentes autores y sus teorías, la investigación que se expone se sustenta en el Modelo de habilidades construido por Salovey y Mayer en 1990, que entiende la IE como: "la habilidad para unificar las emociones y el razonamiento, utilizar las emociones para facilitar un razonamiento más efectivo y pensar de forma más inteligente sobre la vida emocional" (Extremera \& Fernández-Berrocal, 2003, p. 100). Es decir que las personas emocionalmente inteligentes, son las que conocen los pensamientos y sentimientos que incitan determinados estados de ánimo con el fin de prevenir las dificultades que su manejo inadecuado puedan ocasionarles.

Cabe destacar que en la actualidad, este es el concepto más utilizado porque contempla las emociones como fuentes útiles de indagación que hacen posible entender el entorno social y moverse por él. Además plantea que las personas tienen diferentes maneras de procesar información de carácter emocional y también capacidad para relacionar el proce- 
samiento emocional con los aspectos cognitivos. Dicha habilidad se pone de manifiesto en determinadas conductas adaptativas.

Para finalizar, la contraposición entre inteligencia racional e inteligencia emocional continúa. No obstante, la revisión teórica realizada sumada a las investigaciones realizadas, evidencia que la inteligencia no puede ser considerada una sola habilidad, pues su concepto ha avanzado desde una competencia única hacia una habilidad multifactorial, integrada por diversidad de factores, como la herencia y el contexto en el que el individuo se desenvuelve, y asentada en sistemas funcionales cerebrales.

\section{Método}

La metodología fue cuantitativa, con énfasis en la descripción, explicación, comparación e interpretación de los resultados. Según el tipo de diseño se trató de una investigación correlacional de tipo no experimental transversal ya que se recolectaron los datos durante mayo de 2016.

\section{Participantes}

Los participantes fueron 46 estudiantes de séptimo y octavo semestre del período académico Abril-Agosto 2016-I, de las carreras de Ciencias Sociales, Ciencias Exactas y Cultura Estética de la Universidad Nacional de Chimborazo. La muestra se seleccionó a través del método de muestreo no probabilístico, intencionado para estudiar la relación entre el nivel de RLA y los factores de la IE en estudiantes que pertenecen a carreras diferentes.

\section{Instrumentos}

La recopilación de la información se realizó mediante la utilización de tres instrumentos.

\section{Cuestionario base}

Se exploraron datos informativos de los estudiantes que participaron en el estudio como: género, carrera y semestre. 


\section{Prueba de Razonamiento Lógico-Abstracto (RLA)}

Para su elaboración se tomaron como referencia los tests psicotécnicos de Clavijo (2010, pp. 135, 137, 138), Mateos (2006, p.181-183) y Urquizo (2016, s/p) y que estuvo constituida por 33 ítems agrupados en cuatro dimensiones: 14 ítems de series y símbolos abstractos, 10 de operaciones con símbolos abstractos, 5 de analogías gráficas y 4 de razonamiento lógico-analítico, que en conjunto determinaron el nivel de desarrollo del RLA. La evaluación de los ítems se realizó sobre una escala de 100 puntos. Se consideraron dos categorías de valoración: RLA Bueno, si los estudiantes obtienen una puntuación mayor o igual a la media aritmética de su respectiva dimensión y RLA Regular cuando el puntaje es menor a la media. Finalmente, el tiempo asignado para la resolución de los ítems fue de 40 minutos. A continuación se describe el contenido de cada uno de los subgrupos de la prueba.

\section{a. Series gráficas}

Incluyó una secuencia de figuras donde a través de giros, traslaciones, eliminación o adición de elementos, el estudiante debía reconocer los patrones y reglas para identificar la siguiente o siguientes figuras. A través de esta prueba se pretendió identificar el nivel de razonamiento inductivo.

\section{b. Operaciones aritméticas con símbolos abstractos}

Consistió en resolver operaciones de adición, sustracción, multiplicación y división, con símbolos abstractos, en las que los estudiantes debían identificar los valores que tomaban dichos símbolos para cumplir con las operaciones. Esta prueba midió el nivel de comprensión e interpretación abstracta, así como el dominio de operaciones aritméticas básicas.

\section{c. Analogías gráficas}

En esta prueba, los estudiantes identificaron la relación existente entre dos figuras para completar la figura que está asociada a una cuarta. El interés de la prueba fue que los estudiantes enfoquen su atención sobre los rasgos perceptivos de los elementos más que sobre los semánticos, para lo cual fue precisó que representen viso-espacialmente las formas (Blum et al., 2011, p. 134). 


\section{d. Razonamiento lógico-analítico}

En esta prueba se proporcionó a los estudiantes pistas con las cuales se debía completar una matriz que contenía información relacionada entre sí, en base al análisis y deducción. Estos ítems permitieron establecer el nivel del razonamiento deductivo.

\section{Test de Inteligencia Emocional (TMMS-24)}

Se utilizó el Test de Inteligencia Emocional -IE- (Fernández y Berrocal, 2004, pp. 94, 751-755), basado en la Trait Meta-Mood Scale (TMMS-24) del grupo de investigación de Salovey y Mayer $(1995$, pp. 125, 151) integrado por 24 ítems, que proporcionan un indicador de los niveles de IE. La escala está compuesta por tres subfactores: atención a los propios sentimientos (percepción); claridad emocional (comprensión) y reparación de los estados de ánimo (regulación). Cada uno se evalúa mediante ocho ítems. Estos ítems hacen referencia a los tres procesos de percepción, comprensión y regulación. Para esto, los estudiantes valoraron cada una de las afirmaciones acerca de sí mismos en una escala Likert de 1 a 5 puntos que representa su grado de acuerdo con cada una de ellas. El nivel se obtuvo sumando las respuestas de cada subescala, cuyo puntaje oscila en cada una de ellas entre 8 y 40 puntos. Finalmente, el tiempo estimado para contestar el test fue 15 minutos (Fernández y Berrocal, 2004, p. 94).

Para corregir y obtener una puntuación en cada uno de los factores, se suman los ítems del 1 al 8 para el factor percepción, del 9 al 16 para el factor comprensión y del 17 al 24 para el factor regulación. En la subescala de percepción emocional, el puntaje en el rango medio (22 a 32 en hombres; 25 a 35 en mujeres) indica adecuada percepción emocional y la puntuación en rango alto ( $>33$ en hombres; $>$ en 36 mujeres) y bajo ( $<21$ en hombres; $<24$ en mujeres) indica que debe mejorar su percepción emocional. En cambio en la sub escala de comprensión, las puntuaciones del rango bajo indican que debe mejorar la comprensión $(<25$ en hombres, $<23$ en mujeres), las de rango medio (26 a 35 en hombres; 24 a 34 en mujeres) indican adecuada comprensión y las de rango alto ( $>36$ en hombres; > 35 en mujeres) indican excelente comprensión emocional. Así mismo, en la subescala regulación emocional, las puntuaciones bajas ( $<23$ en hombres y mujeres) indican que debe mejorar la regulación; las de rango medio ( 24 a 35 en hombres y 24 a 34 en mujeres) indican adecuada regulación y las puntuaciones altas ( $>36$ en hombres, $>35$ en mujeres) indican excelente Regulación Emocional. 


\section{Análisis estadístico}

La confiabilidad interna de la prueba de RLA se midió utilizando el índice de confiabilidad (Mejía, 2005, p. 28), obteniéndose un valor de $\mathrm{C}_{\mathrm{f}}=0,92$ que corresponde a excelente confiabilidad. Además se realizó un proceso de validación de los constructos aplicándolos a estudiantes que no participaron en la investigación. Estos resultados permiten aseverar que los ítems son homogéneos y que el instrumento mide de forma consistente la característica para la cual fue elaborado.

Para los dos instrumentos se realizó un análisis descriptivo calculando la media aritmética, desviación estándar, y la normalidad según la prueba Kolmogórov-Smirnov, además de un análisis de correlación utilizando el paquete estadístico SPSS.

\section{Resultados}

\section{Datos informativos}

Los datos se tomaron durante mayo del período académico abril-agosto 2016-I. En el estudio participaron 46 estudiantes de tres carreras de la Facultad de Ciencias de la Educación de la UNACH. Un 52\% de los estudiantes pertenecen al género masculino mientras que el $47 \%$ se identifican con el género femenino. En relación a la carrera que estudian, el $32,6 \%$ pertenece a Ciencias Exactas, el $28,3 \%$ a Ciencias Sociales y el $39,1 \%$ a Cultura Estética. Estos datos se pueden visualizar en la Tabla 1.

Tabla 1

Datos informativos

\begin{tabular}{|l|l|l|l|}
\hline \multicolumn{1}{|c|}{ Indicadores } & \multicolumn{1}{c|}{ Característica } & Frecuencia & Porcentaje \\
\hline \multirow{3}{*}{ Género } & Masculino & 24 & $52,2 \%$ \\
\cline { 2 - 5 } & Femenino & 22 & $47,8 \%$ \\
\hline \multirow{2}{*}{ TOTAL } & Ciencias Exactas & 15 & $100 \%$ \\
\hline \multirow{3}{*}{ Carrera } & Sociales & 13 & $32,6 \%$ \\
\cline { 2 - 5 } & Cultura estética & 18 & $28,3 \%$ \\
\hline \multirow{2}{*}{ TOTAL } & & 46 & $39,1 \%$ \\
\hline
\end{tabular}

Fuente: Estudiantes de la Universidad Nacional de Chimborazo, 2016

Elaboración: Patricia Bravo Mancero y Angélica Urquizo Alcívar 


\section{Prueba de Razonamiento Lógico-Abstracto-RLA}

Considerando los resultados de cada componente de la prueba, se observa que de 46 estudiantes, 26 (57\%) manifestaron un razonamiento lógico-abstracto bueno en el sub área de series gráficas; 25 (54\%) alcanzaron igual nivel en la prueba de operaciones con símbolos abstractos, en tanto que 25 (54\%) demostraron un nivel de razonamiento regular en el subárea de analogías gráficas y $30(65 \%)$ en razonamiento lógico analítico. Los resultados finales, revelan que 24 alumnos (52\%) alcanzan un razonamiento lógico abstracto regular, mientras que 22 (48\%) logran un razonamiento lógico abstracto bueno.

Si se examinan los datos por carrera, 5 (11\%) estudiantes de Ciencias Exactas consiguen un razonamiento regular en relación a 10 (21\%)

198 que logran un razonamiento bueno. En la carrera de Ciencias Sociales, el número de estudiantes que obtienen razonamiento regular son $6(13 \%)$ frente a $7(15 \%)$ que presentan un razonamiento bueno; y en la de Cultura Estética 13 (28\%) estudiantes manifiestan razonamiento regular superando a los 5 que alcanzan un razonamiento bueno.

En atención a los resultados obtenidos, la prueba de Kolmogorov-Smirnov realizada en SPSS, revela que la distribución de los datos es normal ya que se obtuvo nivel de significación de 1 que es mayor a 0,05 ; con una media de 59,58 y una desviación estándar de 14,62.

\section{Test de Inteligencia Emocional (TMMS-24)}

Los resultados de la Escala TMMS-24 fueron analizados por factores, género y carrera (ver tabla 3 ).

\section{Resultados por género}

De los 24 (52\%) estudiantes que se identifican con el género masculino, los resultados para el factor de percepción proyectan los siguientes datos: 8 (17\%) presentan baja percepción emocional, 14 (31\%) buena o adecuada percepción emocional y $2(4 \%)$ alta percepción emocional. Respecto al factor de comprensión emocional, 11(24\%) tienen baja comprensión, mientras que $12(26 \%)$ buena comprensión emocional y $1(2 \%)$ alta o adecuada comprensión emocional. Para el factor de regulación emocional, los resultados indican que $3(7 \%)$ estudiantes poseen baja regulación emocional, 15 (33\%) adecuada en tanto que $6(13 \%)$ alta 

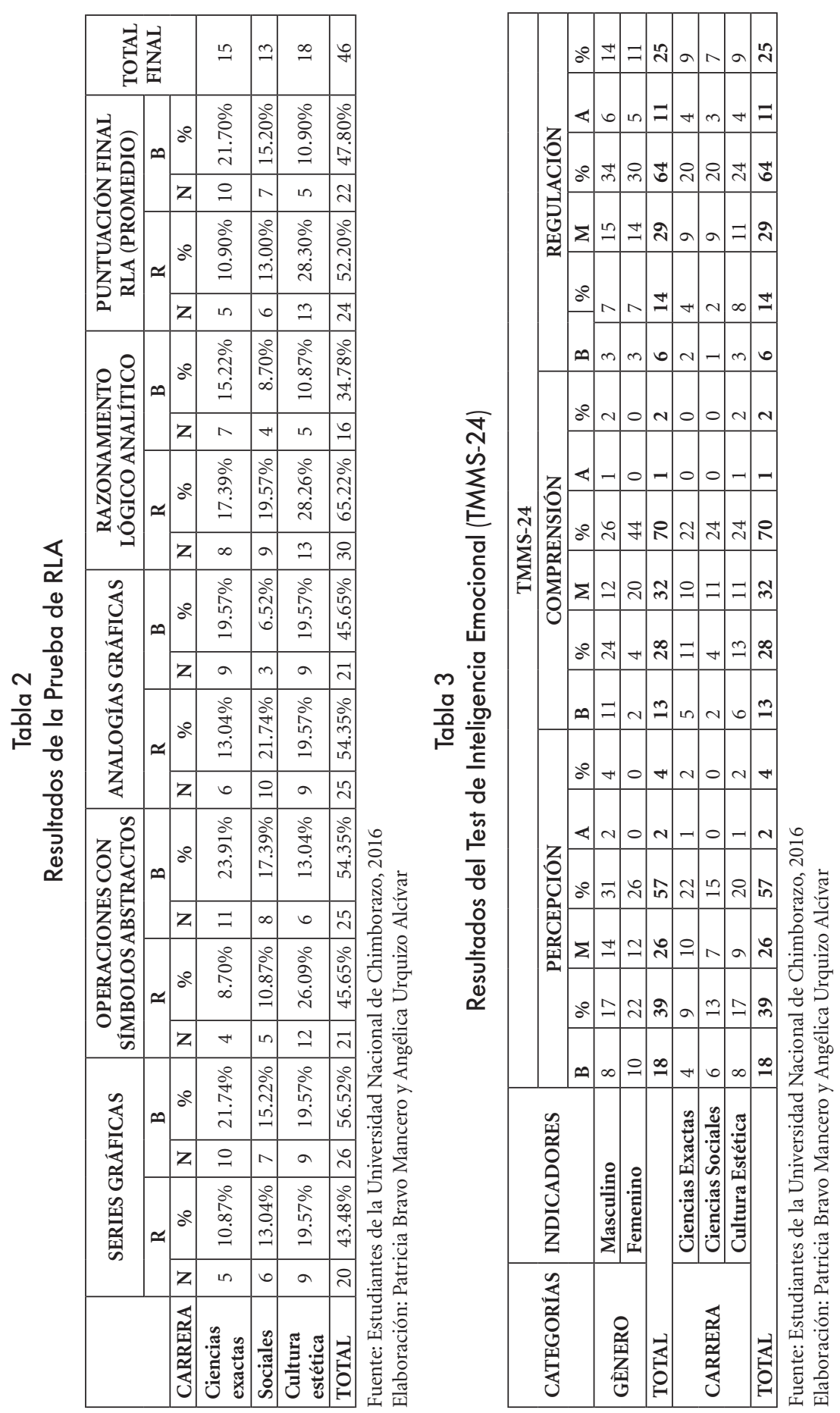
o demasiada percepción emocional. Los datos obtenidos se distribuyen en la curva normal; en el caso de la percepción con una media de 25,54 y la desviación estándar de 5,76; en la comprensión con una media de 25,66 y la desviación estándar de 6,37 y en el caso de la regulación con una media de 30,79 y la desviación estándar de 6,28. Las puntuaciones obtenidas en todas las dimensiones se ubican en la categoría de adecuada percepción, comprensión y regulación emocional respectivamente. De las $22(48 \%)$ estudiantes del género femenino, en el factor de percepción, $10(22 \%)$ se ubicaron con baja percepción emocional, 12 (26\%) con buena o adecuada percepción emocional y no existen estudiantes con alta percepción emocional. En cuanto al factor de comprensión emocional, 2 (4\%) asumen baja comprensión, a la vez que 20 (44\%) buena o adecuada y tampoco existen estudiantes con alta comprensión emocional. 200 Finalmente, en el factor de regulación emocional, los datos indican que $3(7 \%)$ estudiantes obtienen baja regulación emocional, 14 (30\%) alta regulación y $15(33 \%)$ alta o demasiada percepción emocional. Los resultados del género femenino se ubican en la curva normal. Para la prueba de percepción, con una media de 25,68 y una desviación estándar de 4,83; en la comprensión con una media de 27,7 y una desviación estándar de 3,69 y en el caso de la regulación con una media de 29,45 y una desviación estándar de 5,68.

\section{Resultados por carrera}

En lo referente a la distribución de la IE por carreras, se observó que en el factor de percepción de las emociones, de los 15 estudiantes de la carrera de Ciencias Exactas, 4 (10\%) prestan poca atención a su percepción emocional, 10 (22\%) tienen buena o adecuada y 1 (2\%) presta demasiada atención a sus emociones. En el factor de comprensión de las emociones se encontró que $6(13 \%)$ deben mejorar su comprensión, 7 (15\%) tienen adecuada comprensión. En lo concerniente al factor de regulación emocional, los datos indican que $2(4 \%)$ estudiantes deben mejorar su regulación emocional, 8 (20\%) tiene adecuada regulación y 4 (9\%) presentan excelente regulación de sus emociones.

De 13 participantes que estudian en la carrera de Ciencias Sociales, en el factor de percepción emocional, 6 (13\%) le dan baja atención a su percepción y 7 (15\%) mantienen buena o adecuada percepción emocional. Respecto al factor de comprensión de las emociones, se encontró que $2(4 \%)$ deben mejorar su comprensión, 11 (24\%) tienen adecuada 
comprensión. En cuanto al factor de regulación emocional, los resultados expresan que 1 (2\%) estudiante debe mejorar su regulación emocional, 9 (20\%) tienen adecuada regulación y $3(7 \%)$ presentan excelente regulación de sus emociones.

Los 18 participantes que cursan la carrera de Cultura Estética obtienen los siguientes datos: para el factor de percepción emocional, 8 (17\%) le dan baja atención a su percepción, 9 (20\%) manifiestan buena o adecuada percepción emocional, en tanto que 1 (2\%) presta demasiada atención a sus emociones. En el factor de comprensión emocional, 5 (13\%) deben mejorar su comprensión, 11 (24\%) mantienen adecuada comprensión y $1(2 \%)$ tiene adecuada comprensión. En el factor de regulación emocional, 3 (7\%) estudiantes deben mejorar su regulación emocional, $11(24 \%)$ poseen adecuada regulación y 4 (9\%) expresan excelente regulación de sus emociones.

De modo general, el análisis de los factores de inteligencia emocional muestra que el $57 \%$ de los estudiantes alcanzaron niveles adecuados de percepción emocional, un considerable 39\% bajo nivel y el $4 \%$ adecuado o excelente nivel; en cuanto al factor de comprensión, el $28 \%$ de la población tiene baja comprensión, el $70 \%$ adecuada y el 2\% excelente comprensión de las emociones; finalmente en el factor de regulación emocional, el $64 \%$ se ubica con adecuada regulación, en tanto que el $25 \%$ tiene excelente regulación y el 14\% debe mejorar.

\section{Correlaciones entre la Prueba de RLA y el TMMS-24}

Existe una correlación significativa moderada positiva entre los factores de la IE, específicamente entre percepción y comprensión con un valor del coeficiente de correlación de Pearson de 0,6 , pero no existe ningún otro valor de significancia menor a 0,05 ni otro de correlación cercano a -1 o a 1. Finalmente, no se evidencia relación entre el RLA y la IE, pues ningún valor del coeficiente de correlación de Pearson es significativo; sin embargo, se observa concordancia en los niveles de desarrollo de las dos habilidades.

\section{Discusión de los resultados}

Se observa que en mayor porcentaje, los estudiantes de la carrera de Ciencias Exactas obtienen mejor nivel de razonamiento bueno en las subcategorías: series gráficas, operaciones con símbolos abstractos y analogías gráficas, mientras que en razonamiento lógico analítico hay 
una mínima diferencia entre las categorías regular y buena. En el caso de Ciencias Sociales, los resultados son buenos en series gráficas y operaciones con símbolos abstractos, al contrario de la prueba de analogías gráficas y razonamiento lógico analítico, donde los participantes obtienen niveles regulares. Los estudiantes de Cultura Estética logran un empate entre las categorías bueno y regular en series gráficas y analogías gráficas, mientras que la mayoría logra un resultado regular en operaciones con símbolos abstractos y razonamiento lógico analítico. En el total general vemos que la diferencia entre la categoría de razonamiento regular y bueno es mínima.

Este resultado se puede entender ya que los estudiantes de Ciencias Exactas por la naturaleza la carrera, trabajan varias asignaturas y desde los primeros semestres, con herramientas del pensamiento como análisis, síntesis, imaginación espacial, reconocimiento de patrones, símbolos abstractos e hipótesis, que requieren demostraciones matemáticas, proposiciones y cuantificadores. Por otro lado, los resultados más homogéneos de los estudiantes de Cultura Estética fueron en series gráficas y analogías gráficas, debido a las características de su profesión, en la que reciben asignaturas relacionadas con el dibujo y el arte. También se puede deducir que a los estudiantes de Ciencias Sociales y Cultura Estética les falta desarrollar el razonamiento inductivo y deductivo, procesos a través de los cuales se realizan inferencias, que son necesarias para potenciar el razonamiento lógico analítico.

Por otra parte, el estudio realizado mediante el TMMS-24, ha ratificado algunas evidencias de validez predictiva de la IE, valorada con medidas de auto-informe y de habilidad. En términos generales, los datos demuestran que las habilidades de manejo emocional de los estudiantes, son adecuadas y predicen apropiados niveles de percepción, comprensión y regulación emocional. Los estudiantes que se encuentran en esta categoría, son capaces de identificar sus propias emociones y las de los demás, generando mejores relaciones positivas y menores interacciones negativas.

A la vez, usan conscientemente las emociones para lograr un crecimiento emocional e intelectual. No obstante, existe un número considerable de sujetos que deben prestar mayor atención a los sentimientos así como a la percepción, comprensión y regulación de las emociones, usándolas para mejorar su razonamiento, solucionar problemas y cambiar su realidad, ya que éstas son una valiosa brújula en el viaje hacia la búsqueda del bienestar. Finalmente, deben construir una relación más fuerte entre la energía y el mensaje que les aportan para pasar a las decisiones de forma sana. 
En cuanto a los indicadores de la IE por género, se encontró que las mujeres poseen un mayor nivel comprensión de sus emociones, mientras que los hombres un mejor nivel de percepción y regulación. Estos hallazgos coinciden con la teoría que sostiene que las mujeres se perciben como más capaces de atender sus emociones así como también de comprenderlas, mientras que los hombres lo hacen en relación con el control de impulsos y tolerancia al estrés (Fernández, Berrocal y Extremera, 2003; Mayer, et al., 1999). Los bajos niveles de percepción de las emocionas alcanzados por las mujeres, señalan que tienen dificultades en la valoración adecuada de sus emociones. Por otro lado, existe un mayor porcentaje de hombres que le conceden excesiva atención a sus emociones, esto, sin niveles adecuados de comprensión y regulación podría extender sus estados de ánimo negativos, como tristeza, depresión y ansiedad (Fernández- Berrocal, y Extremera y 2005).

Además, se constató que no existen diferencias significativas en los resultados que obtienen los estudiantes en relación a la carrera que estudian. Sin embargo, los estudiantes de la carrera de Ciencias Exactas demuestran mejor percepción emocional, mientras los de Ciencias Sociales y Cultura Estética, superior comprensión. En cuanto a la regulación de las emociones, los alumnos de Cultura Estética logran mejores puntajes. Cabe destacar que los niveles menos adecuados en los tres factores los obtienen los estudiantes de Cultura Estética, sin alejarse significativamente de esta realidad, la población de las otras carreras investigadas. Las consecuencias prácticas de este estudio sugieren que existen determinados factores que están afectando a los estudiantes conforme avanzan en su carrera profesional, lo cual amerita una intervención educativa positiva para fomentar el desarrollo emocional, ya que la docencia lo exige.

Es preciso señalar que la mayor parte de los diseños curriculares de las carreras investigadas, están centrados en el desarrollo de las habilidades de pensamiento lógico y, cuando se observa un déficit en ciertas asignaturas, se recurre a estrategias de recuperación como clases o trabajos adicionales. No obstante estas medidas, si bien necesarias, son insuficientes para abordar otras problemáticas que no guardan relación con los contenidos o formas de enseñar y evaluar, pero que subyacen en dificultades académicas. Es claro que existe una ausencia de programas dirigidos a potenciar las habilidades afectivas, emocionales y sociales de los alumnos, futuros profesores, con el objeto de afrontar y superar las continuas demandas de la carrera docente.

Los datos obtenidos revelan que no existe relación entre el RLA y la IE; pero sí hay concordancia en los niveles de desarrollo de las dos ha- 
bilidades. La experiencia dice que en el ámbito educativo se continúa privilegiando el desarrollo de la mente racional sobre la mente emocional. Si bien, las dos habilidades presentan características propias que reflejan el funcionamiento de circuitos cerebrales distintos aunque interrelacionados, en la práctica, están estrechamente relacionadas porque las emociones son básicas para el pensamiento así como el pensamiento para las emociones. Al respecto, la neurociencia pone de manifiesto que RLA e IE no pueden ni debe separarse ya que responden al diseño anatómico y funcional del cerebro. Esto quiere decir que la información sensorial, antes de ser procesada por la corteza cerebral en sus áreas de asociación (procesos mentales, cognitivos), pasa por el sistema límbico o cerebro emocional, en donde adquiere un tinte, un colorido emocional. Por lo tanto, es necesario concebir que para aprender se necesita de las emocio204 nes, y, para enseñar también.

Por todo lo dicho, se establece que trabajar de manera conjunta y organizada para desarrollar el RLA y la IE, elevaría la formación profesional de los estudiantes universitarios, porque les permitiría mejorar aspectos personales y profesionales; además, favorecería una relación efectiva con sus estudiantes, al interpretar y manejar las emociones tanto propias como las de los demás, ayudándoles a adaptarse a los cambios, a resolver problemas de naturaleza personal e interpersonal y hacer frente de manera eficiente a las demandas diarias, desafíos y presiones.

\section{Conclusiones}

- Se encontró que no existe relación entre el RLA y los factores de la IE, situación que advierte de la prioridad que se continúa otorgando al desarrollo cognitivo sobre las competencias emocionales.

- Las diferencias de los resultados por carreras no advierten variaciones significativas en los niveles de RLA e IE.

- En relación a los factores de la IE por género, el femenino alcanza mayor frecuencia de niveles adecuados de comprensión emocional, mientras que el masculino de la percepción y regulación.

- Los estudiantes manifiestan diferentes habilidades, las mismas que no son atendidas en el aula ya que los docentes continúan manejando sus clases con un enfoque tradicional. El reconocimiento de la pluralidad de habilidades que poseen los alum- 
nos, es el primer paso para generar nuevos planteamientos metodológicos en el aula.

- Por último, las consecuencias prácticas de este estudio subrayan la necesidad de desarrollar las dos habilidades, el razonamiento lógico abstracto y la inteligencia emocional, más las otras que se han analizado, como un mecanismo para lograr una educación de calidad en la que todos los alumnos puedan participar con igualdad de oportunidades.

\section{Bibliografía}

ABARCA, Mireya

2003 La educación emocional en la Educación primaria. Currículo y práctica. Tesis doctoral. Universitat de Barcelona. Disponible en: http://www.tdx.cat/bitstream/handle/10803/2349/01.MMAC_PRIMERA_PARTE.pdf

ARMSTRONG, Thomas

2000 In their own way: Discovering and encouraging your child's multiple intelligences. Nueva York: Penguin Putnam.

2003 You're smarter than you think: A kid's guide to multiple intelligences. Minneapolis, MN: Free Spirit Publishing.

BAR-ON, Reuven

2006 The Bar-On model of emotional-social intelligence. University of Texas Medical Branch Psicothema 18. Texas.

BLUEDORN, Harvey

1995 Dos métodos de razonamiento. http://www.contra-mundum.org/castellano/ bluedorn/Met_Razonamiento.pdf

BLUM, Diego, ABAL, Facundo, LOZZIA, Gabriela, PICÓN JANEIRO, Jimena \& ATTORRESI, Horacio

2011 Analogías de figuras: teoría y construcción de ítemes. Interdisciplinaria, 28(1), 131-144. Centro Interamericano de Investigaciones Psicológicas y Ciencias Afines Buenos Aires, Argentina. http://www.redalyc.org/articulo. oa?id=18022327008vincular, 30 de junio de 2016.

BRIZZIO, Analía, CARRERAS, María Alejandra \& FERNÁNDEZ, Mercedes

2008 La evaluación de las habilidades de razonamiento verbal y abstracto en estudiantes universitarios. su relación con el rendimiento académico. XV Jornadas de Investigación y Cuarto Encuentro de Investigadores en Psicología del Mercosur. Facultad de Psicología - Universidad de Buenos Aires, Buenos Aires.

CABRERA, Marlene

2011 Inteligencia emocional y rendimiento académico de los alumnos del nivel secundario de una institución educativa de la región callao. En: $\mathrm{Ca}$ brera_Inteligencia Emocional y Rendimiento Académico. 2011. Universidad San Ignacio de Loyola. http://repositorio.usil.edu.pe/bitstream/123456789/ 1120/1/2011_Cabrera_Inteligencia\%20emocional\%20y\%20rendimiento \%20acad\%C3\%A9mico\%20de\%20los\%20alumnos\%20del\%20nivel\%20 
secundario $\% 20$ de $\% 20$ una $\% 20$ insituci\%C3\%B3n $\% 20$ educativa $\% 20$ de $\% 20$ la\%20regi\%C3\%B3n\%20Call.pdf. 17 de julio 2016.

CLAVIJO, Rocío

2010 Cuestionario Psicotécnico. México: Limusa.

DAMASIO, Antonio

1994 Descartes Error: Emotion, reason and the human brain. New York, Grossett/ Putnam y Sons, (trad. cast. Grijalbo Mondadori, 1996).

EXTREMERA PACHECO, Natalio, \& FERNÁNDEZ BERROCAL, Pablo

2003 La inteligencia emocional en el contexto educativo: hallazgos científicos de sus efectos en el aula. Revista de Educación. España: Universidad de Málaga.

FERNÁNDEZ-BERROCAL, Pablo, \& EXTREMERA PACHECO, Natalio

2004 Validity and reliability of the Spanish modified version of the Trait MetaMood Scale. Psychological Reporte.

2005 La Inteligencia Emocional y la educación de las emociones desde el Modelo de MayerySalovey. RevistaInteruniversitariadeFormacióndelProfesorado.Departamento de Psicología Básica Universidad de Málaga. ISSN 0213-8464.http:// emotional.intelligence.uma.es/documentos/pdf61modelo_de_mayer_ salovey.pdf. 20 de julio de 2016.

FONSECA MORA, María

2007 Las inteligencias múltiples en la enseñanza del español: Los estilos cognitivos de aprendizaje. En Pastor Villalba, C. (ed.).

GARDNER, Howard

1993 Inteligencias múltiples. La teoría en la práctica. Barcelona: Editorial Paidós.

1993a Frames of mind: The theory of multiple intelligences. (2aed.). Nueva York: Basic Books.

GUZMÁN, Belkys, \& CASTRO, Santiago

2005 Las inteligencias múltiples en el aula de clase. Revista de Investigación, 58. Universidad Pedagógica Experimental Libertador. Venezuela.

GUTIÉRREZ, Germán

1991 Joy Paúl Guilford (1897-1987) III. El Mundo de la Psicología. Revista Latinoamericana de Psicología, 23(001). Fundación Universitaria Konrad Lorenz. Bogotá-Colombia.

IRIARTE, Fernando, ESPELETA, Álvaro, ZAPATA, Emperatriz, CORTINA, Liliana, ZAMBRANO, Elizabeth \& FERNÁNDEZ, Federico

2010 El razonamiento lógico en estudiantes universitarios. Zona Próxima, 12 enero- junio. Instituto de Estudios en Educación. Universidad del Norte.

LAZEAR, David

1991 La enseñanza de las inteligencias múltiples. Fastback 342 Bloomington, Fundación Phi Delta Kappa para la Educación (ERIC Reproducción de Documentos Servicio No. ED 356 227).

MARTÍNEZ, Felipe

2010 Las pruebas de rendimiento y sus consecuencias. Al Tablero, 55. Revista del Ministerio de Educación de Colombia. http://www.mineducacion.gov. co/1621/article-241800.html; 16 de julio de 2016.

MATEOS, Andrés

2006 Test psicotécnicos. Madrid: Tébar. 
MATTHEWS, Gerald, ROBERTS, Richard, \& ZEIDNER, Moshe

2004 Seven Myths About Emotional Intelligence. Psychological Inquiry, 15(3), 179-196. Interdisciplinary Research on Emotions University of Haifa, Israel.

MAYER, John \& SALOVEY, Peter

1997 Emotional attention, clarity, and repair: exploring emotional intelligence using the Trait Meta-Mood Scale. En: J. W. Pennebaker (Ed.), Emotion, Disclosure, \& Health. Washington. American Psychological Association.

MEJÍA, Elías

2005 Técnicas e instrumentos de investigación. Lima: CEPREDIM.

MORCHIO, María

2004 Enseñanza de una lengua extranjera desde las inteligencias múltiples. Córdoba, España: Universidad Nacional de Córdoba, Programa Universitario de Adultos Mayores.

NARVÁEZ, Freddy

2015 Guía práctica para el examen de ingreso a universidades, evaluación docente y servidores públicos. Quito: Educatemas.

PÉREZ PORTO, Julián \& GARDEY, Ana

2011 Definición de pensamiento matemático. http://definicion.de/pensamientomatematico/\#ixzz4DM7ovM33. 5 de julio de 2016.

SALOVEY, Peter, MAYER, John

1995 Emotional attention, clarity, and repair: exploring emotional intelligence using the Trait Meta-Mood Scale. En: J. W. Pennebaker (Ed.), Emotion, Disclosure, \& Health. Washington. American Psychological Association.

PALFAI, Tibor, \& SALOVEY, Peter

1993 The influence of depressed and elated mood on deductive and deductive reasoning. Imagination, Cognition and Personality. Washington. American Psychological Association.

SÁNCHEZ, María

2014 Una pincelada sobre creatividad Matemáticas. En: Aprendizaje y razonamiento matemático. Universidad de Málaga.

SERNA, Edgar

2013 La abstracción como componente crítico de la formación en ciencias computacionales. Revista Avances en Sistemas e Informática, 8(3), 79-83. Universidad Nacional de Colombia.

SERNA, Edgar, \& FLOREZ, Giovanny

2013 El razonamiento lógico como requisito funcional en Ingeniería. En Innovation in Engineering, Technology and Education for Competitiveness and Prosperity. August 14-16,2013 Cancun,Mexico. http://www.laccei.org/LACCEI2013-Can cun/RefereedPapers/RP221.pdf

SERNA, Edgar, \& POLO, José

2014 Lógica y abstracción en la formación de ingenieros: una relación necesaria. Ingeniería, investigación y tecnología, 15(2), 299-310.

http://www.scielo.org.mx/scielo.php?script=sci_arttext\&pid=S1405-77432014000 200012\&lng=es\&tlng=es.

SHANNON, Alicia

2010 La teoría de las inteligencias múltiples en la enseñanza del español. Universidad de Salamanca. España. http://www.mecd.gob.es/dctm/redele/Material- 
RedEle/Biblioteca/2014bv15/2014-BV-15-01AliciaMarieShannon.pdf?docu mentId=0901e72b818c6a9e. 19 de julio de 2016.

SMITH, Elizabeth

2001 Implications of multiple intelligences theory for second language learning. Journal of Knowledge Management, 5(4). University Press. ISSN 1367-3270, Faculty of Education.

TAPIA, Jesús Alonso, \& Colaboradores

1992 Leer, comprender y pensar. Madrid: Centro de Publicaciones del Ministerio de Educación y Ciencia: C.I.D.E.

Fecha de recepción del documento: 5 de julio de 2016 Fecha de aprobación del documento: 15 de agosto de 2016 


\title{
ABP COMO ESTRATEGIA PARA DESARROLLAR
}

EL PENSAMIENTO LÓGICO MATEMÁTICO

EN ALUMNOS DE EDUCACIÓN SECUNDARIA

\section{$\overline{\mathrm{ABP}}$ as a strategy to develop mathematical logical thinking in high school students}

\author{
FELIPE LEIVA SÁNCHEZ \\ Multidiversidad Mundo Real Edgar Morin/México \\ felipeleivaunam@gmail.com
}

\begin{abstract}
Resumen
En la última evaluación de PISA realizada en México (2015), los alumnos de tercer grado de secundaria, en promedio, se ubicaron en el nivel dos: "los estudiantes pueden interpretar y reconocer situaciones en contexto que requieren únicamente de inferencias directas", por lo que el proyecto de investigación propone implementar estrategias para alcanzar el nivel IV sobre habilidades matemáticas, especificadas por PISA. Este nivel considera que los "estudiantes sean capaces de trabajar efectivamente con modelos explícitos para situaciones complejas concretas" favoreciendo el pensamiento lógico matemático de los estudiantes. La investigación se realizó con 60 sujetos de 14 a15 años que asisten a la Escuela Secundaria Técnica No. 78 "Dr. Guillermo Massieu Helguera", en el Municipio de Chimalhuacán en el Estado de México. La muestra es no probabilística sin asignación al azar con un grupo intacto con pretest y postest. Es una investigación cuantitativa de alcance exploratorio. El propósito es realizar una primera aproximación que permita obtener datos para conocer y proponer insumos y estrategias que favorezcan el desarrollo de competencias lógico matemáticas y de pensamiento abstracto. De la implementación de un diseño instrumental considerando la estrategia de Aprendizaje Basado en Problemas, que permite generar nuevos conocimientos significativos, se tuvo como resultado que de la estrategia implementada el 92.4\% de los alumnos utilizó el conocimiento adquirido para seleccionar alternativas viables de solución a problemas, el $73.3 \%$ estableció relaciones entre variables de un problema mediante el lenguaje matemático y el $66 \%$ pudo plantear mediante el lenguaje algebraico un problema para su solución. Los resultados se consideran relevantes sin embargo no son representativos.
\end{abstract}

Palabras clave

Competencias, pensamiento abstracto, pensamiento lógico-matemático, aprendizaje basado en problemas y estrategia.

Forma sugerida de citar: Leiva Sánchez, Felipe (2016). ABP como estrategia para desarrollar el pensamiento lógico matemático en alumnos de educación secundaria. Sophia, colección de Filosofía de la Educación, 21(2), pp. 209-224.

* Licenciatura en Ingeniería Petrolera por la UNAM, Maestría en Ciencias en Educación Familiar por Enlaces Educativos y Doctorante en Pensamiento Complejo por Multidiversidad Mundo Real Edgar Morin. Trabajo en nivel secundaria. 


\begin{abstract}
In the latest PISA assessment conducted in Mexico (2015), the third graders of high school, on average, were located on level two "students can interpret and recognize situations in context that require only direct inferences " by what the research project proposes to implement strategies to achieve the level IV on mathematics skills specified by PISA. This level considers "students are able to work effectively with explicit models for complex concrete situations" favoring the mathematical logical thinking of students.

The research was conducted with 60 subjects from 14 to 15 years attending the Technical Secondary School No. 78 " Dr. Guillermo Massieu Helguera”, in the Municipality of Chimalhuacán in the State of Mexico. The sample is not random without randomization with an intact group with pretest and posttest. It is an exploratory quantitative research scope. The purpose is to make a first approximation to obtain data to meet and propose inputs and strategies that support the development of mathematical and logical skills of abstract thinking.

Implementation of an instrumental design considering the strategy of problem-based learning, which can generate significant new knowledge was resulted that the strategy implemented $92.4 \%$ of students used the knowledge gained to select viable alternative solutions to problems, $73.3 \%$ established relationships between variables of a problem using mathematical language and $66 \%$ through language could pose a problem for algebraic solution. The results are considered relevant but are not representative.
\end{abstract}

Keywords

Competence, abstract thought, mathematical-logical thought, problem based learning thought and strategy.

\title{
Introducción
}

Aprender mediante la resolución de problemas en el salón de clases requiere aglutinar una serie de situaciones, actitudes y habilidades intelectuales en donde se puede observar dos actores: un docente como mediador que interviene y ofrece ayuda pedagógica regulada para que el alumno sea constructor de su propio conocimiento, desarrollando habilidades tanto a nivel individual como en interacción con sus pares. Emplear el ABP (Aprendizaje Basado en Problemas) en un salón de clases es enfrentar a los alumnos a dilemas que parten de la realidad brindando estrategias que le permitan obtener información y diferentes alternativas para solucionar un problema concreto.

Con base a lo anterior se propone desarrollar el pensamiento lógico-matemático implementando la estrategia $\mathrm{ABP}$ acorde a la edad de los alumnos de tercer grado de secundaria.

De los resultados obtenidos en la última evaluación del Programa para la Evaluación Internacional de Estudiantes (PISA, por sus siglas en inglés) los estudiantes de tercer grado de educación secundaria se ubican en el nivel dos, lo cual se traduce en ejecutar procedimientos descritos 
con claridad, seleccionar y aplicar estrategias simples para solucionar problemas, así como realizar un razonamiento directo.

Es decir, se carece de las competencias que permiten tener un pensamiento lógico matemático capaz de:

1. Conceptualizar, generalizar y utilizar información.

2. Elaboración de modelos personales para resolver problemas complejos.

3. Habilidades para aplicar conocimientos y destrezas en situaciones nuevas.

Los docentes no pueden enseñar a los estudiantes si estos no comprenden las bases académicas, tienen carencias de conocimientos y de habilidades matemáticas, sobre todo los profesores de segundo y tercer periodo de educación básica (de primero a sexto grado de primaria), debido a su formación docente. Los alumnos llegan a la educación secundaria con seberas deficiencias, incluso desde el manejo de operaciones básicas, lo que no permite el desarrollo de habilidades acordes a su edad. Aunado a lo anterior no todos los docentes manejan estrategias que permitan un aprendizaje significativo.

La educación en México se encuentra en crisis, ya que existen muchos vacíos en las áreas de formación de los estudiantes de educación básica, la transición paradigmática plantea la necesidad de innovar las orientaciones en la forma cómo son definidos los problemas y son diseñados métodos de estudio que proponen interacciones dinámicas entre las ciencias.

La enseñanza de las matemáticas, en todos los niveles, es una actividad compleja ${ }^{1}$, no solo se refiere al desarrollo de habilidades en el manejo de operaciones básicas, de acuerdo al perfil de egreso de educación básica el alumno de educación básica debe ser capaz de identificar problemas, analizar, organizar e interpretar datos en diferentes formatos, además de buscar la forma de comunicar dicha información, emitir juicios y aplicar estrategias que permitan construir su conocimiento.

En México las matemáticas en nivel básico ocupa un lugar primordial en los planes y programas de estudio, cuyo objetivo es desarrollar las habilidades de razonamiento para que los estudiantes tengan "la capacidad de resolver problemas en forma creativa, y no para aplicar algoritmos y procedimientos rutinarios" (SEP, 2012, p. 23). Se basa en el pensamiento abstracto el cual un alumno de este nivel educativo está en condiciones de desarrollar, de acuerdo a Piaget, porque se ubica en la etapa de pensamiento abstracto que le brinda la capacidad de deducir, sintetizar, 
interpretar y analizar fenómenos, y situaciones abstractas como el pensamiento lógico matemático.

Sin embargo, al interior de las aulas en educación primaria solo se considera el pensamiento concreto porque de acuerdo a Piaget "para enseñar a un niño pequeño a sumar es probable que le tengamos que mostrar dos elementos y luego otros dos ... poco a poco podrá hacer éstas y otras operaciones cada vez más complejas sin tener por delante los objetos" (Frigermann, 2011, p. 1). Al pasar a la educación secundaria si bien es cierto que los alumnos se encuentran en la etapa del pensamiento abstracto cuya característica es que "podemos imaginar, extrapolar lo aprendido a nuevas situaciones, construir esquemas, ubicarnos en otros tiempos y lugares, deducir, sacar conclusiones y comparar" (Frigermann, 2011, p. 1). El tener la capacidad no da por hecho que el conocimiento 212 lógico-matemático surja espontáneamente, se deben brindar situaciones para favorecer que tales capacidades se manifiesten.

Por lo que es necesario utilizar estrategias como el Aprendizaje Basado en Problemas (ABP), con el que se puede mejorar el proceso enseñanza-aprendizaje al adecuarlo a las características y necesidades específicas de los estudiantes, lo que posibilita rediseñar las acciones a realizar en dicho proceso.

Según la SEP (2012) a lo largo de los años el proceso enseñanza aprendizaje busca estrategias para que los estudiantes se apropien de su conocimiento y desarrollen tanto el pensamiento crítico, como el complejo. Los estudiantes de educación básica no aprenden matemáticas, porque no saben relacionar los conocimientos que se les proporciona en la escuela (leyes, teoremas, formulas) con los problemas que se le presen$\tan$ en la vida real.

Tomando en cuenta lo anterior se puede decir que si se aplican estrategias que favorezcan su comprensión y utilidad, los estudiantes tendrán una actitud favorable al momento de ejecutarlas.

La mayoría de los docentes de los tres primeros periodos de educación básica enseñan matemáticas de una forma rutinaria, expositiva y tediosa siguiendo el modelo tradicionalista, no se preocupan por innovar en su forma de enseñar lo cual repercute en el aprendizaje de los alumnos. Según la teoría del aprendizaje contextual "el aprendizaje tiene lugar sólo cuando el alumno procesa información y conocimientos nuevos de tal manera que le da sentido en su marco de referencia (su propio mundo interno de memoria, experiencia y respuesta)" (CORD, 2003, p. 14).

Los docentes de hoy deben de considerar los conocimientos que se producen en las investigaciones del proceso enseñanza-aprendizaje para 
usarlos en la práctica docente, esto quiere decir que hay que reelaborar la forma de cómo se debe enseñar las matemáticas para que los estudiantes aprendan no sólo los contenidos de la materia sino que deben aprender a aprenderla, enseñándoles a conocer e identificar las dificultades que se presentan y los errores que incurren al resolver los problemas planteados. Es importante enseñar a los estudiantes a reflexionar y autoevaluarse para que sean capaces de reconocer sus habilidades, poniendo en práctica sus propios procedimientos que les permitan hacer un balance de lo que saben y como podrían subsanar sus deficiencias.

En el ABP, los estudiantes guiados por el profesor pueden adquirir de manera autónoma conocimientos a través de un proceso de búsqueda y solución de problemas en situaciones didácticas planteadas por el docente. Por lo anterior, estos deben desarrollar habilidades metacognitivas para que el estudiante reoriente las acciones que le permitirán un aprendizaje duradero, significativo y aplicarlo en diferentes áreas y momentos de su vida. "El aprendizaje resulta de la interrelación de tres elementos clave: la intención (motivación) de quien aprende, el proceso que utiliza (estrategia) y los logros que obtiene (rendimiento)" (Biggs, 1988, p. 56).

En la presente investigación se implementó la estrategia $A B P$ (Aprendizaje Basado en Problemas) en 60 alumnos como una alternativa para desarrollar el pensamiento lógico-matemático en las actividades dentro del aula.

También se exponen los propósitos y resultados de la última evaluación del Programa para la Evaluación Internacional de Estudiantes (PISA, por sus siglas en inglés) en el área de matemática, en México, del mismo modo se describe la estrategia del ABP considerando enfoque, propósitos, elementos y pasos a seguir para desarrollarlo.

\section{Programa para la Evaluación Internacional de Estudiantes}

Es un proyecto de la Organización para la Cooperación y Desarrollo Económico (OCDE) cuyo objetivo es "evaluar la formación de los alumnos cuando llegan al final de la etapa de enseñanza obligatoria, hacia los 15 años" (OCDE, 2006, p. 3). Es importante considerar los resultados que presenta porque esto permite "a los países miembros a adoptar las decisiones y políticas publicas necesarias para mejorar los niveles educativos" (OCDE, 2006, p. 3). Es decir, se puede tomar como una evaluación diagnostica para implementar acciones que favorezcan el desarrollo de com- 
petencias para la vida. La evaluación se realiza en tres áreas: Competencia lectora, matemática y científica.

Para matemáticas, PISA evalúa las habilidades y las aptitudes de los alumnos para analizar y poder resolver problemas en situaciones de la vida cotidiana.

PISA no está diseñado para evaluar aprendizaje de los contenidos específicos fijos en los programas de las escuelas, tampoco para evaluar el desempeño de los docentes, ni de los programas vigentes, se centra en el reconocimiento y valoración de las destrezas y conocimientos (OCDE, 2002, p. 5).

PISA (OCDE, 2002) en el área de matemáticas clasifica sus resultados en seis niveles de competencia:

1. Nivel seis (más de 668 puntos). Los estudiantes son capaces de conceptualizar, generalizar y utilizar información basada en sus investigaciones.

2. Nivel cinco (de 607 a 668 puntos). Los estudiantes pueden desarrollar y trabajar con modelo para situaciones complejas.

3. Nivel cuatro (de 545 a 606 puntos). Los estudiantes son capaces de trabajar efectivamente con modelos explícitos para situaciones complejas concretas.

4. Nivel tres (de 483 a 544 puntos). Los estudiantes son capaces de ejecutar procedimientos descritos claramente, incluyendo aquellos que requieren decisiones secuenciales.

5. Nivel dos (de 421 a 482 puntos). Los estudiantes pueden interpretar y reconocer situaciones en contexto que requieran únicamente de inferencias directas.

6. Nivel uno (de 358 a 420 puntos). Los estudiantes son capaces de contestar preguntas que impliquen contextos familiares donde toda la información relevante esté presente y las preguntas estén claramente definidas.

El examen de PISA, se elabora para, "conocer las competencias ... las habilidades, la pericia y las aptitudes de los estudiantes para analizar y resolver problemas, para manejar información y para enfrentar situaciones que se les presentaran en la vida adulta y que requerirán de tales habilidades" (OCDE, 2006, p. 5).

En el 2012 México ocupó uno de los últimos lugares de la evaluación de PISA, por lo que la OCDE (2012) propuso al gobierno mexicano desarrollar mecanismos para realizar un seguimiento para conocer las habilidades relevantes alcanzadas por los alumnos e incluir en los planes 
de estudio tanto en matemáticas como en las áreas del conocimiento qué deben aprender y bajo que secuencia. No olvidando que los resultados de la evaluación tienen sentido sólo si se utilizan para tomar decisiones que permitan mejorar el sistema educativo y, en consecuencia, mejorar la enseñanza y el aprendizaje en las aulas.

En la evaluación de 2015 de PISA, Rodríguez (2015) reporta lo siguiente, el $55 \%$ de los alumnos no alcanzó el nivel de competencias básicas en la asignatura de matemáticas, qué si bien aumentó algunos puntos, esto no fue suficiente, ya que México quedo en último lugar, logrando en promedio el nivel 2 de 6, ya que varios obtuvieron el nivel 1.

\section{Aprendizaje basado en problemas}

La mayoría de los docentes de los tres primeros periodos de educación básica enseñan matemáticas de una forma rutinaria, expositiva y tediosa siguiendo el modelo tradicionalista, no se preocupan por innovar en su forma de enseñar lo cual repercute en el aprendizaje de los alumnos. Según la teoría del aprendizaje contextual "el aprendizaje tiene lugar sólo cuando el alumno procesa información y conocimientos nuevos de tal manera que le da sentido en su marco de referencia (su propio mundo interno de memoria, experiencia y respuesta)" (CORD, 2003, p. 14).

Los docentes de hoy deben de considerar los conocimientos que se producen en las investigaciones del proceso enseñanza-aprendizaje para usarlos en la práctica docente, esto quiere decir que hay que reelaborar la forma de cómo se debe enseñar las matemáticas para que los estudiantes aprendan no sólo los contenidos de la materia sino que deben aprender a aprenderla, enseñándoles a conocer e identificar las dificultades que se presentan y los errores que incurren al resolver los problemas planteados. Es importante enseñar a los estudiantes a reflexionar y autoevaluarse para que sean capaces de reconocer sus habilidades, poniendo en práctica sus propios procedimientos que les permitan hacer un balance de lo que saben y como podrían subsanar sus deficiencias.

Ante la globalización en la educación, el ABP es de los procesos de enseñanza aprendizaje que se pueden establecer, como una estrategia innovadora que se centra en el estudiante y promueva el trabajo interpersonal-colaborativo.

El aprendizaje basado en problemas (ITESM, 2011) parte del principio de plantear problemas como un punto de partida para la adquisición e integración de nuevos conocimientos, trabajando en pequeños 
grupos de alumnos y a través de la facilitación que hace el tutor se analizan y resuelven problemas seleccionados o diseñados especialmente para el logro de ciertos objetivos de aprendizaje.

$\mathrm{El} \mathrm{ABP}$ "es un enfoque educativo orientado al aprendizaje y a la instrucción en el que las y los estudiantes abordan problemas reales o hipotéticos en grupos pequeños y bajo la supervisión de un tutor" (Guevara, 2010, p. 4). El ABP "es una estrategia de enseñanza aprendizaje en la que tanto la adquisición de conocimientos como el desarrollo de habilidades y actitudes resulta importante" (ITESM, 2011, p. 4).

Se sabe que las estrategias tradicionales solamente se basan en la transmisión y adquisición de conocimientos, la estrategia del ABP permite que los alumnos aprendan a identificar y resolver problemas. de acuerdo a Barrel (1999), el ABP motiva a los individuos a buscar situaciones 216 con el objetivo de construir soluciones a través de procedimientos inherentes a la investigación.

El ABP mejora aspectos muy importantes en el proceso enseñanza-aprendizaje con respecto a la enseñanza tradicional, como lo mencionan Blumerg, Mitchell, Norman y Achimidt (citados en Vizcarro, 2010) de la siguiente manera:

- Favorece la asimilación de los aprendizajes para la solución de problemas.

- El trabajo se establece en pequeños grupos (equipo).

- Hay un aumento en las habilidades de auto aprendizaje.

- El alumno aplica la problemática de su vida cotidiana.

- Se profundizan las aptitudes intelectuales, sociales y afectivas.

- Se agrupan los recursos a utilizar.

- Continúa un perfeccionamiento en el aprendizaje.

- Se obtiene los conocimientos necesarios.

De acuerdo a Guevara (2010) el papel del docente es:

- Ayudar a sus alumnos a tener una actitud reflexiva.

- Favorecer la detección de información requerida para la solución de un problema.

- Monitorear que las acciones del alumno no se dispersen para que logre su objetivo propuesto.

- Brindar cuestionamientos que guíen y faciliten el aprendizaje.

Con respecto al papel de los alumnos Guevara (2010) menciona que el alumno debe tener "motivación profunda y clara sobre la necesi- 
dad de aprendizaje, disposición para trabajar en grupo, tolerancia para enfrentarse a situaciones ambiguas ...habilidades para la solución de problemas, habilidades de comunicación" (p. 161).

$\mathrm{Al}$ respecto Milla considera que el $\mathrm{ABP}$, "remarca dos aspectos fundamentales por un lado el papel que juega el docente como orientador del proceso y por otro lado el hecho de que la solución debe ser producto de la interacción de un equipo (2012, p. 33). De manera general estas estrategias específicamente ven la enseñanza de las matemáticas se puede implementar como lo proponen Moust, Bouhijs y Schmidt (citados en Vizcarro, 2010).

1. Enumerar los conceptos a utilizar.

2. Identificar el problema en cuestión.

3. Interpretar el tipo de problema, para que los estudiantes pongan en práctica sus conocimientos.

4. Anotar todos los conceptos relacionados con el problema y discutirlos.

5. Exponer los postulados del problema y plantar los objetivos de aprendizaje.

6. Investigación individual, con lo planteado en el paso anterior.

7. Se realiza un resumen en base a toda la información recabada, para estructurar las conclusiones del problema.

\section{Desarrollo metodológico}

Esta propuesta se encuentra enmarcada dentro de la docencia, que se imparte en educación básica y se fundamenta en la pedagogía como un medio de acción en la educación, usando enfoques más flexibles y dinámicos.

El universo poblacional en el que se desarrolló esta investigación, es en la institución educativa Escuela Secundaria Técnica No. 78 "Doctor Guillermo Massieu Helguera". La muestra consta de 1 grupo de los 36 que forman la institución, 60 alumnos de tercer grado (grupo intacto). Los criterios de inclusión son alumnos de 14 a 16 años que cursan el tercer grado de educación secundaria grupo "A".

La investigación tiene un diseño cuantitativo de alcance exploratorio, con Pretest y Postest.

Realizar una primera aproximación que permita obtener datos para conocer y proponer insumos que favorezcan el desarrollo de competencias lógico matemáticas y de pensamiento abstracto. A través de la implementación de un diseño instrumental considerando la estrategia de ABP. 


\section{Procedimiento}

1. Se hizo una evaluación inicial (Pretest, ver anexo 1) a todos los alumnos del grupo para conocer el nivel de competencias para la solución de problemas mediante el uso de las matemáticas, encontrándose que la mayoría de ellos se encuentran en el nivel dos (de acuerdo a la taxonomía del dominio del conocimiento de Marzano) "comprensión de la información", que les permite recordar e identificar detalles de la información siendo capaces de sintetizarla y representarla en categorías cuando requieren de ella. Lo que significa que el alumno requiere tener a la mano la información necesaria para poderla consultar y utilizar el lenguaje algebraico, establecer relaciones entre variables, seleccionar alternativas, buscar y corregir soluciones a problemas mediante el uso de las matemáticas.

El 54.7\% comprende los contenidos abordados para plantear mediante el lenguaje algebraico un problema para su solución. El 58.4\% recupera cómo establecer relaciones entre variables de un problema mediante el lenguaje matemático. El 50.9\% comprende la selección de alternativas viables de solución a problemas planteados. El 47.1\% comprende la solución de problemas mediante el uso de las matemáticas. El 62.2\% comprende la corrección a las soluciones dadas a diversos problemas planteados mediante la identificación del tipo de error que se cometió. $66 \%$ comprende e identifica sus intereses y gusto por las matemáticas y la solución de problemas.

2. En 20 sesiones se implementó la estrategia ABP (ver anexo 2), tomando en cuenta a Morales \& Landa (2004), que mencionan los siguientes pasos:

Analizar el escenario del problema

Lluvia de ideas a la solución del problema

Listar lo que se conoce del problema

Listar lo que se desconoce del problema

Listado de pasos a seguir para dar solución del problema

Definir exactamente lo que se desea resolver

Obtener información pertinente para la solución

Presentar la solución del problema

3. Evaluación final (Postest, ver anexo 3)

Después de la implementación de la estrategia ABP, los resultados obtenidos del postest muestran que la mayoría de los alumnos se ubican en el nivel cuatro (de acuerdo a la taxonomía del dominio del 
conocimiento de Marzano), "utilización del conocimiento" que les permite aplicar el conocimiento en situaciones específicas para resolver problemas, generar y evaluar hipótesis, Es decir la mayoría de los alumnos son capaces de aplicar conocimientos adquiridos para utilizar el lenguaje algebraico, establecer relaciones entre variables, seleccionar alternativas de solución, planteando y evaluando hipótesis que se hacen al respecto siendo capaces de autocorregirse.

El 66\% utilizan el conocimiento adquirido para plantear mediante el lenguaje algebraico un problema para su solución. El 77,3 \% utilizan el conocimiento adquirido para establecer relaciones entre variables de un problema mediante el lenguaje matemático. El 92.4\% utiliza su conocimiento adquirido para seleccionar alternativas viables de solución a problemas planteados. El $56.6 \%$ utiliza su conocimiento para solucionar problemas mediante el uso de las matemáticas. El $47.1 \%$ utiliza sus conocimientos para corregir las soluciones dadas a diversos problemas planteados mediante la identificación del tipo de error que cometió. El $79.2 \%$ analiza para identificar sus intereses y gusto por las matemáticas y la solución de problemas.

En la siguiente gráfica se comparan los resultados obtenidos en el pretest y postest.

\section{Gráfico 1}

Moda del nivel de competencias para la solución de problemas matemáticos ${ }^{2}$

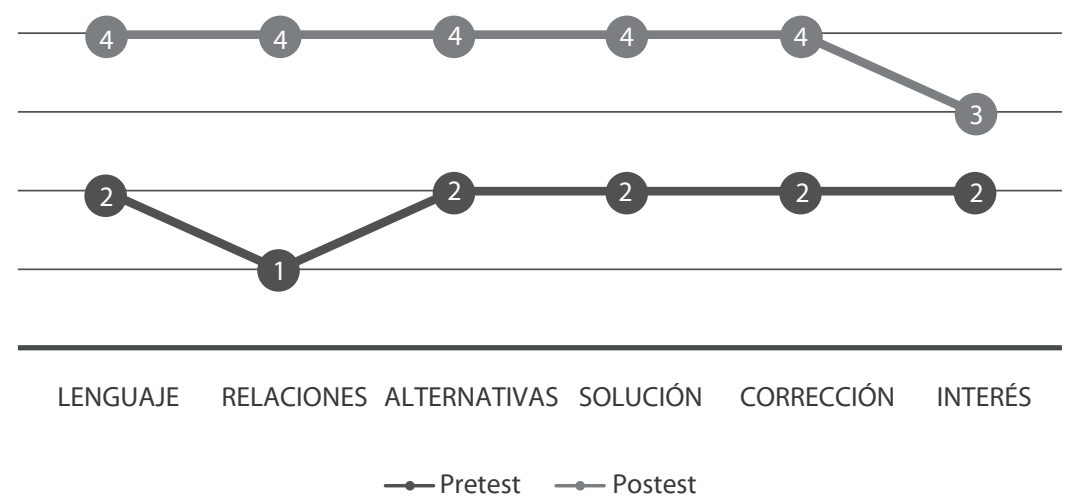

Elaboración propia 


\section{Discusión}

El propósito de esta investigación fue realizar una primera aproximación que permita obtener datos preliminares de las habilidades y actitudes que presentan alumnos de tercer grado de secundaria a partir de los cuales se pueden proponer actividades que favorezcan el desarrollo de competencias lógico matemáticas y de pensamiento abstracto utilizando el ABP. De los resultados, se puede observar un incremento del 52.8\% de alumnos que utilizan los conocimientos adquiridos para plantear mediante el lenguaje algebraico un problema propuesto por ellos mismos, un incremento del $73.7 \%$ de alumnos que lograron establecer relaciones entre variables de un problema mediante el lenguaje matemático, el aspecto que más se incrementó en un $83 \%$ fue el selecciona alternativas viables de solución a problemas planteados, sin embargo hubo un ligero incremento en el número de alumnos que identifica sus intereses y gusto por las matemáticas.

Otros aspectos relevantes que pueden mencionarse es que más del $70 \%$ de los alumnos saben definir variables, formular ecuaciones, formar sistemas de ecuaciones y encontrar la solución de la forma que consideran más conviene.

La enseñanza de las matemáticas debe ser un proceso que seleccione diferentes estrategias que favorezcan el desarrollo del pensamiento abstracto y habilidades que permitan un desempeño adecuado en esta disciplina por lo que sería interesante identificar qué estrategias favorecen el proceso de enseñanza- aprendizaje y que actividades.

\section{Conclusiones}

El estudio de las matemáticas suele considerarse una actividad reservada a algunos pocos privilegiados porque se considera que es necesario ser muy inteligente o tener el manejo de ideas, cosas o situaciones muy elaboradas. Sin embargo, las competencias desarrolladas por los alumnos de la presente investigación contradicen tal premisa debido a que estos pertenecen al Municipio de Chimalhuacán, Estado de México, el cual es considerado con cierta desventaja cultural, social y económica, y en 20 sesiones pasaron del nivel dos "comprensión de la información" al nivel cuatro "utilización del conocimiento" de lo que se deduce, que las competencias se pueden perfeccionar si se propician situaciones para ello. 
Partiendo de la premisa de que todos los alumnos de 14 y 15 años se encuentran, de acuerdo a Piaget, en la etapa de operaciones abstractas y que el proceso de enseñanza-aprendizaje se lleva a cabo mediante la implementación de estrategias, el ABP puede ser utilizado en cualquier escuela de educación secundaria para favorecer el aprendizaje de las matemáticas con la única observación de que el profesor debe tener un adecuado manejo de dicha estrategia. Porque generalmente quienes enseñan matemáticas se limitan a "explicar" "un método de resolución de problemas y hacer un $\mathrm{N}$ número de ejercicios para que "aprenda” a resolverlos.

De los resultados obtenidos se concluye que el ABP facilita el aprendizaje de las matemáticas y favorece el desarrollo de competencias y habilidades propias del pensamiento abstracto, como representar situaciones de la realidad a través del lenguaje matemático, separando la información que no es relevante y destacando aquella que permite la solución de problemas utilizando el análisis de la información generalizando procedimientos y representando de manera abstracta problemas matemáticos.

\section{Anexos}

El problema que se utilizó para obtener los resultados fue: Karla pago \$41 por una pasta dental y dos jabones. Bety compró dos pastas dentales y 3 jabones por \$74. ¿Cuánto cuesta cada pasta dental y cada jabón?

\section{Anexo 1}

\section{Evaluación inicial}

\begin{tabular}{|c|c|c|c|c|c|c|c|c|c|}
\hline $\begin{array}{l}\text { Competencias } \\
\text { en la solución } \\
\text { de problemas }\end{array}$ & $\begin{array}{c}\text { Evidencia necesaria } \\
\text { para identificar } \\
\text { que se desarrolló la } \\
\text { competencia evaluar. } \\
\text { Se deben enunciar } \\
\text { tantos indicadores } \\
\text { como el grupo cole- } \\
\text { giado determine que } \\
\text { es suficiente. }\end{array}$ & \multicolumn{6}{|c|}{$\begin{array}{l}\text { Niveles de complejidad sugeridos } \\
(\%)\end{array}$} & \multicolumn{2}{|c|}{$\begin{array}{l}\text { 1.Recuperación } \\
\text { 2. Comprensión } \\
\text { 3. Análisis } \\
\text { 4.Utilización del } \\
\text { conocimiento } \\
\text { 5. Metacognición } \\
\text { 6.Autosificiencia }\end{array}$} \\
\hline \multirow[t]{2}{*}{$\begin{array}{l}\text { Bloques } \\
\text { o rasgos de } \\
\text { competencia }\end{array}$} & $\begin{array}{l}\text { Indicadores de } \\
\text { Aprendizaje }\end{array}$ & 1 & 2 & 3 & 4 & 5 & 6 & Dominio & $\begin{array}{l}\text { Ponde- } \\
\text { ración }\end{array}$ \\
\hline & $\begin{array}{l}\text { Plantea mediante el } \\
\text { lenguaje algebraico } \\
\text { un problema para su } \\
\text { solución }\end{array}$ & 28.3 & 54.7 & 1.8 & 13.2 & 0 & 1.8 & & \\
\hline
\end{tabular}




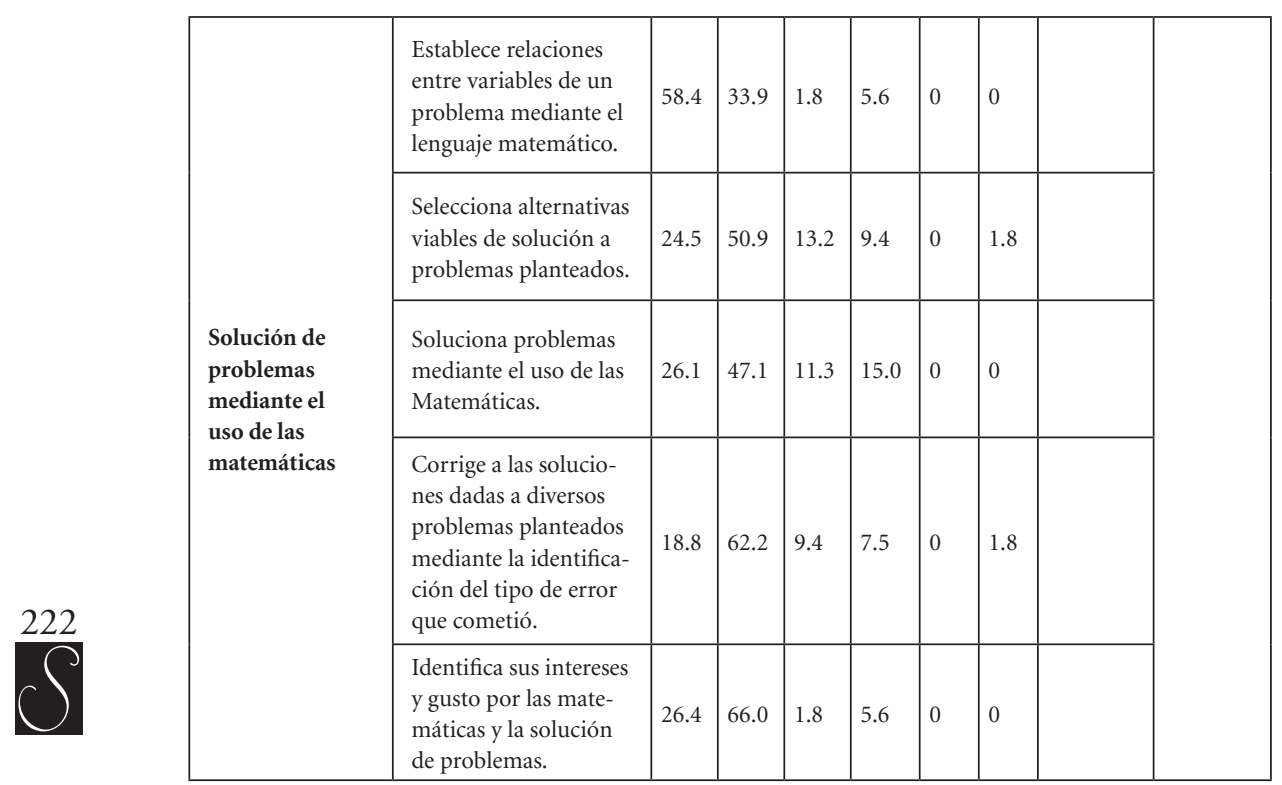

Tabla de especificaciones de cómo evaluar un curso de matemáticas de Yolanda E. Leyva Barajas (2010).

\section{ANEXO 2}

\begin{tabular}{|c|c|c|l|}
\hline Etapa & Sesiones & $\begin{array}{c}\text { Paso } \\
\text { ABP }\end{array}$ & \multicolumn{1}{c|}{ Descripción } \\
\hline 1 & 3 & - & Conocimiento de operaciones básicas. \\
\hline 2 & 3 & - & Utilización de operaciones básicas. \\
\hline 3 & 3 & $1,2,3$ & $\begin{array}{l}\text { Aplicación de operaciones básicas a proble- } \\
\text { mas sencillos. }\end{array}$ \\
\hline 4 & 3 & 4,5 & $\begin{array}{l}\text { En equipos formulan problemas y ofrecen } \\
\text { soluciones utilizando diferentes formas de } \\
\text { llegar al mismo resultado. }\end{array}$ \\
\hline 5 & 2 & 6,7 & $\begin{array}{l}\text { Rotación de integrantes de los equipos con- } \\
\text { formándolos de manera heterogéneo (50\% } \\
\text { de alumnos con pocas habilidades y 50\% } \\
\text { con habilidades y actitud positiva). }\end{array}$ \\
\hline 6 & 6 & 8 & $\begin{array}{l}\text { Exposición y retroalimentación por equi- } \\
\text { pos del procedimiento utilizado para la re- } \\
\text { solución de problemas planteados por ellos } \\
\text { mismos. }\end{array}$ \\
\hline
\end{tabular}




\section{Evaluación final}

\begin{tabular}{|c|c|c|c|c|c|c|c|c|c|}
\hline $\begin{array}{c}\text { Competencias } \\
\text { en la solución } \\
\text { de } \\
\text { Problemas }\end{array}$ & $\begin{array}{c}\text { Evidencia necesaria para } \\
\text { identificar que se desarro- } \\
\text { lló la competencia evaluar. } \\
\text { Se deben enunciar tantos } \\
\text { indicadores como el gru- } \\
\text { po colegiado determine } \\
\text { que es suficiente. }\end{array}$ & \multicolumn{6}{|c|}{$\begin{array}{c}\text { Niveles de complejidad sugeridos } \\
(\%)\end{array}$} & \multicolumn{2}{|c|}{$\begin{array}{l}\text { 1.Recuperación } \\
\text { 2. Comprensión } \\
\text { 3. Análisis } \\
\text { 4.Utilización del } \\
\text { conocimiento } \\
\text { 5. Metacognición } \\
\text { 6.Autosuficiencia }\end{array}$} \\
\hline $\begin{array}{l}\text { Bloques } \\
\text { o rasgos de } \\
\text { competencia }\end{array}$ & $\begin{array}{l}\text { Indicadores de } \\
\text { Aprendizaje }\end{array}$ & 1 & 2 & 3 & 4 & 5 & 6 & Dominio & $\begin{array}{l}\text { Ponde- } \\
\text { ración }\end{array}$ \\
\hline \multirow{6}{*}{$\begin{array}{l}\text { Solución } \\
\text { de problemas } \\
\text { mediante } \\
\text { el uso de las } \\
\text { matemáticas }\end{array}$} & $\begin{array}{l}\text { Plantea mediante el } \\
\text { lenguaje algebraico un pro- } \\
\text { blema para su solución. }\end{array}$ & 5.6 & 11.3 & 13.2 & 66.0 & 0 & 3.7 & & \\
\hline & $\begin{array}{l}\text { Establece relaciones entre } \\
\text { variables de un problema } \\
\text { mediante el lenguaje } \\
\text { matemático. }\end{array}$ & 0 & 0 & 3.7 & 77.3 & 0 & 18.8 & & \\
\hline & $\begin{array}{l}\text { Selecciona alternativas } \\
\text { viables de solución a } \\
\text { problemas planteados. }\end{array}$ & 7.5 & 0 & 0 & 92.4 & 0 & 0 & & \\
\hline & $\begin{array}{l}\text { Soluciona problemas } \\
\text { mediante el uso de las } \\
\text { Matemáticas. }\end{array}$ & 1.8 & 0 & 11.3 & 56.6 & 0 & 30.1 & & \\
\hline & $\begin{array}{l}\text { Corrige a las soluciones } \\
\text { dadas a diversos problemas } \\
\text { planteados mediante la } \\
\text { identificación del tipo de } \\
\text { error que cometió. }\end{array}$ & 0 & 3.7 & 9.4 & 47.1 & 0 & 39.6 & & \\
\hline & $\begin{array}{l}\text { Identifica sus intereses y } \\
\text { gusto por las matemáticas } \\
\text { y la solución de problemas. }\end{array}$ & 0 & 1.8 & 79.2 & 5.6 & 0 & 13.2 & & \\
\hline
\end{tabular}

Tabla de especificaciones de cómo evaluar un curso de matemáticas de Yolanda E. Leyva Barajas (2010)

\section{Notas}

1 Los perfiles de egreso no son alcanzados por los alumnos de dicho nivel educativo, carencias que se reflejan en los resultados de las evaluaciones de carácter nacional e internacional a las que son sometidos.

2 Se muestra el nivel competencia en el que la mayoría de los alumnos se ubicó antes y después de la utilización de la estrategia del ABP, observándose a incremento en todos los indicadores de aprendizaje.

\section{Bibliografía}

BARREL, John

1999 El aprendizaje basado en problemas-un enfoque investigativo. Buenos Aires: Manantial SRL. 
BIGGS, John

1988 Approaches to learning and to assay writing. Learning strategies and learning styles. New York: R. Sarachek.

CORD

2003 Enseñanza contextual de las matemáticas, piedra angular del cambio de paradigmas. Estados Unidos de América: CORD Comunications.

GUEVARA, Gabriela

2010 Aprendizaje basado en problemas como técnica didáctica para la enseñanza del tema de la recursividad. Revista Intercedes, XI(XX). Revista electrónica de las sedes regionales de la Universidad de Costa Rica.

2011 Vicerrectoría Académica, Dirección de Investigación y Desarrollo Educativo. El Aprendizaje Basado en Problemas como técnica didáctica. http://www. sistema.itesm.mx/va/dide/inf-doc/estrategias/, 31 de mayo de 2016.

LEYVA B., Yolanda

2010 Evaluación del aprendizaje: una guía práctica para profesores. www.ses.unam. $\mathrm{mx} /$ curso2012/pdf/Guía_evaluación_aprendizajes2010.pdf.porYELBa rajas-2010, 9 de mayo de 2016.

MILLA, Milagros

2012 Pensamiento crítico en estudiantes de $5^{\circ}$ de secundaria de los colegios de Carmen de la Legua Callao (Tesis de maestría). Lima: Universidad San Ignacio de Loyola. www.academia.edu./.../2012_Milla_Pensamiento-crítico-en-estu diantesde quinto-de-secundaria. 3 de junio de 2016.

MORALES, Patricia \& LANDA, Virginia

2004 Aprendizaje basado en problemas. Lima: PUCP Departamento de Ciencias, sección química.

OCDE

2002 Aptitudes para lectura, matemáticas y ciencias. París: OCDE. México: Aula XXI. Santillana.

2006 El programa de PISA de la OCDE, qué es y para qué sirve. Paris: OCDE. México: Grupo Santillana

2012 Assessing Scientific, Reading and Mathematical Literacy. A Framework for PISA 2012. OECD Publishing.

RODRÍGUEZ, Fernando

2015 Reprueba la educación en México. http://expansión.mx/.../2015/06/.../ocdereprueba-la-educación-en-méxico-graficas-de-la-semana. 5 de junio de 2016.

SECRETARÍA DE EDUCACIÓN PÚBLICA

2012 Educación por Niveles. México: SEP.

VIZCARRO, Carmen

2010 La metodología del aprendizaje basado en problemas. ¿Qué es y cómo funciona el aprendizaje basado en problemas? Madrid: Universidad Autónoma de Madrid. http://ub.edu/dikasteia/LIBRO_MURCIA.pdf, 6 de junio de 2016.

Fecha de recepción del documento: 5 de julio de 2016

Fecha de aprobación del documento: 15 de agosto de 2016 


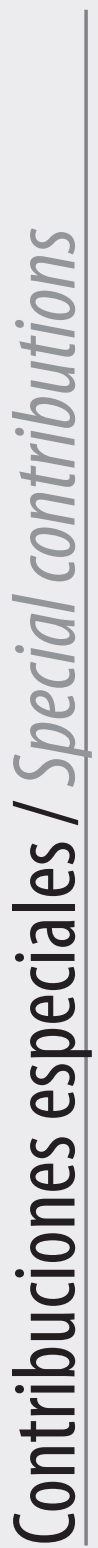





\section{Desafíos para la educación actual Challenges for the current education}





\title{
FORMACIÓN DOCENTE Y DIÁLOGO DE SABERES
}

\author{
EN EL KAIROS EDUCATIVO
}

\section{Teacher training and dialogue of knowledges in the educational kairos}

\author{
VIRGINIA GONFIANTINI* \\ Multiversidad Edgar Morin/México \\ Universidad Nacional de Rosario/Argentina \\ vgonfiantini@hotmail.com
}

\begin{abstract}
Resumen
Cierta ausencia de procesos recursivos y dialógicos en la formación docente-en el contexto actual caracterizado por grandes cuestionamientos glocales, sociales, políticos, culturales y epistemológicos- genera la necesidad de un debate sobre la construcción de "otras" vías de mejoramiento. Es indudable que esta formación docente -en el nuevo milenio- aparece en una trama que entreteje discusiones en las diversas teorías que conforman su andamiaje: pedagogía, didáctica, filosofía, antropología, sociología y estudios culturales, por mencionar sólo algunos de esos hilos. Y es lógico que esa urdimbre exista en tanto se habla de una profesión que se desarrolla unida y dependiente de un sistema político que marca los fundamentos y directrices que deben optarse.

Se suma a ello que en la institución educativa -en cualquiera de sus niveles- se tensionan mandatos fundacionales, tradiciones, normativas y trayectorias que no terminan de ubicarse en el actual desafío que significa hoy educar al ciudadano para una sociedad democrática, pluralista, inclusiva, compleja. Es decir, la formación docente se da en una institución que aún guarda en su matriz los principios e ideales de siglos anteriores, con aulas comenianas, gestión fuertemente vertical y escasa comunicación.

Como aporte en la búsqueda de otra forma de pensar tal formación, en esta instancia se procura analizar cómo el campo disciplinar de la didáctica dialógica o complexa prepara a los futuros profesores para pensar su praxis con autonomía, responsabilidad y escrutinio crítico. Un nuevo modelo requiere una nueva lógica de construcción constituida por una epistemología compleja que brinde herramientas para pensar la formación docente, su práctica, los sujetos pedagógicos involucrados en la misma y la recursividad gnoseológica compleja que los determina.
\end{abstract}

Forma sugerida de citar: Gonfiantini, Virginia (2016). Formación docente y diálogo de saberes en el kairos educativo. Sophia, colección de Filosofía de la Educación, 21(2), pp. 229-245.

* Doctora en Pensamiento Complejo y Diplomada en Transformación Educativa (Multiversidad Mundo Real Edgar Morin, Hermosillo, México. Revalidado por California University); Magister en Educación, con orientación en Gestión, Evaluación y Acreditación (Universidad El Salvador, Argentina) y Cientista de la Educación (Universidad Nacional de Rosario). En la actualidad se desempeña como profesora en Multiversidad Mundo Real Edgar Morin, en Universidad Nacional de Rosario y en distintos Institutos de Formación Docente (Rosario y Arroyo Seco). 
Teacher training and dialogue of knowledges in the educational kairos

Palabras clave

Recursividad, formación docente, didáctica dialógica-complexa, kairos educativa.

\begin{abstract}
A certain absence of recursive and dialogical processes in teacher training, in a context characterized by great glocal, social, political, cultural and epistemological questionings, demands the need for a discussion about the construction of other ways of improvement. Undoubtedly, teacher training in the new millennium is woven within a fabric of discussions about the different theories that constitute its framework: pedagogy, didactics, philosophy, anthropology, sociology and cultural studies, just to mention a few of those threads. It stands to reason that such weft exists as long as we are discussing a profession developed as connected and dependent to a political system which determines the fundamentals and directives to be made.

In addition, within the educational institution, at any level, there is tension among the founding mandate, tradition, regulations and history, which are not able to find their place in the challenge of educating the citizen for a democratic, pluralist, inclusive and complex society. That is to say, teacher training takes place within an institution that still keeps in its core the principles and ideals of previous centuries, with comenian classrooms, highly vertical management, and lack of communication.
\end{abstract}

As a contribution to the search of new ways to think training, this time, we try to analyze how the disciplinary field of dialogic or complexa didactics prepares future teachers to think their praxis with autonomy, responsibility and critical and thorough examination.

A new model requires a new logic of recursive and metacognitive construction, formed by a complex epistemology which provides the tools for thinking about teacher training, its practice, the pedagogical subjects involved and the gnoseological recursiveness that determines them.

Keywords

Recursiveness, teacher training, dialogica complexa dialectics, educational kairos.

\title{
Introducción
}

Cada día resulta más evidente que el siglo XX se inauguró a partir de la "extrañeza de su horizonte" , como se ha analizado en numerosos artículos tanto propios como de la numerosa literatura existente sobre el tema. Esta extrañeza deviene de las profundas rupturas epistemológicas producidas en el contexto planetario a partir de fuertes autocríticas en numerosos campos disciplinares que obligaron a profundas revisiones al percatarse que la realidad no es tan sencilla como parece y por ende, sus premisas no son tan "simples, universales, cerradas y perfectas" (Gonfiantini, 2014, p. 34).

En ese contexto que se prolonga y expande en el nuevo milenio, la formación docente aparece en un entramado que entreteje discusiones en las diversas teorías que conforman su andamiaje: pedagogía, didáctica, filosofía, antropología, sociología y estudios culturales, por mencionar 
sólo algunos de esos hilos. Y es lógico que ello ocurra porque en la institución educativa -en cualquiera de sus niveles- se tensionan mandatos fundacionales, tradiciones, normativas y trayectorias que no terminan de ubicarse en el actual desafío que significa hoy educar al ciudadano para una sociedad democrática, pluralista, inclusiva, compleja ${ }^{2}$.

Entonces, ¿desde dónde comenzar el lento pero imperativo proceso de redefinir metas, objetivos, dispositivos, estrategias y modalidades para asumir la problemática? A partir de esta situación problemática que enmarcó un trabajo de campo de cierta intensidad en un establecimiento de formación docente ${ }^{3}$, el objetivo fundamental fue observar y analizar la práctica de los formadores de formadores, con el fin de encontrar un dispositivo que permitiese al educador adueñarse de su profesión, al comprender la interrelación entre teorías de uso y teorías adoptadas (Anijovich, 2009). La autora -al retomar un texto de 1974, de Argyris y Schön- afirma que los individuos cuentan con dos teorías de la acción que no se oponen, sino que se implican. La distinción entre ambas es que unas están implícitas en la cotidianeidad y otras se ponen en juego al hablar de estas acciones a otros, es decir, cuando se conceptualiza y verbaliza. Aquellas implícitas se denominan "teorías en uso" y habitualmente, son las que efectivamente gobiernan las acciones del educador. De allí que a través de encuestas y entrevistas a educadores, fue posible plasmar la necesidad de fijar una línea: Es fundamental aprender a "reflexionar sobre la propia práctica también significa reflexionar sobre la propia historia, los habitus, la familia, la cultura, los gustos y aversiones, la relación con los demás, las angustias y la obsesiones" (Perrenoud, 2004, p. 50). Desde esa premisa -al reunir práctica docente y reflexión- resulta claro que al poner en foco la formación, emerge la problemática central para pautar la necesaria re-significación.

Por ende, el punto inicial, la matriz desde donde se proyectará el cambio es la formación docente, la práctica de los formadores de formadores, el espacio en el que se consolidará la concepción de un aprendizaje que -constante y recursivamente- se debe abrir a nuevos retos. Esta es la perspectiva a desarrollar en este artículo a partir de poner en debate las siguientes aristas: la didáctica compleja, el diálogo de saberes y la recursividad dialógica como constituyentes de un trinomio imprescindible para enseñar y aprender en el kairos educativo.

La emergencia de las teorías de la complejidad, como una de las rupturas epistemológicas del siglo XX, nos invita a pensar desde la alteridad las nuevas problemáticas que encierra la educación en la actualidad. Ello implica partir desde la perspectiva de un enfoque pedagógico alter- 
nativo en la formación de educadores para generar modelos que posibiliten la investigación, la reflexión, el diálogo de saberes y las modalidades de aprendizajes que se concreticen en armonía con la esencia de los sujetos, los requerimientos de las sociedades y el necesario respeto a las diferencias.

\section{La formación docente en perspectiva compleja}

...la tarea más difícil consiste en poner la cultura cientifica en estado de movilización permanente, sustituir el saber cerrado y estático por un conocimiento abierto y dinámico, dialectizar todas las variables experimentales, dar finalmente a la razón motivos para que evolucione

(Bachelard, 1995).

Ahora bien, si hablamos de problemáticas tendremos que introducir necesariamente el cuestionamiento para destejer los hilos que traman el campo de la formación docente y replantear estrategias y metodologías que permitan cambiar:

- El dogmatismo por la problematización.

- Lo disciplinar por lo transdisciplinar.

- La certeza por la incertidumbre.

- La transmisión reproductora por una transmisión lograda (Hassoun, 1996).

- Una didáctica instrumental por otra didáctica cuyo eidos sea dialógica ó complexa.

En otras palabras, re-fundar todo un estilo que lleva sobre sus espaldas una pesada mochila de éxitos y fracasos, para atrevernos a mirar con amplitud y sin preconceptos la realidad en que nos movemos como formadores.

\section{Didáctica dialógica - complexa como eidos epistémico para la formación docente que queremos}

Coincidimos y retomamos los aportes de los didactistas reconceptualistas cuando definen que la didáctica es la ciencia que se ocupa de los procesos de enseñanza y aprendizaje y entendemos a la metacognición-siguiendo a Fla- 
vell (1978) - en tanto conocimiento de los propios procesos cognitivos, de los resultados de los mismos y de cualquier aspecto relacionado a esos procesos.

La metacognición se refiere, entre otros aspectos, a la continua observación de estos procesos en relación con los objetos cognitivos sobre los que se apoyan, generalmente al servicio de alguna meta concreta $\mathrm{u}$ objetivo. Burón Orejas (s/f, pp. 15-16) considera que Flavell destaca como aspectos esenciales de la actividad mental metacognitiva madura:

1. Conocimiento de los objetivos que se quieren alcanzar con el esfuerzo mental: qué objetivos se pueden ver en el texto más que la repetición de una actividad que resulta completamente ajena a quien se acerca a ese texto.

2. Elección de estrategias para conseguirlo: no existe la palabra elegir en clases autoritarias.

3. Autoobservación de la ejecución para comprobar si las estrategias seleccionadas son las adecuadas: no se produce la "autoobservación" en situaciones opresoras.

4. Evaluación de los resultados para saber hasta qué punto se han logrado los objetivos que se plantearon.

En resumen, si revisamos la bibliografía sobre metacognición surge que la madurez metacognitiva supone que todo educando es cognitivamente maduro cuando puede dilucidar qué es comprender y cómo puede llegar a alcanzar esa meta (qué estrategias ha de usar, cómo manejará la información para transformarla en conocimiento, cuáles son los modos de dotarla de sentido, etc.) (Imagen 1).

\section{Imagen 1 \\ Características de la cognición madura}

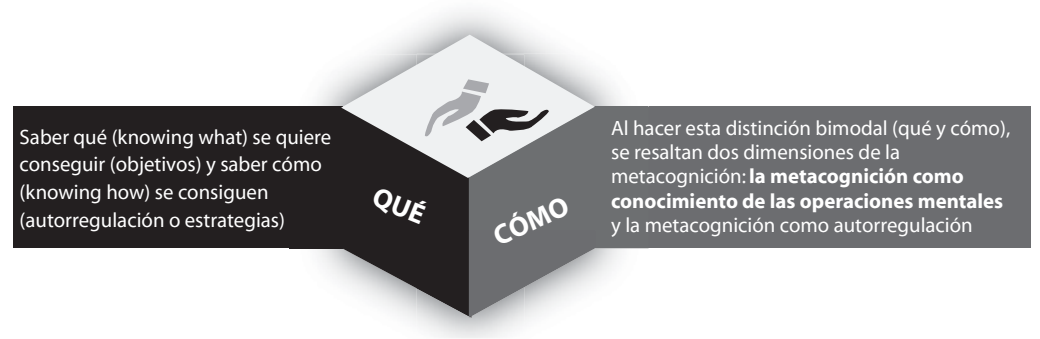

Elaboración propia 


\section{La práctica de los formadores de formadores: Procesos metacognitivos}

Al ubicar esta premisa en el área de los institutos y universidades en los cuales se forma a los futuros educadores, aparece una pista inicial. Para poder enseñar y aprender los procesos metacognitivos es necesario detenernos en la construcción de la didáctica como disciplina teórica y como campo epistemológico de saber. Emerge una punta fundamental, que nos obliga a no obviar lo que permanece subyacente, como estructura que determina modos de ser educador y educar.

Ángel D. Barriga (1995 [1991]) resalta la urgencia de un estudio cada día más extenso y profundo en relación con los problemas conceptuales de la didáctica, atendiendo a las posibilidades de su conformación teórica. Coincidentemente con él, José Domingo Contreras (1991) plantea cierto desconocimiento respecto al saber didáctico y una serie de reduccionismos que infantiliza el campo. Por lo tanto ambos teóricos se preguntan sobre la construcción del campo disciplinar ¿qué es la didáctica? Desde ese interrogante inicial -en un intento de definirla y delimitarla, siempre reconociendo que todo definición es aproximación provisional- se suceden nuevos cuestionamientos: ¿cuáles son sus características, sus fronteras materiales, su objeto de estudio?; ¿cómo explicarla, construirla o transformarla?; ¿de qué se ocupa?; ¿qué es lo que le preocupa, cuáles son las características y consecuencias de esas preocupaciones?; ¿en qué circunstancias y con qué compromisos tiene que desarrollar su trabajo? Finalmente, ¿es una disciplina dentro de las Ciencias de la Educación, acorde a la tradición académica de Europa continental (central y mediterránea) diferenciándose de los países anglosajones (Gran Bretaña y Estados Unidos)?

Más adelante en su bibliografía, coinciden en aseverar que -al igual que sucede en la actualidad con otras disciplinas sociales- en el caso de la didáctica se impone una estricta revisión de los planteamientos efectuados a lo largo de su desarrollo, como una forma de encontrar y construir nuevos análisis que permitan avanzar en el tratamiento de esta problemática.

Si volvemos a Díaz Barriga, surge la paradoja de un saber negado en forma permanente en tanto se cierra o se ignora la exigencia de una reflexión constante de las premisas fundamentales de ese pensamiento. Es decir, pueden conocerse los textos esenciales de los clásicos (Comenio, Pestalozzi, Herbart, Montessori, Dewey, Freinet) o las situaciones y problemáticas socio-históricas que se suceden a lo largo del tiempo, pero en 
tanto esas líneas se sigan en estancos, con parches, con urgencias ante la necesidad de enfrentar circunstancias especiales en el aula, se mantendrá oculto el punto esencial: el auténtico debate por lo propiamente didáctico, su campo, su objeto de estudio, su saber propio.

Al focalizar esta arista aparece una cuestión cardinal de la didáctica, como es la triple dimensión que la conforma y la necesaria interrelación entre las mismas: teórica (que responde a concepciones amplias respecto a la educación, enlazando teorías de la educación, de la sociedad y del sujeto); histórica (por cuanto sus propuestas se contextualizan en circunstancias históricas específicas) y política (en tanto se corresponden a un determinado proyecto social). Al desconocer esa triple dimensión, es posible que se profundicen ciertas deformaciones sobre el saber didáctico con una doble carga negativa. Por un lado, su devaluación al considerar este saber en tanto conocimiento sin fundamento, necesidad ni rigurosidad; por el otro, su resquebrajamiento y vulgarización, al entender que sobre la didáctica ya se sabe todo, equiparándola con el sentido común.

Díaz Barriga (1995) sostiene que para volver a darle sentido a la didáctica hay que trabajar en dos temáticas centrales:

1. La didáctica es una disciplina que responde a reclamos históricos-sociales y es en estos donde debe ser examinada para comprender su valor.

2. Existe una ignorancia social y disciplinaria de este saber.

No es posible que la reflexión sobre los saberes didácticos oriente solamente hacia la estructuración de propuestas para el trabajo en el aula, como por ejemplo, la manera de enseñar, las alternativas para lograr la participación de los estudiantes, frente a una cierta ausencia de reflexión conceptual sobre la misma. Desde este punto se disminuye su reflexión y como disciplina, queda relativamente despreciada, por distintas razones.

Seeligman expresa que la situación de esta disciplina se debe a que se encuentra inmersa en una visión instrumental que epistemológicamente se apoya en el positivismo y el funcionalismo, "de aquí (este) carácter instrumental de la didáctica, su silencio respecto a los fines de la educación que son aceptados como supuestos incuestionables o condiciones preexistentes" (Díaz Barriga, 1995, p. 14).

Ello explica el carácter instrumental de la didáctica, su silencio respecto a los fines de la educación que son aceptados como supuestos incuestionables o condiciones preexistentes. Como afirma Díaz Barriga, una revisión de la historia de la didáctica y más aún de la historia de las formas de enseñanza muestra que éstas son el resultado de un momen- 
to histórico en específico (Comenio $=>$ educación simultánea). Ello es motivo suficiente para reconocer la articulación de las dimensiones señaladas y no podemos entenderla como una forma instrumental que brinda estrategias para responder a determinadas problemáticas. Siempre, la didáctica será la expresión de una forma concreta de ubicarse temporal y espacialmente en una institución educativa. De allí que resulte totalmente contradictorio que no se contemple el contexto cuando se intenta comprender cómo opera esta disciplina.

\section{De la no dialéctica... hacia lo dialógico, diferencia conceptual}

La dialéctica hegeliana, si bien se distanció de la dialéctica clásica, no rebasó los límites de la racionalidad clásica. ¿Por qué?, porque la racionalidad cerrada se hace presente en las nociones dialécticas en la tendencia a la dicotomización de los contrarios y al reconocimiento de una polaridad que simplifica la relación (tesis-síntesis-antítesis). En oposición a ello, Morin destaca la necesidad de una unidad compleja, no en el discurso, sino en la reflexión, en el pensamiento, en el conocimiento, las nociones antagónicas.

Es importante, para tratar de comprender lo dialógico, retomar a Paulo Freire (2002, pp. 40-43 [1970]) cuando diferencia con claridad la "educación bancaria" de la "educación crítica" y podríamos agregar, "compleja", para seguir pensando bucleica y recursivamente.

Más allá del extenso recorrido reflexivo a partir de Freire, en Latinoamérica la educación todavía permanece vertical. Los roles no responden aún con total claridad al binomio educador y educando, puesto que -en muchos aspectos- se mantienen estereotipos de un docente que todo lo sabe frente a un alumnado pasivo que debe recibir lo que éste imparte, ser un depósito que acepta y archiva datos. Sin obviar que -en la actualidadcon el aporte de las nuevas tecnologías que permiten mejores métodos de archivos, permanece esa concepción "bancaria" (Freire, 2002 [1970]) que transforma al hombre en una mera pieza de un engranaje que repite acciones, pero no tiene la más mínima capacidad de reacción y creación. En tal escenario, el educador o educando que rompe ese molde es el inadaptado y desaparece la esencia del conocimiento como búsqueda, como investigación, como construcción, enfatizándose la conciencia ingenua (pensamiento simple en Morin o transmisión reproductora en Hassoun).

Hablamos de conciencia ingenua cuando se tiende a simplificar la interpretación de una problemática, sin profundizar en las diversas aristas 
que inciden en ella para llegar a conclusiones apresuradas y superficiales; también se manifiesta en quienes creen que todo tiempo pasado fue mejor o aceptan estereotipos y modas masificadas de comportamiento. Pero no puede obviarse que en sí misma, la conciencia ingenua encierra una paradoja al subestimar lo simple y basarse sólo en experiencias, con discursos triviales o dogmáticos. Por ende, carece de herramientas y estrategias para el abordaje de los problemas y si bien polemiza, no esclarece al ignorar la criticidad ni busca la verdad sino que trata de imponerla, aún con el riesgo del fanatismo o sectarismo por cuanto considera que la realidad es estática.

En cambio, la conciencia crítica (pensamiento complejo en Morin o transmisión lograda en Hassoun) apunta por lógica a revertir cada una de las características propias de la conciencia ingenua; busca la profundidad en el análisis del problema y aún reconociéndose desprovista de instrumentos para ello, articula variables, estrategias, caminos, explicaciones que puedan verificarse y queden abiertas a revisiones; se atreve a interrogar la realidad, dialoga y acepta que tanto en lo nuevo como en lo viejo, existen instancias que se interrelacionan y cuestionan para que aparezca la validez que da permanencia.

\section{Propuesta didáctica desde el diálogo de saberes: Morin, Freire, Piaget}

Si tenemos en cuenta el recorrido realizado hasta el momento, vemos que si queremos hablar de didáctica dialógica y complexa, como nueva categoría de análisis, es necesario comenzar a delinear algunas vías de acción para la construcción de procesos de enseñanza y aprendizaje que sean recursivos y metacognitivos. Definimos recursividad como la interacción y la retroacción entre los efectos y sus causas, pero teniendo en claro que esa retroacción no va hacia el infinito como la dialéctica hegeliana sin salir de su propia estructura, sino que la didáctica dialógica y complexa, construida desde esta recursividad necesita de un sujeto epistémico-pedagógico, de una transmisión lograda y de un diálogo de saberes.

Podemos inferir que tanto en Piaget como en Freire y en Morin las pretensiones de recursividad refieren al plano biológico, crítico y dialógico y por ello están constituidas por meta-saberes. La idea de recursividad como propuesta didáctica dialógica ó complexa lleva a pensar que los sujetos pedagógicos producen, mediante la transmisión lograda de conocimientos (Hassoun, 1996, p. 17), sujetos pedagógicos a través de 
interacciones. Las interacciones se reflejan como aportes y restricciones del entorno (kairos educativo que se construye con una relación en un tiempo y un espacio que le es propio: el educativo), produciéndose un conjunto de cambios en el sistema, que a la vez afectan al medio, debiendo por tanto el sistema adaptarse a esos continuos cambios, demostrando que la causa actúa sobre el efecto, recursivamente (Imagen 2).

La propuesta que hacemos de construir una didáctica dialógica o complexa desde el diálogo de saberes se hace indispensable para entretejer los diversos saberes grupales relacionándolos con el contexto. En esta integración bucleica de los saberes se sostiene la recursividad, a través de procesos inter y transdisciplinarios, donde se produce, democráticamente, el intercambio y la cooperación.

Es fundamental enfocarnos en una enseñanza radicalmente diferente, en la que el educando encuentre el modo de construir y reconstruir el conocimiento, potenciar su arista crítica y alcanzar la visión holística ${ }^{4}$ de la realidad para participar con el fin de transformar (Gonfiantini, 2016, p. 61).

\section{Imagen 2}

\section{EL kairos educativo: la construcción del conocimiento}

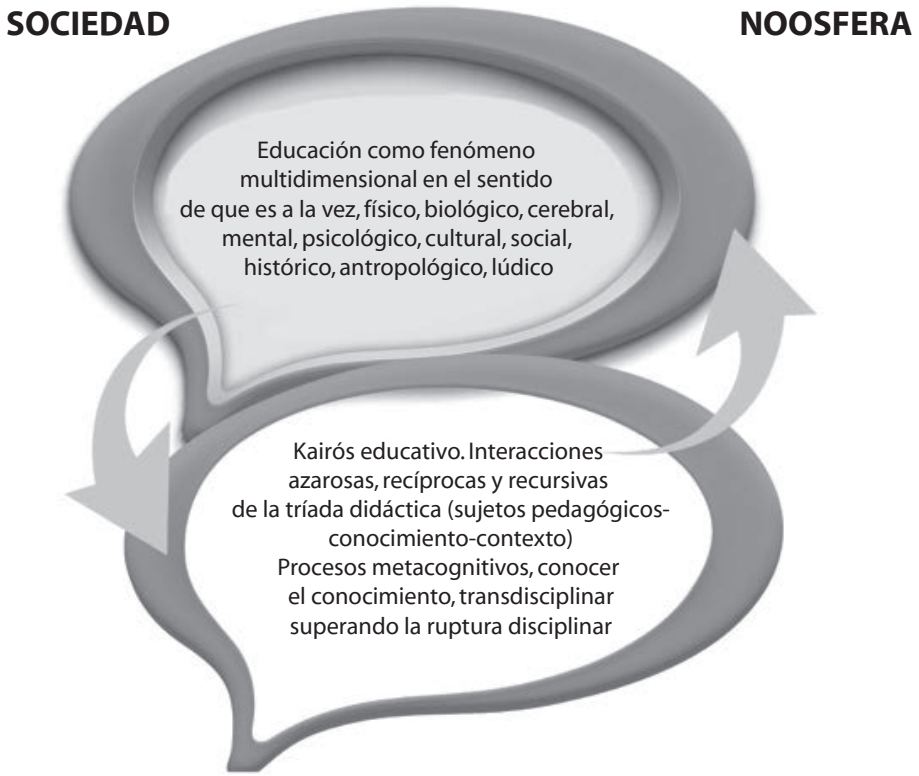

Elaboración propia 
No es este un punto menor por cuanto entra en juego el valor de la palabra. No puede haber diálogo si no se ubica a la palabra en su vínculo indisoluble entre acción y reflexión para que refleje la auténtica praxis. La palabra no auténtica no puede transformar pues al invalidar la acción es simple vocalización o recitado sin capacidad de concientizar, pero sí de alienar y masificar. De allí que la práctica docente debe ser en realidad praxis de educadores que se atreven a ubicar su tarea en un complejo entramado.

\section{El kairos educativo}

El kairos educativo surgió como un dispositivo actual en la formación docente tras un largo tiempo de investigación y observación de la práctica docente de los formadores. Como un rompecabezas, iban encajando cada una de las piezas recolectadas: textos, encuestas, palabras, evidencias de trabajo. Pero en un camino lógico de revisar, re-pensar, dudar o retomar experiencias surgía que el material más rico en todas sus expresiones se daba cuando se reflexionaba en grupos, en los cuales aparecían dudas que no quedaban expresadas en ningún registro ni libros de temas. Entonces, ¿por qué ese espacio y ese tiempo permitía la emergencia de temas profundos, de dudas, de silencios, de palabras que habían sido acalladas y se derramaban con pasión?

Esa percepción nos permitió comprender que un modo de hacer realidad la didáctica complexa era permitir ponerla en diálogo sin omitir ninguna de sus dimensiones, crear el escenario en una institución que aún muchas veces se cierra ante cambios que modifican sus estructuras, sus manifestaciones fundacionales. Ese espacio tendría que permitir una concepción complexa, abierta y recursiva que facilitase una postura que no se asustase ante la "extrañeza del horizonte". Es decir, dejar de naturalizar y por ende de aceptar como inmovible, cada una de las instancias que se dan en las aulas, en las direcciones, en las salas de profesores, en los lugares de recreo.

Tal postura es programática. ¿Por qué? Porque necesariamente requiere extender el debate puertas afueras para buscar reformas profundas, no de formas, sino epistemológicas, filosóficas, sociológicas, psicológicas, tanto de contenidos como de infraestructuras que hablen de apertura y no cerrazón, de luz y no de oscuridad. Porque para ello será fundamental asumir un modo de pensar complejo como estilo de vida que conduzca a educadores, educandos y a todos los agentes de una institución educa- 
tiva a aprender a relacionar y re-vincular. Porque para que tales premisas cobren vida, será prioritario una reconceptualización desde tres dimensiones: lo gnoseológico, lo metodológico y lo axiológico.

Desde esta óptica se desprende que la verdadera esencia del kairos educativo es el placer asociado al verdadero deseo de enseñar o aprender; des-enseñar-aprender o re-enseñar-aprender. Es decir, alcanzar el verdadero sentido de la racionalidad meta-complexa y recursiva.

Algunas especificaciones para comprender mejor por qué hablamos de kairos educativo. Para que se construya, es esencial un espacio específico (el escolar), un tiempo específico (el educativo) y unos sujetos pedagógicos (que dialógica y recursivamente construyen el enseñar y el aprender). A ello, deben sumarse como canales comunicacionales, sucesivos bucles recursivos, dialógicos, metacognitivos y metacreativos entrete240 jiendo desde la transdisciplinariedad el siguiente escenario que configura y re-construye la triada didáctica tensionando desde lo teórico, práctico, simbólico o educativamente:

- Conocimiento científico, contenido escolar y competencias.

- Lo individual y lo grupal.

- Lo inconsciente y lo colectivo.

- La autoridad y el poder.

- La circulación de la palabra.

- La construcción del sujeto pedagógico (definido como reconfiguración del docente enseñante ó aprendiente y del alumno enseñante ó aprendiente).

- La institucional y lo instituido.

Y es justamente desde la tensión de estos escenarios que se logra el kairos educativo, definido como el lugar donde algo importante sucede: sucede el diálogo entre sujetos pedagógicos; suceden los saberes, ecologizados-problematizados y sucede -desde lo metacreativo y metacognitivo bucleica y recursivamente, dialógica y complejamente- una nueva vinculación con el conocimiento. Queda atrás la repetición opresora para que surja la complexidad liberadora.

\section{¿Para qué educamos hoy?}

Educamos para personalizar. En el respeto a la subjetividad y a la diferencia, cada educando puede encontrarse consigo mismo, comprender y entender la necesidad de tomar conciencia de las condiciones históricas, 
culturales, sociales en las cuales se determina el intento de conocer el conocimiento. Sin dudas, las necesidades educativas actuales, para vivir en la era planetaria, demandan de todos los participantes del proceso educativo creatividad, ingenio, capacidad de aprender y tomar decisiones para mejorar, en tanto bucle recursivo, el accionar.

Educamos para liberar. Recordemos que desde fines de la década del 60, se multiplicaron las publicaciones sobre el rol constitutivo de la educación, a partir de diversos abordajes ideológicos, filosóficos y pedagógico-críticos. Morin y Freire nos hablan de resistencia, una resistencia con inteligencia y responsabilidad, frente al dominio del pensamiento único, simple, opresor que propugna el escepticismo y la resignación. Es importante destacar que ambos hablan de insistencia y de persistencia, de estimular para un nuevo despertar, de sembrar para recoger, del eros y del amor.

Podemos observar claramente que tanto la propuesta de Freire como la de Morin es reaccionar frente a la educación unidireccional y bancaria, simplificada y disciplinar proponiendo el diálogo entre educador y educando posibilitando, en ese mismo "dialogar", la liberación de la conciencia. La liberación y la independencia destruyen la pasividad del educando y lo incitan a la búsqueda de la transformación de la realidad, en la que opresor y oprimido encontrarán la liberación humanizándose (Gonfiantini, 2014, p. 40).

Educamos en la complejidad. En La Vía, Morin (2011) identifica el problema crucial de este tiempo como la necesidad de un pensamiento que pueda asumir el desafío de la "complejidad de lo real, esto es, de captar las relaciones, interacciones e implicaciones mutuas, los fenómenos multidimensionales, las realidades solidarias y conflictivas a la vez" (p. 142). Para ello:

El conocimiento debe saber contextualizar, globalizar, multidimensionar, es decir, debe ser complejo. Sólo un pensamiento capaz de captar la complejidad de nuestras vidas, nuestros destinos y la relación individuo/ sociedad/ especie, junto con la de la era planetaria, puede intentar establecer un diagnóstico del curso actual de nuestro devenir, y definir las reformas vitalmente necesarias para cambiar de vía (p. 143).

Educamos en la recursividad. Debemos procurar procesos de enseñanza y aprendizaje construidos desde la capacidad crítica, creadora, ética y reflexiva en cuanto antídoto para el dogmatismo teórico, instrumental y pragmático. Una epistemología de la recursividad que reconozca las interacciones sociales, cognitivas, vivenciales que se retroalimentan, 
que no son predecibles en sus próximos movimientos, no son esquematizables, no son determinadas. Esta epistemología tiene que ver con el hecho de que todo acto educativo está mediado por el diálogo, por la autonomía, por la imaginación, por la pregunta, por el azar, por el amor...

\section{In-conclusión para seguir pensando}

Es evidente entonces, que debemos centrar nuestra preocupación en cómo lograr que la formación docente rompa las líneas directrices (transmisoras, seleccionadoras, individualistas) y eduque para la vida, dejando atrás enfoques que la alejan del carácter relacional, cultural y contextual al servicio de las comunidades. Necesitamos introducir una episteme crítica capaz de incentivar en los formadores la capacidad para aprehender y seguir aprehendiendo, de modo que puedan abandonar la raíz decimonónica de donde procede como hemos visto y que ha quedado absolutamente arcaica.

La propuesta implica repensar la formación docente "como práctica de la libertad" (Freire, 1969), desarrollada en contextos democráticos, concientizando a todos los sujetos pedagógicos de la necesidad del cambio, para vivir en la era planetaria donde el intercambio devenga del compromiso por la tarea, del respeto hacia la otredad, de la abolición de las certezas, de la pasión y del deseo de conocer por el conocer mismo.

En síntesis, de una educación capaz de confrontar el conocimiento parcelado de especialistas para trabajar con un conocimiento transdisciplinar. Esta reformulación de la formación docente significa entenderla desde lo multirreferencial de su tarea, desde el abrirse e imbricarse con lo social, lo político, lo económico, lo biológico, lo cultural, lo filosófico, lo discursivo, lo comunicacional, porque es ese intercambio con el entorno lo que permite que se mantenga vivo y se reformule constantemente.

Sólo si logramos pensar a la institución y a los educadores desde esta perspectiva será factible transitar una formación acorde a la complejidad social, que se exprese a través de sus manifestaciones y sensibilidades: democrática, social, solidaria, intercultural y equitativa. Responder a estos retos requiere asumir la gestión de esa formación desde ciertas características esenciales como la capacidad de reflexionar y comunicar, la capacidad de generar conocimiento pedagógico como proceso cooperativo, inclusivo y comprometido; la capacidad de gestar auténticas comunidades a aprendizaje que permita conocer y reconocer su contexto y desarrollar una práctica que se cuestione y acepte la revisión de su hacer. 
Las instituciones de formación docente tienen en sus manos la posibilidad de dar un giro y restituir a sus educandos el derecho a soñarse como educadores. Para ello, más allá de las innovaciones que se proponen habitualmente y que bien recibidas son, se requiere:

- Pensar en cómo trabajar inter y transdiciplinarmente a partir de sus planes de estudio, políticas educativas y contexto socio-económico.

- Dedicar espacio y tiempo a un debate didáctico que vuelva a tomar a los principales teóricos poniéndolos en diálogo con los enfoques, modelos y premisas que en la actualidad buscan su lugar.

- Abrir espacios y situaciones de diálogo para que educandos y educadores puedan reflexionar sobre las dimensiones de la didáctica en su aspecto general y en sus especificidades en relación a sus carreras.

- Dirigir todos los esfuerzos a una educación problematizadora, que acepte la crítica y a partir de ella, se atreva a reformular las aristas que mantienen rastros de autoritarismo, pasividad, falta de solidaridad.

- Gestionar auténticos canales de comunicación, que permitan el acceso a todas las acciones, revisiones, normas, trabajos, etcétera y el aporte para enriquecer cada uno de ellos.

- Formar a los educandos en la investigación, con suficientes criterios y herramientas que despierte en ellos el deseo de profundizar esta faceta, imprescindible para conocer la realidad, determinar las necesidades y leer las emergencias las problemáticas que aparecen en un aula.

Y, fundamentalmente, cada institución tendrá que gestar comunidades de aprendizaje en las cuales sus educadores compartan experiencias y búsquedas que ayuden a comprender sin mutilar la esperanza.

\section{Notas}

1 Leopoldo Zea considera que la filosofía surge cuando el hombre se enfrenta a un problema, a algo que no es familiar. Al recuperar un concepto de X. Zubiri, ubica en el propio horizonte de quien se cuestiona aspectos que son familiares y cotidianos. Por ende todo aquello que produce "extrañeza" se presenta como una problemática que pide una respuesta para ubicarse y tomar su lugar correspondiente en ese horizonte propio.

2 Hemos desarrollado ampliamente este punto y específicamente en Gonfiantini (2016), nos referimos al extrañamiento de la formación docente en el capítulo 3, 
luego de trabajar sobre la práctica de los formadores. “..cuando hablamos de cambio, no necesaria y únicamente nos referimos a estructuras físicas, sino de la premura de conceptualizar el espacio de las propuestas pedagógicas que se necesitan en cada situación" (p.61).

3 Hablamos de cierta intensidad, por cuanto se desarrolló en un solo establecimiento de Formación docente de nivel inicial, pero a lo largo de un año en todas las áreas y años, como continuación de un trabajo anterior que abarcó la totalidad de los establecimientos de dicho nivel superior de educación pública, de la ciudad de Rosario, pero delimitado en la temática Formación docente y pensamiento complejo.

4 Holístico: En general, designa la manera de considerar globalmente una totalidad en vez de considerarlo como un montaje de partes. Lo holístico se suele asociar con lo ambiguo y la vaguedad, debido a que con frecuencia la atención en la totalidad no se acompaña de la necesaria contextualización. Su validez radica en que la totalidad tiene propiedades irreductibles a la suma de las propiedades de sus partes (Malinowki, N. 2012, Módulo 8. Multiversidad Edgar Morin).

ANIJOVICH, Rebeca

2009 Transitar la formación pedagógica. Dispositivos y estrategias. Buenos Aires: Paidós.

BACHELARD, Gastón

1995 Epistemología. Buenos Aires: Siglo XXI.

BURÓN OREJAS, Javier

s/f Enseñar a aprender. Introducción a la metacognición. España: Ediciones Mensajero.

DÍAZ BARRIGA, Ángel

1995 [1991] Didáctica. Aportes para una polémica. 3ra. Edición. Buenos Aires: Aique.

DOMINGO, José

1991 Enseñanza, curriculum y profesorado. Madrid: Ed. Akal.

FLAVELL, John

1978 Metacognition and cognitive monitoring. American Psychologist, 34, 906-911. FREIRE, Paulo

1969 La educación como práctica de la libertad. Montevideo: Tierra Nueva.

1970 Pedagogía del oprimido. Montevideo: Tierra Nueva.

2002 Educación y cambio. Buenos Aires: Ed. Galerna.

GONFIANTINI, Virginia

2014 “Enseñar y aprender en el kairos educativo". http://www.grupocieg.org/archivos_revista/5-2-3\%20(29-43)\%20Gonfiantini\%20\%20noviembre\%20 14_articulo_id155.pdf

2014 b “Para qué educamos hoy? de horizontes complejos y liberadores”, Conferencia en el Encuentro Educación hoy. Aportes desde la complejidad. 14 de enero 2014, Santiago de Chile.

2016 El kairós educativo. Re-significar la formación docente desde la práctica del formador. Rosario: Editorial Laborde. 
HASSOUN, Jacques

1996 Los contrabandistas de la memoria. Buenos Aires: Ediciones de la Flor. MORIN, Edgar

2011 La vía. Para el futuro de la humanidad. Barcelona: Paidós.

PERRENOUD, Philippe

2004 Desarrollar la práctica reflexiva en el oficio de enseñar. Profesionalización y razón pedagógica. Barcelona: Graó.

Fecha de recepción del documento: 5 de julio de 2016 Fecha de aprobación del documento: 15 de agosto de 2016 



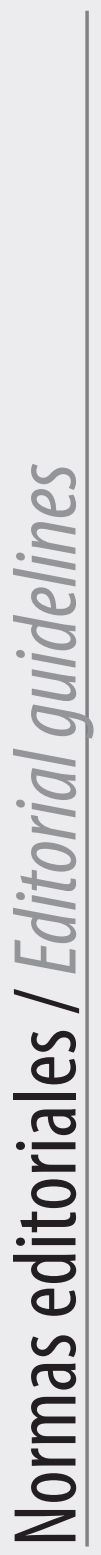





\section{CONDICIONES EDITORIALES BÁSICAS}

\section{Organismo regulador del proceso de publicación}

El organismo encargado de realizar el seguimiento, control y ejecución de la publicación de los números de Sophia es el Consejo Editorial Interno, el cual se encarga de la operación regular de la revista.

\section{Funciones y obligaciones del Consejo Editorial Interno}

1. Su función principal es determinar la política editorial de Sophia: Colección de Filosofía de la Educación, conforme a los objetivos establecidos.

2. Planificar, analizar, evaluar y aprobar el contenido y la estructura general de cada uno de los números de Sophia.

3. Establecer y ejecutar las normas de calidad y/o los criterios para la evaluación técnica y académica de los trabajos propuestos para la publicación en Sophia.

4. Definir y aprobar el grupo de árbitros conformado por personas destacadas en el campo de su especialización. Este grupo estará compuesto por académicos internos y externos a la institución.

5. Asignar árbitros o evaluadores para cada uno de los trabajos propuestos para su publicación en los números de Sophia.

6. Aprobar el informe final o la validación de cada artículo, a partir de los dictámenes solicitados y de la evaluación general a la que sean sometidos los trabajos.

7. Organizar la edición y distribución de cada número, de acuerdo a las disposiciones establecidas por el Consejo de Publicaciones de la UPS.

8. Proponer modificaciones a la línea editorial y a las políticas de difusión y distribución.

9. Contribuir a la promoción de la revista en ámbitos externos a la institución y a la localidad, a través del intercambio editorial con otras publicaciones e instituciones.

10. Fortalecer mecanismos para promover las colaboraciones de académicos externos a la institución, tanto para la presentación de trabajos a publicarse como para el arbitraje de artículos. 
11. Propiciar acuerdos de publicidad y promoción con revistas e instituciones relacionadas con los temas de interés de Sophia.

\section{Política editorial}

\section{Contenido}

El contenido de los trabajos presentados para la publicación en Sophia: Colección de Filosofía de la Educación deberá ser original e inédito. Los artículos $^{1}$ no deben haber sido publicados con anterioridad. Podrán incluirse trabajos de investigación, comunicación científica, informes técnicos, ponencias, artículos breves, trabajos teóricos, artículos monográficos de revisión y/o estados del arte, que contribuyan a re-pensar la educación.

Dependiendo de la relevancia y pertinencia del artículo, se considerarán como contribuciones especiales y ocasionalmente se publicarán:

1. Trabajos que superen la extensión manifestada

2. Trabajos que no se correspondan con el tema objeto de la reflexión para el número respectivo

3. Trabajos de traducción de obras que originalmente se encuentren en un idioma diferente al español y que todavía no hayan sido publicadas

4. Recensión o reseñas de textos recientes

\section{Extensión y formato}

Los trabajos tendrán una extensión de 15 a 20 páginas, en hojas A4, a espacio interlineal de 1,5 y en tipografía Times New Roman tamaño 12. La mencionada extensión no incluye notas al pie de página, bibliografía, cuadros, gráficas estadísticas y/o anexos, que irán al final de cada artículo.

Se aceptan trabajos en los idiomas: español, inglés y portugués.

1 Existen diferentes tipos de artículos, a saber: • Investigación: describe un trabajo de investigación realizado por uno o varios autores. Revisión: analiza críticamente el estado de conocimiento en un área o un tema concreto a partir de la bibliografía publicada. - Retracción: un autor corrige o retira un trabajo propio anterior debido a factores como: imposibilidad para replicar los resultados, denuncias de fraude, errores cometidos, dificultades en el equipo de trabajo, etc. $\bullet$ Comentarios y críticas: un autor comenta o critica un trabajo anterior publicado por otros investigadores. - Trabajo teórico: se plantea un modelo, una teoría o un sistema para entender un fenómeno o conjunto de fenómenos, una realidad concreta o un dominio de conocimientos (Campanario en: López Santos, 2010: 2). 


\section{Propiedad intelectual}

Las ideas y opiniones expresadas en los artículos publicados en Sophia son de exclusiva responsabilidad del autor, en tal sentido, tanto el Comité Editorial como la Universidad Politécnica Salesiana declinan cualquier responsabilidad sobre el mencionado material.

Todas las personas e instancias encargadas de llevar adelante los procesos de publicación de Sophia: Colección de Filosofía de la Educación no garantizan ni apoyan las afirmaciones realizadas en cada uno de los artículos.

\section{Calidad}

Los artículos presentados para la publicación deberán tener un alto nivel académico, producto del análisis crítico y reflexivo que cumpla con las exigencias propias de evaluación internacional. Esto implica que los trabajos deberán aprobar el proceso de dictaminación técnica y científica que realizará el Consejo Editorial, así como la dictaminación académica que realizarán los especialistas externos nombrados por el mismo consejo.

\section{Recepción de artículos y cierre de edición}

La recepción de artículos es permanente, sin embargo, considerando que por su periodicidad semestral de la publicación, los números de Sophia aparecen en los meses de enero y julio, el envío de los trabajos originales y sus resúmenes deberá efectuarse en archivo electrónico (formato digital en procesador Word, sin ningún tipo de formato automático como sangrías, listas numeradas, saltos, etc.) hasta el 15 de enero y el 15 de julio, respectivamente.

Los artículos deberán enviarse a la dirección electrónica de Sophia: Colección de Filosofía de la Educación: revista-sophia@ups.edu.ec/ florocio ag@gmail.com

\section{Responsabilidad del autor}

El autor es el responsable absoluto del contenido y se obliga a entregar su artículo de acuerdo a los lineamientos emitidos por el Consejo Editorial.

El autor deberá tener presente que su artículo será revisado y aprobado por un Consejo Editorial Interno, que luego será dictaminado por un Consejo Editorial Externo y que finalmente será validado por un Consejo de Publicaciones; en tal sentido, el autor se compromete a realizar los ajustes que sean requeridos por los editores en el tiempo establecido para el efecto. 
Asimismo, el autor se compromete a entregar artículos inéditos y originales.

\section{Arbitraje}

Los árbitros son el conjunto de especialistas seleccionados para realizar el dictamen de cada uno de los artículos que formarán parte de cada número de Sophia: Colección de Filosofía de la Educación. Estarán integrados por especialistas nacionales e internacionales que forman parte del Consejo Editorial Externo. Su participación tendrá un carácter rotativo dependiendo de las necesidades temáticas de cada número.

Los artículos enviados deberán pasar por los siguientes filtros previos a su publicación:

1. Recepción de trabajos

2. Revisión preliminar y preselección por parte de la editora responsable

3. Evaluación por parte del Consejo Editorial

4. Preaprobación de trabajos

5. Dictamen por parte de dos especialistas externos ${ }^{2}$

6. Recepción del dictamen por parte del Consejo Editorial

7. Aprobación o rechazo de los trabajos por parte del Consejo Editorial

8. Aprobación de trabajos por parte del Consejo de Publicaciones

\section{Guía básica para la dictaminación}

\begin{tabular}{|l|l|}
\hline \multicolumn{2}{|l|}{ Título del artículo: } \\
\hline & $\begin{array}{l}\text { Fecha de recepción } \\
\text { del artículo: }\end{array}$ \\
\hline Arbitro o Dictaminador: & $\begin{array}{l}\text { Fecha de evaluación } \\
\text { del artículo: }\end{array}$ \\
\hline $\begin{array}{l}\text { Instrucciones para la evaluación: } \\
\text { El cumplimiento de cada uno de los ítems será valorado con un punto } \\
\text { La suma total de los ítems determinará la aprobación del artículo } \\
\text { El puntaje mínimo para que el artículo sea aprobado será de } 17 / 20\end{array}$ \\
\hline
\end{tabular}

2 Como parte del procedimiento empleado para la selección y aprobación de los artículos, será imprescindible acudir al criterio de especialistas externos a la institución editora, quienes serán responsables de evaluar, validar y emitir su dictamen sobre la calidad de los trabajos presentados. 


\begin{tabular}{|c|c|c|}
\hline ASPECTOS & CRITERIOS DE EVALUACIÓN & VALORACIÓN \\
\hline \multirow{8}{*}{ 1. Contenido } & $\begin{array}{l}\text { a. Pertinencia del título de acuerdo a la natu- } \\
\text { raleza y el contenido del artículo }\end{array}$ & \\
\hline & b. Presentación del tema & \\
\hline & c. Actualidad e importancia del tema & \\
\hline & $\begin{array}{l}\text { d. Planteamiento del problema u objeto de } \\
\text { estudio }\end{array}$ & \\
\hline & e. Planteamiento de objetivos & \\
\hline & $\begin{array}{l}\text { f. Formulación de la idea a defender o de la } \\
\text { hipótesis central }\end{array}$ & \\
\hline & $\begin{array}{l}\text { g. Desarrollo de argumentos (relación con } \\
\text { los objetivos planteados, fundamentación } \\
\text { teórica y contextualización) }\end{array}$ & \\
\hline & $\begin{array}{l}\text { h. Adecuada redacción (articulación cohe- } \\
\text { rente de ideas) }\end{array}$ & \\
\hline \multirow{9}{*}{$\begin{array}{l}\text { 2. Aspectos } \\
\text { Formales }\end{array}$} & $\begin{array}{l}\text { a. Extensión del artículo de acuerdo a lo esti- } \\
\text { pulado ( } 15 \text { a } 20 \text { páginas) }\end{array}$ & \\
\hline & $\begin{array}{l}\text { b. Título (en castellano y en inglés), subtí- } \\
\text { tulos, incisos y subincisos marcados con } \\
\text { claridad }\end{array}$ & \\
\hline & c. Autor (nombres y apellidos) & \\
\hline & $\begin{array}{l}\text { d. Datos de identificación del autor del artí- } \\
\text { culo (títulos de mayor jerarquía, ocupación, } \\
\text { institución a la que pertenece, país y direc- } \\
\text { ción electrónica) }\end{array}$ & \\
\hline & e. Resumen (extensión: 250-300 palabras) & \\
\hline & f. Palabras Clave ( 5 o 6 términos) & \\
\hline & g. Abstract & \\
\hline & h. Key Words (5 o 6 términos) & \\
\hline & $\begin{array}{l}\text { i. Estructura general del cuerpo del artículo. } \\
\text { Se identifican claramente sus partes constitu- } \\
\text { tivas: introducción, desarrollo del tema con } \\
\text { sus subdivisiones, conclusiones y bibliografía }\end{array}$ & \\
\hline
\end{tabular}




\begin{tabular}{|c|c|c|c|c|c|}
\hline & \multicolumn{4}{|c|}{$\begin{array}{l}\text { j. Presentación de las referencias bibliográ- } \\
\text { ficas, al final del artículo o en el cuerpo del } \\
\text { texto, de acuerdo a las normas Harvard- } \\
\text { APA, indicando apellido del autor, año de } \\
\text { publicación y número de página }\end{array}$} & \\
\hline & \multicolumn{4}{|c|}{$\begin{array}{l}\text { k. Presentación formal de la bibliogra- } \\
\text { fía, de acuerdo a las normas Harvard-APA } \\
\text { establecidas }\end{array}$} & \\
\hline & \multicolumn{4}{|c|}{$\begin{array}{l}\text { 1. Tipo de letra (Time News Roman, tama- } \\
\text { ño } 12 \text { ), espacio interlineal }(1,5) \text { y tamaño de } \\
\text { página (A4) }\end{array}$} & \\
\hline \multicolumn{5}{|c|}{ PUNTAJE TOTAL } & $/ 20$ \\
\hline \multicolumn{6}{|c|}{ OBSERVACIONES Y/O SUGERENCIAS (optativo): } \\
\hline \multicolumn{6}{|c|}{ RECOMENDACIÓN PARA SU PUBLICACIÓN EN SOPHIA } \\
\hline \multicolumn{2}{|l|}{ Criterio } & Sí & No & ¿Por qué? & \\
\hline \multicolumn{2}{|c|}{ Ampliamente recomendado } & & & & \\
\hline \multicolumn{2}{|c|}{$\begin{array}{l}\text { Recomendado solo si se mejora } \\
\text { su calidad (ver observaciones y/o } \\
\text { sugerencias) }\end{array}$} & & & & \\
\hline \multicolumn{2}{|c|}{ No se recomienda su publicación } & & & & \\
\hline \multicolumn{6}{|c|}{ f: Dictaminador/evaluador } \\
\hline
\end{tabular}

Aprobación de los artículos

Si el artículo es aceptado para la publicación, los editores combinarán los comentarios de los evaluadores o dictaminadores con sus propios comentarios editoriales y regresarán el documento al autor principal para su revisión final. El autor deberá realizar las correcciones y los cambios necesarios. Dictaminadores y autores se mantendrán en el más completo anonimato.

\section{Negación o postergación de los artículos}

El Consejo Editorial se reserva el derecho de rechazar o posponer la publicación de artículos que ameriten ser mejorados en su calidad. La edito- 
ra responsable se reserva el derecho de hacer las correcciones de estilo y los cambios editoriales que estime necesarios para mejorar la calidad del trabajo.

En caso que un artículo no sea aprobado por el Consejo Editorial, este será devuelto al autor, lo cual no implica que el artículo no pueda ser mejorado y presentado para un nuevo dictamen, en una próxima publicación.

\section{Corrección de pruebas}

Luego de la aprobación de los artículos, estos pasarán a la fase de edición y diseño. La prueba de composición del artículo será enviada al autor para la revisión correspondiente. En un plazo de cinco días, y para avanzar con el proceso de publicación, el autor deberá regresar el trabajo con sus observaciones, posibles modificaciones y/o la aprobación respectiva. Por su parte, los responsables de la redacción se reservarán el derecho de admitir o rechazar las correcciones realizadas por el autor en este proceso de revisión y de ser necesario, se acudirá a una segunda prueba.

\section{Diversificación}

Sophia promueve la publicación de trabajos con enfoques teóricos, analíticos, criterios y opiniones plurales sobre el tema objeto de cada uno de los números. Sophia privilegia el rigor científico, la creatividad analítica, crítica, reflexiva, interpretativa, argumentativa y propositiva, reflejados en cada uno de los artículos.

\section{Criterios editoriales}

Los criterios editoriales aquí establecidos responden a los requerimientos académicos y editoriales de la Secretaría Nacional de Educación Superior, Ciencia, Tecnología e Innovación (SENESCYT) del Ecuador.

\section{Instructivo para los autores}

\section{Aspectos formales y metodológicos}

Extensión aproximada: Los trabajos tendrán una extensión de 15 a 20 páginas sin considerar las partes preliminares y la bibliografía.

Formato de la hoja: A4

Espacio interlineal:

Tipo de letra:

1,5

Notas y referencias:

Times New Roman, tamaño 12

Tipo de artículo.

Colocadas al final del artículo

De carácter científico 


\section{Características del contenido}

El contenido de los trabajos presentados para la publicación en Sophia Colección de Filosofía de la Educación deberá cumplir con las características propias de una investigación científica:

1. Ser original, inédito y relevante

2. Abordar temáticas que respondan a problemáticas y necesidades actuales

3. Aportar para el desarrollo del conocimiento científico

4. Responder a los requerimientos del estado de conocimiento vigente

5. Utilizar un lenguaje adecuado, claro, preciso y comprensible

\section{Estructura del artículo}

1. Título: indica la denominación del trabajo. El título del artículo deberá ser breve, interesante, claro, preciso y atractivo para despertar el interés del lector. Deberá describir el contenido del artículo y deberá estar formulado en dos idiomas: español e inglés.

2. Autor y afiliación: señala al responsable del artículo. El autor deberá adjuntar un breve currículo en no más de 4 líneas y deberá considerar los títulos de grado y postgrado más relevantes. Además deberá explicar la actividad laboral actual y su lugar de trabajo principal.

3. Resumen: deberá ser claro y deberá sintetizar el contenido de todas las secciones del artículo. No podrá exceder de 300 palabras.

4. Palabras clave: el autor deberá identificar entre 5 y 6 palabras o conceptos clave que describan con claridad el contenido abordado en el artículo, para lo cual deberá evitar términos muy genéricos, muy específicos y/o palabras vacías.

5. Abstract: es un requisito indispensable de los artículos científicos, consiste en el resumen del documento en inglés.

6. Keywords: son las palabras clave ya seleccionadas, en inglés.

7. Introducción: presenta el tema, su importancia, relevancia y actualidad, y los objetivos planteados al inicio del proceso investigativo. Ofrece una visión general del texto: plantea el problema que se pretende enfrentar, explica las aportaciones que hace el artículo, el marco conceptual del problema o de la idea a defender, expone brevemente el marco metodológico -en el caso de ser necesario- $y$ las partes que conforman el texto. 
8. Desarrollo o cuerpo del artículo: implica poner en práctica, a lo largo de toda la exposición, una actitud crítica que deberá tender hacia la interpelación, a efectos de concitar la atención del tema y el problema tratados. El escritor deberá generar en el lector la capacidad de identificar la intención dialógica de la propuesta y propiciar en él una discusión abierta.

9. Conclusiones: expone de manera objetiva los resultados y hallazgos, ofrece una visión de las implicaciones del trabajo, las limitaciones, la respuesta tentativa al problema y las posibles líneas de continuidad (para cumplir con este objetivo se sugiere no incluir todos los resultados obtenidos en la investigación). Las conclusiones deberán ser debidamente justificadas de acuerdo a la investigación realizada.

10. Bibliografía: es el conjunto de obras utilizadas en la estructuración del artículo. Deberá incluir únicamente la referencia de los trabajos utilizados en la investigación. La elaboración de las referencias bibliográficas deberá ordenarse alfabéticamente y ajustarse a las normas internacionales Harvard-APA.

La Carrera de Filosofía y Pedagogía está conformada por tres ejes básicos: Filosofía, Pedagogía y Psicología. Estos ejes deben ser tomados en cuenta en mayor o menor medida, según la temática de cada tomo, sin embargo, nunca debe olvidarse que Sophia es una colección de filosofía de la educación y por lo tanto no puede faltar la reflexión filosófica sobre el tema abordado.

\section{Citas textuales y referencias bibliográficas ${ }^{3}$}

Son copias textuales de fragmentos de libros, artículos o cualquier tipo de publicación. Estas citas deberán ir entre comillas y en la misma línea del párrafo cuando tenga una extensión de cuatro líneas o menos. Cuando las citas superen las cuatro líneas deberán escribirse en un párrafo aparte, sin comillas y con márgenes más amplios.

El sistema Harvard-APA no utiliza notas al pie de página para las referencias bibliográficas de las citas. Las notas al pie deberán ser empleadas, según el criterio de los autores, para ampliar explicaciones, definir conceptos, ofrecer información adicional, realizar acotaciones o digresiones, entre otros fines pertinentes.

3 Este apartado es una síntesis sobre las formas de citar bajo el sistema de Harvard, estilo APA. Para obtener ejemplos a este respecto se recomienda revisar los artículos publicados en el presente número de Sophia. 
Las referencias bibliográficas de las citas textuales en el sistema Harvard-APA se escriben entre paréntesis luego del texto citado. Si el autor no es mencionado directamente antes o durante la cita, se incluyen en el paréntesis el apellido o apellidos del autor, el año de la edición utilizada y la página o rango de páginas citadas; en cambio, si el autor ya ha sido mencionado directamente, dentro del paréntesis solo se incluye el año y las páginas.

Por ser Sophia una revista de carácter filosófico, generalmente sus artículos contarán con citas de autores clásicos, cuyas obras han sido editadas en gran cantidad de ocasiones. En dichos casos se recomienda escribir entre corchetes, junto al año de la edición utilizada, el año original de publicación de la obra citada. Entiéndase por "obras clásicas" a los textos publicados antes del siglo XX y a los textos que, habiendo sido publicados durante el siglo XX, cuentan con un sinnúmero de ediciones de libre reproducción. Sin embargo, cuando se trate de referencias bibliográficas a las obras de autores de antes de nuestra era (por ejemplo: Aristóteles, Lao-tsé, Platón, etc.) o cuando su año original de publicación no ha sido determinado, puede omitirse esta información.

\section{Paráfrasis}

$\mathrm{Al}$ no ser copias textuales, sino apropiaciones de ideas con palabras propias, no necesitan ir entre comillas ni en un párrafo aparte y su referencia bibliográfica se deberá incluir donde la paráfrasis termine o al final del párrafo que la contenga, siguiendo las mismas reglas del enunciado anterior.

Ejemplo 1: según Kierkegaard, la filosofía por primera vez establece la relación del hombre con lo Absoluto (Buber, 2000).

Ejemplo 2: de acuerdo con Buber (2000), con el pensamiento de Kierkegaard la filosofía por primera vez establece la relación del hombre con lo Absoluto.

Sin embargo, la paráfrasis puede convertirse en una cita dentro de otra cita, cuando la copia es textual.

Ejemplo 3: "la filosofía por primera vez establece la relación del hombre con lo Absoluto" (Kierkegaard en: Buber, 2000: 52).

\section{Referencia directa al autor dentro del texto}

Cuando el nombre del autor aparezca en el cuerpo del escrito, la referencia se deberá escribir inmediatamente después, entre paréntesis, incluyendo el año de la publicación y de ser necesario el número de página.

Ejemplo: Los irónicos interludios finales de Kierkegaard (1999 [1845]: 73-96) enfatizan la desesperación del hombre estético frente a las exigencias de un mundo que le rebasa. 


\section{Referencia indirecta al autor dentro del texto}

Cuando se toma la idea de un autor sin mencionar su nombre, se debe colocar la referencia ya sea antes o después de exponer la idea (dependiendo del estilo de redacción).

Ejemplo 1: otros pensadores (Simmel, 2002: 87), miran a la sociología más como a un método que como a una disciplina constituida.

Ejemplo 2: en algunos momentos de su historia, la sociología ha sido vista más como un método que como una disciplina constituida (Simmel, 2002: 54).

Cuando se utilicen obras de un mismo autor publicadas en un mismo año, se ordenarán alfabéticamente y se les distinguirá con una letra minúscula después del año.

\section{Referencia a una obra de dos autores}

Cuando se utilice una obra escrita por dos autores se colocará en la referencia el apellido de ambos separados por la conjunción " $y$ ". Esta regla se aplica tanto a las referencias directas como a las indirectas.

Ejemplo: en El arte del cambio (Watzlawick y Nardone, 2000) se desarrolla esta idea con mayor profundidad.

\section{Referencia a una obra con más de dos autores}

En el caso de obras de más de dos autores se colocará después del apellido del primer autor la abreviatura "et al.".

Ejemplo: el axioma de acuerdo con el cual es imposible no comunicar (Watzlawick et al., 2002: 49-52) es uno de los puntos de partida más revolucionarios de la nueva psicología cognitiva.

Cuando se trata de varios autores, con obras diferentes pero que se refieren al mismo tema, es necesario separar a cada uno de ellos.

Ejemplo: tanto Kuhn (1971) como Popper (1972) y Tarski (1956) plantean el problema de la ciencia llegando cada uno a conclusiones distintas.

Diagramas, gráficos e ilustraciones. Las referencias para los diagramas o ilustraciones sigue la misma forma utilizada para las citas textuales. Diagrama 1. Relación entre el medio teórico y el empírico. (Berthier, 2004: 65).

\section{Estructura de la bibliografía}

\section{Estructura de la bibliografía cuando se trata de libros:}

AUTOR (todo el apellido con mayúsculas y el nombre con minúsculas, a excepción de la primera letra) año (en una línea aparte, con

4 Para obtener más ejemplos de este apartado se recomienda revisar las bibliografías de los artículos publicados en el presente número de Sophia. 
sangría e incluyendo, si es necesario, entre corchetes el año original de la publicación, de acuerdo a las normas dispuestas en los incisos anteriores). Título de la obra (en cursivas, con mayúsculas solo en la primera letra y en los nombres propios que pueda contener el título). Ciudad o País (lugar donde ha sido editado el libro): Editorial (no necesita incluir la palabra "Editorial" antes del nombre propio de la casa editora).

Cuando el libro tiene dos autores, los nombres del segundo autor se escriben de forma ordinaria: primero el nombre y luego el apellido, y con mayúsculas solo en la primera de cada uno.

Asimismo, cuando se citan varias obras del mismo autor, se escribe el nombre del autor solo ante el primer libro, mientras los restantes se ordenan cronológicamente de acuerdo al año de edición, sin necesidad de volver a escribir el nombre del autor.

Estructura de la bibliografía cuando se trata de artículos de revistas:

AUTOR (todo el apellido con mayúsculas y el nombre con minúsculas, a excepción de la primera letra) año (en una línea aparte y con sangría). "Título del artículo" (entre comillas, con mayúsculas solo en la primera letra y en los nombres propios que pueda contener el título). En: Nombre de la Revista (en cursivas, con mayúsculas en la primera letra y en todos los términos significativos: verbos, sustantivos y adjetivos). Número del volumen (Vol.). Número de la revista ( $\mathrm{N}^{\circ}$ ). Ciudad o País. Editorial (no necesita incluir la palabra "Editorial" antes del nombre propio de la casa editora), mes y año, número de páginas entre las que se encuentra el artículo ().

Ejemplo:

RIELO, Fernando

1990. “Concepción genética de lo que 'no es' el sujeto absoluto y fundamento metafísico de la ética”. En: Raíces y Valores Históricos del Pensamiento Español. No 7. Sevilla. Fundación Fernando Rielo, junio de 1990, 25-45.

\section{Estructura de la bibliografía cuando se trata de recursos electró- nicos (libros y revistas electrónicas y páginas web):}

Se siguen las mismas normas estipuladas en los incisos anteriores para libros y revistas, pero atendiendo a las siguientes particularidades: 1) los títulos tanto de libros como de artículos de revistas van entre comillas; 2) luego del título del libro o del nombre de la revista o del nombre del sitio web consultado, se escribe entre corchetes la leyenda: [En línea]; 3) no es necesario el lugar de edición, la editorial ni el número de páginas; 4) al final de la referencia se escribe la leyenda: "disponible en:" y se transcribe la dirección electrónica completa, seguida por la leyenda "Accesado el" entre corchetes, para citar la fecha de consulta del mencionado sitio web.

Ejemplo 1: 
ARNOLD, Mario y Fernando Osorio

1998. "Introducción a los conceptos básicos de la teoría general del sistemas". En: Revista Cinta de Moebio. [En línea]. No 3. Abril de 1998. Universidad de Chile, disponible en: http://rehue.csociales.uchile.cl/ publicaciones/moebio.htm [Accesado el 20 de enero de 2005].

Ejemplo 2:

FREIRE, Paulo

[1967]. "La educación como práctica de la libertad" en Links Olé. [En línea], disponible en: http://www.linksole.com/k0gbzu [Accesado el 31 de diciembre de 2010].

\section{IMPORTANTE}

Considerando que por su periodicidad semestral de la publicación, los números de Sophia aparecen en los meses de enero y julio, el envío de los trabajos originales y sus resúmenes deberá efectuarse en archivo electrónico (formato digital en procesador Word, sin ningún tipo de formato automático como sangrías, listas numeradas, saltos, etc.) hasta el 15 de enero y el 15 de julio, respectivamente.

Los artículos deberán enviarse a la dirección electrónica de Sophia: Colección de Filosofía de la Educación:

revista-sophia@ups.edu.ec / florocioag@gmail.com

El autor deberá tener presente que su artículo será revisado y aprobado por un Consejo Editorial Interno, que luego será dictaminado por un Consejo Editorial Externo y que finalmente será validado por un Consejo de Publicaciones.

Se sugiere que antes de enviar el artículo, el autor revise cuidadosamente su texto. Este proceso es indispensable para asegurar la calidad de la publicación.

Una vez publicada la revista, la institución editora le hará llegar un ejemplar del número respectivo. 


\section{BASIC EDITORIAL CONDITIONS}

\section{Regulatory body of the publishing process}

The body in charge of monitoring, control and execution of the publication of the issues of Sophia is the Internal Editorial Board, which manages the regular operation of the magazine.

\section{Functions and obligations of the Internal Editorial Board}

1. Its main function is to stablish the editorial policy of Sophia: Colección de Filosofía de la Educación, in accordance with stablished objectives.

2. Plan, analyze, evaluate and approve content and the general structure of each issue of Sophia.

3. Stablish and execute the quality standards and/or criterion for the technical and academic evaluation of the works proposed for publication in Sophia.

4. Define and approve the group of arbiters formed by prominent figures in their specialization fields. This group would be formed by both internal academics and external academics.

5. Assign arbiters or reviewers for each of the proposed works for their publication in Sophia.

6. Approve the final report or the validation for each article, based on the requested guidelines and the general assessment of each article.

7. Organize the publication and distribution of each issue, in accordance with the guidelines stablished by the Publications Board of the UPS.

8. Propose modifications to the editorial line and the dissemination and publication policies.

9. Contribute to the promotion of the magazine in spheres external to the institution and the locality, through editorial exchange with other publications and institutions.

10. Strengthen the mechanisms to promote the collaboration of academics external to the institution, both for the presentation of the articles to being published as for the review of articles. 
11. Foster advertising and promotion agreements with magazines and institutions related with the themes of interest of Sophia.

\section{Editorial Policy}

\section{Content}

The content of the works presented for the publication in Sophia: Colección de Filosofía de la Educación should be original and unpublished. The articles ${ }^{1}$ should not have been published before. Work that cover research, scientific communication, technical reports, papers, short articles, theoretical papers, case review articles and / or state of the art, contributing to re-think education may be included.

Depending on the relevance and pertinence of the article some work could be considered as special contribution and occasionally would be published:

1. Works exceeding the manifested extension

2. Works thematically dissonant with the theme of the issue.

3. Translations of works which were written in a different language from Spanish and that were unpublished.

4. Review of recent texts.

\section{Extension and format}

The articles would have an extension of 15 to 20 pages, in A4 sheets, with line spacing of 1.5 and font Times New Roman 12. The mentioned extension does not include foot notes, bibliography, charts, statistical graphics and / or annexes, which will go at the end of the article.

Works in English, Spanish and Portuguese would be accepted.

\section{Intellectual Property}

The ideas and opinions expressed in the published articles Sophia are exclusive responsibility of its author, as such, both the Editorial Board

1 There are different types of articles: $\bullet$ Research: describes the research work done by one or more authors. - Review: analyses critically the state of knowledge of a discipline or a concrete theme based upon published bibliography. $\cdot$ Retraction: an author corrects or removes his/her previous article due to: impossibility to replicate the results, fraud allegations, mistakes made, difficulties within the work team, etc. -Commentaries or critics: an author comments or critics an article published by other researchers. $\cdot$ Theoretical papers: a model, a theory or a new system is proposed to understand a phenomenon or phenomena, a case or a knowledge dominion (Campanario en: López Santos, 2010: 2). 
as the Universidad Politécnica Salesiana decline any responsibility on the mentioned material.

All the persons and instances in charge of the publishing process of Sophia: Colección de Filosofía de la Educación do not guarantee or support the affirmations presented in each article.

\section{Quality}

The articles presented for publication should have a high academic level, product of critical and reflective analysis that complies with the demands of international evaluation. This implies that the works should approve the technical and academic assessment process performed by the Editorial Board, as well as the academic assessment performed by the external specialists named by the Board.

\section{Acceptance of articles and closing of the edition}

The acceptance of articles is permanent; however, considering the biannual publication schedule, the issues of Sophia are released in the months of January and July. The original works and their abstracts should be sent in digital format (in Microsoft Word, without any type of auto format such as indentations, numbers lists, jumps, etc.) until the $15^{\text {th }}$ of January and the $15^{\text {th }}$ of July, respectively.

The articles should be sent to the email address of Sophia: Colección de Filosofía de la Educación: revista-sophia@ups.edu.ec / florocioag@ gmail.com

\section{Author's responsibility}

The author has absolute responsibility over the content and is bound to submit his/her article in accordance with the guidelines issued by the Editorial Board.

The author must be aware that his/her article would be reviewed and approved by an internal Editorial Board, that later will be assessed by an external Editorial Board, and that, finally, it will be validated by a Publishing Board; as such, the author must commit to perform the adjustments required by the editors within the stablished timeframe.

Moreover, the author is committed to deliver original and unpublished articles. 


\section{Arbitration}

The arbiters are the group of specialists selected to perform the assessment of each of the articles that would form each issue of Sophia: Colección de Filosofía de la Educación. They will be national and international specialists who are part of the external Editorial Board. Their participation would be rotational, depending on the thematically needs of the issue.

The sent articles should undergo the following filters prior to publication:

1. Reception of works

2. Preliminary review and preselection by the responsible editor $^{2}$

3. Assessment by the Editorial Board

4. Pre-approval of works

5. Assessment by two external specialists

6. Acceptance of the assessment by the Editorial Board

7. Approval or rejection of the works by the Editorial Board

8. Approval of the works by the Publishing Board

\section{Basic guidelines for assessment}

\begin{tabular}{|l|l|}
\hline Title of the article: & $\begin{array}{l}\text { Article's reception } \\
\text { date: }\end{array}$ \\
\hline & $\begin{array}{l}\text { Article's assessment } \\
\text { date: }\end{array}$ \\
\hline Arbiter or evaluator: & \multicolumn{2}{|l}{} \\
\hline $\begin{array}{l}\text { Instructions for the assessment: } \\
\text { The total sum of the items determines the approval of article } \\
\text { The minimum score for the approval of an article Is } 17 / 20\end{array}$ \\
\hline
\end{tabular}

2 As part of the procedure for the selection and approval of articles, it would be indispensable to resort to judgement of external specialists to the editorial institution, whom would have the responsibility to evaluate, validate and emit their assessment of the quality of the presented works. 


\begin{tabular}{|c|c|c|}
\hline Key Aspects & EVALUATION CRITERIO & VALUE \\
\hline \multirow{8}{*}{ 1. Content } & $\begin{array}{l}\text { a. Pertinence of the title in accordance with } \\
\text { the nature and content of the article }\end{array}$ & \\
\hline & b. Presentation of the topic & \\
\hline & c. Relevance and actuality of the topic & \\
\hline & $\begin{array}{l}\text { d. Formulation of the problem or the object } \\
\text { of study }\end{array}$ & \\
\hline & e. Established objectives & \\
\hline & f. Formulation of the main thesis & \\
\hline & $\begin{array}{l}\text { g. Development of the arguments (relation } \\
\text { between the stablished objectives, theoreti- } \\
\text { cal foundations and contextualization) }\end{array}$ & \\
\hline & $\begin{array}{l}\text { h. Adequate composition (coherent articu- } \\
\text { lation of ideas) }\end{array}$ & \\
\hline \multirow{9}{*}{$\begin{array}{l}\text { 2. Key } \\
\text { Formales } \\
\text { Aspects }\end{array}$} & $\begin{array}{l}\text { a. Length of the article in accordance with } \\
\text { stipulated parameters ( } 15 \text { a } 20 \text { pages) }\end{array}$ & \\
\hline & $\begin{array}{l}\text { b. Title (in Spanish and English subtitles, } \\
\text { sections and subsections clearly marked }\end{array}$ & \\
\hline & c. Author (First and last names) & \\
\hline & $\begin{array}{l}\text { d. Data for the identification of the author } \\
\text { (highest hierarchy titles, occupation, ins- } \\
\text { titution to where he/she belongs, country, } \\
\text { email address) }\end{array}$ & \\
\hline & $\begin{array}{l}\text { e. Abstract in Spanish (length: } 250-300 \\
\text { words) }\end{array}$ & \\
\hline & f. Key words in Spanish ( 5 or 6 terms) & \\
\hline & g. Abstract & \\
\hline & h. Key Words ( 5 or 6 terms) & \\
\hline & $\begin{array}{l}\text { i. Article's general body structure. Its cons- } \\
\text { titutive elements can be clearly identified: } \\
\text { introduction, development of the subject } \\
\text { with its subdivisions, conclusions and } \\
\text { bibliography. }\end{array}$ & \\
\hline
\end{tabular}




\begin{tabular}{|c|c|c|c|c|c|}
\hline & \multicolumn{4}{|c|}{$\begin{array}{l}\text { j. Presentation of bibliographical references, } \\
\text { at the endo of the text, in accordance with } \\
\text { the Harvard-APA standards, indicating the } \\
\text { last name of the author, year of publication } \\
\text { and page number }\end{array}$} & \\
\hline & \multicolumn{4}{|c|}{$\begin{array}{l}\text { k. Formal presentation of the bibliogra- } \\
\text { phy in accordance with the Harvard-APA } \\
\text { standards }\end{array}$} & \\
\hline & \multicolumn{4}{|c|}{$\begin{array}{l}\text { 1. Font (Time News Roman, size 12), interli- } \\
\text { ne space }(1,5) \text { page size (A4) }\end{array}$} & \\
\hline \multicolumn{5}{|c|}{ TOTAL SCORE } & $/ 20$ \\
\hline \multicolumn{6}{|c|}{ OBSERVATIONS AND/OR RECOMMENDATIONS (optional): } \\
\hline \multicolumn{6}{|c|}{ RECOMENDATIONS FOR THE PUBLICATION IN SOPHIA } \\
\hline \multicolumn{2}{|l|}{ Criterion } & $\mathbf{Y}$ & $\mathbf{N}$ & Why? & \\
\hline \multicolumn{6}{|c|}{ Strongly recommended } \\
\hline \multicolumn{2}{|c|}{$\begin{array}{l}\text { Recommended only if the quality } \\
\text { is improved (see observations } \\
\text { and/or recommendations) }\end{array}$} & & & & \\
\hline \multicolumn{2}{|c|}{ Publication is not recommended } & & & & \\
\hline S: Evaluato & iter & & & & \\
\hline
\end{tabular}

\section{Article approval}

If the article is accepted for publication, the editors will combine the comments made by the evaluators or arbiters with their own editorial comments and return the document to the main author for a final revision. The author should implement the corrections and necessary changes. Arbiters and authors would be kept in complete anonymity.

\section{Negotiations or delay of the articles}

The Editorial Board reserves the right to reject or postpone the publication of articles that merit to be improved upon. The editor responsi- 
ble reserves the right to make the style corrections and editorial changes deemed necessary to improve the quality of the text.

In the vent an article is not approved by the Editorial Board, it will be returned to its author, which does not imply that the article could be improved and be considered for future publications.

\section{Proof corrections}

After the approval of the articles, they will go through the edit and design phase. The Article's composition proof will be sent to the author for its corresponding review. To advance in the publication process, the author will have a five day period to return the text with its observations and possible modifications and /or respective approval. For their part, the ones responsible for the redaction reserve their right to admit or reject the corrections made by the author during the review process, and if necessary, perform a second assessment.

\section{Diversification}

Sophia promotes the publication of articles with a wide arrange of perspectives, including but not limited to theoretical and analytical texts, reviews and plural opinions, all under the main theme of each issue. Sophia privileges scientific rigor, analytic, reflexive, interpretative, argumentative and propositive creativity reflected in each of the articles.

\section{Editorial criteria}

The editorial criteria hereby stablished are In accordance with the academic and editorial requirements of the Secretaría Nacional de Educación Superior, Ciencia, Tecnología e Innovación (SENESCYT) of Ecuador.

\section{Guidelines for authors}

\section{Formal and methodological aspects}

Approximated length: The articles will have a length of 15 to 20 pages without the preliminary parts and bibliography

Page format: A4

Interlineal space:

1,5

Font: Times New Roman, size 12

Notes and references: At the end of the article

Type of the article: $\quad$ Scientific 


\section{Characteristics of the content}

The content of the works presented for publication in Sophia Colección de Filosofía de la Educación should comply with the own characteristics of scientific research:

1. Being original, unpublished and relevant

2. Approach topics that address current problematics and needs

3. Contribute to the development of scientific knowledge

4. Answer to the requirements of the valid state of knowledge

5. Utilize adequate, clear, precise and comprehensible language

\section{Structure of the article}

1. Title: Indicates the denomination of the text. The article's title should be brief. Interesting, clear, precise and attractive to interest the reader. It should describe the content of the article and should be formulated in two languages: Spanish and English.

2. Author and affiliation: Indicate the one responsible for the article. The author should attach a brief curriculum in no more than 4 lines and should consider the more relevant graduate and post graduate titles. Also, he/she should explain his/her current occupation and institution of work.

3. Abstract in Spanish: It should be clear and synthetize the content of all the sections in the article. It must not exceed 300 words.

4. Key words in Spanish: The author should identify between 5 and 6 words or key concepts which clearly describe the content of the article, for which the author should avoid too generic, too specific terms or/and empty words.

5. Abstract: an indispensable requirement for scientific articles.

6. Key words: as mention in number 4

7. Introduction: the topic is presented, its importance, and relevance, and the objectives stablished at the start of the research process. It offers a general overview of the text: formulates the problem that will be addressed, explain the contribution that the article makes, the conceptual framework of the idea to defend, exposes briefly the methodological framework (if needed) and the parts that constitute the text. 
8. Body of the article: it implies to use, throughout the exposition, a critical attitude that tends rising questions, with the desired effect of gathering the attention to the topic and the problem being solved. The writer should generate in the reader the capacity to identify the dialogical intention of the proposition and to incite in it an open discussion.

9. Conclusions: it exposes objectively the results and findings; it offers a vision of the work's implications, its limitations, the tentative response to the problem and the possible lines of continuity (to achieve this objective, it is suggested to not include all the results obtained during research). The conclusions should be properly justified in the research done.

10. Bibliography: is the group of texts used in the structuration of the article. It should only include references to the works used during the research process. The bibliographical references should be organized in alphabetical order and in accordance with the Harvard-APA International standards.

The school of Philosophy and Pedagogy is formed by three basic elements: Philosophy, Pedagogy and Psychology. These elements should be taken into account with more or less weight, depending with the theme of each issue, however, it should be never be forgotten that Sophia is a collection of philosophy and education, therefore it should always be a philosophical approach to the subject at hand.

\section{Direct Quotations and bibliographical references ${ }^{3}$}

They are textual copies of fragments of books, articles or any other type of publication. These quotations should be written between quotation marks and in the same paragraph line when it is four or less lines. When the quote is longer than four lines, they should be written in a separate paragraph without quotation marks and with wide margins.

The Harvard-APA system does not use footnotes for bibliographical referencing. Footnotes should be employed, according to the author's criteria, to expand explications, define concepts, offer additional information, and make annotations or digressions, among other pertinent end.

3 This section is a synthesis of the Harvard reference system, APA style. To obtain examples it is recommended to refer to the published articles in the current issue of Sophia. 
The bibliographical references of direct quotations in the HarvardAPA system are written between parentheses after the quoted text. If the author is not mentioned directly before or during the quotation, the last name or names of the author are included within the parentheses, also the year of the utilized edition and the page number or range of quoted pages. However, if the author was directly mentioned, in the parentheses are only written the year and the page number.

By being Sophia philosophical in nature, generally its articles will include quotations from classical authors, whose works have been edited a great amount of times. In these cases it is recommended to write between square brackets, along the year of the used edition, the original year of publication. By "classical works" it meant texts that have been published before the XX Century. The same treatment is recommended for texts that have been published during the XX Century but that have countless editions of free reproduction. However, when dealing with bibliographical references of works made by authors before our time (for example. Aristotle, Lao-tsé, Plato, etc.) or when its original year of publication is uncertain, this information can be omitted.

\section{Paraphrase}

By not being textual copies, rather appropriation of ideas using own words, they don't need to go between parentheses nor a separate paragraph. its bibliographical reference should be Included where the paraphrase ends or at the end of the paragraph that contains it, following the rules stated earlier.

Example 1: according to Kierkegaard, philosophy for the first time stablishes the relationship between man and the absolute. (Buber, 2000)

Example 2: according to Buber (2000), with Kierkegaard's thoughts philosophy for the first time stablishes the relationship between man and the absolute.

However, the paraphrase can become a quote inside a quote when the copy is textual.

Example 3: "philosophy for the first time stablishes the relationship between man and the absolute" (Kierkegaard in: Buber, 2000: 52)

\section{Direct reference to the author in the text}

When the name of the author appears on the body of the text, the reference should be written immediately after, between parentheses, including year of publication and, if necessary, page number. 
Example: The final ironic interludes of Kierkegaard (1999 [1845]: 73-96) emphasize the desperation of the aesthetic man facing the overwhelming demands of the world.

\section{Indirect reference to the author in the text}

When one takes an author's Idea without mentioning his/her name, a reference should be included either beforehand or after exposing the idea.

Example 1: other thinkers (Simmel, 2002: 87), consider sociology a method rather than discipline on its own.

Example 2: in some moments of its history, sociology has been considered more a method rather than discipline on its own. (Simmel, 2002: 54).

When using works from the same author published the same year, they will be alphabetically ordered and will be distinguished with a lower case letter after the year.

\section{Reference to a text from two authors}

When using a text from to authors, the last names of both would be included in the reference using the conjunction "and" between them. This rule applies both to direct and indirect references.

Example: In The Art of change (Watzlawick and Nardone, 2000) the idea is more deeply developed.

\section{Reference to a text with more than two authors}

When using a text from more than two authors the abbreviation "et al." should be included after the last name of the first author.

Example: the axiom according to which is impossible not to communicate (Watzlawick et al., 2002: 49-52) is one of the most revolutionary starting points of the new cognitive psychology.

When it is about various authors, with different works but that refer to the same topic, it is necessary to separate each one of them.

Example: all Kuhn (1971) Popper (1972) and Tarski (1956) consider the problem of science reach each one a different conclusion.

Diagrams, graphics and Illustrations. The references for these follow the same rules of textual quotations. Diagram 1. Relationship between the theoretical and empiric medium. (Berthier, 2004: 65). 


\section{Bibliographical Structure ${ }^{4}$}

\section{Bibliographical structure using books:}

AUTHOR (the whole last name in upper case and the name with lower case, except for the first letter) year (in a separate line, with indentation and Including, If necessary, between square brackets the original year of publication, in accordance with the rules exposed earlier). Title of the work (in italic, with upper case only the first letter and the first letters of any own names that may contain the text) City or Country (place where the book was edited): Publisher (the word "publisher" doesn't have to be included before the name).

When the book has two authors the names of the second author are written normally: first the name and then the last name, with upper case just the first letters. Additionally, when quoting different books from the same author, his/her name is written only before the first book, while the rest are chronologically arranged according to their edition year, without the need of writing the name of the author again.

\section{Bibliographical structure using magazines:}

AUTHOR (the whole last name in upper case and the name with lower case, except for the first letter) year (in a separate line, with indentation) "Title of the article" (between quotation marks, with upper case only the first letter and the first letters of any own names that may contain the text). In: Name of the Magazine (in in italic, with upper case only the first letter and the first letters of any meaningful term: verbs, substantives and adjectives). Number of volume (Vol.) Number of issue $\left(\mathrm{N}^{\circ}\right)$. City or Country Publisher (the word "publisher" doesn't have to be included before the name), month and year, number of the pages where the article is found ().

Example:

RIELO, Fernando

1990. "Concepción genética de lo que 'no es' el sujeto absoluto y fundamento metafísico de la ética”. In: Raíces y Valores Históricos del Pensamiento Español. No 7. Sevilla. Fundación Fernando Rielo, junio de 1990, 25-45.

Bibliographical structure using digital resources (books, digital magazines and web pages):

The same rules stipulated for books and magazines are used, but addressing the following particularities: 1) the titles of both books and

4 To obtain more examples it is recommended to refer to the published articles in the current issue of Sophia. 
magazines are written between quotation marks; 2) after the title of the book or magazine or the consulted web page, the legend [Web] is written within square brackets; 3 ) it is not necessary the place of publication, the publisher nor the page number; 4) at the end of the reference the following legend should be written: "available In:" followed by the web address and then the legend between square brackets "retrieved" followed by the date of consultation in that web site.

Example 1:

ARNOLD, Mario y Fernando Osorio

1998. "Introducción a los conceptos básicos de la teoría general del sistemas". In: Revista Cinta de Moebio. [Web]. No 3. April 1998. Universidad de Chile, available in: http://rehue.csociales.uchile.cl/ publicaciones/moebio.htm [retrieved January 20, 2005].

\section{Example 2:}

FREIRE, Paulo

[1967]. "La educación como práctica de la libertad" en Links Olé. Web], available in: http://www.linksole.com/k0gbzu [retrieved December 31, 2010].

\section{IMPORTANT}

Considering the biannual publication schedule, the issues of Sophia are released in the months of January and July. The original works and their abstracts should be sent in digital format (in Microsoft Word, without any type of auto format such as indentations, numbers lists, jumps, etc.) until the $15^{\text {th }}$ of January and the $15^{\text {th }}$ of July, respectively.

The articles should be sent to the email address of Sophia: Colección de Filosofía de la Educación:

revista-sophia@ups.edu.ec / florocioag@gmail.com

The author must be aware that his/her article would be reviewed and approved by an internal Editorial Board, that later will be assessed by an external Editorial Board, and that, finally, it will be validated by a Publishing Board

It is recommended that before sending his/her text, the author should carefully revise the article. This process is essential to ensure the quality of the publication.

Once the magazine is published, the publishing institution will send you a copy 


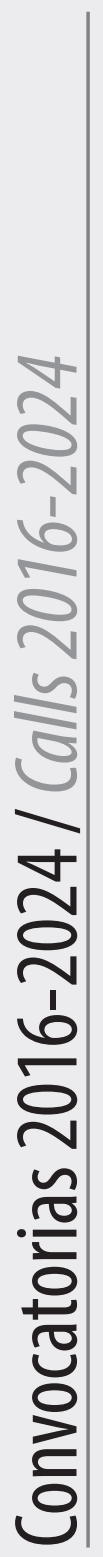




\section{CONVOCATORIAS 2016 - 2024}

Sophia 22

Filosofia analitica y educación

Descriptores: Problemática en torno a la filosofía analítica contemporánea; críticas y perspectivas de la filosofía analítica; incidencias de la filosofía analítica en los procesos educativos; estudio del lenguaje y análisis lógico de los conceptos; filosofía del lenguaje y educación; naturaleza, sentido y significado de la filosofía analítica; reflexiones sobre los principales hitos de la filosofía del lenguaje; estrategias de enseñanza - aprendizaje de la filosofía analítica; enfoques psicológicos de la filosofía analítica.

Generación de artículos desde representantes de la filosofía destacados en el tema central y sus implicaciones en la psicología, en la pedagogía o en otras disciplinas.

Fecha límite para la recepción de manuscritos: 15 de agosto de 2016 Fecha de publicación de esta edición: enero de 2017

\section{Sophia 23}

Fundamentos filosóficos de la sociologia de la educación

Descriptores: Teorías filosóficas de la sociología de la educación; principios y problemas de la sociología de la educación; enfoques y perspectivas de la sociología de la educación; aportes de la filosofía para la sociología de la educación; presupuestos sociológicos de la educación; relaciones de filosofía, sociología y educación; contribuciones para el debate entre filosofía y sociología de la educación.

Generación de artículos desde representantes de la filosofía destacados en el tema central y sus implicaciones en la psicología, en la pedagogía o en otras disciplinas.

Fecha límite para la recepción de manuscritos: 15 de octubre de 2016

Fecha de publicación de esta edición: julio de 2017

Sophia 24

Filosofía de la religión y educación

Descriptores: Reflexiones filosóficas sobre la religión; naturaleza y objeto de la filosofía de la religión; filosofía de la religión y racionalidad; acerca- 
miento fenomenológico del hecho religioso; naturaleza y existencia de Dios; el problema del mal; relación entre religión y ciencia; relación entre religión y ética; ¿quién nos creó?; ¿cuál es la verdadera naturaleza humana?; formas de entender el cielo, el infierno, los milagros y otros misterios; la enseñanza-aprendizaje de la filosofía de la religión; fundamentación psicológica de la filosofía de la religión; filosofía de la religión y pedagogía.

Generación de artículos desde representantes de la filosofía destacados en el tema central y sus implicaciones en la psicología, en la pedagogía o en otras disciplinas.

Fecha límite para la recepción de manuscritos: 15 de enero de 2017

Fecha de publicación de esta edición: enero de 2018

\section{Sophia 25}

Relación sujeto-objeto del conocimiento

Descriptores: El fenómeno del conocimiento; el sujeto y el objeto en las ciencias empíricas; el sujeto - objeto en las ciencias humanas; relación entre el observador y lo observado; sujeto-sociedad y educación; subjetivismo y objetivismo en la educación, realismo y educación; concepciones idealistas en la educación; gestión del conocimiento; el sujeto y el objeto en el proceso educativo.

Generación de artículos desde representantes de la filosofía destacados en el tema central y sus implicaciones en la psicología, en la pedagogía o en otras disciplinas.

Fecha límite para la recepción de manuscritos: 15 de julio de 2017

Fecha de publicación de esta edición: julio de 2018

\section{Sophia 26}

Filosofia de la biología y educación

Descriptores: Filosofía de la biología; fundamentos filosóficos de la biología; la interdisciplinariedad de la biología; enfoques y perspectivas de la biología del conocimiento; sociobiología; bioética; la reductibilidad de la biología; teoría del vitalismo; el determinismo biológico y el determinismo genético; teoría evolutiva; epistemología evolucionista; la biología en la práctica pedagógica; estrategias de enseñanza-aprendizaje de la biología.

Generación de artículos desde representantes de la filosofía destacados en el tema central y sus implicaciones en la psicología, en la pedagogía o en otras disciplinas.

Fecha límite para la recepción de manuscritos: 15 de enero de 2018

Fecha de publicación de esta edición: enero de 2019 


\section{Sophia 27}

\section{Ontología del lenguaje en la educación}

Descriptores: Fundamentación filosófica de la ontología del lenguaje; los retos del aprendizaje transformacional en la educación; inteligencias, aprendizaje transformacional e innovación disruptiva; fundamentos filosóficos del lenguaje; el sentido y el significado de la ontología del lenguaje; implicaciones de la ontología del lenguaje para la educación.

Generación de artículos desde representantes de la filosofía destacados en el tema central y sus implicaciones en la psicología, en la pedagogía o en otras disciplinas.

Fecha límite para la recepción de manuscritos: 15 de julio de 2018

Fecha de publicación de esta edición: julio de 2019

\section{Sophia 28}

Filosofía, tecnología e innovación en la educación

Descriptores: Filosofía de la tecnología; fundamentos filosóficos de la tecnología; filosofía de la innovación educativa; filosofía y teorías educativas para la sociedad red; innovación y tecnología educativa; pensamiento computacional; teorías pedagógicas del pensamiento computacional; de la conectividad al pensamiento crítico; experiencias pedagógicas de la tecnología; propuestas educativas innovadoras.

Generación de artículos desde representantes de la filosofía destacados en el tema central y sus implicaciones en la psicología, en la pedagogía o en otras disciplinas.

Fecha límite para la recepción de manuscritos: 15 de enero de 2019

Fecha de publicación de esta edición: enero de 2020

\section{Sophia 29}

El pensamiento complejo y las ciencias de la complejidad en la educación

Descriptores: Paradigmas de la complejidad y la transdisciplinariedad; epistemología del conocimiento y los aprendizajes desde la complejidad; comunidades de pensamiento complejo y aprendizaje transformacional; teorías de la complejidad; problema del método en el pensamiento complejo; aportes del pensamiento complejo para la educación; educación y pensamiento complejo; críticas al paradigma de la complejidad; el ser y la existencia en el paradigma de la complejidad.

Generación de artículos desde representantes de la filosofía destacados en el tema central y sus implicaciones en la psicología, en la pedagogía o en otras disciplinas. 
Fecha límite para la recepción de manuscritos: 15 de julio de 2019

Fecha de publicación de esta edición: julio de 2020

\author{
Sophia 30
}

Filosofía de las ciencias cognitivas y educación

Descriptores: Filosofía y ciencia cognitiva; debate filosófico sobre las ciencias cognitivas; problemas y relaciones existentes entre mente y cuerpo; fundamentación filosófica de la cibernética, fundamentos epistemológicos de la teoría cognitivista; fundamentos filosóficos de la teoría conexionista; tendencias actuales de la ciencia cognitiva; teoría de la mente y ciencias cognitivas; psicología evolutiva y educación; relaciones entre ciencias cognitivas y ciencias de la educación; aportes de las ciencias cognitivas para la educación.

Generación de artículos desde representantes de la filosofía destacados en el tema central y sus implicaciones en la psicología, en la pedagogía o en otras disciplinas.

Fecha límite para la recepción de manuscritos: 15 de enero de 2020

Fecha de publicación de esta edición: enero de 2021

\title{
Sophia 31
}

El problema de la verdad en las ciencias y en la práctica pedagógica

Descriptores: Diversas concepciones de verdad en la historia de la filosofía y sus implicaciones en los procesos educativos; fundamentos filosóficos, psicológicos y pedagógicos de la verdad; verdad, hecho y ciencia; la verdad en las ciencias sociales; la verdad en las ciencias naturales; la verdad en las ciencias exactas; la verdad en las ciencias humanas; la verdad en las ciencias de la información y de la comunicación; nuevas tendencias, enfoques y perspectivas sobre la verdad; la verdad en la educación.

Generación de artículos desde representantes de la filosofía destacados en el tema central y sus implicaciones en la psicología, en la pedagogía o en otras disciplinas.

Fecha límite para la recepción de manuscritos: 15 de julio de 2020

Fecha de publicación de esta edición: julio de 2021

\section{Sophia 32}

Reflexión filosófica sobre la calidad integral en la educación

Descriptores: Filosofía de la calidad integral en la educación; fundamentos filosóficos, psicológicos y pedagógicos de la calidad; filosóficos de los 
modelos educativos integrales e inclusivos; bases filosóficas de las competencias complejas en la educación; la calidad y las competencias en la educación.

Generación de artículos desde representantes de la filosofía destacados en el tema central y sus implicaciones en la psicología, en la pedagogía o en otras disciplinas.

Fecha límite para la recepción de manuscritos: 15 de enero de 2021

Fecha de publicación de esta edición: enero de 2022

\section{Sophia 33}

Filosofía de la mente y educación

Descriptores: Efectos, causas de los estados mentales; fundamentación ontológica de la naturaleza de los estados mentales; respuestas monistas al problema mente-cuerpo; teorías sobre la filosofía de la mente; críticas a la filosofía de la mente; filosofía de la mente y la relación con otras ciencias; filosofía de la mente; fundamento de la actividad mental y de la conducta; relación filosofía de la mente con la psicología; filosofía de la mente y educación; el poder de la mente en la educación; estrategias pedagógicas para el desarrollo de la mente.

Generación de artículos desde representantes de la filosofía destacados en el tema central y sus implicaciones en la psicología, en la pedagogía o en otras disciplinas.

Fecha límite para la recepción de manuscritos: 15 de julio de 2021

Fecha de publicación de esta edición: julio de 2022

\section{Sophia 34}

Filosofía de la cultura y educación

Descriptores: Fundamentos filosóficos de la etnografía; bases filosóficas de las teorías culturales; aspectos fundamentales de la antropología cultural y social; evolución de la cultura; fundamentación filosófica del diálogo entre culturas; relaciones entre cultura y otras disciplinas; el dinamismo y la transformación intercultural; el quehacer de la filosofía en el diálogo de saberes; el pensamiento de la diversidad; la actividad humana y la cultura como categorías integradoras de saberes; ecosofía, cultura y transdisciplinariedad.

Generación de artículos desde representantes de la filosofía destacados en el tema central y sus implicaciones en la psicología, en la pedagogía o en otras disciplinas.

Fecha límite para la recepción de manuscritos: 15 de enero de 2022

Fecha de publicación de esta edición: enero de 2023 


\section{Sophia 35}

\section{Corrientes filosóficas y su incidencia \\ en las orientaciones pedagógicas}

Descriptores: La filosofía como base fundamental de las orientaciones pedagógicas. El idealismo base para la generación de orientaciones pedagógicas; el racionalismo fundamento del disciplinarismo educativo, el empirismo como sustento del realismo educativo; la ilustración como apoyo del iluminismo educativo; otras corrientes filosóficas como base de teorías u orientaciones pedagógicas a través de la historia; fundamentos filosóficos de las nuevas pedagogías, andragogías y tecnología del Siglo XXI; bases filosóficas del constructivismo y de otras teorías pedagógicas.

Generación de artículos desde representantes de la filosofía destacados en el tema central y sus implicaciones en la psicología, en la pedagogía o en otras disciplinas.

Fecha límite para la recepción de manuscritos: 15 de julio de 2022

Fecha de publicación de esta edición: julio de 2023

\section{Sophia 36}

Enfoque filosófico del aprendizaje como proceso cognitivo

Descriptores: Bases filosóficas del aprendizaje; el aprendizaje como proceso cognitivo; el aprendizaje como producto y como proceso del conocimiento; fundamento filosófico de las teorías del aprendizaje; fundamentos psicológicos y pedagógicos del aprendizaje; fundamentos filosóficos de las inteligencias múltiples y educación; inteligencia emocional y su incidencia en los procesos educativos; sentido y significado de los procesos cognitivos; memoria, pensamiento y lenguaje como principales procesos cognitivos del ser humano; procesos cognitivos y aprendizajes significativos.

Generación de artículos desde representantes de la filosofía destacados en el tema central y sus implicaciones en la psicología, en la pedagogía o en otras disciplinas.

Fecha límite para la recepción de manuscritos: 15 de enero de 2023

Fecha de publicación de esta edición: enero de 2024

\section{Sophia 37}

Filosofía de la física y educación

Descriptores: Reflexiones filosóficas acerca de la interpretación de la física; problemas de la filosofía de la física; aspectos filosóficos relevantes de las teorías de la física; la física de Aristóteles; la física de Descartes; la física de Newton; relaciones entre concepciones de la física en la historia de la filosofía; problema del sentido y de la verdad en la filosofía de la física; naturaleza e implicaciones 
de la termodinámica; epistemología y principios rectores de las teorías físicas; fundamentos filosóficos de la mecánica cuántica; aportes de Newton y Kant para la física contemporánea; implicaciones filosóficas de la teoría cuántica; implicaciones filosóficas de la física newtoniana; implicaciones filosóficas de la teoría de la relatividad; estrategias pedagógicas en la enseñanza-aprendizaje de la física; propuestas educativas para dinamizar la comprensión de la física.

Generación de artículos desde representantes de la filosofía destacados en el tema central y sus implicaciones en la psicología, en la pedagogía o en otras disciplinas.

Fecha límite para la recepción de manuscritos: 15 de julio de 2023

Fecha de publicación de esta edición: julio de 2024

\section{Sophia 38}

El método inductivo en las humanidades

Descriptores: La actividad científica y el método; el método entre la ciencia y la filosofía; el método inductivo en las ciencias sociales; los métodos en las humanidades; el método científico en la comprensión del dinamismo de las ciencias humanas, reflexiones filosóficas sobre los métodos de las ciencias formales; reflexiones filosóficas sobre los métodos de las ciencias fácticas; aplicaciones del método inductivo en la educación; utilidad del método inductivo para la psicología; propuestas pedagógicas de carácter inductivo en las ciencias humanas.

Generación de artículos desde representantes de la filosofía destacados en el tema central y sus implicaciones en la psicología, en la pedagogía o en otras disciplinas.

Fecha límite para la recepción de manuscritos: 15 de enero de 2024

Fecha de publicación de esta edición: enero de 2025

\section{Sophia 39}

Fundamentos filosóficos de la neurociencia y educación

Descriptores: fundamentos filosóficos de la neurociencia; epistemología de la neurociencia; aportes de la neurociencia aplicada a la educación; neurociencia y aprendizaje; neurociencia y educación; la neuoroeducación; estrategias pedagógicas para aplicar la neurociencia en el aula; modelos mentales y educación; neurociencia computacional ; la neurociencia cognitiva; neurociencias descriptivas; relaciones entre neurociencia y psicología; nuevas maneras de entender el cerebro y la conciencia; problemas de la neurociencia; mecanismos biológicos del aprendizaje; funciones de las neuronas en los procesos de aprendizaje; mente y cerebro en la neurociencia contemporánea; las neuronas sensorial, motora e interneurona en la educación.

Fecha límite para la recepción de manuscritos: 15 de julio de 2024

Fecha de publicación de esta edición: julio de 2025 


\section{Normas Editoriales de la Revista Sophia: Colección de Filosofía de la Educación}

Las Normas Editoriales las puede encontrar en la sección Envíos, en el link: Directrices para Autores, situado en la siguiente dirección: http://revistas. ups.edu.ec/pdf/docs/Sop_Normas.pdf

\section{Excepciones de publicación}

Dependiendo de la relevancia y pertinencia del artículo, se considerarán como contribuciones especiales y ocasionalmente se publicarán:

1. Trabajos que superen la extensión manifestada

2. Trabajos que no se correspondan con el tema objeto de la reflexión para el número respectivo

3. Trabajos de traducción de obras que originalmente se encuentren en un idioma diferente al español y que todavía no hayan sido publicadas

4. Recensión o reseñas de textos recientes

\section{Extensión y formato}

Los trabajos tendrán una extensión de 15 a 20 páginas, en hojas A4, a espacio interlineal de 1,5 y en tipografía Times New Roman tamaño 12.

La mencionada extensión no incluye partes preliminares, notas al pie de página, bibliografía, cuadros, gráficas estadísticas y/o anexos, que irán al final de cada artículo.

El resumen estará conformado por un mínimo de 250 palabras y un máximo de 300 palabras.

El autor deberá identificar entre 5 y 6 palabras o conceptos clave que describan con claridad el contenido abordado en el artículo.

Instrucciones de envío de los manuscritos

Los interesados pueden enviar sus documentos a través de la Plataforma OJS de la Revista:

http://revistas.ups.edu.ec/index.php/sophia/about/submissions\#onlineSubmissions http://revistas.ups.edu.ec/index.php/sophia/index

Idiomas de los manuscritos

Se receptan documentos en español, inglés y portugués.

Información sobre la Revista Sophia: Colección de Filosofía de la Educación Floralba del Rocío Aguilar-Gordón, Editora de la Revista/Teléfono: 0995611513 revista-sophia@ups.edu.ec

florocioag@gmail.com

faguilar@ups.edu.ec 


\section{ANNOUNCEMENTS 2016 - 2024}

Sophia 22

Analythical philosophy and education

Descriptors: Problems about contemporary analytic philosophy; critiques and perspectives of analytic philosophy; incidences of analytic philosophy in educational processes; study of language and logical analysis of concepts; philosophy of language and education; nature, mean and significance of analytical philosophy; reflections on the major milestones about philosophy of language; teaching strategies - learning of analytic philosophy; psychological 284 perspectives of analytic philosophy.

Producing articles from most important representatives of philosophy in central theme and its implications in psychology, pedagogy or other disciplines.

Deadline for receipt of manuscripts: August 15, 2016

Date of publication of this edition: January 2017

\section{Sophia 23}

Philosophical Foundations of sociology of education

Descriptors: philosophical theories of educational sociology; principles and problems about educational sociology; approaches and perspectives of educational sociology; contributions from philosophy to sociology of education; sociological budgets for education; relations between philosophy, sociology and education; contributions to the debate between philosophy and sociology of education.

Producing articles from most important representatives of philosophy in central theme and its implications in psychology, pedagogy or other disciplines.

Deadline for receipt of manuscripts: October 15, 2016

Date of publication of this edition: July 2017

\section{Sophia 24}

Philosophy of religion and education

Descriptors: Philosophical Reflections on religion; nature and purpose of philosophy of religion; philosophy of religion and rationality; phenomenological approach of religion; nature and existence of God; the problem of evil; relationship between religion and science; relationship between religion and 
ethics; iwho created us?; ¿What is the true human nature?; ways of understanding heaven, hell, miracles and other mysteries; teaching and learning of philosophy of religion; psychological foundation of the philosophy of religion; philosophy of religion and education.

Producing articles from representatives of the leading philosophy in central theme and its implications in psychology, pedagogy or other disciplines.

Deadline for receipt of manuscripts: January 15, 2017

Date of publication of this edition: January 2018

\section{Sophia 25}

Subject-object of knowledge

Descriptors: The phenomenon of knowledge; the subject and object in the empirical sciences; the subject - object in the human sciences; relationship between the observer and the observed; subject-society and education; subjectivism and objectivism in education, realism and education; idealist conceptions in education; knowledge management; the subject and object in the educational process.

Producing articles from representatives of the leading philosophy in central theme and its implications in psychology, pedagogy or other disciplines.

Deadline for receipt of manuscripts: July 15, 2017

Date of publication of this edition: July 2018

\section{Sophia 26}

Philosophy of biology and education

Descriptors: Philosophy of biology; philosophical foundations of biology; interdisciplinary of biology; approaches and perspectives of biology knowledge; sociobiology; bioethics; reducing biology; theory of vitalism; biological determinism and genetic determinism; evolutionary theory; evolutionary epistemology; biology in pedagogical practice; strategies teaching and learning of biology.

Producing articles from representatives of the leading philosophy in central theme and its implications in psychology, pedagogy or other disciplines.

Deadline for receipt of manuscripts: January 15, 2018

Date of publication of this edition: January 2019

Sophia 27

Ontology of language in education

Descriptors: Philosophical Foundations of ontology language; the challenges of transformational learning in education; intelligences, learning trans- 
formational and disruptive innovation; philosophical foundations of language; the meaning and significance of the ontology of language; implications of ontology language for education.

Producing articles from representatives of the leading philosophy in central theme and its implications in psychology, pedagogy or other disciplines.

Deadline for receipt of manuscripts: July 15, 2018

Date of publication of this edition: July 2019

\section{Sophia 28}

Philosophy, technology and innovation in education

Descriptors: Philosophy of technology; philosophical foundations of technology; philosophy of educational innovation; philosophy and educational theories to the network society; innovation and educational technology; computational thinking; pedagogical theories of computational thinking; connectivity to critical thinking; educational experiences of technology; innovative educational proposals.

Producing articles from representatives of the leading philosophy in central theme and its implications in psychology, pedagogy or other disciplines.

Deadline for receipt of manuscripts: January 15, 2019

Date of publication of this edition: January 2020

\section{Sophia 29}

Complex thinking and complexity science in education

Descriptors: Paradigms of complexity and transdisciplinary; epistemology of knowledge and learning from the complexity; communities and transformational learning complex thinking; theories of complexity; problem of method in complex thinking; contributions of the complex thought for education; education and complex thinking; criticism of the paradigm of complexity; being and existence in the paradigm of complexity.

Producing articles from representatives of the leading philosophy in central theme and its implications in psychology, pedagogy or other disciplines.

Deadline for receipt of manuscripts: July 15, 2019

Date of publication of this edition: July 2020

\section{Sophia 30}

Philosophy of cognitive science and education

Descriptors: Philosophy and cognitive science; philosophical discuss on cognitive sciences; problems and relationships between mind and body; philosophical foundation of cybernetics, epistemological foundations of cognitive 
theory; philosophical foundations of connectionist theory; current trends in cognitive science; theory of mind and cognitive sciences; evolutionary psychology and education; relations between cognitive sciences and education; contributions of cognitive science to education.

Producing articles from representatives of the leading philosophy in central theme and its implications in psychology, pedagogy or other disciplines.

Deadline for receipt of manuscripts: January 15, 2020

Date of publication of this edition: January 2021

\section{Sophia 31}

The problem of truth in science and in pedagogical practice

Descriptors: Different conceptions of truth in the history of philosophy and its implications in education; philosophical, psychological and pedagogical foundations of truth; truth, fact and science; the truth in the social sciences; the truth in the natural sciences; the truth in the exact sciences; the truth in the human sciences; the truth in the sciences of information and communication; new trends, approaches and perspectives on the truth; the truth in education.

Producing articles from representatives of the leading philosophy in central theme and its implications in psychology, pedagogy or other disciplines.

Deadline for receipt of manuscripts: July 15, 2020

Date of publication of this edition: July 2021

\section{Sophia 32}

Philosophical reflection on the overall quality in education

Descriptors: Philosophy of total quality in education; philosophical, psychological and pedagogical foundations of quality; philosophy of comprehensive and inclusive educational models; philosophical bases of complex skills in education; quality and competence in education.

Producing articles from representatives of the leading philosophy in central theme and its implications in psychology, pedagogy or other disciplines.

Deadline for receipt of manuscripts: January 15, 2021

Date of publication of this edition: January 2022

\section{Sophia 33}

Philosophy of mind and education

Descriptors: Effects, causes of mental states; ontological foundation of the nature of mental states; monistic answers to the mind-body problem; theories on the philosophy of mind; criticism of the philosophy of mind; philosophy of mind and the relationship with other sciences; philosophy of mind; basis of mental activity and behavior; relationship philosophy of mind with 
psychology; philosophy of mind and education; the power of the mind in education; pedagogical development strategies of mind.

Producing articles from representatives of the leading philosophy in central theme and its implications in psychology, pedagogy or other disciplines.

Deadline for receipt of manuscripts: July 15, 2021

Date of publication of this edition: July 2022

\section{Sophia 34}

Philosophy of culture and education

Descriptors: Philosophical Foundations of ethnography; philosophical foundations of cultural theories; fundamental aspects of cultural and social anthropology; evolution of culture; philosophical foundation of dialogue between cultures; relations between culture and other disciplines; dynamism and intercultural transformation; the task of philosophy in the dialogue of knowledge; the thought of diversity; human activity and culture as inclusive categories of knowledge; ecosophy, culture and transdisciplinary.

Producing articles from representatives of the leading philosophy in central theme and its implications in psychology, pedagogy or other disciplines.

Deadline for receipt of manuscripts: January 15, 2022

Date of publication of this edition: January 2023

\section{Sophia 35}

Philosophical currents and their impact on teaching guidelines

Descriptors: Philosophy as fundamental basis of the teaching guidelines. The basis for generating idealism teaching guidelines; rationalism foundation of educational disciplinary, empiricism and maintenance of educational realism; illustration to support the educational enlightenment; other philosophical basis of theories or learning paths through history; philosophical foundations of new pedagogies, andragogy and technology of the XXI Century; philosophical foundations of constructivism and other pedagogical theories.

Producing articles from representatives of the leading philosophy in central theme and its implications in psychology, pedagogy or other disciplines.

Deadline for receipt of manuscripts: July 15, 2022

Date of publication of this edition: July 2023

\section{Sophia 36}

Philosophical approach to learning and cognitive process

Descriptors: Philosophical foundations of learning; learning as a cognitive process; learning as product and process knowledge; philosophical 
foundation of learning theories; psychological and pedagogical foundations of learning; philosophical foundations of multiple intelligences and education; emotional intelligence and its impact on educational processes; meaning and significance of cognitive processes; memory, thinking and language as major human cognitive processes; cognitive processes and significant learning.

Producing articles from representatives of the leading philosophy in central theme and its implications in psychology, pedagogy or other disciplines.

Deadline for receipt of manuscripts: January 15, 2023

Date of publication of this edition: January 2024

\section{Sophia 37}

Philosophy of physics and education

Descriptors: Philosophical Reflections on the interpretation of physics; problems of philosophy of physics; relevant philosophical aspects of physics theories; Aristotle's physics; Descartes physics; Newton's physics; relationships between concepts of physics in the history of philosophy; problem of meaning and truth in the philosophy of physics; nature and implications of thermodynamics; epistemology and guiding principles of physical theories; philosophical foundations of quantum mechanics; Newton and Kant contributions to contemporary physics; philosophical implications of quantum theory; philosophical implications of Newtonian physics; philosophical implications of the theory of relativity; teaching strategies in teaching and learning of physics; educational proposals to boost the understanding of physics.

Producing articles from representatives of the leading philosophy in central theme and its implications in psychology, pedagogy or other disciplines.

Deadline for receipt of manuscripts: July 15, 2023

Date of publication of this edition: July 2024

\section{Sophia 38}

The inductive method in the humanities

Descriptors: Scientific activity and method; the method between science and philosophy; the inductive method in the social sciences; methods in the humanities; the scientific method in understanding the dynamics of the human sciences, philosophical reflections on methods of formal sciences; philosophical reflections on methods of factual sciences; applications of inductive method in education; usefulness of the inductive method for psychology; pedagogical proposals inductive nature in the human sciences.

Producing articles from representatives of the leading philosophy in central theme and its implications in psychology, pedagogy or other disciplines.

Deadline for receipt of manuscripts: January 15, 2024

Date of publication of this edition: January 2025 


\section{Sophia 39}

Philosophical foundations of neuroscience and education

Descriptors: philosophical foundations of neuroscience; epistemology of neuroscience; contributions of neuroscience applied to education; neuroscience and learning; neuroscience and education; the neuoroeducación; teaching strategies for applying neuroscience in the classroom; mental models and education; computational neuroscience; cognitive neuroscience; descriptive neurosciences; relations between neuroscience and psychology; new ways of understanding the brain and consciousness; neuroscience problems; biological mechanisms of learning; functions of neurons in the learning process; mind and brain in contemporary neuroscience; the sensory, motor neurons and interneurons in education.

Deadline for receipt of manuscripts: July 15, 2024

Date of publication of this edition: July 2025 


\section{Sophia Publishing Standards Magazine: Collection of Philosophy of Education}

Editorial Guidelines can be found on the Shipping section, in the link: Guidelines for Authors, located at the following address:

http://revistas.ups.edu.ec/pdf/docs/Sop_Normas.pdf

\section{Exceptions publishing}

Depending on the importance and relevance of the article, they are considered as special contributions and occasionally published:

1. Work exceeding manifested extension

2. Work not correspond to the subject of reflection for the respective number

3. Work of translation of works originally found in a different Spanish language and still not have been published

4. Reviews of recent texts

Length and format

The work will have a length of 15 to 20 pages, A4 sheets, a 1.5 line spacing and font Times New Roman size 12.

Said extension doesn't include preliminary parts, notes, bibliography, tables, statistical graphs and / or attachments, which will be at the end of each article.

The summary will consist of a minimum of 250 words and a maximum of 300 words.

The author must identify between 5 and 6 key words or concepts that clearly describe the content addressed in the article.

Shipping instructions manuscripts

Those interested can send their documents through OJS Platform Magazine:

http://revistas.ups.edu.ec/index.php/sophia/about/submissions\#onlineSubmissions http://revistas.ups.edu.ec/index.php/sophia/index

Languages of manuscripts

Documents in Spanish, English and Portuguese take

Information to Sophia Magazine: Collection of Philosophy of Education

Floralba del Rocio Aguilar-Gordon, Editor of the Journal

Phone: 0995611513

revista-sophia@ups.edu.ec

florocioag@gmail.com

faguilar@ups.edu.ec 
